\author{
Universidade de São Paulo \\ Escola de Engenharia de São Carlos \\ Programa de Pós-Graduação em Engenharia de Produção
}

\title{
Fatores críticos sobre manifestações de interesse em parcerias público-privadas e as propriedades da visão do produto
}

Tiago Vieira Caproni

São Carlos

2018 


\title{
TIAGO VIEIRA CAPRONI
}

\section{Fatores críticos sobre manifestações de interesse em parcerias público-privadas e as propriedades da visão do produto}

\begin{abstract}
Tese apresentada à Escola de Engenharia de São Carlos da Universidade de São Paulo para obtenção do título de Doutor em Engenharia de Produção

Área de Concentração: Processos e Gestão de Operações

Orientador: Professor Associado Daniel Capaldo Amaral
\end{abstract}

São Carlos

2018 


\section{AUTORIZO A REPRODUCÃO TOTAL OU PARCIAL DESTE TRABALHO, POR QUALQUER MEIO CONVENCIONAL OU ELETROONICO, PARA FINS DE ESTUDO E PESQUISA, DESDE QUE CITADA A FONTE.}

Ficha catalográfica elaborada pela Biblioteca Prof. Dr. Sérgio Rodrigues Fontes da EESC/USP com os dados inseridos pelo(a) autor(a).

Vieira Caproni, Tiago

Fatores críticos sobre manifestações de interesse em parcerias público-privadas e as propriedades da visão do produto / Tiago Vieira Caproni; orientador Daniel Capaldo Amaral. São Carlos, 2018.

Tese (Doutorado) - Programa de Pós-Graduação em Engenharia de Produção e Área de Concentração em Processos e Gestão de Operações -- Escola de Engenharia de São Carlos da Universidade de São Paulo, 2018.

1. Parceria Público-Privada (PPP/PFI). 2. Procedimento de Manifestação de Interesse (PMI) . 3. Proposta Não Solicitada (PNS). 4. Indicadores. 5. Indice. 6. Visão do Produto. 7. Escopo. I. Título.

Eduardo Graziosi Silva - CRB - 8/8907 


\section{FOLHA DE JULGAMENTO}

Candidato: Bacharel TIAGO VIEIRA CAPRONI.

Título da tese: "Modelo de indicadores para avatiaçāo de manifestaçōes dé interesse em parcetias público-privadas".

Data da detesa: 08/03/2018

Comissäo Julgodora:

Resultado:

Prot. Associado Daniel Capaldo Amaral (Orientador)

APROUADO

(Escola de Engenharia de São Carlos/EESC)

Prol. Dr. Sandro Cabral

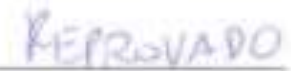

(Insper Instituto de Ensino e Pesquisa)

Profa. Dra. Janaina Mascarenhas Hornos da Costa (Escola de Engenharia de Sáo Carios/EESC)

Prot. Dr. Kiênio de Souza Barbosa

APRONADO

(insper Instituto de Ensino e Pesquisa)

Proła. Dra. Ana Lúcia Vitale Torkomian

APROOVADO

[Universidade Federal de Săo Carlos/UFSCar)

REPROVADO

Coordenador do Programa de Pós-Graduaçōo em Engenharia de Produção:

Prot, Associado Aldo Roberto Ometto

Presidente da Comissâo de Pós-Graduaçâo:

Prot. Associado Luis Fernando Costa Alberto 
A Osvaldo Pereira Caproni meu pai. 


\section{AGRADECIMENTOS}

À energia da vida, que me é atribuída por Deus. O tempo passou rápido e se apossou de muitos momentos que gostaria de, aqui, novamente, vivenciá-los. Parece que foi ontem o momento em que decidi me lançar no desafio de fazer o doutorado nesta Escola, em uma cidade que só conhecia por breves passagens, mas que me marcou definitivamente. Fui agraciado pelos sinceros ditames dos professores José Octavio Armani Paschoal, Guilherme Ary Plonski e Désirée Moraes Zouain que, mais do que conselheiros nas etapas do pré-doutorado, tornaram-se amigos verdadeiros, esclarecendo dúvidas e lançando luz às sombras que eu ainda trazia da academia.

Ao professor, amigo e mentor Doutor Daniel Capaldo Amaral, pessoa com quem partilho grandiosamente os prováveis créditos deste trabalho. Obrigado, Daniel, por ter acreditado em mim quando, muitas vezes, até duvidei de que seria possível alcançar este resultado.

À minha amada avó Guiomar Assumpção Vieira pela dedicação, carinho e incentivo espiritual ao longo dos anos do doutoramento e pelos incontáveis ensinamentos e palavras de segurança e conforto nos momentos mais agudos de minha vida. Nunca me esquecerei de suas palavras de que lutaria "do alto de seus longevos anos para contemplar a plenitude do resultado deste trabalho".

À Helena de Fátima Aguiar Zerlote, pela conexão imediata e carinho de mãe, nunca se olvidando de mim no continuum da vida, zelando para que eu tivesse tranquilidade e foco para a realização de todas as tarefas, viagens e atos despendidos nesta caminhada.

A minha irmã Paula, meu cunhado Douglas e minha sobrinha Maria Eduarda, cujo pouco contato não diminuiu o carinho que nutro por todos.

Por todos os momentos vivenciados, mesmo aqueles em que, em alguns estágios, fiquei distante fisicamente, agradeço esta pessoa que sempre me "colocou para cima" e sempre quis minha alegria e sucesso, constituindo-se na companheira leal e compreensível (nem sempre tão!): Juliana Maruyama da Motta. Meu sincero agradecimento a você, aos seus pais (Meros e Glória) e ao seu irmão (Júlio César), que supriram a ausência de meus familiares, preenchendo com alegria inúmeros finais de semana. 
À sempre companheira Isabel Paula Meneses de Morais, pela dedicação extrema à minha família, que transpôs todos os limites físicos auxiliando nos incontáveis instantes de lutas, com todo meu respeito e reconhecimento honroso.

Às senhoras Neusa Terezinha Mossin Celere, Elena Luzia Palloni Gonçalves e ao senhor Eduardo Graziosi Silva, servidores dedicados da Biblioteca da Escola de Engenharia de São Carlos e ao senhor Antonio Gonçalves Lima, técnico da gráfica do ICMC, os quais rendo este tributo por, em momentos decisivos, terem colaborado para que não me faltasse a motivação necessária para superar os obstáculos do processo de ingresso no curso e sua finalização; na figura deles, rendo também minha homenagem a todos os bibliotecários e serventuários da Biblioteca Central da EESC/USP.

Muito obrigado ao Professor Marcel Andreotti Musetti, pelas monitorias partilhadas ao longo de 2015. Sem dúvidas, o Programa de Aperfeiçoamento de Ensino - PAE foi uma experiência única para que eu tivesse maior segurança na condução da atividade de docência em todos os seus aspectos.

À professora Janaina Mascarenhas Hornos da Costa, pelas valiosas contribuições e críticas, sempre construtivas, direcionadas ao meu aprimoramento; não nego que foi difícil ouvir algumas de suas considerações, mas eu sempre soube que eram fundamentais para assegurar o rigor técnico da USP. Eu agradeço por me fazer acreditar que é possível ser e fazer sempre mais.

À toda a equipe de colaboradores do Departamento de Engenharia de Produção da EESC/USP, pela brilhante condução dos ritos que subsidiaram a realização deste trabalho. Jessyca Aparecida Duarte de Francisco, Suely Regina Ferreira, Juliana Aparecida Paganelli e Talita Maiorano Rabello Caetano, obrigado! Os colaboradores referidos, desde as etapas iniciais, como em um simples esclarecimento ou na busca de informações complexas, jamais perderam a doçura e a paciência nas explanações.

Ao "time" do Núcleo de Manufatura Avançada - NUMA, saúdo nas figuras do Lucas Portilho Camargo Gomes e do Icaro Portilho, reconhecendo que a unidade é composta por pessoas dedicadas que fizeram e fazem a diferença em minha vida.

Aos amigos do doutorado da Escola de Engenharia de São Carlos EESC/USP, da Escola Politécnica de São Paulo - POLI/USP e da Universidade Federal de São Carlos - UFSCar, que me propuseram ricos momentos de reflexões 
e discussões em aulas, seminários, palestras e artigos elaborados em conjunto. "Valeu a pena" cada quilômetro deslocado para poder assistir às aulas com vocês.

À amiga Ana Paula Hayashi, pelo compartilhamento de conhecimento e participação conjunta em publicações e seminários. Certamente, nossa ambivalência de ideias nos proporcionou crescimento profissional. "Valeu muito" a sua ajuda!

Aos valorosos ensinamentos das professoras Marly Monteiro de Carvalho, na abordagem do tema Gestão de Projetos da Escola Politécnica da USP.

Aos colegas de trabalho da Prefeitura de Votuporanga-SP, que depositaram confiança em meu projeto e que vivenciaram uma parte significativa desta trajetória, despertando-me o interesse pelo tema Parcerias Público-Privadas. Cumprimento a todos na figura do ex-Prefeito Junior Marão, a quem dedico o mais profundo apreço.

Aos amigos do Centro de Liderança Pública - CLP/MLG, na figura do presidente Luiz Felipe d'Avila, do time de docentes do Brasil e parceiros da Kennedy School of Government - KSG que, diretamente, influenciaram o meu interesse em avançar nos estudos voltados à causa pública.

Ao Pedro Pullen Parente pelo altruísmo e pelo voto de confiança em acreditar em minha capacidade técnica.

Aos brilhantes amigos e cientistas políticos Humberto Dantas de Mizuca e Fernando de Souza Coelho, pela fé depositada neste trabalho. Não tenham dúvidas que suas dicas e contribuições foram essenciais para os caminhos aqui escolhidos.

A toda equipe da Biblioteca e laboratórios do Centro Universitário de Votuporanga - UNIFEV que sempre me recebeu com grande alegria, por ter propiciado singular espaço para o desenvolvimento deste trabalho.

Ao professor e amigo Carlos Alexandre do Nascimento, que viabilizou o contato com personalidades de expressão mundial no tema das Parcerias PúblicoPrivadas, na London School of Economics - LSE.

Ao amigo Ricardo de Aquino Filho, prático e pragmático, pelas grandes discussões sobre as temáticas deste trabalho.

À Thais Nigri, da Qualtrics Experience MGMT, pelo compartilhamento de conhecimentos sobre metodologias de pesquisa/estruturação de questionários e entrevistas.

Aos meus compadres, Renata e Claudio Juny Figueredo, e ao pequeno Juan Paulo, pelo apoio emocional e suporte no provimento de materiais e livros. 
Ao Luiz Eduardo Baginski e Sergio Vidal, customer consulting da Elsevier Editora, pelos ensinamentos, paciência e didática nas instruções das ferramentas de buscas bibliográficas, possibilitando uma estratégia de busca rigorosa dos artigos do referencial teórico adotado.

Aos amigos Kal Nelson, Michael de Melo e Camilo Augusto Giamatei Esteluti, pela ajuda voluntária na revisão de parte significativa do material tratado neste trabalho, tornando-o mais elegante e melhor estruturado.

Aos Professores Doutores, Sandro Castro, Klênio de Souza Barbosa, Ana Lúcia Vitale Torkomian e Janaina Mascarenhas Hornos da Costa que compuseram a banca de avaliação final deste trabalho, presidida pelo Professor Daniel. Muito obrigado pela paciente leitura de meu texto.

Às instituições de pesquisa, organizações públicas e a iniciativa privada que disponibilizaram dados e informações para que o trabalho pudesse ser realizado.

A todos os inominados amigos e pessoas que acompanharam anonimamente esta trajetória, auxiliando direta ou indiretamente, a quem reputo gratidão e reconhecimento.

À lembrança de minha mãe Maria Lucia (in memoriam) que vive em meu sorriso e que me acompanha com a sua luz, no plano superior em que se encontra, deixando-me seguro quanto a sua satisfação sobre este trabalho.

Por fim, mas não menos importante, ao meu dedicado pai, fonte perene de admiração e inspiração, homem que não mediu esforços para moldar o meu caráter.

Eu dedico este trabalho e toda minha vida a ele. 
"O fracasso ensina a virtude da humildade".

Guiomar Assumpção Vieira (2018) 


\section{RESUMO}

CAPRONI, T. V. Fatores críticos sobre manifestações de interesse em parcerias público-privadas e as propriedades da visão do produto. 2018. 290f. Tese (Doutorado) - Escola de Engenharia de São Carlos, Universidade de São Paulo, São Carlos, 2018.

Os Procedimentos de Manifestação de Interesse (PMI) e Propostas Não Solicitadas (PNS) são mecanismos para a viabilização de projetos de Parcerias PúblicoPrivadas (PPP/PFls). Contudo, a ausência de critérios claros para avaliação e priorização de parceiros, de forma transparente e técnica, leva à seleção adversa de propostas, contribuindo para o insucesso dos projetos. O principal instrumento utilizado na avaliação PPP/PFIs é uma análise quantitativa baseada no Value For Money (VfM). O propósito deste trabalho foi investigar os problemas relacionados com os processos de avaliação das propostas dos PMI submetidas aos órgãos demandantes dos serviços. Iniciou-se com a análise do Fatores Críticos para 0 Sucesso (FCSs) das PPP/PFls, dos PMI e PNS, identificadas na literatura. Os Fatores Críticos foram apresentados a um conjunto de 78 especialistas que responderam também sobre a processo de análise das propostas. No questionário os autores foram confrontados também com as propriedades da visão. O resultado indica que a análise com o VfM seria incompleta e insuficiente para capturar a complexidade do escopo destes projetos. A pesquisa possibilitou ainda organizar os fatores críticos em 7 dimensões a serem consideradas na avaliação destes projetos. Essas dimensões podem ser utilizadas para a criação de instrumentos de avaliação e um exemplo foi proposto, um indicador nomeado de índice "T", avaliado por um grupo de 12 especialistas em projetos de PPP/PFIs. A pesquisa contribui, portanto, para apoiar a criação de instrumentos de avaliação de PPP/PFIs que considerem uma análise mais ampla, considerando aspectos qualitativos e quantitativos.

Palavras-chave: Parceria Público-Privada (PPP/PFI); Procedimento de Manifestação de Interesse (PMI); Proposta Não Solicitada (PNS); Indicadores; Índice; Visão do Produto; Escopo. 


\section{ABSTRACT}

CAPRONI, T. V. Critical Success Factors of Unsolicited Proposal in PublicPrivate Partnerships and Product Vision Properties. 2018. 290f. Thesis (Ph.D.) São Carlos School of Engineering, São Paulo University, São Carlos, São Paulo State, Brazil, 2018.

Unsolicited Proposals (UNPs) are one of the main mechanisms for verifying the feasibility of Public-Private Partnerships (PPP/PFIs / PFIs) projects. However, the lack of clear criteria to evaluate and to prioritize the partner, in a transparent and technical way, has led to adverse selection of proposals increasing the level of failure of these projects. The main instrument used in the PPP/PFIs evaluation is a quantitative analysis based on Value for Money. The purpose of this research was to investigate the problems related with the processes of evaluation of the Unsolicited Proposals (UNPs) that are submitted to the respective government offices. The study compiles the analysis of Critical Success Factors (CSFs) for Public-Private Partnerships (PPP/PFI) and the Unsolicited Proposals (UNPs), identified in the literature, and synthetized by the evaluation of a group of 78 specialists, resulting in the organization of 7 (seven) dimensions to be considered in the evaluation of these projects. This study also demonstrated that, according to these experts, the analysis with VfM would be incomplete and insufficient to capture the complexity of the scope of these projects. As an alternative a set of 7 (seven) indicators where created related to each dimension and a general index that synthetize the performance in the dimensions, considering qualitative and quantitative aspects. The index was labeled as "T" index and evaluated by a group of 12 (twelve) experts on PPP/PFI projects. The results from the analyses indicate that the index allows a linear comparative analysis between the proposals received by the public entity requesting the PublicPrivate Partnership (PPP/PFI) services. The model of indicators decreases the subjectivity of the choices made by public managers, resulting in greater transparency for the process of proposal qualification and security to the market.

Keywords: Public-Private Partnership (PPP/PFI); Request for Proposal (RFP); Unsolicited Proposal (UNPs); Indicator; Index; Product Vision; Scope. 


\section{LISTA DE FIGURAS}

Figura 1 - Graduação de participação da iniciativa privada em projetos públicos ....34

Figura 2 - Estrutura padrão de modelagem de PPP/PFls .....................................35

Figura 3 - Diagrama do ciclo de vida de projeto de PPP/PFI .................................36

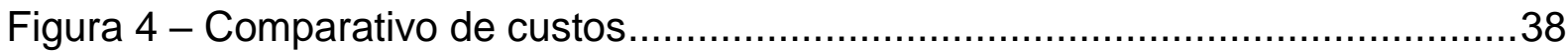

Figura 5 - Fluxograma comparativo das fases da PMI ......................................50

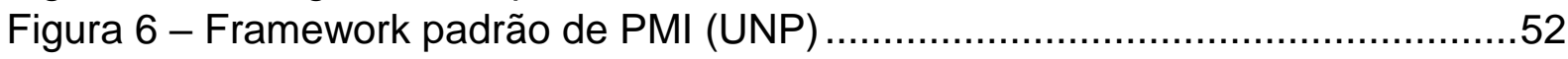

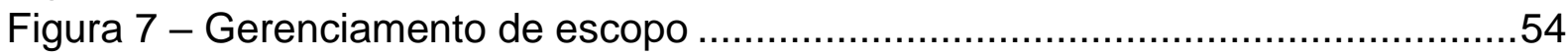

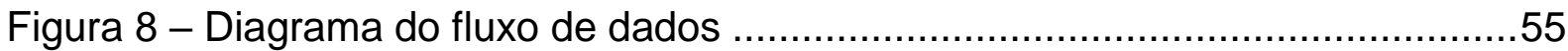

Figura 9 - Gráfico do grau de responsabilidade e risco ........................................57

Figura 10 - Grau de observação de transparência e concorrência...........................59

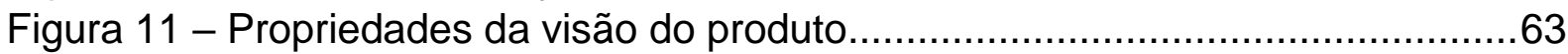

Figura 12 - Fatores críticos para o sucesso de PMls ..........................................71

Figura 13 - Estrutura para a análise de opções de aquisição..................................78

Figura 14 - Metodologia para a organização dos FCSs .....................................128

Figura 15 - Agrupamento de FCSs positivos ................................................147

Figura 16 - Agrupamento de FCSs negativos..................................................149

Figura 17 - Variáveis de análise do índice "T" ....................................................165

Figura 18 - Macro sequenciamento dos ritos da PMI no processo de avaliação....169

Figura 19 - Sequenciamento dos critérios de avaliação de proposta de PMI .........171

Figura 20 - Sequência de etapas operacionais de avaliação das PMls .................172

Figura 21 - Sequência de etapas operacionais de avaliação das PMls ..................172

Figura 22 - Sequência de etapas operacionais de avaliação das PMls .................176

Figura 23 - Sequência de etapas operacionais de avaliação das PMls .................178

Figura 24 - Dimensões de avaliação dos indicadores do índice............................244

Figura 25 - Peso atribuído pelo entrevistado a classe do critério ..........................246

Figura 26 - Layout do índice "T" (nota geral) dos indicadores consolidados (a) ....250

Figura 27 - Layout do índice "T" (nota geral) dos indicadores consolidados (b) .....251

Figura 28 - Definição do indicador de Qualificação .............................................256

Figura 29 - Layout proposto do indicador de Qualificação (a) ...............................257

Figura 30 - Layout proposto do indicador de Qualificação (b) .............................258

Figura 31 - Definição do indicador de Governança ..............................................262

Figura 32 - Layout proposto do indicador de Governança...................................263

Figura 33 - Definição do indicador Técnico/Operacional .....................................266

Figura 34 - Layout proposto do indicador Técnico/Operacional (a) .......................268

Figura 35 - Layout proposto do indicador Técnico/Operacional (b) .......................269

Figura 36 - Definição do indicador Econômico ...................................................272

Figura 37 - Layout proposto do indicador Econômico .........................................273

Figura 38 - Definição do indicador Financeiro …….........................................276

Figura 39 - Layout proposto do indicador Financeiro .......................................277

Figura 40 - Definição do indicador Ambiental ....................................................281

Figura 41 - Layout proposto do indicador Ambiental ........................................281

Figura 42 - Definição do indicador Social ...................................................286

Figura 43 - Layout proposto do indicador Social .............................................28 


\section{LISTA DE GRÁFICOS}

Gráfico 1 - Propostas apresentadas convertidas em contratos ..............................86

Gráfico 2 - Experiência na condução de projetos de PPP/PFls e PMls ..................135

Gráfico 3 - Número Ideal de submissões .......................................................137

Gráfico 4 - Origem do conjunto de variáveis para o edital da PPP/PFI .................137

Gráfico 5 - Qualidade do marco regulatório vigente no Brasil ..............................138

Gráfico 6 - Stopping rule analysis FCSs positivos ...........................................146

Gráfico 7 - Dendograma agrupamentos positivos ………...............................148

Gráfico 8 - Stopping rule analysis FCSs negativos.........................................149

Gráfico 9 - Dendograma agrupamentos negativos ..........................................150

Gráfico $10-1^{\circ}$ ao $5^{\circ}$ Posto de relevância das propriedades de visão do produto...154

Gráfico $11-6^{\circ}$ ao 10ํㅜ Posto de relevância das propriedades de visão do produto 155

Gráfico 12 - Questão 3.B da pesquisa com especialistas .....................................289 


\section{LISTA DE QUADROS}

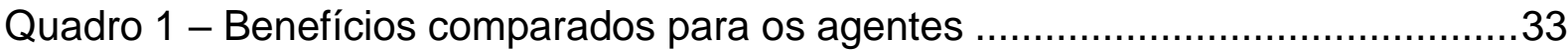

Quadro 2 - Métodos de pesquisa de FCSs ........................................................40

Quadro 3 - Fatores críticos para o sucesso das PPP/PFls ...................................41

Quadro 4 - Terminologia de manifestações de interesse comparadas......................49

Quadro 5 - Resumo de cinco modelos de relações públicas...................................75

Quadro 6 - Expectativa dos principais participantes na fase de pré-proposta..........79

Quadro 7 - Fatores causadores de custos transacionais em PMls de PPP/PFIs .....81

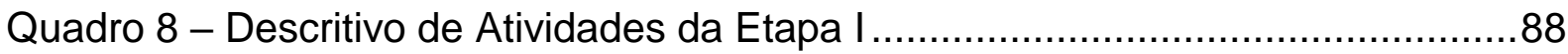

Quadro 9 - Descritivo de Atividades da Etapa II ..................................................89

Quadro 10 - Descritivo de Atividades da Etapa III ..............................................92

Quadro 11 - Descritivo de Atividades da Etapa IV.............................................93

Quadro 12 - Descritivo de Atividades da Etapa V................................................94

Quadro 13 - Descritivo de Atividades da Etapa VI...............................................97

Quadro 14 - Descritivo de Atividades da Etapa VII...............................................98

Quadro 15 - Fatores críticos para o sucesso de PPP/PFIs e PMIs .......................101

Quadro 16 - Fatores críticos de sucesso de PPP/PFls e PMls (a) ........................103

Quadro 17 - Fatores críticos de sucesso de PPP/PFls e PMls (a) .......................105

Quadro 18 - Fatores críticos de sucesso de PPP/PFls e PMls (a) .......................107

Quadro 19 - Fatores críticos de sucesso de PPP/PFls e PMls ............................109

Quadro 20 - Fatores críticos de sucesso de PPP/PFls e PMls ............................111

Quadro 21 - Fatores críticos de sucesso de PPP/PFls e PMls ............................112

Quadro 22 - Fatores críticos de sucesso de PPP/PFls e PMls (a) .......................113

Quadro 23 - Fatores críticos de sucesso de PPP/PFls e PMls ...........................115

Quadro 24 - Fatores críticos de sucesso de PPP/PFls e PMls (a) .......................116

Quadro 25 - Fatores críticos de sucesso de PPP/PFls e PMls (a) .......................118

Quadro 26 - Integração [macro nível] dos FCSs de PPP/PFIs e PMls ....................122

Quadro 27 - Integração [macro nível] dos FCSs de PPP/PFIs e PMls ...................123

Quadro 28 - Integração [macro nível] dos FCSs de PPP/PFIs e PMls ...................124

Quadro 29 - Integração [micro nível] dos FCSs de PPP/PFls e PMls ....................125

Quadro 30 - Integração [micro nível] dos FCSs de PPP/PFIs e PMls ...................126

Quadro 31 - Variáveis omitidas nas avaliações de PMls.......................................140

Quadro 32 - Fatores críticos para o sucesso - FCSs (a) ..................................142

Quadro 33 - Associação dos agrupamentos às dimensões .................................159

Quadro 34 - Matriz de relacionamentos do índice "T" .........................................177

Quadro 35 - Pontos fortes do índice proposto (a)..........................................187

Quadro 36 - Pontos fortes do índice proposto (b) ...........................................188

Quadro 37 - Consultados preliminarmente para a produção da tese (a) ................226

Quadro 38 - Consultados preliminarmente para a produção da tese (b) ...............227

Quadro 39 - Definição do Índice "T" ...............................................................250

Quadro 40 - Descritivo do indicador Qualificador ............................................252

Quadro 41 - Descritivo do indicador de Governança ..........................................259

Quadro 42 - Descritivo do indicador Técnico/Operacional ..................................264

Quadro 43 - Descritivo do indicador Econômico..................................................270

Quadro 44 - Descritivo do indicador Financeiro..............................................274

Quadro 45 - Descritivo do indicador Ambiental ...............................................278 
Quadro 46 - Descritivo do indicador Social ...............................................283 


\section{LISTA DE TABELAS}

Tabela 1 - Fatores críticos de sucesso de PPP/PFls e PMls não enquadrados ....127

Tabela 2 - Experiência em projetos de Parcerias Público-Privadas (PPP/PFI) ......134

Tabela 3 - Áreas de atuação e projetos de interesse ..........................................135

Tabela 4 - Postos de posições dos FCSs positivos .............................................143

Tabela 5 - Postos de posição FCSs negativos ................................................145

Tabela 6 - Coeficiente de correlação de Spearman .........................................151

Tabela 7 - Correlação tau b de Kendall ............................................................152

Tabela 8 - Referência cruzada de subjetivismo ................................................153

Tabela $9-1^{\circ}$ ao $5^{\circ}$ Posto de relevância das propriedades de visão do produto ....154

Tabela $10-6^{\circ}$ ao $10^{\circ}$ Posto de relevância das propriedades de visão do produto 155

Tabela 11 - Matriz de propriedade de visão de produto x variáveis qualitativas.....157

Tabela 12 - Pesos das entrevistas aos critérios CQS ..........................................183

Tabela 13 - Pesos das entrevistas aos critérios CCCOU ....................................184

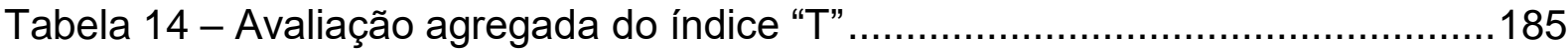

Tabela 15 - Sentenças dos critérios avaliados pelos entrevistados ......................247

Tabela 16 - Questão 3.B da pesquisa com especialistas ....................................28

Tabela 17 - Consolidação dos dados de nota de avaliação agregada ....................290 


\section{LISTA DE SIGLAS}

AA - Análise de Agrupamento

AHP - Analytic Hierarchy Process

AMC - Agência Multilateral de Crédito

APM - Agile Project Management

BOO - Build, Own, Operate

BOOT - Build, Own, Operate, Transfer

CADS - Cash Available for Debt Service

CCCOU - Coerência Conceitual, Coerência Operacional e Utilidade

$\mathrm{CO}$ - Code of Obligations

CQS - Custo, Qualidade do Serviço Prestado e Satisfação do Cidadão

CRI - Certificado de Recebível Imobiliário

CSF - Critical Success Factor

DBFO - Design, Build, Finance and Operate

DCMF - Design Construct, Manage and Finance

DBO - Design-Build-Operate

DCFM - Design, Construction, Finance, Maintain

DCM - Design, Construction, Maintain

EBTIDA - Earnings Before Interest, Taxes, Depreciation and Amortization

EPC - Engineering, Procurement and Construction

EUROSTAT - European Statistics

EVTEFA - Estudos de Viabilidade Técnica, Econômica, Financeira e Ambiental

Eol - Expression of Interest

FC - Fator Crítico

FCS - Fator Crítico para o Sucesso

FIDC - Fundo de Investimento em Direito Creditório

IPEA - Instituto de Pesquisa Econômica Aplicada

ITN - Invitation to Negotiation

GP - Gestão de Projetos

GPA - General Procurement Agreement

GUT - Gravidade, Urgência e Tendência

KBOB - Conference of Federal and Cantonal Real Estate Agency 
LLCR - Loan Life Coverage Ratio

LSA - Latent Semantic Analysis

MIP - Manifestação de Interesse Privado

NCPPP - National Council for Public-Privat Partnership

NDRC - National Development and Reform Commission

OJCE - Official Journal of European Community

OS - Output Specification

PFI - Private Finance Initiative

PIB - Produto Interno Bruto

PPIAF - Public-Private Infrastructure Advisory Facility

PMI - Proposta de Manifestação de Interesse

PNS - Proposta Não Solicitada

PPA - Plano Plurianual

PPP - Parceria Público-Privada (Public-Private Partnership)

RACI - Responsible, Accountable, Consulted and Informed

RSU - Resíduos Sólidos Urbanos

SANRAL - South African National Roads Agency Limited

SIA - Swiss Engineers and Architects Association

SGD - Dólar de Singapura

TCE - Tribunal de Contas do Estado

TPP - Traditional Public Procurement

UNECE - United Nations Economic Commission for Europe

UPGCM - Unweighted pair group centroid method

UNP - Unsolicited Proposal

WBG - World Bank Group

WST - WordSmith Tools 


\section{SUMÁRIO}

1 INTRODUÇÃO

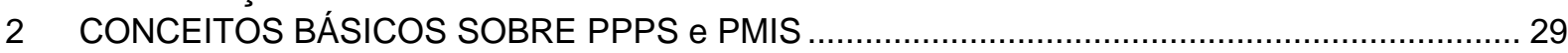

2.1 O CONCEITO DE PARCERIA PÚBLICO-PRIVADA - PPP ........................................... 29

2.2 ORIGEM DAS PARCERIAS PÚBLICO-PRIVADAS ...................................................... 31

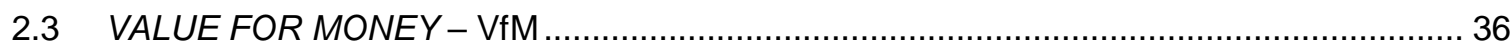

2.4 FATORES CRÍTICOS PARA O SUCESSO - FCSS DE PPP/PFIS ……………………... 40

3 MANIFESTAÇÃO DE INTERESSE E GERENCIAMENTO DE PROJETOS............................... 43

3.1 DEFINIÇÃO DE PMI ................................................................................... 43

3.2 MARCO REGULATÓRIO SOBRE PMIS .................................................................... 47

3.3 TEORIA DE GESTÃO DE PROJETOS PRIVADOS E PÚBLICOS ....................................5

3.4 PMI E A TEORIA DO ESCOPO ………………………………………………. 57

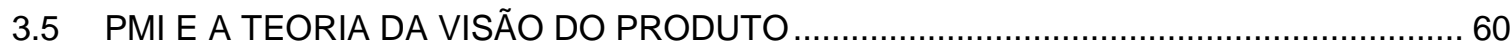

3.5.1 ORIGEM E DEFINIÇÃO DO CONCEITO DE VISÃO …………………………........ 60

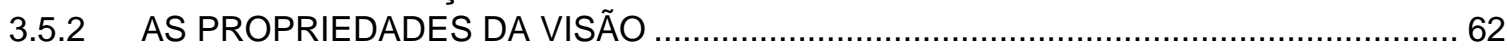

3.5.3 VISÃO EM PROJETOS DA ADMINISTRAÇÃO PÚBLICA …………………………..... 69

4 FATORES CRÍTICOS PARA O SUCESSO DE PMIS ………………………………….... 71

4.1.1 FATORES CRÍTICOS NÍVEL MACRO................................................................. 71

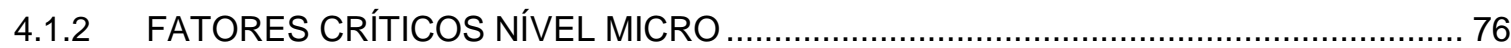

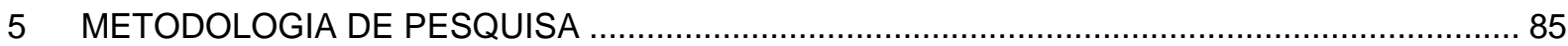

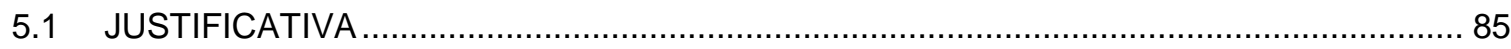

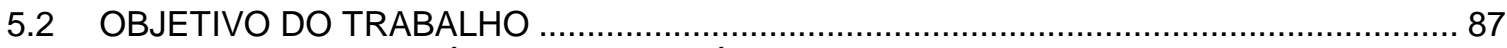

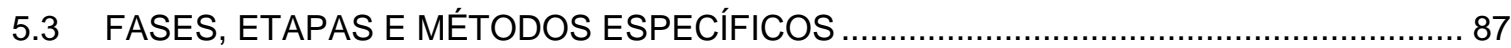

5.3.1 FASE 1 - IDENTIFICAÇÃO DE FCs SOBRE PMIs E PPP/PFIs DA LITERATURA ....... 88

5.3.2 FASE 2 - SÍNTESE DOS FCSS PARA AVALIAÇÃO DE PMIS …………………….... 89

5.3.3 FASE 3 - VERIFICAÇÂO DAS DIMENSÕES PELA PROPOSIÇÂO DE NÚMERO

ÍNDICE PARA AVALIAÇÃO DE PMIS ............................................................................. 95

6 DIMENSÕES PARA AVALIAÇÃO DE PMIS ....................................................................... 99

6.1 INTEGRAÇÃO DOS FCSS DE PPP/PFIS E PMIS …………..................................... 99

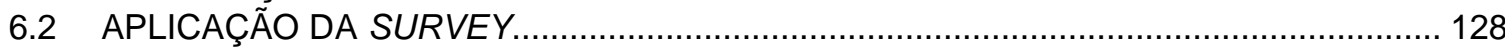

6.3 PERCEPÇÃO DOS ESPECIALISTAS SOBRE A PROPOSIÇÃO DE PMIS........................136

6.4 PERCEPÇÃO DOS RESPONDENTES QUANTO AO GRAU DE SUBJETIVIDADE ........ 139

6.5 FATORES CRÍTICOS E PROPRIEDADES DE PMIS IDENTIFICADAS ………………... 142

6.6 SÍNTESE DAS DIMENSÕES PARA AVALIAÇÃO DE PMIS ………………………..... 158

7 APLICAÇÃO DAS DIMENSÕES NO DESENVOLVIMENTO DE UM NÚMERO ÍNDICE PARA

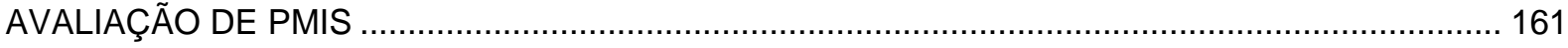

7.1 REQUISITOS PARA O DESENVOLVIMENTO DE PMIS ............................................. 161

7.2 PROPOSTA DE INDICADOR ………………………………………………….... 161

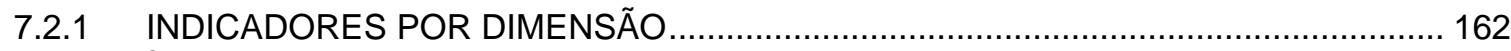

7.2.2 ÍNDICE "T" PARA AVALIAÇÃO DE PMIS ....……………………………………….... 163

7.2.3 PROCESSO DE APLICAÇẪO DO MODELO …………………………………….... 168

7.3 VERIFICAÇÃO DO MODELO DE AVALIAÇÃO DE PMIS …………………………...... 178

7.3.1 AVALIAÇÕES DOS ESPECIALISTAS SOBRE O ÍNDICE "T".................................... 186

7.3.2 POTENCIAIS DIFICULDADES PARA A APLICAÇÃO DO ÍNDICE “T” ......................... 189

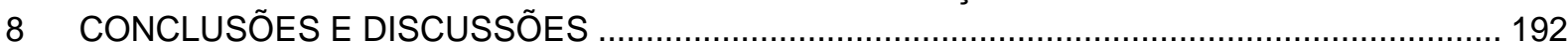

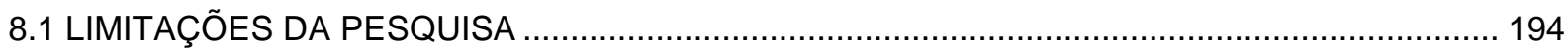

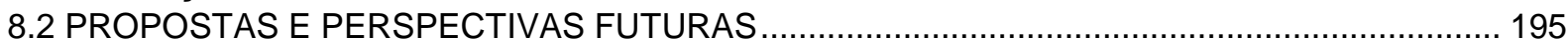

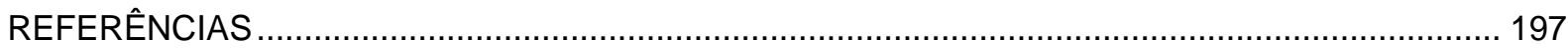

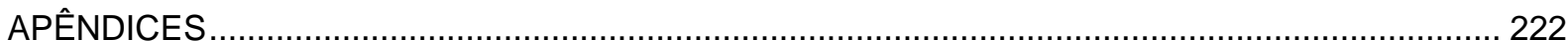

APÊNDICE A - PROTOCOLO DE REVISÃO BIBLIOGRÁFICA SISTEMÁTICA ………………....... 222

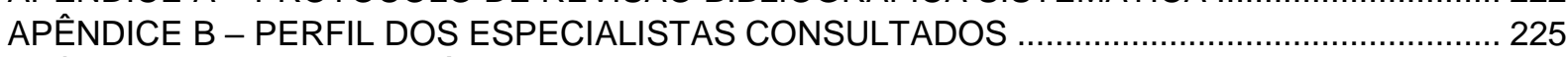

APÊNDICE C - QUESTIONÁRIO PARA A DEFINIÇÃO DOS INDICADORES .................................2233

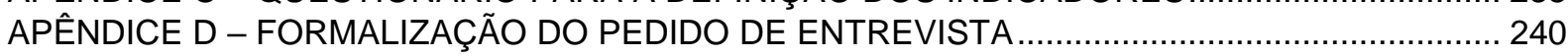




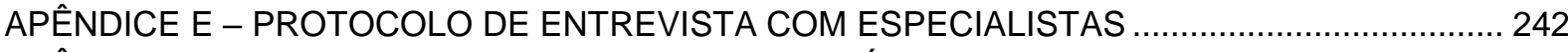

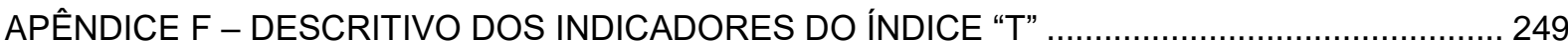

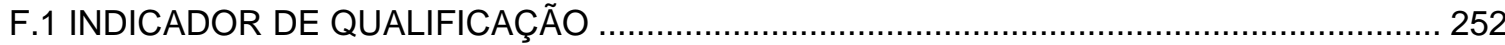

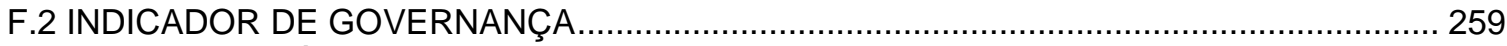

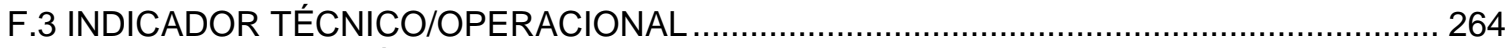

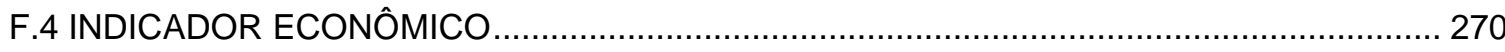

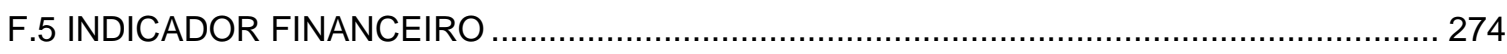

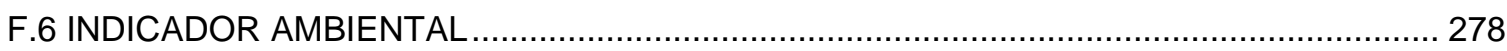

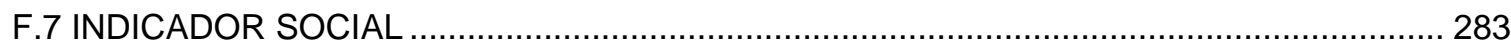

APÊNDICE G - DADOS DA PESQUISA DE CAMPO

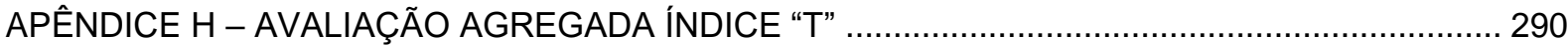


O entusiasmo sobre as Parcerias Público Privadas vivenciado, desde o início dos anos 2000, deve-se, em grande parte, à desregulamentação da legislação vigente sobre privatizações de empresas públicas nos Estados Unidos e ao programa de privatização dessas no Reino Unido. Acrescentam-se a expansão do crédito internacional, justificando a participação da iniciativa privada em áreas antes tidas como de esfera pública, com a expectativa de aumento de estoque, o alcance de receitas adicionais, o equilíbrio fiscal e a redução de ineficiências operacionais decorrentes dos monopólios públicos (GRILO, 2008).

Contribui ainda o fato de os governos, passaram a ser mais exigidos pela população, mesmo contando com menor disponibilidade de recursos (Tang et al. 2013). Logo, faz-se necessário desenvolver políticas públicas capazes de alcançar maior benefício popular mesmo em face da maior limitação do crédito.

Diferentemente dos métodos tradicionais de contratação pública de bens e serviços, vários estudos tem demonstrado as Parcerias Público-Privadas PublicPrivate Partnership/Private Finance Initiative - PPP/PFIs como alternativa efetiva e eficiente para a condução de projetos sociais e de infraestrutura (LOVE et al., 2015). Os projetos versados no instituto da PPP/PFI apresentaram melhor relação de CustoBenefício aos serviços e quantidade de infraestrutura se comparados ao provisionamento pelo ente público (MOTT, 2002).

Os argumentos de apoio a este tipo de instrumento convivem com análises e significativos dados de insucesso. Os principais problemas são: assimetria de informação; conflitos com marcos regulatórios vigentes infralegis (Zhang et al. 2016); capacidade do setor privado no domínio tecnológico; capacidade do setor público em alcançar o valor da contrapartida contratada nos prazos avençados; conflitos entre as partes interessadas devido a ambiguidades na comunicação (Cruz and Marques 2013); compreensão dos agentes públicos nos ritos operacionais das PPPs; atratividade do valor da contraprestação (Arata, Petrangeli, and Longo 2016); disponibilidade e custo do crédito (Tsamboulas, Verma, and Moraiti 2013); comparar as tecnologias adotadas entre os entes proponentes com a devida mensuração dos benefícios trazidas por cada uma; o surgimento de despesas não especificadas ao tempo da submissão das propostas (Hong Kong Institute of Surveyors 2009); compartilhamento de riscos e responsabilidades e transparência do processo de contratação e gestão da parceria entre o público e o privado (Verma 2010). 
Uma das origens deste problema está nas etapas iniciais, ainda na definição do escopo do projeto, como apresentado por EPEC (2010) e Masor et al (2017), autores que indicam a falha nos contratos e escopo como um dos desafios para a execução deste tipo de projeto. Conforme dito por Queiroz e Reddel (2017), há, portanto, a necessidade de se aprimorar os mecanismos de governança.

O Value for Money - VfM tem sido visto como umas das principais ferramentas para otimizar o interesse público em projetos de PPPs (Zhang et al. 2016). A literatura aponta, porém, como um dos problemas justamente o foco na dimensão financeira do VfM, não alcançando assim a complexidade inerente observada em um projeto de PPP, com vários stakeholders, incertezas e riscos (De Schepper, Dooms e Haezendonck, (2014) e Garg e Garg (2017).

Por exemplo, DeCorla-Souza et al. (2016) discorrem especificamente sobre o caso de PPP para conceção de rodovias. Os autores argumentam que a análise do VfM possui uma perspectiva limitada a interesses quantitativos da autoridade que faz a aquisição e não leva em consideração aspectos qualitatitos relacionados aos benefícios dos usuários da rodovia. Isso impede que o valor para o usuário ou público atendido pelo projeto não seja considerado. Portanto, ao contrário do observado nas contratações publicas tradicionais, em que o valor da contraprestação ao serviço ou produto entregue são conhecidos a priori, nos certames de PPP regidos a luz do VfM, o benefício percebido pelo cidadão ao serviço prestado ocorre posteriormente à contratação da empresa ou consórcio vencedor do certame (DeCorla-Souza et al. 2016), não sendo possível assegurar que o montante pago pelo serviço prestado é mais vantajoso para a administração pública que se fosse feito pelo rito tradicional.

$O$ ambiente institucional de interesses plurais das PPPs, faz com que o instituto possua grande complexidade (Grimsey e Lewis 2002), tornando necessário a consideração de aspectos qualitativos nas avaliações das propostas a comporem os editais das PPPs, não somente sob o aspecto financeiro, mas também sob conjunto de variáveis qualitativas. Esta realidade é reforçada ainda em trabalhos como Morallos (2008), Villalba-Romero et al. (2015) e Clerck e Demeulemeester (2016).

O Leilão Score é uma alternativa ao VfM para a contratação de projetos públicos, e que em tese poderia incluir PPPs, aonde

Os lances são ordenados de acordo com a score rule que é uma função $S: \Re$ $2 \rightarrow \Re:(\mathrm{d}, \mathrm{t}) \rightarrow \mathrm{S}(\mathrm{d}, \mathrm{t})$ continua, diferenciável e monótona. Ela representa a relação de preferência do governo entre o desconto na tarifa do serviço prestado e data de entrega. (NOBRE, p. 30, 2014). 
Esta forma de contratação pode considerar aspectos mais subjetivos dos agentes interessados (ASKER; CANTILLON 2008) interpretados por meio de notas, variáveis numéricas com escalas psicológicas, as quais podem então ser somadas e integradas em um valor final, que serve então como referência.

Paralelamente aos trabalhos desenvolvidos em Score Auction, outras técnicas e modelos podem ser adotados para a descrição de projetos complexos, alinhamento de expectativas e mesmo classificação de escolhas pelos órgãos públicos no processo de aquisições, de forma a melhorar a precisão das previsões de qualidade e, portanto, a otimização dos recursos investidos na preparação das propostas e validação destas pelas Câmaras Técnicas dos Conselhos Gestores das Unidades de PPPs.

O aprimoramento das previsões das propostas apresentadas e recepcionadas pelos entes públicos pode se dar com a adoção de técnicas da engenharia de produção para o desenvolvimento de novos produtos. Considerando a singularidade de cada proposta de PMI submetida a um contexto único e específico, é possível inferir que esta seria um novo projeto a concepção de um novo produto entregue na forma de serviço ao cidadão de uma determinada região beneficiada por este. Mas de que forma integrar os conceitos de engenharia de produção para a classificação das propostas recebidas pelos entes públicos a estabelecer critérios de escolha do projeto mais aderente a realidade fática e de demandas existentes?

O conceito de Propriedades de Visão de Produto no gerenciamento de projetos proposto por Benassi e Amaral (2016) é uma ferramenta que tem sido utilizada atualmente na área de Gestão de Projetos Ágeis. Segundo este paradigma, a melhor prática para se definir um projeto passa pela compreensão do valor que ele trará aos usuários finais. $\mathrm{Na}$ abordagem do gerenciamento ágil, portanto, tenta-se tratar estes aspectos considerando o valor final para os stakeholders não só os envolvendo na operação, mas também no design do projeto (NISAR, 2013).

As dimensões da visão do produto, propostas por Benassi e Amaral (2016) poderiam ser utilizadas para a melhoria dos critérios de avaliação Parceria-PúblicoPrivada? A pesquisa teve como objetivo analisar os Fatores Críticos de Sucesso para a preparação de Propostas de Manifestação de Interesse em Parcerias PúblicoPrivadas e sistematiza-las considerando, entre outros aspectos, as propriedades da visão do produto e solucionar o problema da complexidade e consideração de aspectos qualitativos. 
Os objetivos específicos são:

1 - Identificar e organizar os Fatores Críticos para o Sucesso (FCSs) já observados na literatura especializada sobre as PPP/PFls, e dos PMls;

2 - Organizar conjunto de dimensões que impactam no desenho das propostas de PMls recepcionadas pelos entes públicos demandantes do(s) serviço(s).

Além da síntese de um conjunto de dimensões, contempla-se, ao final do trabalho um exemplo de aplicação das dimensões de forma a verificar a pertinência de uso. Isso foi feito aplicando-as na criação de um indicador específico, denominado índice "T".

O trabalho é organizado em 4 (quatro) fases e 7 (sete) etapas. A Fase I contempla a identificação dos Fatores Críticos para o Sucesso de PPPs e PMls, constituído pelas Etapas:

Etapa I - Exploratória, estruturada em 3 (três) atividades; Atividade 01 Definição e Origens das PPPs, VfM, Desafios e FCSs das PPPs; Atividade 02 Definição das PMls e Teoria de Gestão de Projetos Públicos e Privados; Atividade 03 - Definição de Teoria de Escopo e Visão do Produto, Descrição da Visão em Projetos Públicos e FCSs de PMls;

Etapa II - Identificação das variáveis, composto pela Atividade 04 com o reconhecimento das variáveis latentes críticas para a definição de uma PMI baseada em: Relatório Técnico do PPIAF (2014) e artigos técnicos consultados.

A Fase II envolve a síntese dos FCSs para a avaliação de PMls por meio de 3 (três) Etapas, a saber:

Etapa III - Preparação dos instrumentos de coleta, formado pelas Atividades 05 - Integração das variáveis escolhidas as Propriedades de Visão de Produto para reduzir o subjetivismo das avaliações das propostas submetidas pelos proponentes privados; Atividade 06 - Organização dos questionamentos em um questionário único e integrado; Atividade 07 - Entrevista com especialistas em PMls para a validação das perguntas do questionário; Atividade 08 - Ajustes e formatação final do questionário a ser submetido ao grupo de especialistas; Atividade 09 - Organização do grupo de especialistas para a distribuição efetiva dos questionários. 
Etapa IV - Coleta de dados para a Survey; Atividade 10 - Aplicação do procedimento de cobrança de devolutivas dos entrevistados aos questionários submetidos.

Etapa V - Encerra a Fase 02 do trabalho com a Análise dos resultados da Survey, com a descrição da Atividade 11 - Que compreende a organização das devolutivas dos questionários encaminhados e tabulações das respostas.

Já a Fase III por meio da Etapa VI propõe a modelagem de um número índice pautado em indicadores estruturados nas dimensões de avaliação das propostas de PMI, organizados em: Atividades 12 - Proposta de Indicadores para a avaliação de PMls; Atividade 13 - Organização dos indicadores em um índice de avaliação dos projetos submetidos e a Atividade 14 - que descreve a aplicação do modelo de indicadores convertidos no índice.

Por fim, a Fase IV com a Etapa VII prevê a validação do modelo de indicadores convertidos no número índice para a avaliação das PMls, em que a Atividade 15 versa sobre a validação efetiva do modelo a luz do método proposto por CloquellBallester et al. (2006); seguido da Atividade 16 - Com a consolidação das respostas as perguntas e tabulações dos resultados encontrados, finalizando o estudo com a Atividade 17 - Reflexões sobre o índice proposto e desafios a sua aplicação prática. 


\section{CONCEITOS BÁSICOS SOBRE PPPS e PMIS}

Este Capítulo aborda a definição do conceito das PPP/PFIs, com detalhamento da origem do instituto, aprofundamento da discussão dos benefícios de sua adoção e dos desafios enfrentados por gestores públicos e pela iniciativa privada.

\subsection{O CONCEITO DE PARCERIA PÚBLICO-PRIVADA - PPP}

Embora os projetos de PPP/PFIs existam como conceito contratual desde a década de 70, o modelo foi impulsionado na década de 80 na Austrália (TANG et al., 2013) e na década de 90 , na Inglaterra ${ }^{1}$ pelo Primeiro Ministro John Major, líder (de 1990 a 1997) do Partido Conservador. Entretanto, equivocadamente, o modelo tem sido empregado, no pensamento econômico contemporâneo e no imperativo político de eficiência ${ }^{2}$ e qualidade, para definição de institutos correlatos, extrapolando o conceito original e sendo muito difícil de ser redefinido (JEFFERIES; MCGEORGE, 2009). Entende-se que esse é rubricado para a descrição de atividades cooperativas entre Estado(s) e iniciativa privada, comparando-se a um epítome da geração de reformas gerenciais do Estado.

Autores, como Linder (1999), definem o conceito de PPP/PFIs como uma joint venture entre o setor público e o privado, cujo compartilhamento do risco financeiro acontece entre ambos os agentes. De acordo com Reeves et al. (2017), a configuração de PPP/PFls serve como instrumento para a redução das pressões competitivas em mercados, do tempo de negociação do escopo por proponentes que possuam vantagens de monopólio bilateral e estabiliza a volatilidade dos preços nos mercados influenciados por esta cooperação. Todavia, diferentes países, regiões e instituições atribuem ao conceito nomenclaturas distintas. O Banco Mundial atribui a projetos dessa natureza o título de Participação Privada em Infraestrutura (Private Participation in Infrastructure - PPI); na França, Concessão;

\footnotetext{
${ }^{1} \mathrm{O}$ Reino Unido tem sido historicamente um dos maiores mercados para as PPP/PFls em todo o mundo. Entretanto, essas têm sido usadas de maneiras distinta e em diferentes níveis de intensidade (Ghana Public Private Partnership Bill Draft Memorandum To Ghana's Public Private Partnership Bill, 2013). Mesmo sob duras críticas da oposição trabalhista inglesa, as PPP/PFls tornaram-se instrumento do partido como resposta rápida e radical às necessidades de investimentos em projetos públicos (CLARK; ROOT, 1999).

2 Recorte observado no caso brasileiro: Emenda Constitucional no 19, de 04 de junho de 1998.
} 
no Reino Unido, Iniciativa Privada de Financiamento (Private Finance Initiative PFI); na Ásia, Construção, Operação e Transferência (Build - Operate - Transfer BOT) e nas Américas, Parcerias Público Privadas - Public-Private Partnership PPP/PFI (ZHANG et al., 2015).

O governo federal dos Estados Unidos emprega as PPP/PFls como uma ferramenta de estímulo ao investimento privado em projetos de infraestrutura no interior do país (LINDER, 1999). As PPP/PFls estão diretamente relacionadas à teoria e prática da Nova Gestão Pública - NGP, que se originou nos países anglosaxões e fundamenta-se no brocardo de eficiência gerencial (SKIETRYS; RAIPA; BARTKUS, 2015).

Em estudos realizados por Andres e Guasch (2008), Fay e Morrison, (2007) e Grilo (2008), é possível verificar fatores que têm restringido a realização de projetos de PPP/PFI. São esses:

\begin{abstract}
renegociações contratuais expressivas; o uso impróprio de garantias; as cláusulas para manutenção do equilíbrio econômico-financeiro; o comportamento oportunista dos governos e dos investidores; as dificuldade para o aumento das tarifas; a recuperação de custos complexa; os problemas regulatórios e de governança; as projeções de demanda demasiadamente otimistas; insuficiência de esforços para explicar as razões, motivações e benefícios esperados para as partes interessadas; falta de consideração dos planos de demissões; tarifas sociais mal concebidas; participação social reduzida; processos inadequados de préqualificação; corrupção e seleção arbitrária do licitante vencedor; o uso de critérios de julgamento questionáveis; a falha na imposição de requisitos de informação e padrões contábeis nos contratos de concessão, prejudicando a política tarifária e o monitoramento do desempenho; a falta de independência das agências reguladoras; o conflito de competências entre os órgãos executivos e as agências reguladoras (GRILO, 2008, p. 10).
\end{abstract}

Albano, Cesi e lozzi (2017) consideram que PPP/PFls mal formuladas e decorrentes de planejamentos preliminares inapropriados ou com excessiva transferência de risco para contratados acarretam em redução do número de proponentes, motivando condutas oportunistas. A dinâmica consiste no lançamento de valor abaixo do referencial de contratação pelo proponente. O certame é vencido e, consequentemente, têm-se como resultados problemas na prestação do serviço público.

Os problemas podem, inclusive, gerar assimetrias nos certames de contração do serviço alvo que forçam negociações mais favoráveis. O custo adicional recai no 
pagamento pelo órgão público e no serviço entregue à população (XIONG et al., 2017).

Evidencia-se também que, com impacto direto em todos os elementos supracitados, tem-se a variabilidade de escopo. Muito embora os elementos discutidos versem sobre o contratante e o contratado (de ações diretas entre as partes), a variação de escopo de elementos exógenos, como inovação e novos processos, influenciam diretamente no serviço e na qualidade a ser entregues à população. No Brasil, o exemplo que poderia ilustrar a questão descrita, seriam os serviços de iluminação pública disponibilizados com sistemas de dimerização dinâmicos integrados ao grid dos municípios.

\subsection{ORIGEM DAS PARCERIAS PÚBLICO-PRIVADAS}

O instituto das PPPs/PFls tem sido frequentemente visto como uma derivação do movimento de privatização do Estado. Paradoxalmente, há a compreensão generalizada de que o órgão privado possa vir a oferecer serviços de melhor qualidade, em menor tempo, e a um custo inferior ao que seria realizado pelo gestor público, em função da menor quantidade de restrições legais e burocráticas a ser atendidas para a prestação de um serviço.

Ademais, duas configurações se destacam no processo de modelagem de PPP/PFI, a saber: PMI provocadas e PMI motivadas. Em ambos os modelos, os governantes orientam as partes interessadas por meio da promulgação das diretrizes que balizam o certame e estabelecem as regras para o compartilhamento de riscos (BING; AKINTOYE; EDWARDS, 2005). Os investidores privados avaliam a sua capacidade de risco e, assim, propõem o valor referencial para o certame licitatório.

O compartilhamento das responsabilidades a ser constituído e disponibilizado a um determinado grupo de beneficiados resulta no regime de partilha dos riscos (KE et al., 2010), ainda mais se confrontado a um serviço (marginal, provido ou novo) a ser oferecido à população. Nessa esteira, espera-se que o compartilhamento das responsabilidades sobre o projeto possa gerar mútuos benefícios, tanto para o ente privado quanto para o ente público (BLAND; OVERTON, 2014; HAMMAMI; RUHASHYANKIKO; YEHOUE, 2006; HIGGINS; HUQUE, 2015; ISEKI; HOUTMAN, 2012; ISMAIL, 2014). 
Levantamentos realizados pelo governo da Suíça ${ }^{3}$ indicam um ganho econômico de $20 \%$ dos custos do ciclo de vida de projetos executados sob a égides das PPP/PFI para o ente público. Esses ganhos são empregados nos métodos construtivos de instalações, com otimizações de procedimentos (Quadro 1).

${ }^{3}$ Guide pratique PPP/PFI Suisse Bâtiment (2016, p. 20). 
Quadro 1 - Benefícios comparados para os agentes

\section{Benefícios para as autoridades públicas}

Benefícios econômicos (alívio financeiro/Eficiência);

Os custos do ciclo de vida de uma propriedade são sistematicamente geridos por meio de PPP/PFIs, responsabilidade direta do ente privado e subsidiariamente pelo ente público;

Integração dos custos do ciclo de vida do projeto, decisão de aquisição (cálculo da rentabilidade e definição contratual);

As capacidades de inovação(ões) dos parceiros privados podem ser explorada(s);

Operacionalização acelerada dos projetos, com maior respeito aos prazos pactuados;

O uso da PPP/PFI gera o efeito de aprendizado para os órgãos públicos;
Benefícios para o parceiro privado

Novos mercados e setores de atividade;

Aquisição de valor adicional ao longo do ciclo de vida do projeto;

Otimização de competências durante o ciclo de vida do projeto;

Melhor visibilidade do privado em relação à tomada de crédito, em função da credibilidade adquirida fruto da concretude do certame e entrega do serviço;

Relações comerciais de longo prazo com fluxos de caixa estáveis (dada a segurança das garantias);

Profissionalização das relações com as autoridades públicas.

Garantia/otimização de tarefas públicas, atuação de ganhos;

Operação de Know-how privado;

Simplificação de tarefas operacionais da administração;

PPP/PFls podem reduzir as despesas da administração pública por meio da terceirização de trabalhos preparatórios;

Orçamento de manutenção e retenção de valor garantido (perspectiva do usuário);

Preservação de recursos dentro da Administração Pública para alocação em outros projetos;

Fluxo de caixa sustentável em razão da apresentação dos estudos de viabilidade técnica, econômica, financeiro e ambiental.

Fonte: Adaptado de Association PPP Suisse (2016, p. 19). 
O processo de estruturação de PPP/PFls pode sofrer nuances conforme o marco regulatório e legislação vigente do país ou ente subnacional interessado em desenvolver projetos sob este instituto. O campo de aplicação do projeto pode estabelecer o seu formato. Logo, é possível encontrar uma baixa participação do ente privado no processo de prestação do serviço ou uma alta com a entrega definitiva (privatização) de ativos públicos para investidores privados.

Segundo o Public - Private Infrastructure Advisory Facility (PPIAF), o grau de participação decorre do nível de envolvimento nos processos operacionais e nos investimentos de capital para a realização do serviço previsto no objeto do edital de licitação de órgãos públicos. O envolvimento efetivo do setor privado é essencial para que projetos de PPP/PFI não sucumbam a seleção adversa. Com intuito de exemplificar as dinâmicas descritas, na Figura 1, encontra-se a sistematização da graduação de participação da iniciativa privada em projetos públicos; na Figura 2, tem-se a estrutura padrão de modelagem de PPP/PFIs e, na Figura 3, um diagrama do ciclo de vida de Projeto de PPP/PFI.

Figura 1 - Graduação de participação da iniciativa privada em projetos públicos

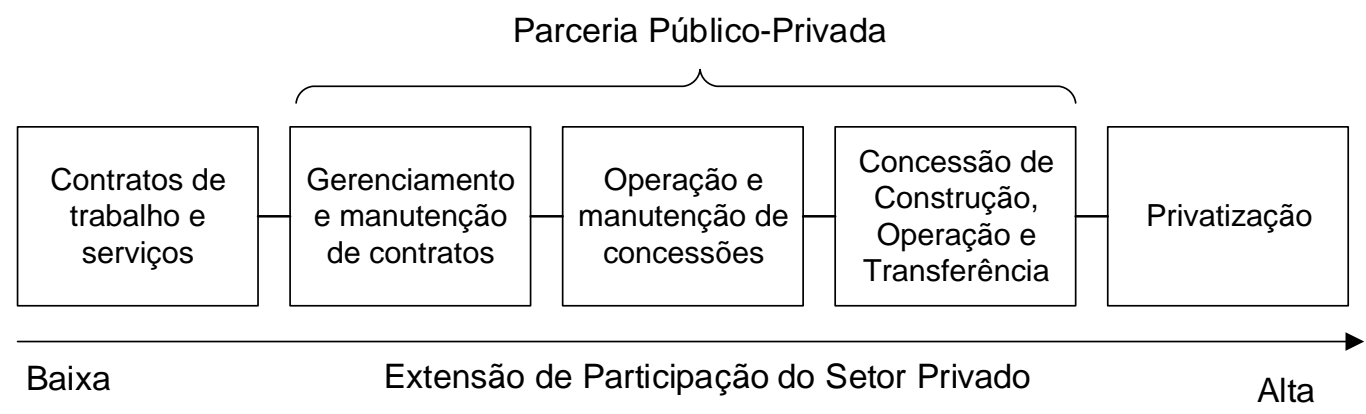

Fonte: Adaptado de PPIAF (2009).

Entretanto há uma padronização na literatura internacional de um framework do rito de contratação conforme demonstrado a seguir. 
Figura 2 - Estrutura padrão de modelagem de PPP/PFIs

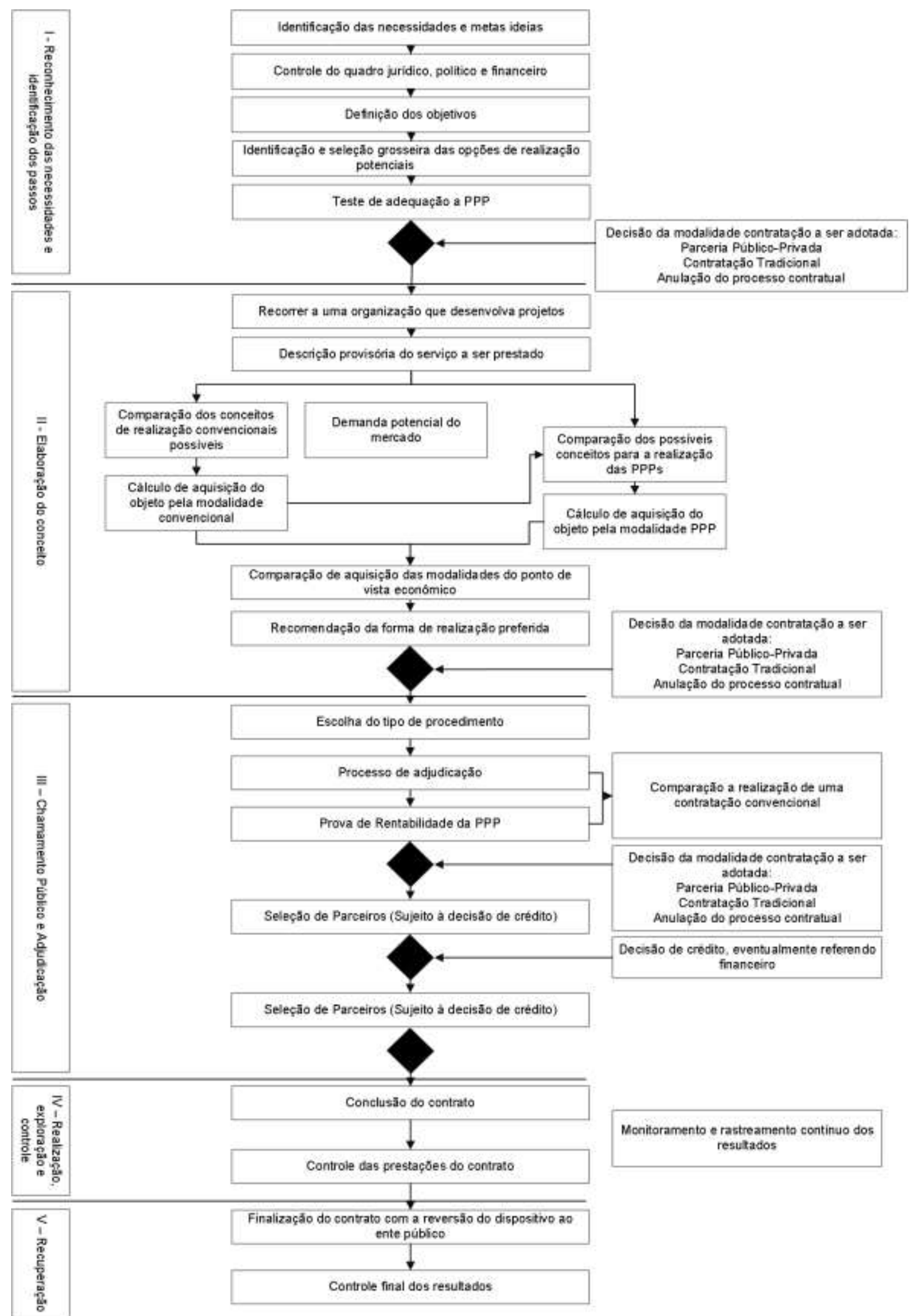

Fonte: Adaptado de Association PPP Suisse (2016, p. 18). 
Figura 3 - Diagrama do ciclo de vida de projeto de PPP/PFI

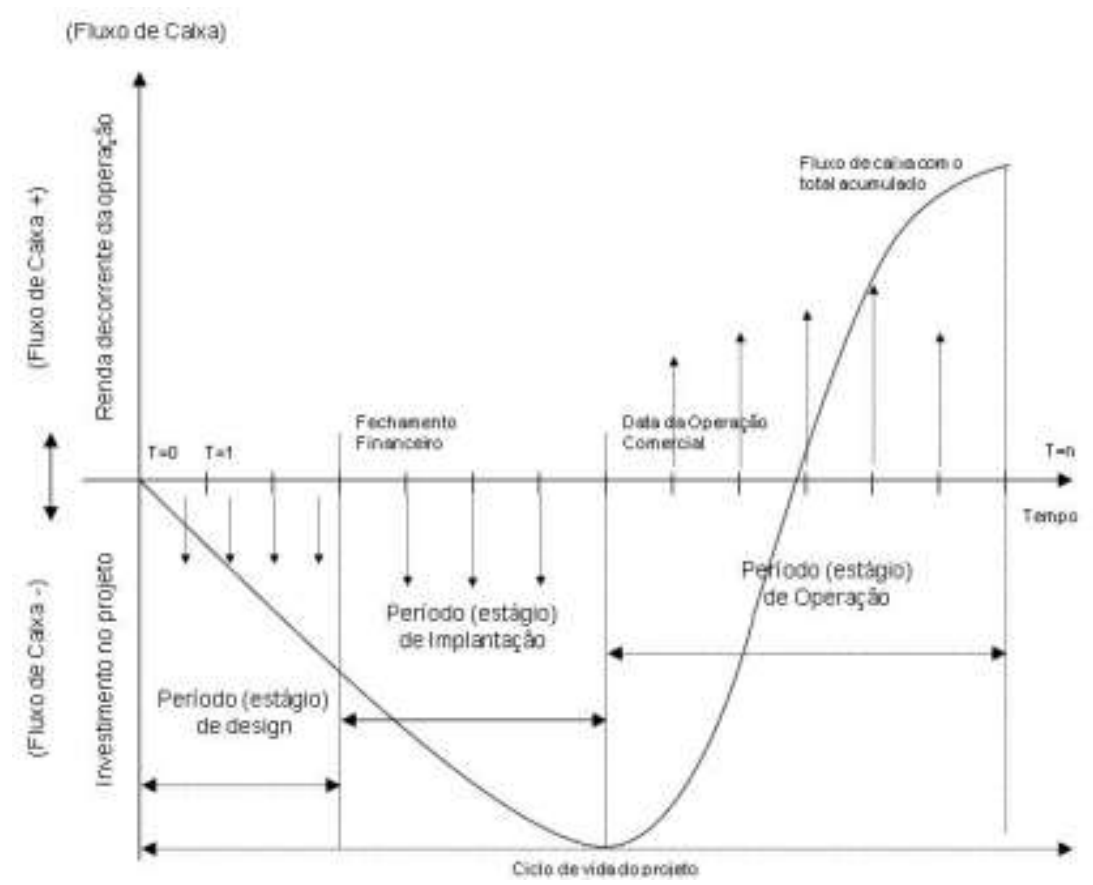

Fonte: Adaptado de Khmel e Zhao (2016).

Percebe-se que, na figura 2, há uma padronização na literatura internacional de um framework do rito de contratação. Na figura 3, visualiza-se o ciclo de vida de um contrato de Parceria Público-Privada. Esse é constituído essencialmente por três etapas: (i) design, (ii) implantação e (iii) operação.

Ainda no escopo da literatura internacional, parte considerável da literatura sobre PPP/PFls analisa à importância de variáveis quantitativas e modelos financeiros (KURNIAWAN; MUDJANARKO; OGUNLANA, 2015), principalmente as relacionadas as restrições de orçamentos decorrentes dos déficits públicos (BUSO; MARTY; TRA, 2014; EMEK, 2015; MARTINS; MARQUES; CRUZ, 2014; MOTA; MOREIRA, 2015). Dessa forma, verifica-se maior prevalência de estudos de PPP/PFIs sob uma perspectiva financeira, sendo, um pouco, relegadas perspectivas de relevância política, jurídica, macroeconômica e até cultural das localidades interessadas em desenvolver projetos sobre a égide do instituto.

\subsection{VALUE FOR MONEY - VfM}

Muito embora, entende-se, nesta tese, que o conceito do Value for Money VfM é fruto da otimização dos custos líquidos no curso do contrato ao serviço prestados a um dado padrão de qualidade definido pelo ente concedente, ou seja, trata-se da medição da relação custo-benefício de um dado projeto (CLARK; ROOT, 
1999), é possível encontrar diferentes definições do conceito na literatura especializada.

Akbiyikli e Eaton (2006) referenciando trabalhos de Rutter e Potter (2003), estabelecem três critérios de desempenho relativos à aquisição de ativos para a operacionalização da PPP/PFI.

\begin{abstract}
A economia reflete a qualidade e o custo dos recursos obtidos através do processo de aquisição nos estágios ao longo da vida útil de um bem. A eficiência reflete o gerenciamento da entrega e operação do bem ao longo de sua vida útil. A eficácia reflete o nível de desempenho alcançado ao longo da vida útil do ativo (HUNTER; KELLY; TRUFIL, 2006, p. 20).
\end{abstract}

Segundo o The Private... (2000, p. 1, § 24, tradução do autor), o VfM é: "A economia, eficiência e eficácia com que uma entidade usou seus recursos para desempenhar suas funções". Johannisse e Coenen (2000), entendem o VfM como um ativo qualitativamente melhor para o mesmo montante financeiro, ou equivalência de qualidade com menor custo pelo serviço entregue ao cidadão.

Akbiyikli e Eaton (2006, p. 20, tradução do autor) definem o VfM como:

O valor para o dinheiro é um problema e um processo que abrange o ciclo de vida completo desde o início até o final da vida útil do bem ou a conclusão do contrato. Os ganhos de valor para o dinheiro são melhorias nos requisitos do usuário.

Destacam ainda a definição do Scottish Government Riagnaltas na h-Alba Gov.Scot (2006) como a

Combinação ideal de custo e qualidade de toda a vida (ou adequação para fins) para atender aos requisitos do usuário e ...". é crucial para o objetivo mais amplo de oferecer serviços públicos de alta qualidade e custo efetivo ".

O VfM de acordo com ACCA (2002) é

A sinergia virtual criada e uma comparação feita entre a Melhor e a Oferta Final e a execução do serviço feita diretamente pela iniciativa pública. "O valor para o dinheiro é uma questão que deve ter continuidade ao longo do ciclo de vida do projeto e a avaliação do risco deve continuar até o final do período da concessão.

Outrossim, nesta tese, considera-se que o VfM é fundamentado na mensuração dos custos aos riscos observados em cada uma das etapas do projeto, sendo possível dimensioná-lo por meio da distribuição de responsabilidades e riscos entre as partes (LI et al., 2005; MY et al., 2017). 
Os setores privado e público assumem o domínio das atividades e riscos mais adequados às suas competências. Riscos remetidos a uma das partes devem ser considerados para a supressão dos valores quando realizados na direção "privado para o público". No caso em que o privado assume mais atribuições que originalmente estabelecido, há como resultado receitas adicionais (HONG KONG INSTITUTE OF SURVEYORS, 2009; ISMAIL, 2014; WU et al., 2016).

Segundo Chang (2015), o VfM baseia-se na comparação dos custos que o setor público assume sob diferentes formas de contratação de serviço, na figura a seguir é possível verificar a composição dos custos na modalidade de contratação direta pelo ente público e sob o rito da PPP/PFI (Figura 4).

Figura 4 - Comparativo de custos ${ }^{4}$

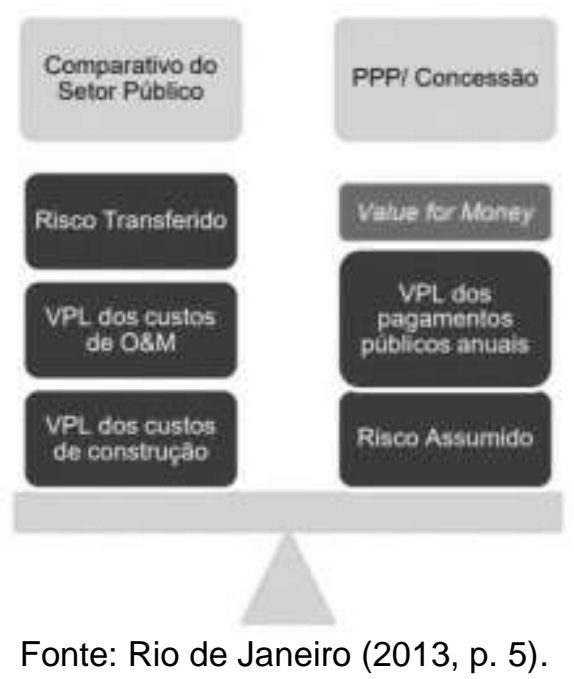

Para Nisar (2013), o VfM deve considerar o modo de aquisição pública tradicional, a saber: i) Cômputo comparativo do custo de implantação, operação e manutenção do projeto pela iniciativa pública a transferência do serviço para ser operado pela iniciativa privada com o pagamento de contraprestações por período pré-determinado e ii) Modelo de concessão ${ }^{5} \mathrm{com}$ a simulação dos fluxos de desembolso realizados pelo ente público à iniciativa privada em função do serviço prestado à população beneficiada por ele.

Fortes críticas têm sido construídas acerca da abordagem do VfM como instrumento legítimo para o processo de tomada de decisão de gestores públicos em razão de sua forte ambiguidade conceitual (MCKEVITT; DAVIS, 2016), subjetividade no processo de transferência de risco (GROUT, 1997) e restrita abordagem da

\footnotetext{
${ }^{4}$ Implantação, Operação e Manutenção de um serviço.

${ }^{5}$ Sendo PPP/PFIs uma das modalidades possíveis.
} 
dimensão financeira (MORALLOS; AMEKUDZI, 2008; SHAOUL, 2005). O VfM se vale de previsão de fluxo futuros de entrada de caixa e do uso da taxa de desconto nos projetos (AKBIYIKLI; EATON, 2006), ocasionando desconfiança aos gestores públicos na adoção do instituto de PPP/PFls.

A pesquisa adota o conceito de VfM proposto por Decorla-Souza, Ham e Timothy (2016), o VfM é o produto da diferença financeira obtida pelo Valor Presente Líquido da implantação, operação e manutenção do serviço realizado pela iniciativa pública e pela privada - durante o período de concessão do serviço (CARBONARA; COSTANTINO; PELLEGRINO, 2014).

Matematicamente, tem-se a fórmula da equação 01.

Equação 01:

$V f M=\sum_{t=0}^{n} \frac{Y C_{t}}{(1+r)^{t}}-\sum_{t=0}^{n} \frac{C C_{t}+O M_{t}+R R_{t}+C O_{t}}{(1+r)^{t}}$

Em que:

$V f M=$ Value for Money;

$Y C_{t}=$ Custo anual da operação do serviço $x$ pela modalidade de PPP/PFI;

$r \quad=$ Taxa de desconto;

$C C_{t}=$ Custo de Implantação do projeto pelo órgão público no ano $t$;

$O M_{\mathrm{t}}=$ Custo de Operação e Manutenção do projeto pelo órgão público no ano $t$;

$R R_{t}=$ Custo de Renovação do projeto pelo órgão público no ano $t ;$

$\mathrm{CO}_{\mathrm{t}}$ = Excedente de gastos no ano t para o provimento do serviço $x$ pelo ente público.

Observa-se que, embora seja um conceito relativo, o VfM não apresenta de forma categórica quais dimensões devem ser avaliadas em um projeto pelo ente público demandante do serviço, tornando possível a seleção adversa de projetos por meio de distorções nas análises de sensibilidade das premissas adotadas, seja na implantação, operação ou manutenção do serviço. 


\subsection{FATORES CRÍTICOS PARA O SUCESSO - FCSs DE PPP/PFIS}

Originalmente cunhado por D. Ronald Daniel, em 1961, os Fatores Críticos para o Sucesso (Critical Success Factors - CSFs) tornaram-se um conceito popular por meio de John F. Rockart (LEIDECKER; BRUNO, 1984). Os CSFs ou FCSs de uma organização ou instituto teórico são elementos essenciais para que um dado projeto organizado por um ente público ou privado alcance o sucesso de sua missão.

De acordo com Rockart (1979), poucas áreas essenciais do negócio precisam ser executadas corretamente para este prospere. Caralli et al. (2004) apresentam as 5 etapas para a derivação dos FCSs no processo de modelagem dos fatores: i) definição do escopo; ii) coleta dos dados; iii) análise dos dados coletados, iv) derivação dos fatores e $\mathrm{v}$ ) análise final dos FCSs para o entendimento colateral de seus efeitos via Analytic Hierarchy Process (AHP) por permitir melhor eficácia na tomada de decisão Padrão Multicritério (MCDM). Caralli et al. (2004) afirmam também que os modelos estruturais conduzem a maior confiabilidade nos resultados.

No âmbito do conjunto de técnicas para a obtenção dos FCSs, considera-se, nesta tese, a proposta de Amberg, Fischl e Wiener et al. (2005) narradas no quadro a seguir e valendo-se dos Métodos de revisão literária, pesquisa via questionários e entrevistas estruturadas.

Quadro 2 - Métodos de pesquisa de FCSs

\begin{tabular}{ll}
\hline \multicolumn{1}{c}{ Método de Pesquisa } & \multicolumn{1}{c}{ Autor } \\
\hline Pesquisa ação & Jenkins, Kock e Wellington (1999) \\
\hline Estudo de Caso & Gibson, Holland e Light (1999), Sumner (1999) \\
\hline Entrevista de Grupo & Khandewal e Miller (1992) \\
\hline Técnica Delphi & $\begin{array}{l}\text { Atthirawong e McCarthy (2001), Brancheau, Janz e } \\
\text { Wetherbe (1996) }\end{array}$ \\
\hline Revisão literária & Esteves e Pastor (1999), Umble e Umble (2001) \\
\hline Análise Multivariada & Dvir et al. (1996) \\
\hline Análise de Cenário & Barat (1992) \\
\hline Entrevistas estruturadas & Rockart e Van Bullen (1986) \\
\hline Pesquisa via questionários & Shah e Siddiqui (2006) \\
\hline Fonte: Adaptado de Amberg, Fischl e Wiener (2005).
\end{tabular}

No Quadro 3, apresentam-se os FCSs de 9 referências da literatura Kurniawan, Mudjanarko e Ogunlana (2015); Kušljić e Marenjak (2013); Li et al. (2005); Mota e Moreira (2015); Ng et al. (2012); Osei-Kyei e Chan (2015); PPIAF (2009); Zhang (2005a, 2005b) - sobre o tema. Nota-se que pode obtido um grupo de 
variáveis e que essas interferem direta ou indiretamente na qualidade e sucesso das PPP/PFIs.

Quadro 3 - Fatores críticos para o sucesso das PPP/PFIs

\begin{tabular}{|c|c|c|}
\hline Li et al. (2005) & Zhang (2005a) & Zhang (2005b) \\
\hline Pesquisa Efetiva & Viabilidade Econômica & $\begin{array}{l}\text { Riscos sociais, } \\
\text { legais e políticos }\end{array}$ \\
\hline Viabilidade do Projeto & $\begin{array}{l}\text { Alocação ajustável de risco e contratos } \\
\text { confiáveis }\end{array}$ & $\begin{array}{l}\text { Condições } \\
\text { econômicas e } \\
\text { comerciais }\end{array}$ \\
\hline Segurança governamental & Pacote financeiro & Demanda pública \\
\hline Condições econômicas & $\begin{array}{l}\text { Ambiente econômico aberto para } \\
\text { investimentos }\end{array}$ & Fatores financeiros \\
\hline \multirow[t]{2}{*}{ Fatores financeiros } & Consórcio confiável com força técnica & $\begin{array}{l}\text { Problemas } \\
\text { relacionados com o } \\
\text { setor público }\end{array}$ \\
\hline & & $\begin{array}{l}\text { Problemas } \\
\text { relacionados com o } \\
\text { setor privado }\end{array}$ \\
\hline PPIAF (2009) & $\mathrm{Ng}$ et al. (2012) & $\begin{array}{c}\text { Kušljić e Marenjak } \\
\text { (2013) }\end{array}$ \\
\hline Volume de investimento & Fatores técnicos & \multirow{5}{*}{$\begin{array}{l}\text { Análise sob a ótica } \\
\text { do cliente (Serviço } \\
\text { realizado, reputação } \\
\text { pública, contribuição } \\
\text { pública, reputação } \\
\text { política, entregas do } \\
\text { projeto) }\end{array}$} \\
\hline $\begin{array}{l}\text { Investimento privado e } \\
\text { financiamento privado }\end{array}$ & Fatores econômicos e financeiros & \\
\hline Enquadramento Jurídico & Fatores sociais & \\
\hline \multirow[t]{2}{*}{ Receitas } & Fatores políticos e legais & \\
\hline & Outros fatores & \\
\hline Mota e Moreira (2015) & $\begin{array}{c}\text { Kurniawan, Mudjanarko e Ogunlana } \\
(2015)\end{array}$ & Kyei e Chan (2015) \\
\hline Restrições orçamentárias & \multirow{3}{*}{$\begin{array}{l}\text { Indicadores financeiros - Entradas (Custo } \\
\text { do Projeto, volume/demanda (tráfego), } \\
\text { Receita prevista, Custo Operacional e de } \\
\text { manutenção, Cronograma de pagamento } \\
\text { de empréstimo, Juros e taxas, Custo do } \\
\text { financiamento) }\end{array}$} & $\begin{array}{l}\text { Apropriada alocação } \\
\text { e compartilhamento } \\
\text { de risco }\end{array}$ \\
\hline Condições de mercado & & $\begin{array}{l}\text { Consórcio privado } \\
\text { forte }\end{array}$ \\
\hline $\begin{array}{l}\text { Ambiente } \\
\text { macroeconômico }\end{array}$ & & Suporte político \\
\hline $\begin{array}{l}\text { Qualidade institucional e } \\
\text { sistema legal }\end{array}$ & \multirow{3}{*}{ 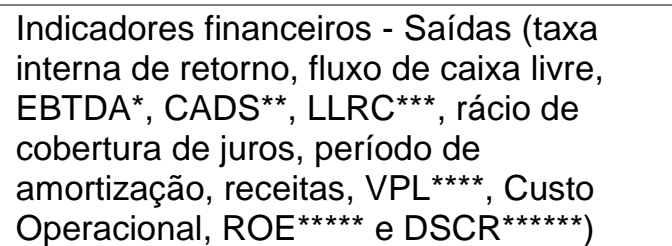 } & $\begin{array}{l}\text { Apoio e suporte } \\
\text { comunitário }\end{array}$ \\
\hline Ambiente político & & $\begin{array}{l}\text { Transparência nas } \\
\text { aquisições }\end{array}$ \\
\hline $\begin{array}{l}\text { Experiências preliminares } \\
\text { com PPP/PFls }\end{array}$ & & \\
\hline
\end{tabular}

Fonte: Adaptado de Mota e Moreira (2015).

${ }^{6}$ EBTIDA - Earnings Before Interest, Taxes, Depreciation and Amortization, tradução livre: Lucros antes de juros, impostos, depreciação e amortização.

${ }^{7}$ CADS - Cash Available for Debt Service tradução livre: Dinheiro Disponível para Serviço da Dívida.

8 LLCR - Loan Life Coverage Ratio tradução livre: Rácio de Cobertura de Vida do Empréstimo.

9 VPL - Valor Presente Líquido.

${ }^{10}$ ROE - Return On Equity tradução livre: Retorno sobre o patrimônio.

${ }^{11}$ DSCR - Debt-Service Coverage Ratio tradução livre: Relação de cobertura da dívida. 
Autores como Opawole e Jagboro (2017) destacam outros fatores que influenciam o desempenho do parceiro privado na relação comercial, a saber: técnicas, maturidade de mercado, política, jurídica, financeira, compras, incentivo e regulação. Em especial, esta última constitui-se um fator forte e eficaz e tende a diminuir as incertezas da regulamentação governamental, aumentando as chances de sucesso dos projetos PPP/PFIs (HAMMAMI; RUHASHYANKIKO; YEHOUE, 2006; WANG, 2015).

Convém ressaltar também que a estabilidade da taxa de câmbio atua como outro fator definitivo em projetos de PPP/PFIs, cuja tecnologia empregada não é necessariamente desenvolvida internamente no país contratante. Ademais, o provisionamento de recursos também versa como fator chave para a sustentabilidade da medida, em caso de mudanças de políticas públicas que venham a causar reversões para reversão de políticas como variáveis altamente significativas para projetos decorrentes de PPP/PFIs.

As diretrizes estipuladas pela iniciativa pública fundamentam o conjunto de fatores que influenciarão na qualidade das PMls e no sucesso das PPP/PFIs, resultado da montagem de editais de PPP/PFIs mais robustos e aderentes as necessidades da comunidade a ser alcançadas pelo serviço. O Capítulo 5 desta tese agrupa informações de FCSs de PMls encontrados de forma esparsa na literatura consultada para expansão do debate sobre FCSs de PPP/PFIs e PMls. 


\section{MANIFESTAÇÃO DE INTERESSE E GERENCIAMENTO DE PROJETOS}

Este Capítulo traz reflexões sobre o problema de modelagem preliminar das PPP/PFls por meio do instituto PMI, suas definições conceituais, suas nuances terminológicas. Ademais, inclui a apresentação dos fatores críticos para o sucesso das PMls e a influência dos fatores críticos para o sucesso das PPP/PFI nos fatores de PMls. Por se tratar de um tema que versa sobre problemas de modelagem de projetos, utiliza-se como, referencial para a crítica de PMI, a teoria de gestão de escopo. Por fim, problematiza-se a questão da interface em projetos públicos e analisa-se a teoria de Visão do Produto ${ }^{12}$.

\subsection{DEFINIÇÃO DE PMI}

A construção institucional de um projeto estruturado nos moldes de uma PPP/PFI encerra um elemento fundamental: o PMI (Procedimento de Manifestação de Interesse). Entendido como um instituto, ou seja, estabelecido como um regulamento ou regime, o PMI serve de base para a modelagem de projetos de PPP e impacta de forma significativa no resultado, isso é, garantindo, ou não, a aderência às diretrizes que regem o serviço demandado pelo ente público requerente.

Todavia, apesar da importância reconhecida internacionalmente deste instrumento, ele não foi incluído no marco regulatório brasileiro, ao tempo da promulgação da Lei Federal ํo 11.079 de 30 de dezembro de 2004. Consequentemente, com a ausência de indicações sobre como manifestar interesse ou necessidades, bem como regras claras para a proposição de PPPs, resultou em insegurança jurídica para as partes interessadas, tanto para a parte proponente quanto a parte concedente.

Operacionalmente, a PMI (motivada ou provocada) possui características similares a Propostas Não Solicitadas (PNS), aproximando-se da terminologia em inglês Unsolicited Proposal (UNP)

Não há, na regulamentação federal [Brasil], qualquer menção expressa a propostas não solicitadas (PNS), ao menos na forma com que esse instrumento é geralmente usado em outros países. Ocorre que uma regra específica do marco legal brasileiro, mencionada a seguir, permitiu uma

$12 \mathrm{O}$ conceito mais recente na literatura especializada sobre gerenciamento de projetos, destacandose as Propriedades de Visão, as quais foram utilizadas na análise e discussão do conceito de PMI. 
prática que, em algum sentido, se assemelha ao conceito de PNS. (SIQUEIRA MORAES; REYES-TAGLE, 2017, p. 20)

E ainda, é importante destacar que:

O governo do estado de São Paulo aprovou o decreto no 57.289 , de 30 de agosto de 2011, que estabelece as manifestações de interesse privado, ou MIP. As MIP aproximam-se mais do conceito internacional de propostas não solicitadas do que os PMI, porque representam estudos espontaneamente entregues pelo setor privado; são avaliações preliminares dos projetos e não constituem estudos detalhados a ponto de representarem propostas concretas para o desenvolvimento de projetos. No caso do governo de São Paulo, as MIP devem se transformar em chamamento público no qual outras empresas poderão contribuir com seus estudos e investigações. Em qualquer caso, o resultado desse processo de contribuições do setor privado, da mesma maneira que os $\mathrm{PMI}$, é a transformação em uma licitação para identificar o parceiro privado com quem o governo assinará o contrato de PPP/PFI. Apesar dessa experiência do estado de São Paulo, a grande maioria dos casos no Brasil tem início com os PMI.

Há importantes semelhanças entre o modelo de PMI geralmente realizado no Brasil e as PNS. Em primeiro lugar, em ambos casos, o setor privado realiza as avaliações financeiras técnicas e jurídicas necessárias à elaboração do modelo de negócios e do contrato. Em segundo lugar, o governo não arca com os custos, tais como a contratação de consultores para a elaboração dos estudos técnicos e a realização de avaliações de engenharia. A diferença fundamental entre os $\mathrm{PMI}$ e a prática internacional de PNS é que os PMI são tipicamente precedidos de uma demanda do governo, que estabelece as características essenciais do projeto aos quais os estudos vão se referir, bem como os parâmetros que deverão ser seguidos pelos elaboradores dos estudos. Assim, enquanto as propostas não solicitadas permitem que o setor privado identifique oportunidades de projetos fora das prioridades governamentais, os PMI reduzem a flexibilidade de decisão do setor privado. Outra diferença importante é que mais de uma empresa pode atender ao convite do governo, criando, na prática, uma competição, já que o poder público pode escolher os estudos que utilizará. Alguns entes subnacionais reconhecem a possibilidade de receber provocações do setor privado referentes a projetos de PPP/PFI a ser desenvolvidos. Contudo essas manifestações espontâneas de interesse não representam, até onde informações são disponíveis, propostas com conteúdo suficiente para a implementação de projetos, sendo, portanto, seguidas de procedimentos de manifestação de interesse, que convidam empresas interessadas a realizar os estudos de avaliação, preparação e planejamento de projetos. (SIQUEIRA MORAES; REYES-TAGLE, 2017, p. 21)

Em suma, ambos institutos, PMls e as PNSs, descrevem as informações básicas que orientam os proponentes durante os estudos preliminares e, consequentemente, influenciam diretamente nas decisões que determinarão os custos das modelagens dos projetos.

Pode-se considerar, porém, que as PMls se distanciam das PNSs na formalização do ato de publicação da iniciativa e no modelo de competição. As PNSs são manifestações de interesse privado formuladas a partir de necessidades identificadas, aproximando-se do instituto das Manifestações de Interesse Privado 
(MIP). Já as PMls partem de iniciativas tomadas pelos entes públicos a uma demanda específica.

Nesta tese estuda-se propostas e soluções para ambos os casos. Portanto, ao longo do texto adota-se o conceito de PMI de forma extensiva, isto é, um instrumento de interface das diretrizes determinadas pelo Estado e um estudo dos serviços a serem prestados pelo ente privado.

Segundo Pereira (2013, p. 3), em publicação eletrônica, a PMI é um mecanismo que "institucionaliza o relacionamento pré-licitação entre o poder concedente e o mercado interessado na futura PPP/PFl", não sendo afetado por qualquer decisão microeconômica sub ótima, após a decisão de contratação da PPP/PFI.

O instrumento habilita a administração pública, por meio de seus representantes, a organizar um determinado serviço à população no qual o ente privado possui competência para atuar. Se a PMI for elaborada de forma a capturar as incertezas dos cenários, variação das tecnologias e previsões de retorno de investimentos, de forma a garantir isonomia entre os potenciais proponentes, essa tornar-se-á um potente instrumento para que a administração pública alcance projetos bem modelados (critérios claros e sem margens dúbias) e para permitir a forte competição entre os proponentes da iniciativa privada.

Outro elemento destacado por Pereira (2013), é a importância do Poder Público estar ciente da visão da iniciativa privada em relação ao projeto no curso dos estudos técnicos que resultará no relatório final afirmando ou contestando a viabilidade de um determinado projeto. De acordo com o Instituto de Pesquisas de Hong Kong, o propósito de uma PMI quando provocada pelo estado é:

notificar o mercado do projeto e o serviço que o setor público busca a ser entregue aos cidadãos, comunicar os mercados dos prazos propostos, critérios de avaliação dos projetos submetidos, dificuldades a serem dirimidas para que o projeto avance, mensurar a percepção de interesse do mercado no projeto - confirmando ou atentando-se a negativa de interesse, viabilizar um canal de comunicação com os proponentes, de forma a tornar viável a execução do certame, obtendo assim respostas do mercado (Hong Kong Institute of Surveyors, p. 17, 2009).

$\mathrm{Na}$ regulamentação contemporânea brasileira, o Procedimento de Manifestação de Interesse - PMI dispõe que todos os estudos técnicos elencando no edital de chamamento público contenham as diretrizes a serem seguidas e custeado pela proponente ou por instituição ou ainda empresa independente 
especializada no objeto do certame, sendo a contraprestação destes serviços (estudos e análises ${ }^{13}$ ) pagos pelo vencedor do certame da PPP/PFI, caso a iniciativa pública entenda ser pertinente a execução do projeto.

Vale destacar que no recorte brasileiro do estudo, em 04 de dezembro de 2017 por meio do Decreto Lei Federal no 13.529 (BRASIL, 2017), significativas alterações ocorrem no marco regulatório, observando-se a flexibilização dos limites de contratação de projetos com escopo financeiro mínimo de 10 (dez) milhões de reais e passando a autorizar a União a participar de fundo que tenha por finalidade exclusiva financiar serviços técnicos profissionais especializados.

A celeridade do processo de modelagem de Parcerias Público-Privadas não depende diretamente da PMI em si, uma vez que não se sobrepõe à capacidade analítica discricionária dos Estados, por seus técnicos constituídos para prover respectivos julgamentos. Porém, deficiências em clareza, objetividade e completude de conteúdo dos projetos apresentados pode resultar em demora e erros na avaliação do modelo a ser adotado. Este problema pode ser acentuado conforme a especialidade de temas. Os entes federativos podem não possuir corpo técnico especializado e preparado para avaliar tais documentos, prolatando assim a tomada de decisão.

Desenvolver um sistema efetivo para gerenciar PMIs não é fácil, entretanto. Governantes se deparam com muitos trade-offs. Desenvolvedores de políticas públicas tem que endereçar questões tais como o montante de reembolso (se algum) pelo custo de desenvolvimento do proponente original, restrições durante o processo de competição e aprovações dos projetos, coordenação entre várias agências, planejamento efetivo para o desenvolvimento do setor, e encontrar incentivos apropriados para o setor privado iniciar os projetos (HODGES; DELLACHA, 2007, p. 11, tradução do autor).

Em conclusão desta seção, apresentam-se os critérios, que poderiam suprir a base dos requisitos para a análise das respostas dos proponentes as PMIs, elaborados pelo Hong Kong Institute of Surveyors (2009, p. 05):

1. O histórico do proponente na prestação de serviços da natureza requerida pelo cliente do setor público;

2. O equilíbrio de conhecimento técnico e vivencial dos membros de um consórcio e a capacidade destes membros trabalharem em conjunto; e

${ }^{13} \mathrm{~A}$ análise de viabilidade de um PMI prevê um grupo de estudos que variam em quantidades de acordo com a característica do projeto alvo (de impacto socioambiental, de demanda prevista, de capacidade de serviço a entregue, econômico-financeiro, de engenharia e mesmo jurídico). 
3. A capacidade do proponente de satisfazer as necessidades financeiras do projeto e a probidade dos membros dos consórcios comprovadamente.

\subsection{MARCO REGULATÓRIO SOBRE PMIS}

O Procedimento de Manifestação de Interesse evoluiu internacionalmente entre o período de 2004 a 2014 e, especialmente no Brasil, com o advento da regulamentação da Lei Federal de PPP/PFls e como resposta aos constantes questionamentos pelos tribunais de contas estaduais, Controladoria Geral da União e representantes do Ministério Público Estaduais e Federais.

As alegações de assimetria de informação entre atores envolvidos no processo e a ausência de indicadores com critérios objetivos e claros para a escolha do melhor estudo ao caso concreto constituem uma crítica à forma com que o instrumento é conduzido. Ampliando a discussão, há o afrontamento ao princípio constitucional da publicidade, isto é, não há a universalização das regras da PMls. Há, todavia, a constrição de novos proponentes em função do exíguo tempo dado à execução dos estudos.

Questionamentos surgiram por órgãos fiscais de Estados, em especial no Brasil, em relação à utilização do PMI como instrumento para se burlar certames licitatórios, oferecendo informações privilegiadas a um determinado grupo de interesse e, consequentemente, acometendo o princípio da isonomia. A interpretação representa uma compreensão equivocada da legislação em razão de a inexistência de regulamentação do processo preparatório para o certame da Parceria Público-Privada.

\footnotetext{
Pode-se dizer que o PMI institucionaliza o relacionamento pré-licitação entre o poder concedente e o mercado interessado na futura PPP/PFI. Trata-se de um instrumento importante, porque (i) permite que o poder público desenvolva o mercado interessado no projeto, de modo que poderá ampliar o grau de competitividade da futura licitação a depender do modo como o PMI for desenhado e gerido; e porque (ii) é salutar que o poder público entre em contato com a visão da iniciativa privada sobre o projeto durante a fase de desenvolvimento dos estudos de viabilidade (PEREIRA, 2013, p. 3).
}

No intuito de uniformizar tal entendimento e garantir a utilização deste instrumento como mecanismo de transparência na fase anterior à licitação com premissas da concessão postas a público e condições claras do certame, países como o Brasil regulamentaram por meio de Decreto Federativos os mecanismos 
gerais de operação das PMls (Decreto no 8.428, de 2 de abril de 2015). Assim, os Estados de Federações regulamentaram os processos de PMI em seus territórios.

No contexto brasileiro, a iniciativa privada, por intermédio de seus representantes físicos e jurídicos, podem se tornar proponente de estudos de viabilidade e de projetos técnicos e complementares em ato volitivo próprio sem a necessidade de anuência prévia do órgão administrativo (Decreto n 8.428 , de 2 de abril de $2015^{14}$ ).

Não há, no campo do conhecimento das PPP/PFI, uniformidade de entendimento de aplicação do instituto das PMI. O ACT Government, Distrito Federal da Austrália e o Centro de Especialidade em PPP/PFI de cidades sustentáveis e inteligentes ${ }^{15}$, definiu as terminologias das fases de construção de uma PPP/PFI, como:

\begin{abstract}
“Eol” - Expressions of interest for a Project: É a primeira fase de um processo formal de adjudicação de licitações para a submissão de propostas mais detalhadas, ou seja, é a seleção de proponentes realmente capazes de submeterem projetos competitivos;

"RFP" - Request for Proposal: É um pedido público de proposta emitido pelo governo para um determinado projeto. Corresponde à fase de licitação, que envolve a divulgação de propostas mais detalhadas e de material contratual aos proponentes selecionadas na "EOI", para que estes apresentem respostas detalhadas e totalmente custeadas, seguida pela avaliação e seleção do licitante que melhor se qualificar nos quesitos apresentados (ACT_GOVERNMENT, 2016, p. 04, tradução do autor).
\end{abstract}

No Brasil, os institutos "Eol" - Expression of Interest e "RFP" - Request for Proposal - Manifestação de Interesse Privado - MIP e Proposta de Manifestação de Interesse - PMI, respectivamente, eram tratados de forma isolada até 2015. Outros países, por exemplo Coréia do Sul e Estados Unidos da América, mantêm os institutos separados para a eventual contratação de serviços. Entretanto, em 02 de abril de 2015, o decreto presidencial do governo brasileiro ํ․ 8.428 uniformizou o entendimento de MIP e PMI conforme apresentado no quadro 4, para exclusivamente PMI - Proposta de Manifestação de Interesse: "apresentação de projetos, levantamentos, investigações ou estudos, por pessoa física ou jurídica de direito privado, a serem utilizados pela administração pública” (BRASIL, 2017). Um dos resultados da ação governamental foi a aproximação lexical e semântica do

\footnotetext{
${ }^{14} \mathrm{~A}$ regulamentação dispõe em detalhes todas as etapas, regras e critérios para a recepção de processos de PMls, da abertura do edital a seleção, aprovação (homologação e adjudicação) do melhor modelo de projeto.

${ }^{15}$ IESE - Escola da Negócios da Universidade de Navarro.
} 
conceito entendido internacionalmente como Unsolicited Proposal - UNP. Nesta tese, adota-se a sigla em português, PMI.

Quadro 4 - Terminologia de manifestações de interesse comparadas

\begin{tabular}{|c|c|c|c|}
\hline Descrição & MIP & PMI & $\begin{array}{l}\text { PMI após o Decreto Presidencial } \\
\text { n. } 8.428 \text { de } 02 \text { de abril de } 2015\end{array}$ \\
\hline Definição & $\begin{array}{l}\text { Manifestação de } \\
\text { Interesse Privado }\end{array}$ & $\begin{array}{l}\text { Procedimento de } \\
\text { Manifestação de } \\
\text { Interesse }\end{array}$ & $\begin{array}{l}\text { Procedimento de Manifestação de } \\
\text { Interesse }\end{array}$ \\
\hline $\begin{array}{l}\text { Conceito de } \\
\text { aplicação }\end{array}$ & \multicolumn{3}{|c|}{$\begin{array}{l}\text { Instrumento pelo qual poderão ser apresentados: projetos, levantamentos, } \\
\text { investigações ou estudos a serem utilizados pela administração pública. }\end{array}$} \\
\hline $\begin{array}{l}\text { Iniciativa de } \\
\text { Proposição }\end{array}$ & $\begin{array}{l}\text { Iniciativa do setor } \\
\text { Privado }\end{array}$ & $\begin{array}{l}\text { Iniciativa do setor } \\
\text { Público }\end{array}$ & $\begin{array}{l}\text { Iniciativa dos setores Público ou } \\
\text { Privado }\end{array}$ \\
\hline Proponentes & \multicolumn{3}{|c|}{$\begin{array}{l}\text { Pessoa física ou jurídica de direito privado nacionais ou estrangeiras e por ente } \\
\text { público nacional (de qualquer uma das } 3 \text { esferas, contemplando ainda } \\
\text { autarquias). }\end{array}$} \\
\hline $\begin{array}{l}\text { Grau de } \\
\text { utilização dos } \\
\text { estudos } \\
\text { apresentados }\end{array}$ & \multicolumn{3}{|l|}{ Integral ou Parcial } \\
\hline $\begin{array}{l}\text { Viabilidade do } \\
\text { Projeto }\end{array}$ & $\begin{array}{l}\text { Estudo preliminar } \\
\text { de viabilidade; } \\
\text { Teste do VfM - } \\
\text { Value for Money }\end{array}$ & $\begin{array}{l}\text { Teste do VfM - } \\
\text { Value for Money }\end{array}$ & Teste do VfM - Value for Money \\
\hline $\begin{array}{l}\text { Critério de } \\
\text { Seleção }\end{array}$ & $\begin{array}{l}\text { * Instalações de } \\
\text { infraestrutura que } \\
\text { são definidas no } \\
\text { Ato de PPP/PFI; } \\
\text { * Estabelecer } \\
\text { prioridade de } \\
\text { investimento } \\
\text { associada ao plano } \\
\text { nacional de } \\
\text { desenvolvimento } \\
\text { de infraestrutura; } \\
\text { *Encontrar } \\
\text { requerimentos de } \\
\text { iniciativas em } \\
\text { PPP/PFI } \\
\text { fundamentado em } \\
\text { princípios de } \\
\text { benefícios e } \\
\text { lucratividade. }\end{array}$ & $\begin{array}{l}\text { * Instalações de } \\
\text { infraestrutura que } \\
\text { não são } \\
\text { promovidas pelo } \\
\text { governo, mas } \\
\text { disponíveis para } \\
\text { ser iniciada por } \\
\text { meio do arcabouço } \\
\text { de PPP/PFI; } \\
\text { * Confirmar se a } \\
\text { satisfação } \\
\text { econômica do } \\
\text { projeto é viável ou } \\
\text { não; } \\
\text { * Verificar se o } \\
\text { processo de } \\
\text { aquisição via } \\
\text { PPP/PFI pode } \\
\text { reduzir o fardo } \\
\text { financeiro do } \\
\text { governo em relação } \\
\text { ao processo } \\
\text { tradicional de } \\
\text { aquisição. }\end{array}$ & $\begin{array}{l}\text { * Cumprimento dos critérios dos } \\
\text { órgãos demandantes pelo serviço, } \\
\text { atendendo o escopo mediante o } \\
\text { termo de referência, dos projetos, } \\
\text { levantamentos, investigações ou } \\
\text { estudos; } \\
\text { * "Coerência e consistência das } \\
\text { informações que subsidiaram sua } \\
\text { realização" (art. 10, II, do Dec. } \\
\text { 8.428); "a adoção das melhores } \\
\text { técnicas de elaboração, segundo } \\
\text { normas e procedimentos científicos } \\
\text { pertinentes, e a utilização de } \\
\text { equipamentos e processos } \\
\text { recomendados pela melhor } \\
\text { tecnologia aplicada ao setor" (art. } \\
\text { 10, III, do Dec. 8.428); "a } \\
\text { compatibilidade com a legislação } \\
\text { aplicável ao setor e com as normas } \\
\text { técnicas emitidas pelos órgãos e } \\
\text { pelas entidades competentes" (art. } \\
\text { 10, IV, do Dec. 8.428); "a } \\
\text { demonstração comparativa de } \\
\text { custo e benefício da proposta do } \\
\text { empreendimento em relação a } \\
\text { opções funcionalmente } \\
\text { equivalentes" (art. 10, V., do Dec. } \\
\text { 8.428); "o impacto socioeconômico } \\
\text { da proposta para o } \\
\text { empreendimento" (art. 10, VI, do }\end{array}$ \\
\hline
\end{tabular}


(A) Períodos referentes a projetos realizados na Coréia do Sul.

(B) Períodos referentes a projetos realizados nos EUA.

Fonte: Adaptado de Yun et al. (2015).

Com o intuito de justiça e coerência nas práticas comerciais vigentes, deverse-ia considerar a simplificação dos processos, a redução de marcos burocráticos, para o processo de autorização da execução do rito da PMI em nível global, e a atribuição de remuneração da empresa ou profissional responsável pelo desenvolvimento dos estudos preliminares e subsidiários para o certame da $\mathrm{PPP} / \mathrm{PFI}$, sendo não mais ônus exclusivo do proponente da PMI, mas do vencedor do certame da PPP/PFI.

Figura 5 - Fluxograma comparativo das fases da PMI

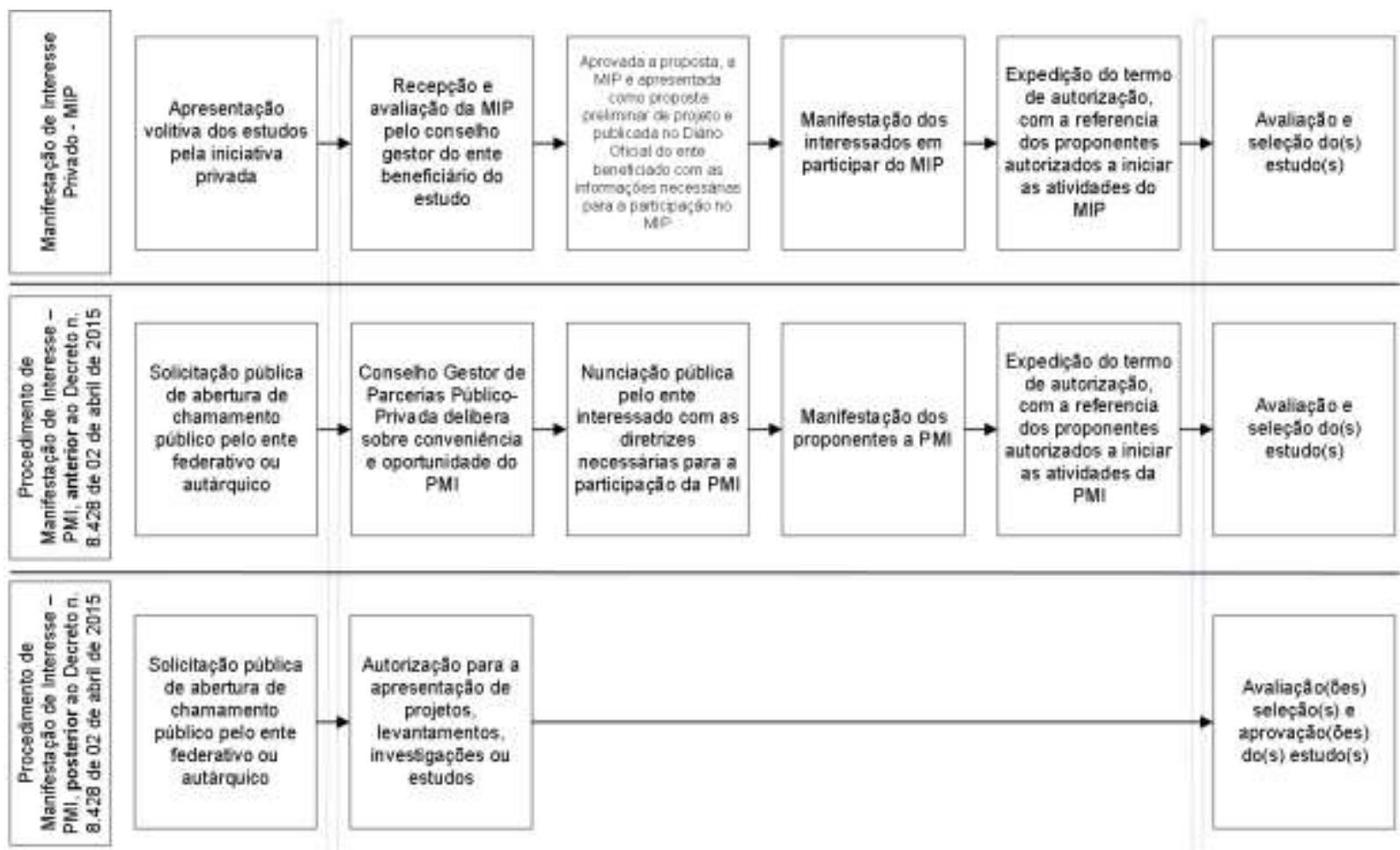

Fonte: Adaptado do Procedimentos... (2016).

A uniformização dos PMls trouxe o apaziguamento e segurança jurídica para tornar o PMI o ponto de partida a todos os estudos preliminares que pautarão as PPP/PFIs, a partir da publicação do chamamento público. A administração direta concede sem efeito exclusivo ou direito de preferência, tampouco o compromisso de realização de certame, ou ressarcimento de valores gastos no processo de elaboração dos estudos, autorização pessoal e intransferível para que o ente privado apresente seu(s) projeto(s). 
Concluídos os estudos, o ente privado aciona o órgão público para a submissão formal destes resultados, o qual constituirá e designará comissão específica para avaliar os projetos de acordo com as normas, regras e critérios preestabelecidos no edital de chamamento que modelou as diretrizes do PMI objeto.

Discute-se a questão ética da participação direta das empresas na condução dos estudos técnicos. Na maioria dos casos, a entidade pública não possui conhecimento técnico necessário, ficando a inovação a cargo da iniciativa privada ou de profissionais externos ao órgão demandante do serviço.

Salienta-se que a definição e, consequentemente a participação prévia de profissionais e empresas na modelagem dos projetos preliminares corroboram para a assimetria entre os competidores do edital da PPP/PFI. Com o intuito de trazer equidade no processo, poderia ser elaborada trava restritiva à participação deste concorrente na PPP/PFI, entretanto, tal restrição feriria o princípio da legalidade e ampla competição representado também pelo princípio administrativo da Impessoalidade. Em todos os casos a potencial assimétrica de informação pode ensejar ato executivo de uma das partes interessadas para a suspensão do certame, sob a alegação do princípio da Moralidade.

Estudos desenvolvidos por PPIAF (2014), em 28 países da África, Ásia, América Latina e Caribe, apontam a presença de significativos investimentos em projetos de infraestrutura nos países que apresentaram PMls. Como resultados, os estudos mostraram que $75 \%$ do ranking dos que mais receberam investimentos possuem um framework oficial para recepcionar as PMIs, 55\% e $65 \%$ possuem algum tipo de política/normativa dedicada às PMls e $85 \%$ dos países possuem algum mecanismo para a inserção do instituto dentro de seus ordenamentos jurídicos.

De acordo com PPIAF (2014, p.10, tradução do autor):

- "Documentos de políticas públicas que delineiam princípios gerais para o tratamento das PMls;

- Orientações diretivas ou circulares que estabeleçam pormenores específicos vinculativos ou meramente recomendados;

- Alterações legislativas a leis existentes, genéricas, de contratos públicos e/ou leis de PPP/PFI; e

- Novas leis de PPP/PFI, incluindo regulamentos relativos ao tratamento de PMIs". 
Na Figura 6, tem-se o framework universal do instituto das PMI (UNP).

Figura 6 - Framework padrão de PMI (UNP)

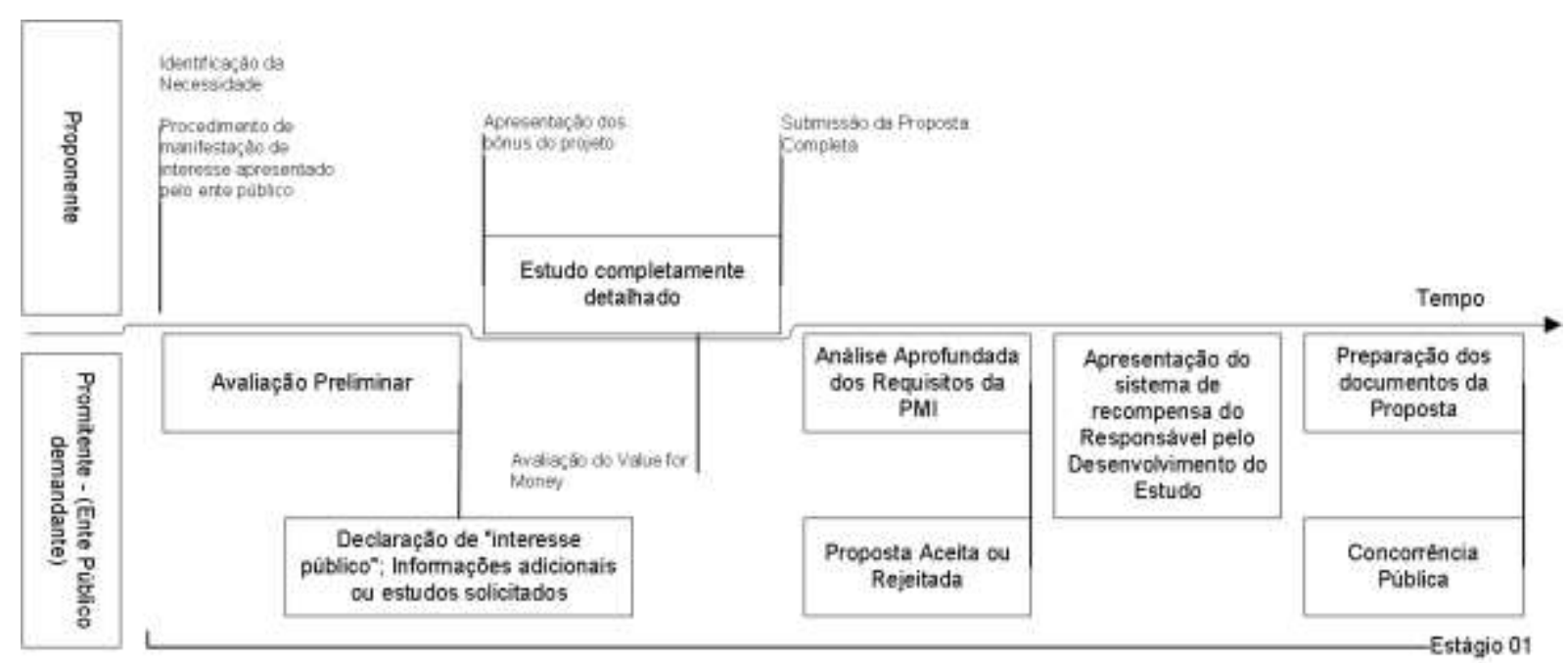

Fonte: Adaptado de Hodges e Dellacha (2007).

\subsection{TEORIA DE GESTÃO DE PROJETOS PRIVADOS E PÚBLICOS}

Esta seção aborda a teoria de Gestão de Projeto, mais especificamente a Teoria de Escopo. Primeiramente, apresenta-se a definição clássica, disponível no Book of Knowledge (PMBoK $\left.{ }^{\circledR}\right)$, $5^{\text {a }}$ edição, do Project Management Institute - PMI.

Segundo o PMBoK ${ }^{\circledR}$ (UM GUIA..., 2013), o gerenciamento de escopo de projetos é a reunião de um conjunto de processos necessários para garantir a inclusão do trabalho para a conclusão ótima da ação projetada. As palavras-chave da categoria são: definição e controle. Deste modo, define-se o que se encontra abarcado pelo escopo do projeto e o que não é compreendido por este.

Observa-se a estratificação dos procedimentos de escopo em 6 níveis de acompanhamento no PMBoK ${ }^{\circledR}$ :

"1 Planejar o gerenciamento do escopo - O processo de criar um plano de gerenciamento do escopo do projeto que documenta como tal escopo será definido, validado e controlado.

2 Coletar os requisitos - O processo de determinar, documentar e gerenciar as necessidades e requisitos das partes interessadas a fim de atender aos objetivos do projeto.

3 Definir o escopo - O processo de desenvolvimento de uma descrição detalhada do projeto e do produto.

4 Criar a EAP - O processo de subdivisão das entregas e do trabalho do projeto em componentes menores e mais facilmente gerenciáveis.

5 Validar o escopo - O processo de formalização da aceitação das entregas concluídas do projeto. 
6 Controlar o escopo - O processo de monitoramento do andamento do escopo do projeto e do produto e gerenciamento das mudanças feitas na linha de base do escopo". (PMI, 2013, p.105)

$\mathrm{Na} 5^{\mathrm{a}}$ edição do $\mathrm{PMBoK}{ }^{\circledR}$, é possível notar uma atenção dada à segregação de gerenciamento de escopo de produto e de projeto. Separam-se as características e funções que caracterizam um produto, serviço ou resultado e o escopo de projeto: "O trabalho que deve ser realizado para entregar um produto, serviço ou resultado com as características e funções especificadas. $O$ termo escopo do projeto às vezes é visto como incluindo o escopo do produto" (UM GUIA..., 2013, p. 105).

$\mathrm{Na}$ Figura 7, segue o quadro de visão geral do gerenciamento do escopo do projeto, segundo o PMBoK ${ }^{\circledR}$ (UM GUIA..., 2013, p.106). 
Figura 7 - Gerenciamento de escopo

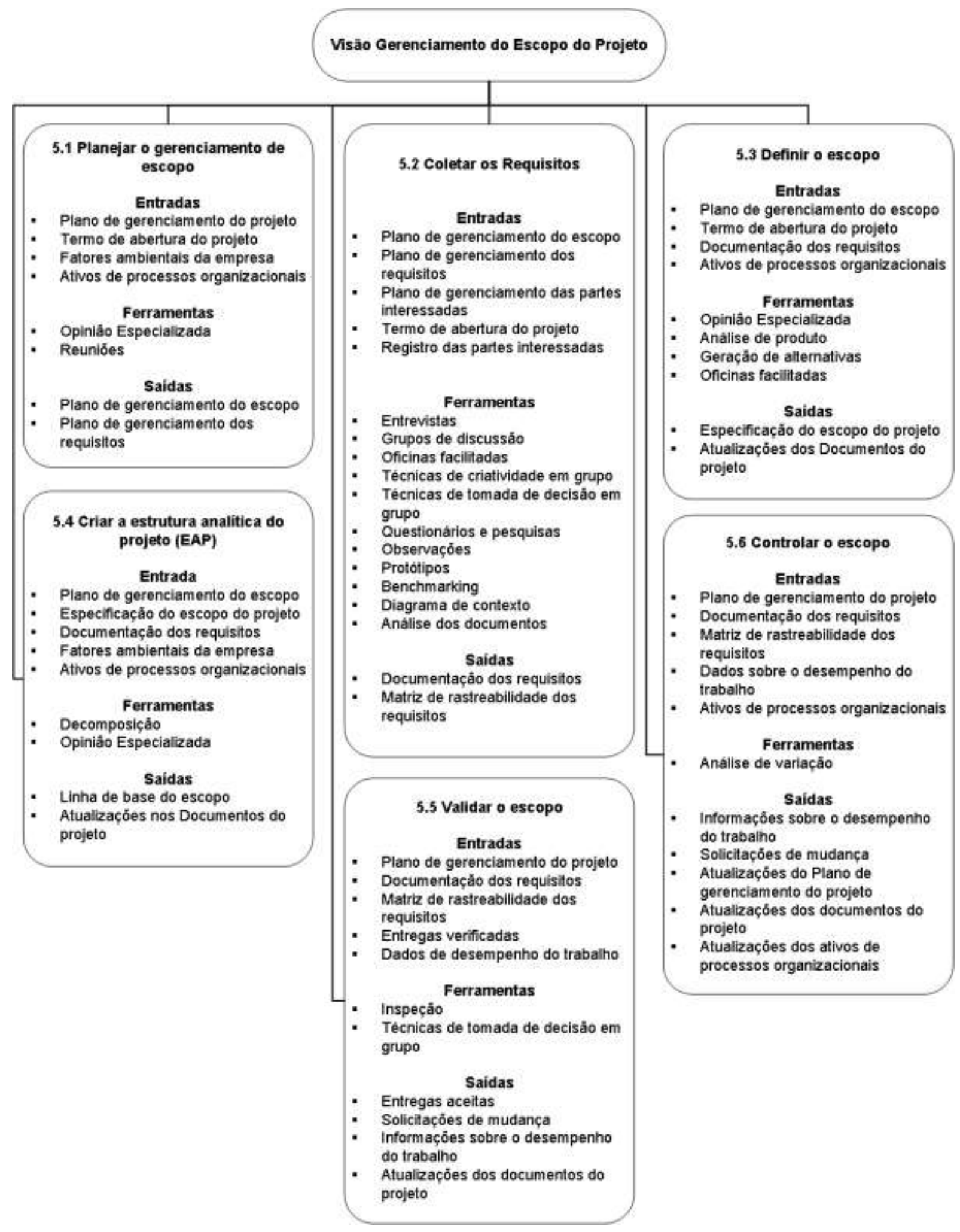

Fonte: Um Guia... (2013, p. 106).

De acordo com o PMBoK@ (UM GUIA..., 2013, p. 107), deve-se

(...) criar um plano de gerenciamento do escopo do projeto que documenta como tal escopo será definido, validado e controlado. O principal benefício 
deste processo é o fornecimento de orientação e instruções sobre como o escopo será gerenciado ao longo de todo o projeto.

A prática mais viável a existência de requisitos e de um plano de gerenciamento desses como um componente do plano de gerenciamento do projeto.

No PMBoK $^{\circledR}$ (UM GUIA..., 2013), é possível encontrar destacadas as atividades dos requisitos. Essas devem ser planejadas, rastreadas e relatadas e configuradas (alterações e modificações incrementais). Ademais, devem compreender análise dos impactos, monitoramento/rastreamento e registros, priorização de requisitos e métricas dos produtos e serviços.

Na Figura 8, tem-se o diagrama do fluxo de dados do processo - Para o planejamento do gerenciamento do escopo:

Figura 8 - Diagrama do fluxo de dados

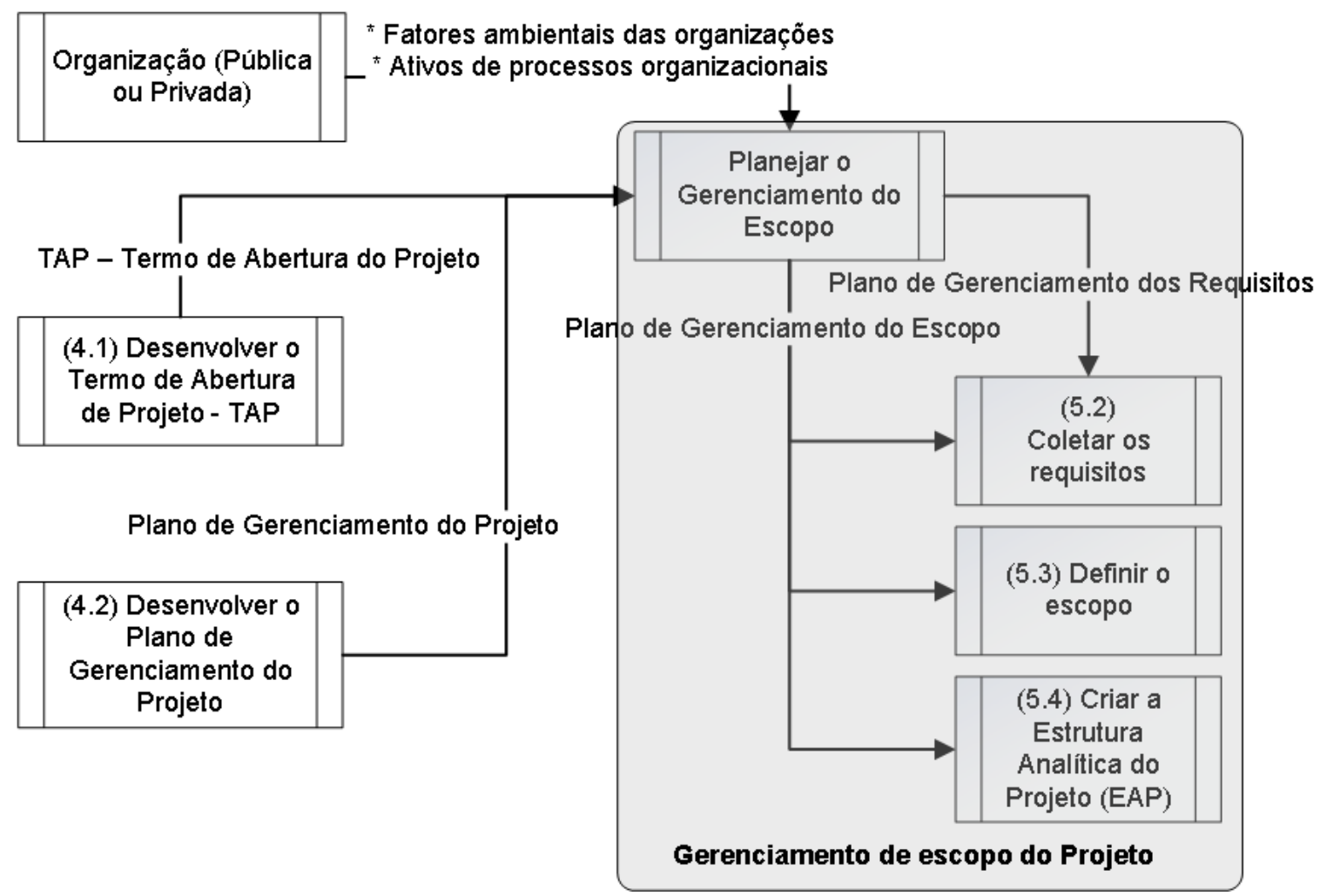

Fonte: Um Guia... (2013, p. 107).

O item 5.2 ilustrado, na Figura 8, direciona o olhar para a "coleta de requisitos", isto é, projetos de PPP/PFI tradicionais resultam em novos projetos cujo o output dos PMls são escopos estanques a cumprir visões clássicas de gerenciamento de projetos. 
De acordo com Lynch, Bertolino e Cloutier (2003), um dos principais problemas da gestão eficiente de projetos reside na definição do conteúdo do projeto em si, na acurácia, na abrangência, na compatibilidade e na consistência das informações que compõem a estrutura do projeto (CHO; GIBSON, 2001). Há indícios no trabalho de Kärnä e Junnonen (2017) de que o grau de satisfação do cliente está relacionado com o resultado entregue, medido pela eficiência do uso dos recursos públicos. Quanto maior o projeto, mais complexa é a mensuração de satisfação do cliente final.

Wu et al. (2016) adota, como critério para medir a eficiência do uso dos recursos públicos, a equação $E^{P R}=$ Saídas/Entradas. A quantidade de variáveis que impactam na modelagem do escopo de um determinado projeto, porém, é muito mais ampla, uma vez que é necessário considerar as variáveis de Planejamento preliminar de projeto, Avaliação de requisitos de conformidade, Condições ambientais existentes, Estudo de capacidade, Envolvimento público (BOYER; VAN SLYKE; ROGERS, 2016), Financiamento e programação (EUROSTAT, 2016), Características geotécnicas (para projetos de infraestrutura) (CHO; GIBSON JR., 2001) e questões culturais para projetos que envolvam atores de regiões diferentes (por exemplo, consórcios internacionais) (AMSTER; BÖHM, 2016).

Impende destacar que os escopos de PPP/PFI constituem um bom exemplo de complexidade, pois precisam ser elaborados de forma a atender uma ampla variedade de necessidades, muitas vezes antagônicas. É o caso de serviços complexos que exigem, por exemplo, velocidade e produtividade, mas também alto nível de acerto. Ademais, há necessidades distintas para cada parte interessada envolvida, seja o contratante, seja o contratado.

Os potenciais proponentes podem atuar, desde a modelagem das diretrizes iniciais do projeto pelo órgão concedente, como consultores ad hoc com o objetivo de conduzirem a implantação, construção e operação de um serviço. 
Figura 9 - Gráfico do grau de responsabilidade e risco ${ }^{16}$

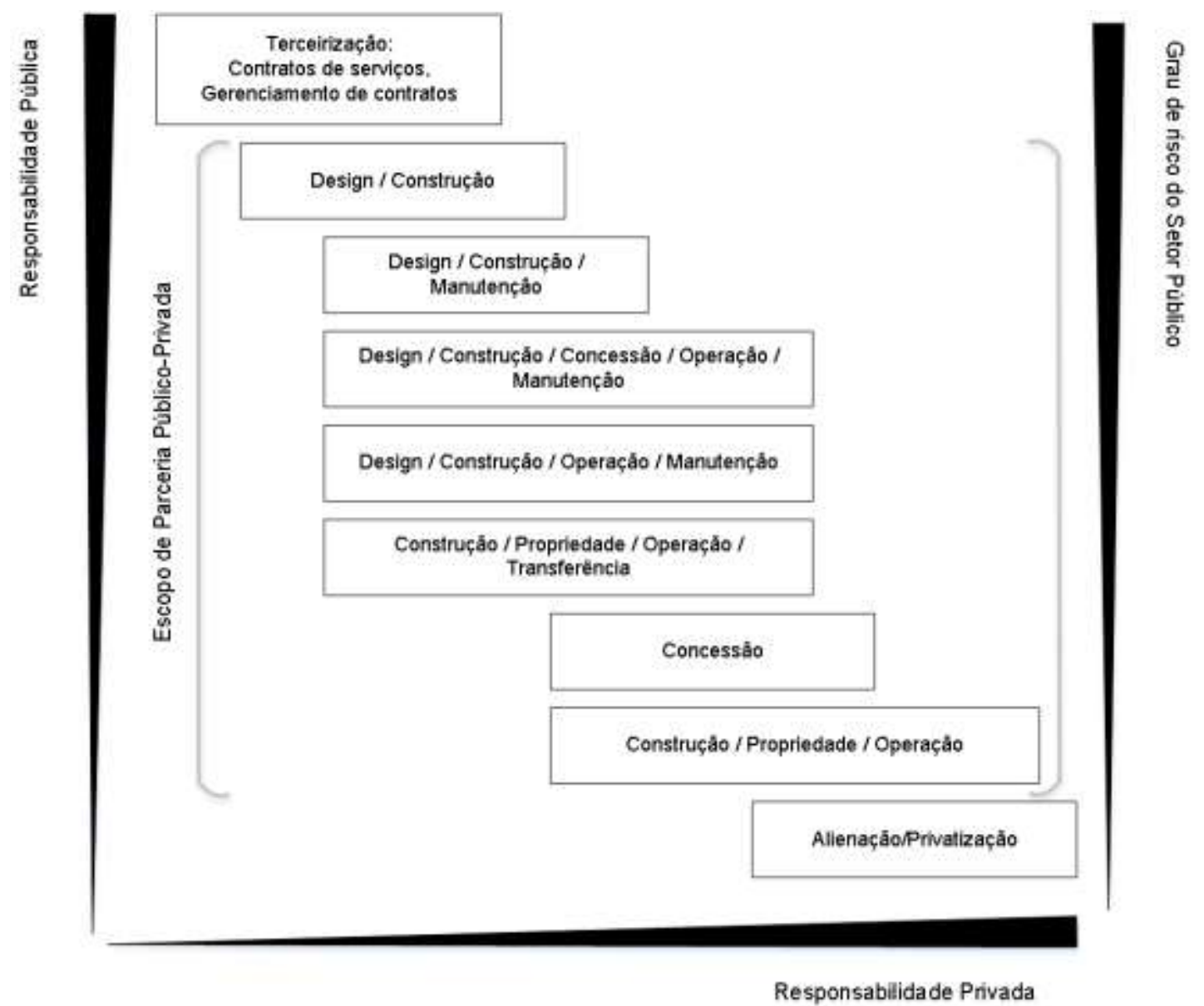

Fonte: Adaptado de Roehrich, Lewis e George (2014 , p. 111) e UNECE (2008, p. 32).

\subsection{PMI E A TEORIA DO ESCOPO}

Dentro do contexto de um projeto de implantação de PPP/PFI, as PMls possuem o mesmo papel que o escopo: definem o produto final do projeto, o serviço ofertado (e suas condições) e os meios para obtê-lo. Teoricamente, essas têm a função de instrumento principal na compreensão das necessidades, das externalidades e das forças. Além disso, servem para oferecer às partes interessadas definições das expectativas de entrega.

No âmbito do desenho dos PMls, há a reunião de 3 (três) áreas principais de incertezas:

(i) incerteza associada com as estimativas: custo, duração ou qualidade relacionados a determinadas atividades planejadas no curso de um processo inovador. Esta primeira incerteza é causada pela ausência de especificação clara de

${ }^{16}$ (Setor Público x Setor Privado). 
escopo, do ineditismo do procedimento (falta de experiência da equipe em lidar com o processo), da complexidade do procedimento, da avaliação limitada dos processos envolvidos na inovação, dos eventos exógenos que impactam no fluxo do trabalho, do imponderável e das estimativas enviesadas;

(ii) incerteza associada com as partes do projeto: sob o nível de desempenho a ser alcançado, motivações individuais dos participantes do certame, confiança entre as partes envolvidas. Por conseguinte, falta de credibilidade que poderá afetar a probabilidade do setor privado entrar ou não em uma PPP/PFI, uma vez que o governo tem sua imagem associada à possibilidade de não cumprir os contratos (MOTA; MOREIRA, 2015);

(iii) incertezas associadas às fases do ciclo de vida do projeto (ATKINSON; CRAWFORD; WARD, 2006).

No caso dos projetos públicos, há ainda a necessidade de atenção aos princípios constitucionais e normativos legais, intensificando a restrição à possibilidade de flexibilidade e ao ajuste de escopo do objeto (SCHAPPER; VEIGAMALTA; GILBERT, 2006). Por conseguinte, o risco de insucesso de projetos conduzidos sob a égide das "PPP/PFls" via "PMls" é ampliado. Embora os processos de aditamento sejam aceitos por necessidade e interesse recíproco, esses são resguardados de questionamento pelos órgãos de controle e compliance em governos democráticos.

Salienta-se que os dispositivos normativos ganharam força a partir da década de 90, com o surgimento do New Public Management - NPM (TEICHER; ALAM; GRAMBERG, 2006). De acordo com Noordhoek e Saner (2005), os regramentos deram ao Estado um contorno mais legalista do que usualmente se observara. Segundo Hood, James e Scott (2000), o resultado foi um aumento exponencial da burocracia consagrada na literatura como audit explosion e um consumo extra de recursos públicos em rituais de verificação questionáveis.

Desenvolver uma métrica que uniformize as PMls e traga transparência para o processo não só reduzirá a assimetria de informação de projetos aceitos, mas alcançará os preceitos do NPM, viabilizará a possibilidade de maior competição do mercado interessado, tornando excepcional a aceitação de projetos singulares. Tal mecanismo agirá não só como compliance jurídico dos gestores públicos, mas como 
um "ativo econômico" para o Estado na mensuração do(s) serviço(s) a serem entregue(s) e medido(s) pelo VfM. Assim, pode-se eleger o projeto de melhor valor (PALMA; PRUNIER; LERUTH, 2009), ou seja, que atenda adequadamente às diretrizes da administração pública.

Convém pôr em relevo que muitas PMls são vistas como projetos pouco transparentes e correlacionados a grupos de interesse restritos (CARRILLO et al., 2008), suscitando a baixa concorrência no mercado e alto custo se comparado aos métodos tradicionais de contratação. Parte da situação descrita decorre de concessões exclusivas, resultando em certames que, para alguns órgãos de controle, como Tribunais de Contas e Ministério Público, podem se caracterizar pouco transparentes.

Por outro lado, há o argumento que os detentores de propriedade intelectual têm direito de exclusividade na modelagem do projeto, sendo o único desenvolvedor interessado nele. Consequentemente, resultaria em ganho de tempo e economia de recursos para o erário público (HODGES; DELLACHA, 2007). De acordo com Hodges e Dellacha (2007), falta de competitividade e ausência de transparência são fatores que influenciam na modelagem das PMls.

A Figura 10, descreve os benefícios que um método de validação por parte do ente público pode trazer as propostas apresentadas pela iniciativa privada.

Figura 10 - Grau de observação de transparência e concorrência

\begin{tabular}{|l|l|l|}
$\begin{array}{l}\text { Aumento da } \\
\text { transparência }\end{array}$ & $\begin{array}{l}\text { Proposta solicitada } \\
\text { concedido por meio de } \\
\text { negociações com uma } \\
\text { única fonte }\end{array}$ & $\begin{array}{l}\text { Proposta solicitada } \\
\text { concedido por meio de } \\
\text { negociações com } \\
\text { fontes abertas }\end{array}$ \\
$\begin{array}{l}\text { Proposta Não } \\
\text { Solicitada concedido } \\
\text { por meio de } \\
\text { negociações com uma } \\
\text { única fonte }\end{array}$ & $\begin{array}{l}\text { Proposta Não } \\
\text { Solicitada concedido } \\
\text { por meio de } \\
\text { negociações com } \\
\text { fontes abertas }\end{array}$ \\
\hline
\end{tabular}

Fonte: (PEREIRA, 2013).

A ausência de transparência na exposição das diretrizes para a elaboração das PMls, bem como a não publicação dos estudos da PMI, podem ocasionar a manifestação de representantes do Parquet sob a alegação de que a ocultação da publicidade ocasionaria a redução da concorrência entre as empresas e consórcios 
proponentes, por ferir os princípios jurídicos: "princípio da isonomia entre os licitantes" e "princípio da informação". Tais questionamentos podem redundar em disputas judiciais protelatórias da marcha do processo de licitação das PPP/PFIs e inseguranças jurídicas, como demonstra julgado do Tribunal de contas do Estado de Santa Catarina, Brasil (TCE/SC, 2012, p. 9):

\begin{abstract}
Resta demonstrado que as condições e critérios firmados em um procedimento de manifestação de interesse, seja pela exiguidade de prazo para a apresentação de proposta técnica e financeira, pelo preço atribuído aos projetos, estudos, levantamentos ou investigações, ou pelos parâmetros e meios para a escolha da melhor proposta técnica e financeira, podem sim prejudicar eventual contratação para a exploração dos serviços de esgotamento sanitário das áreas urbanas do Distrito de Palhoça, razão pela qual se entende pelo cabimento da representação.
\end{abstract}

\title{
3.5 PMI E A TEORIA DA VISÃO DO PRODUTO
}

Nesta seção, apresenta-se o conceito de visão do produto como alternativa para o gerenciamento de escopo conforme sugestionado pela teoria clássica de gerenciamento de projetos. Discute-se a definição de visão, sua relação com o escopo do projeto e, em seguida, a proposta de pesquisa produzida por Benassi, Ferreira Jr. e Amaral (2012) é revista com o intuito de 1) contextualizar a origem e conceito de Visão do Produto e 2) refletir sobre a descrição das Propriedades de Visão, utilizadas na pesquisa.

\subsubsection{ORIGEM E DEFINIÇÃO DO CONCEITO DE VISÃO}

O gerenciamento de escopo é, na teoria clássica de gerenciamento de projetos, a área de conhecimento que reúne as melhores práticas para a definição de um projeto. É por meio destas práticas que, segundo os especialistas em torno do PMBoK, que se deve estabelecer as "regras do jogo" ou os parâmetros e diretrizes do projeto que harmonizam as expectativas dos vários envolvidos, ou stakeholders. É a definição do escopo do projeto que, portanto, se aproxima ao conceito de PMI quando se aborda o projeto de estruturação e implantação de uma Parceria Público Privada. Pode-se considerar que a PMI abrange o escopo do projeto.

A teoria clássica de gestão de projetos, porém, vem sendo desafiada por uma nova abordagem conhecida como Gerenciamento Ágil (Amaral et al., 2011). Esta 
nova abordagem, mais voltada para produtos de inovação, questiona a forma tradicional de se preparar o escopo do produto e, como resultado, propõe-se inclusive um novo nome, visão no lugar do escopo, para reforçar esta diferença, que é reconhecida por Amaral e Benassi (2011) como uma das quatro diferenças entre as abordagens clássica e ágil de gerenciamento de projetos.

$O$ conceito de Visão do Produto versa em indicar um futuro a ser construído (SCHWABER; BEEDLE, 2001). Aplicado ao gerenciamento de projetos, isso significa criar uma declaração de valor, de mais alto nível que sirva como diretriz para o projeto. A visão encerra os valores principais que precisam ser atingidos, mais do que delimitações rigorosas de regras, condições e resultados específicos do projeto (Benassi e Amaral, 2011).

Benassi, Ferreira Jr. e Amaral (2012) realizaram uma compilação das diferentes definições de Visão do Produto em projetos de inovação e a definem como a descrição que fundamenta a essência de um produto futuro do projeto, do resultado do projeto. Ademais, a visão do produto pode ser definida como a descrição ampla de um projeto, com seus contornos não restritos.

O desenvolvimento de produto no conceito do Agile Project Management APM, segundo Benassi, Amaral e Ferreira Jr. (2016) possui inovação relativa à temporalidade do emprego da Visão do produto na modelagem inicial de um dado artefato ${ }^{17}$. Nessa perspectiva, consideram-se projetos inovadores e equipes pequenas. No entanto, atualmente têm-se grandes projetos, contendo várias partes interessadas que demandam a apresentação de resoluções dos problemas por meio de abordagem in loco (no canteiro de obra) e melhoria de comunicação das equipes de projetos multidisciplinares.

O conceito de Visão do Produto a luz do APM assume o lugar de Declaração de Escopo do Projeto (PMI, 2013), tornando-se um caminho para coadunar os interesses e alinhar as expectativas e perspectivas das partes envolvidas em projetos de grande abrangência.

De acordo com Clarck e Wheelwright (1993) referenciados por Benassi, Ferreira Jr. e Amaral (2012), a Visão do Produto pauta a capacidade interna das organizações e realidade do mercado e trata-se de "um propósito compartilhado e

\footnotetext{
${ }^{17}$ A etimologia da palavra deriva do latim "arte factus", ou seja, "feito com arte". Segundo, NG et al. (2013), artefato é dado por: "toda conclusão enganosa derivada de ensaio científico ou de medição (...), objeto manufaturado; instrumento ou mecanismo que se constrói para um propósito específico: um artefato de engenharia mecânica". Para o Dicionário Cambridge (2008) trata-se de "um objeto produzido por uma pessoa como uma ferramenta (...), especialmente algo que tenha interesse histórico".
} 
um plano de ação que esclarece a missão, alinhamento estratégico e lista metas e prioridades do projeto".

Segundo Edvandro C. Conforto (2013) a adoção do conceito de Visão do Produto no Ágil oferece como vantagens: (a) permitir acomodar a necessidade de projetos complexos de inovação que demandam ajustes e que precisam ser alterados ao longo da sua elaboração para que atendam às necessidades do usuário; (b) viabilizar a criação de uma definição de produto resultante do projeto fundamentado na necessidade do usuário.

Considerando que uma das dificuldades dos métodos como VfM e Leilão de Score, na definição da PPP/PFI, reside justamente na captura do valor principal ou harmonização entre as expectativas dos agentes públicos e usuários, apresentado na forma de serviço entregue à população, seria possível analisar as PMI sobre esta ótica?

Propõe-se, nesta tese, a discussão se sua adoção é plausível, contribuindo como mais um dos elementos, além dos Fatores Críticos, para que se possa avançar na análise e validação de PMls recepcionadas pelos órgãos demandantes. A complexidade inerente dos projetos de inovação que é hoje enfrentada com o conceito de visão, dentro do paradigma da agilidade, se aproxima da complexidade de PPPs. Ambos enfrentam o problema da previsibilidade, justamente um dos motivadores do surgimento e desenvolvimento do conceito de visão, conforme origem identificada por Benassi, Ferreira e Amaral, 2016).

\subsubsection{AS PROPRIEDADES DA VISÃO}

Esta subseção objetiva apresentar as Propriedades de Visão de Produto organizadas por Benassi, Ferreira Jr e Amaral (2016) que foram utilizadas na pesquisa. Portanto, comenta-se em cada propriedade a relação com projetos públicos. 
Figura 11 - Propriedades da visão do produto ${ }^{18}$

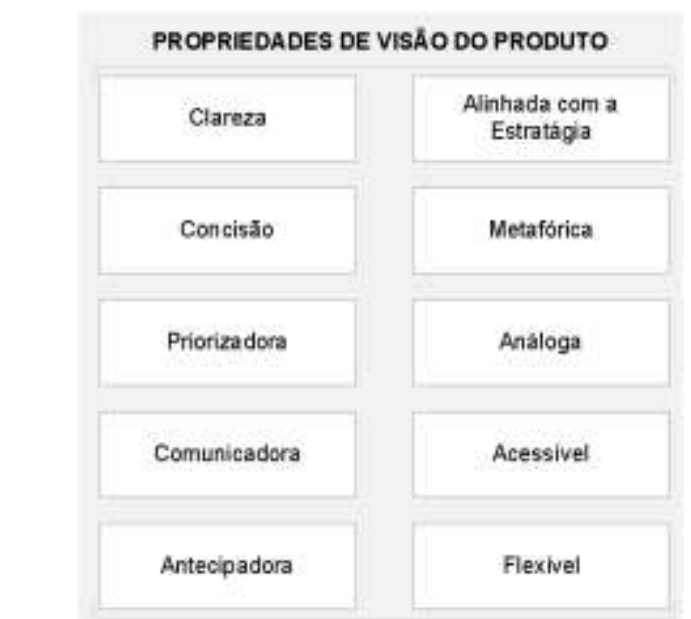

Fonte: Adaptado de Benassi et al. (2012, p. 67).

\subsubsection{CLAREZA}

A "clareza" é definida por Benassi e Amaral (2011) como as características de um dado produto, mercado-alvo, preço otimizado, custo diretos e indiretos claramente definidos e cadeia de distribuição são exemplos de elementos materiais que tornam a visão do produto inicialmente baseada em conceitos teóricos e ideias abstratas, convertidas em objetos tangíveis para a tomada de decisão (HERMAN, 1993) dos gestores do projeto e avaliadores de propostas.

\subsubsection{CONCISÃO}

A propriedade "concisa" foi definida por Benassi e Amaral (2011) como uma extensão da clareza, tal propriedade uniformiza os dados em um único repositório. No escopo da linguística aplicada à tradução, concisão é a técnica empregada para redução de prolixidade textual, sendo alcançada com a organização básica de um documento original (XIAO-MEI; XIAO-JUN, 2011), sendo neste trabalho utilizada da terminologia "Concisão" para a representação de tal propriedade.

O escopo central de projetos deve ser destacado e mitigados os riscos na concepção desses. De acordo com Xiao-mei e Xiao-jun (2011), está intimamente ligada a métodos de tomada de decisão multicritério, especialmente no que diz respeito a pragmatismo e sistemática.

${ }^{18}$ Observado no Gerenciamento Ágil de Projetos. 
Segundo esta propriedade uma declaração de visão de um projeto deveria ser a mais simples, menor possível. Propriedade que força à observância e foco nos elementos fundamentais e facilita o acesso por parte de todos os envolvidos.

\subsubsection{PRIORIZAÇÃO}

A "Priorização" é definida por como as necessidades de entregas em função de urgência, impacto e orientação Benassi (2013). Segundo a teoria do gerenciamento ágil, a definição da visão, apesar de curta, clara e indicativa do direcionamento, precisa estabelecer as prioridades fundamentais, que são compartilhadas pelos envolvidos. Já no gerenciamento de projetos, tais elementos são visualizados na matriz GUT - Gravidade, Urgência e Tendência, cujo projeto/problema é identificado, atribuído peso sobre cada um dos elementos da GUT, realizada a multiplicação dos elementos e alcançado o valor múltiplo. Logo, é obtido o projeto/problema crítico. Adotando-se, portanto, aspecto mais analíticos de identificar todas as prioridades.

No caso de PMls há modelos para a priorização na seleção de projetos em três camadas: qualificação, priorização e arbitragem. A qualificação acontece pelo envolvimento de todos os stakeholders engajados para a realização do projeto. A priorização é obtida por meio da divisão de cada ideia requerida. Por fim, a arbitragem, com a aplicação transversal da gestão do portfólio em que as ideias de todos os stakeholder são colhidas, desafiadas e arbitradas (OTAIRU et al., 2014). A visão do projeto de uma $\mathrm{PPP} / \mathrm{PFI}$, concebido preliminarmente com a $\mathrm{PMI}$ deverá contemplar além das variáveis essências, o maior número total de anseios da coletividade (BADI, 2016; HORSLEY; LIU, 2007; ZHANG; CHEN, 2013).

A definição de prioridade é um processo crítico e, portanto, um documento de $\mathrm{PPP} / \mathrm{PFI}$, concebido preliminarmente com a PMI, deveria também contemplar além das variáveis essenciais, o maior número total de anseios da coletividade. Aplicando aqui o conceito de visão, supõe-se como hipótese que seria interessante que seria útil que PMls descrevessem de forma clara prioridades essenciais que seriam comuns e fundamentais para todos os envolvidos. 


\subsubsection{COMUNICADORA}

A propriedade definida por "comunicadora", rebatizada aqui em "Comunicação" indica que a visão do produto não deve ser estabelecida exclusivamente textual, mas visual e com o emprego de mecanismos como figuras e imagens, capazes de facilitar a compreensão de terceiros alheios aos detalhes do projeto. No caso das PMls, entende-se que o serviço não pode ser visualizado, mas os insumos e processos de aplicação, ou mesmo o desenho por meio de gráficos de temperatura no mapa da área do espaço público alvo do projeto, sim.

A comunicação deve ser construída coletivamente entre os stakeholders e visualmente atrativa para o público (especialmente para os avaliadores dos projetos e conselhos gestores de PPP/PFIs). De acordo com Benassi (2012, p. 68),

A visão do produto ao comunicar eficientemente as informações relacionadas ao projeto, alinhando as perspectivas funcionais com as metas de desenvolvimento, proporciona tanto integração interna quanto externa, participação direta de stakeholders nos estágios iniciais do PDP e diminuição no tempo de desenvolvimento do produto.

\subsubsection{ANTECIPADORA}

A propriedade definida como "Antecipação" por Benassi versa sobre a características de projetos de inovação. Aqui renomeada de "Antecipadora". Projetos que envolvem resultados construídos a partir de conceitos, ferramentas e modelos de negócio conhecidos pelos envolvidos são mais bem "comportados" e apresentam menor complexidade no que se diz respeito ao resultado esperado dos usuários. Há projetos, porém, que possuem um caráter de inovação (novas tecnologias, novos modelos de negócio ou contextos e ambientes não conhecidos) que dificultam o entendimento do resultado esperado, conforme discutido no conceito de complexidade desenvolvido por Shenhar e Dvir (2007).

Conforme Benassi, Amaral e Ferreira Jr. (2016) uma declaração de visão do projeto precisaria descrever de algum modo o resultado principal, tal que os envolvidos tenham acesso a uma descrição mínima do resultado fundamental alcançado a propriedade denominada por eles de "Antecipadora". No desenho dos projetos de $\mathrm{PMI}$, as diretrizes iniciais se assemelham à propriedade. $\mathrm{O}$ aperfeiçoamento decorre de consultas e audiências públicas. Ademais, a visualização da proposta do projeto permite melhor aderência e possibilidade de 
afinamento do previsto para o realizado, dado que a antecipação do ajuste permite menor custo de adequação, redução do tempo de execução e diminuição de custos indiretos no curso do lead time ${ }^{19}$.

\subsubsection{ALINHAMENTO ESTRATÉGICO}

De acordo com Laitinen et al. (2008), a representação da visão do produto poderia ocasionar um estreitamento entre a alta administração e o setor de Pesquisa e Desenvolvimento, proporcionando melhor empatia entre as áreas.

A explicação que subsidia esta propriedade é o relacionamento da visão do projeto como o propósito de caráter mais geral, e contextual, subjacente. Por exemplo, eu posso propor o desenvolvimento de um projeto de produto geladeira com uma inovação para obter diferencial significativo no consumo de energia e que este esforço esteja relacionado com a estratégia de se posicionar com empresa que preza pelo menor impacto no meio ambiente. Ter esta percepção permite que futuras discussões e ações da equipe de projeto se norteiem também por esta estratégia, reconhecendo assim de maneira mais clara o valor do projeto com os stakeholders.

Esta dimensão se aplica aos projetos do setor Público. Entende-se que as relações externas do ente federado com o ente privado ou mesmo representantes do terceiro setor existem diretrizes estratégicas que permeiam a agenda dos envolvidos na PPP. Explicitá-las pode permitir que os envolvidos na PPP busquem a manutenção do direcionamento e um compromisso de mais longo prazo.

Consequentemente, pode facilitar o compartilhamento de informações com áreas-chave do processo diminuindo a distância entre agentes públicos, empresas ou organizações responsáveis pelo serviço e usuários. Benassi (2013) em sua tese de doutorado enfatiza que os artefatos de visão cumprirão seu papel de reduzir a lacuna semântica entre equipe e clientes se medidas de preenchimentos de componentes forem adotadas. O modelo de indicadores para a avaliação de PMI a ser descrito no Capítulo 6 busca compreender as expectativas das partes interessadas por meio do alinhamento estratégico de longo prazo das instituições (representadas, nesta tese, pelo Plano Plurianual - PPA) ao descritivo técnico do

\footnotetext{
${ }^{19}$ A utilização da terminologia de lead time para projetos de PPP/PFI aduz ao tempo decorrido entre a chegada de um pedido de PMI pela iniciativa privada à entrega do serviço ao cidadão.
} 
escopo do projeto. Compreendem-se as variáveis quantitativas e qualitativas das propostas de projetos base para a modelagem dos editais de PMIs.

\subsubsection{METAFÓRICA E ANÁLOGA}

As propriedades: metafórica e analógica estão intimamente relacionadas com a questão da inovação. Segundo autores como Nonaka (1991, p. 100), as figuras de linguagem como metáfora e analogia permitem que as pessoas "expressem o que elas sabem em outros formatos, bem como permitem expressar o que não se sabe". Segundo os autores, com isso é possível criar conceitos que geram um senso de direção (Nonaka, 1991, p. 104)

Um exemplo clássico de metáfora ofertado pelos autores em um projeto de inovação de desenvolvimento de produto é o do projeto do carro Honda City. O gerente de projeto utilizou uma metáfora para expressar o resultado esperado do projeto à equipe: "um carro grande por dentro e pequeno por fora". Desta forma, ele conseguiu expressar o desafio, mesmo não tendo conhecimento sobre o resultado concreto e preciso a ser obtido.

Por meio de analogias, é possível, segundo Benassi (2013), a conversão do entendimento de um tema não compreendido em interpretação explícita. $\bigcirc$ uso destas práticas oferece dois benefícios. Primeiro, permite declarar o problema de forma desafiadora para a equipe, convidando os membros a buscarem soluções inesperadas e não previstas antecipadamente pelo gerente de projeto.

Esta propriedade versa, portanto, sobre a capacidade da produção criativa dos formuladores de projetos de PMls e à amplificação das perspectivas do projeto. As características são positivas para projetos que envolvam grandes somas e múltiplas partes interessadas.

No caso de projetos das PMls, a extensão e complexidade podem resultar em proposições diametralmente opostas uma das outras, em razão dos interesses das partes envolvidas. Elas também podem necessitar de soluções inovadoras para o problema, como novos modelos de negócio entre as partes, ente pública, organizações produtivas e usuários, convidando assim ao uso desta propriedade.

Figuras de linguagem poderiam também viabilizar melhor compreensão do desenho técnico e modelo de negócio a ser adotado, principalmente em razão da baixa quantidade de especialistas que dominam o conhecimento necessário para a implantação dos institutos PPP/PFI e PMI nas iniciativas públicas e privadas 
(CARRILLO et al., 2008), conduzindo a excessivos atrasos em projetos desta natureza (HO; TSUI, 2009). Por exemplo, uma PMI que tivesse em seu texto descrendo um serviço de locomoção compartilhado como o "UBER da cidade $\mathrm{X}$, facilitaria a transmissão da informação sobre o valor principal da proposta aos olhos de um dos envolvidos, como o cidadão.

Autores, como Kensing e Madsen (1992), sustentam que a adoção de símbolos para a uniformização do entendimento das pessoas sobre um dado construto.

Porém, há que se pensar nas limitações. Considerando os princípios de legalidade e publicidade, inerentes à gestão pública, a adoção desta propriedade pode ser inapropriada. Caso o valor é definido neste formato apena, como um desafio ou problema a esperar uma solução de compromisso, haveria um impacto significativo em tratativas legais e margem para abusos da lei e resultados.

Além disso, a propriedade pode ser interpretada como uma deficiência na limitação de escopo e, portanto, não adequada para projetos de $\mathrm{PMI}$, dada a dificuldade de decomposição do conceito e adequação às normas legais impostas pela maioria dos ordenamentos jurídicos que se valem do instituto.

\subsubsection{ACESSÍVEL}

Devem existir espaços físicos e virtuais para a troca de informações relativas à visão do produto entre os envolvidos no projeto. Segundo Benassi, Ferreira Jr e Amaral (2016), para que seja uma visão, o conteúdo deve estar disponível todo o tempo e para todos os envolvidos, incluindo no período de sua criação.

O envolvimento de todas as partes impactadas durante a elaboração da visão deve ser reforçada, ou seja, quanto mais acessível as informações e melhores descritas as variáveis qualitativas, menores são as possibilidades de seleção adversa de projetos.

Esta propriedade não seria simples de ser alcançada no caso das PMls. O processo de descrição e publicação requer grande esforço para a elaboração de variáveis detalhadas. $O$ acesso às informações contidas nas propostas exige tecnologia de softwares para a mineração do dado de forma eficaz e interpretativa.

Embora seja um dos mais avançados dentre todos os institutos públicos de contratação, por permitir a participação popular na construção de marcos técnicos e de impacto do projeto, ainda há grande dificuldade no provimento de mecanismos de 
propagação das propostas na sociedade e das ferramentas técnicas de avaliação das propostas com uniformidade nas métricas e menor subjetividade.

Um aspecto favorável, no entanto, pode ser encontrado dado que o princípio da publicidade na administração pública é coerente com a participação e ferramentas interativas de comunicação, como portais web, permitiriam o engajamento de multidões em construções coletivas de propostas. Explorar estes mecanismos e possiblidades de construção coletiva de PMls, pode ser uma importante área de pesquisa na gestão pública.

\subsubsection{FLEXÍVEL}

Esta propriedade fundamenta-se em dois verbos: atualizar e corrigir. Segundo Benassi (2013), os ajustes são derivados das interações entre as partes envolvidas. No processo de construção de PMls, as variáveis críticas do escopo, que comtemplam procedimentos nunca testados e tecnologias disruptivas (testadas em laboratório ou de pouco domínio pelo campo de aplicação), precisam agrupar um conjunto de elementos ou de valores com amplitude de segurança.

No caso de um projeto específico de produto inovador, como previsto na literatura do gerenciamento ágil, esta propriedade não é difícil de ser alcançada sem dificuldades, pois a equipe é co-localizada e bem definida. Assim, bastam mecanismos de comunicação visual ou digital e regras de conduta e procedimento para que sejam possíveis o compartilhamento e a mudança constante no decorrer do projeto.

A adoção desta propriedade em PMls não parece, em uma análise teórica trivial. A complexidade dos projetos e, por sua vez, a amplitude tornam difícil operar estas mudanças. O impacto de mudanças também é significativamente complexo. Elas podem representar custos adicionais para o projeto, mudanças de equilíbrio na relação entre as partes (umas tendo maior ou menor benefício) e podem gerar impactos e riscos inesperados a todos os envolvidos. Assim, não seria trivial operacionalizar este conceito no caso das PMls.

\subsubsection{VISÃO EM PROJETOS DA ADMINISTRAÇÃO PÚBLICA}

Não é possível encontrar artigos indexados sobre a aplicação do conceito de Visão de Projetos na Administração Pública. Os projetos oriundos da iniciativa 
privada foram utilizados na aproximação, como parte do corpo de conhecimento de gerenciamento de design, gerenciamento de projeto e desenvolvimento de processos de novos produtos (MERGEL, 2014).

A inovação em órgãos públicos segue, conjuntamente, com os conceitos de New Public Management - NPM (LANE, 2000; THOMPSON et al., 2008) e open government, sendo este segundo relativamente recente e inexplorado pela literatura especializada (NISAR, 2013). Cabe destacar que organizações governamentais reconhecem a necessidade da criação de processos inovadores, seja para alcançar maior transparência ou para maior participação e colaboração (PUBLIC..., 2003).

Neste aspecto a investigação de soluções como a adaptação de conceitos de gerenciamento ágil, tal qual a visão passa a ser interessante. É neste sentido que este trabalho intenta convergir e verificar a aderência do conjunto de variáveis que formam o escopo ${ }^{20}$ de uma Proposta de PMI às Propriedades da Visão do Produto do Gerenciamento Ágil de Projetos, proposto por Benassi et al. (2016).

${ }^{20}$ Previsto no Diagrama do fluxo de dados do $\mathrm{PMBoK}^{\circledR}$ (5 $5^{\mathrm{a}}$ edição). 


\section{FATORES CRÍTICOS PARA O SUCESSO DE PMIS}

O Public-Private Infrastructure Advisory Facility - PPIAF, enumera 10 (dez) fatores críticos para a análise e consolidação dos maiores desafios para a implantação eficiente de PMls.

Figura 12 - Fatores críticos para o sucesso de PMls

\begin{tabular}{|c|c|}
\hline $\begin{array}{l}\text { Fatores Chave de } \\
\text { Macro nivel }\end{array}$ & $\begin{array}{l}\text { 1. Interesse do setor privado; } \\
\text { 2. Capacidade do setor privado; } \\
\text { 3. Capacidade pública; } \\
\text { 4. Coordenação pública; } \\
\text { 5. Clarificação de procedimentos e aprovações. }\end{array}$ \\
\hline $\begin{array}{l}\text { Fatores Chave de } \\
\text { Micro nível }\end{array}$ & $\begin{array}{l}\text { 6. Preço competitivo; } \\
\text { 7. Inovação; } \\
\text { 8. Capacidade de cobrir custos transacionais; } \\
\text { 9. Alocação eficiente de riscos; } \\
\text { 10. Processo transparente; }\end{array}$ \\
\hline $\begin{array}{l}\text { Objetivos dos } \\
\text { Procedimentos de } \\
\text { Manifestação de } \\
\text { Interesse (PMIs) }\end{array}$ & $\begin{array}{l}\text { - Identificar, preparar e implementar a projetos } \\
\text { economicamente valiosos; } \\
\text { - Criar valor a dicionado (melhor acordo que } \\
\text { alternativa). }\end{array}$ \\
\hline
\end{tabular}

Fonte: PPIAF (2014, p. 24)

Como qualquer outro projeto público, o objetivo final é reverter os esforços na criação de valor e benefício direto para os usuários e contribuintes diretos (LEVITT; ERIKSSON, 2016; MORLEDGE; OWEN, 1998). Importante é destacar que os fatores de micro e macro nível se correlacionam. Contudo, esses estão se abalroando nos projetos reais que usam a PPP/PFI como mecanismo de viabilização financeira. A maturidade política e transparência institucional são fatores críticos (KIPLI et al., 2016) para que governos centrais e subnacionais consigam gerir os ritos necessários para a operacionalização das PPP/PFIs.

\subsubsection{FATORES CRÍTICOS NÍVEL MACRO}

\subsubsection{O INTERESSE DO SETOR PRIVADO}

O interesse do setor privado está diretamente correlacionado com a capacidade do setor público em modelar uma proposta que tenha taxa de retorno suficientemente correspondente ao custo de oportunidade de alocação do capital no projeto, para evitar falência do projeto ou mesmo devolução do serviço concedido ao 
ente concedente (XIONG et al., 2017). Embora haja a percepção de trivialidade, há (i) a obscuridade na apresentação dos cenários de risco e regras de cálculo para se alcançar o valor esperado (SANTANDREA et al., 2017), (ii) o nível de detalhamento da regra de cálculo da taxa interna de retorno (IRR) (SUNDARAJ; EATON, 2013) e (iii) a robustez jurídica da proposta (LIU et al., 2016) empregada na modelagem.

\subsubsection{CAPACIDADE DO SETOR PRIVADO}

A capacidade do setor privado está intimamente ligada ao sucesso da PPP, pois os casos aonde este instituto apresenta o maior potencial de aplicação são justamente nos quais o serviço necessita de competência especializada, inovação e eficiência competitiva (FROUD, 2003) e transparência (ISMAIL, 2014), que possa não ser claramente observado no ente público. Elas dependem, portanto, do ente concedente compensar o projeto submetido e executado pelo ente privado, seja por antecipação ou por compensação do valor empenhado para a realização dos estudos.

O valor deve refletir os custos relativos à realização das análises, aos estudos preliminares (COUTINHO, et al. 2014), aos ensaios laboratoriais, aos laudos, aos gastos com mão-de-obra especializada, aos equipamentos empregados na modelagem, aos insumos em geral e aos demais documentos que viabilizem a clareza do escopo do projeto da PPP/PFI. A ausência de parâmetros claros de reembolso, sem considerar fatores técnicos ou avaliação profissional, pode oferecer incentivos oportunistas (REEVES, et al. 2017) e comportamento lesivo do ente privado ao erário público.

\subsubsection{CAPACIDADE PÚBLICA}

De acordo com Gomes (2016), a carência de capacidade financeira e de recursos humanos treinados dentro do setor público para identificar, priorizar, preparar e adquirir projetos de infraestrutura é um dos principais motivadores das PMls. Os conhecimentos podem não estar na Indústria Nacional, forçando o ente público abrir o processo para a participação de concorrentes internacionais importando as tecnologias, induzindo a vinda de novas tecnologias, mesmo que por meios indiretos. 
A implantação de PMls bem-sucedidas exige nível de especialização no desenvolvimento de projetos e nas etapas preparatórias (por exemplo, elaboração do termo de referência, projeto base, memorial descritivo, estudos de avaliação da viabilidade econômica e financeira de planos de projeto, dentre outros) (GUERRA; D'AMATO, 2017). O fato de o instituto PPP/PFI ser considerado recente em países em desenvolvimento motiva a sua não adoção por Agências e/ou Ministérios. Até em países com maior maturidade de utilização do instituto, não necessariamente transfere-se um projeto para outro.

A adoção de marcos regulatórios estritos para a submissão das PMls, sem mecanismos computacionais para triagem das propostas, pode gerar grande desconforto e desestabilidade dentro das unidades gestoras das PPP/PFIs, dado o volume e a complexidade dos modelos apresentados. Uma vez autorizada a proposição, se o objeto for de interesse do mercado, um número considerado de projetos pode ser submetido, pressionando unidades de PPP/PFIs não organizadas. Como resultados, ocorreriam atrasos consideráveis nas devolutivas e efeitos de desincentivo aos proponentes.

De acordo com Shepherd e Valencia (1996), a alternativa a tal incidência é a ampliação dos quadros funcionais de servidores públicos, para gerirem os contratos ou realizar a terceirização das atividades, com intuito de diminuir o acúmulo de tarefas, buscando maior eficiência por meio da contratação de consultores e ferramentas de otimização das avaliações. Contudo, a contratação externa não é viável e tão pouco popular, em alguns governos, por demandarem certames de concurso/licitações que tomam um tempo considerável para a formalização do contrato e para início do acompanhamento das atividades.

A contratação onera os cofres públicos com procedimentos que não necessariamente se materializarão, além de potencial perda de controle da administração pública pelo processo (BADI, 2016). Países em desenvolvimento, por sua vez, encorajam a iniciativa privada a desenvolverem as PMls, como forma de terceirizar o desenvolvimento dos projetos e apresentá-los, já enquadrados no formato exigido pelo ente público, facilitando as avaliações finais.

Para Mansor e Rashid (2016), a abertura de chamamentos públicos incentiva a concorrência para a construção de projetos que alcancem as melhores práticas possíveis no mercado. No entanto, pode resultar também em projetos e estudos redundantes onerados. Convém ressaltar que tais gastos são fonte de debates inconclusos na esfera acadêmica e mercadológica. 


\subsubsection{COORDENAÇÃO PÚBLICA}

Operacionalizar uma PMI depende de comunicação e coordenação intra e entre setores públicos. Entes de alcance nacional, como Agências e Ministérios, que possuam um modelo executivo descentralizado, para a realização de projetos de infraestrutura sob a égide das PPP/PFI, possuem uma matriz de comunicação transversal que alcança múltiplos agentes. Há, então, a dificuldade de rastreamento das PMls recebidas, tornando os processos menos transparentes e propícios a abusos. A maneira mais eficaz de lidar com os desafios da coordenação do setor público parece ser a permissão de uma unidade centralizada. No entanto, a centralização das ações envolve desafios, como a perda de celeridade processual e concentração de atividades.

O relatório do PPIAF (2014, p. 29) aponta que unidades centrais de PPP/PFI podem suprir três importantes papéis nas fases iniciais da modelagem dos processos de PMls no intuito de direcionar linhas de ações ministeriais e contratos de agências.

- Pode servir para o aprimoramento das PMls quando houver a ausência de requerimentos para aplicar competição;

- Sendo viável, promover e aconselhar o melhor caminho para introduzir competição no processo das PMls e

- Se o projeto é enquadrado para atender as necessidades do ente federativo, há a possibilidade de promoção e aconselhamento em favor do desenvolvimento regular competitivo da oferta ao mercado (estruturação do certame).

\subsubsection{CLARIFICAÇÃO DE PROCEDIMENTOS E OPERAÇÕES}

Segundo Liu e Horsley (2007), a capacidade de comunicação dos agentes públicos pode resultar em custos transacionais, perda de interesse pelo mercado a ser proponente e a própria percepção do público a ser beneficiada com o projeto, dada a forma com que os governos se comunicam, interna e externamente (ITTMANN, 2017). Os envolvidos diretamente nas análises das propostas podem não estar familiarizados com a existência e o conteúdo dos procedimentos das PMls, principalmente se o framework de acompanhamento for feito por consultores externos aos quadros de serventuários do ente demandante do serviço a ser objeto da PPP/PFI.

Bimber (1999), ressalta que há necessidade de maior atenção para a comunicação e socialização de tais ritos operacionais. Um caminho, segundo o autor, seria integrar a estrutura operacional das PMls dentro das redes internas de 
comunicação dos governos, isto é, construir intranets dos poderes e portais externos

para o público, resultando em maior mobilização populacional acerca de um determinado tema.

Kelman (2008), apresenta um comparativo de 5 modelos de comunicação da Iniciativa Pública com a comunidade (Quadro 5).

Quadro 5 - Resumo de cinco modelos de relações públicas

$\begin{array}{ccc}\text { Modelo } & \text { Força } & \begin{array}{c}\text { Elementos aplicados ao } \\ \text { governo para a tomada de } \\ \text { decisão }\end{array}\end{array}$

$\begin{array}{llll} & \text { Endereçamentos das } & & \text { Inclusão das restrições } \\ \text { Modelo do } & \begin{array}{l}\text { restriçóes ambientais } \\ \text { do setor público, }\end{array} & \begin{array}{l}\text { Só permite } \\ \text { comunicação }\end{array} & \begin{array}{l}\text { ambientais para o setor público, } \\ \text { conceito de adaptação da }\end{array} \\ \text { Processo de } & \text { identifica quando } & \text { assimétrica, tipologia } & \text { estratégia de comunicação } \\ \text { Comunicação } & \text { selecionar vários } & \text { em vez de uma } & \text { baseada nas restrições } \\ \text { do governo } & \text { veículos de } & \text { fundação para uma } & \text { ambientais de específica área do } \\ & \text { comunicação para o } & \text { teoria. } & \text { setor público. }\end{array}$

\begin{tabular}{ll}
\hline Modelo de & Aborda um grande \\
síntese do & conjunto de \\
governo para a & $\begin{array}{l}\text { restrições ambientais } \\
\text { comunicação de } \\
\text { crise }\end{array}$ \\
do setor.
\end{tabular}

Só se aplica a situações de crise, somente aplicado Inclusão de restrições ambientais por meio de do setor público.

comunicação assimétrica.

Tendência em

Modelo de processos de

Explica como as organizações relações interagem com seu públicas ambiente e quando já mudanças. direção ao setor corporativo, necessita de maiores detalhes na

Conceito de super sistema e dimensão do subsistema. subsistema.

Combina motivações mistas e simetria bidirecional, explica como as

Modelo simétrico bidirecional organizações adaptam estratégias para efetivamente encontrar os interesses das organizações e do público.

Não permite a comunicação; não leva em conta a unicidade ambiental do setor público.
Combinação de dois sentidos de comunicação: simétrico e assimétrico; conceito das organizações adaptarem estratégias para atender efetivamente as necessidades de interesse público.

\begin{tabular}{|c|c|c|c|}
\hline $\begin{array}{l}\text { Teoria da } \\
\text { contingência }\end{array}$ & $\begin{array}{l}\text { Explica como a } \\
\text { prática das relações } \\
\text { públicas é } \\
\text { contingenciada em } \\
\text { fatores que variam } \\
\text { ao longo do tempo, } \\
\text { situação, ambiente e } \\
\text { público. }\end{array}$ & $\begin{array}{l}\text { Aplicada apenas } \\
\text { para a resolução de } \\
\text { conflitos; foco } \\
\text { predominantemente } \\
\text { em } 86 \text { fatores } \\
\text { considerados na } \\
\text { iniciativa privada. }\end{array}$ & $\begin{array}{l}\text { Conceito de que não há uma } \\
\text { abordagem única para todas as } \\
\text { práticas de relações públicas. }\end{array}$ \\
\hline
\end{tabular}

Fonte: Kelman (2008). 
Comparando as normas internacionais, dispositivos legais e manuais de modelagem e análise dos estudos das PMls, não há indícios sistematizados e claros de que esses instrumentos são realmente adotados na prática para a avaliação dos projetos. Todavia, se adotados, esses estão agregando valor para a esfera pública, segundo relatório do PPIAF (2014). Em algumas jurisdições, agências governamentais e alguns tipos de projetos são considerados exceções, não sendo analisados pela regulamentação das PMls, exemplo: África do Sul (PPP/PFI UNIT SOUTH AFRICA, 2017). As instituições governamentais não são obrigadas a considerar todas as PMIs, mas apenas as que enquadrarem a critérios estipulados pelo ente contratante.

\subsubsection{FATORES CRÍTICOS NÍVEL MICRO}

\subsubsection{PREÇO COMPETITIVO}

O objetivo das PMls é alcançar i) preços justos na contratação da PPP/PFI, se comparadas a outros modelos de aquisição pública (IOSSA; MARTIMORT, 2015) e ii) um VfM atrativo para ambas as partes. Logo, é necessário um processo competitivo justo, mitigando assimetria de informação e comportamento adverso pelos árbitros da seleção de projetos.

Os governos têm adotado mecanismos de remuneração de projetos concebidos pelas PMls, a saber: (i) Swiss Challenge ${ }^{21}$, (ii) Sistema de bonificação, (iii) Lista curta automática (admissão da oferta final e melhor) e (iv) Sistema de competição plena. A regulamentação/instruções normativas/guias de recomendações de países indica o mecanismo que será empregado para a remuneração dos projetos submetidos e aprovados. No entanto, tais métricas devem ser questionadas. Comportamentos oportunistas ou imaturidade do núcleo de projetos de PPP/PFIs podem validar PMls, sem a consideração dos devidos critérios (por nepotismo, direcionamentos/favorecimentos e corrupção ${ }^{22}$ ativa ou passiva). Logo, não há possibilidade de competição igualitária.

21 O Swiss Challenge se assemelha as PMls onde uma autoridade pública recebe propostas da iniciativa privada para a prestação de um determinado serviço e publica tal proposta para terceiros adequarem a execução deste ou mesmo melhorar a proposta inicialmente apresentada. Neste modelo de contratação a parte que primeiro apresentou a proposta pode apresentar melhorias dentro do próprio projeto inicialmente submetido e participar do certame licitatório para a execução e operação do serviço (HOPPE; SCHMITZ, 2013).

${ }^{22}$ Especialmente observada em países em transição de desenvolvimento, a ausência de maturidade institucional leva a corrupção e comportamentos oportunistas com financiamentos de curto prazo 
De acordo com Liu et al. (2016), parte da solução poderia ser alcançada com mecanismos ex post de controle dos resultados, como auditorias, e decisões de escolhas devidamente justificadas, conducentes à garantia da integridade do Processo de PPP/PFI (TEO; BRIDGE, 2016).

Outro fator que interfere no estabelecimento do valor de face do projeto a ser modelado, na $\mathrm{PMI}$, é o número de competidores interessados em pleitear a ideia concebida pelo ente público. Poder-se-ia ocorrer monopólio. A fim de evitá-lo, o ente concedente poderia introduzir uma competição excessiva ou uma regulação exagerada (incorrendo em riscos regulatórios) (NG; LOOSEMORE, 2007). No entanto, os controles podem sufocar inovações (GRIMSEY; LEWIS, 2009), resultando no efeito contrário ao esperado, isto é, em menor número de competidores. Uma forma viável para reduzir o problema seria o Market sounding que permite verificar detalhes de viabilidade do projeto, dá ciência ao mercado da existência do certame e, também, serve para obter sugestões e ideias de sua definição para garantir a participação do setor privado e fomentar competição entre proponentes.

A realização do Market sounding não pode ocorrer muito antes do chamamento público da PMI porque a ausência de variáveis, como magnitude, capacidade operacional e escopo do projeto, poderia indicar imprecisão e falta de direcionamento do gestor público em comando sobre o que se busca empreender em uma dada localidade(s). A figura 13, apresenta o passo a passo das etapas executivas do Market Sounding. 
Figura 13 - Estrutura para a análise de opções de aquisição

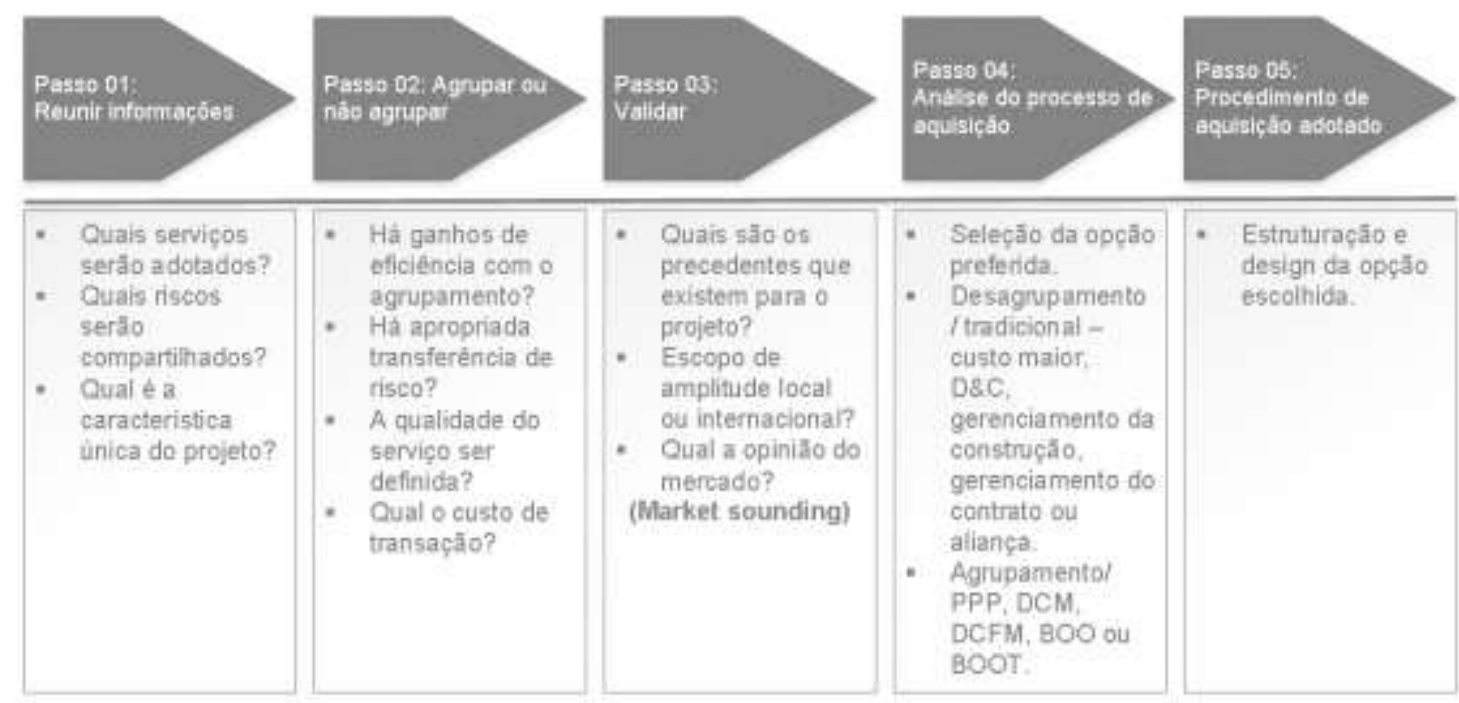

Caso do negócio

Fonte: Grimsey e Lewis (2009, fig. 8.1, tradução do autor).

A fase ideal para a realização do Market sounding seria durante a fase de estruturação do projeto. Nesse momento, há espaço para incorporar, no escopo do projeto, recomendações e sugestões técnicas da iniciativa privada, alinhando as especificações de saídas (Ordem de Serviço) (LAM et al., 2011) aos termos do contrato. Dessa forma, as necessidades e expectativas do mercado são supridas. Kurniawan (2015) elenca as expectativas das partes interessadas, na fase de modelagem da PMI, conforme apresentado no quadro 6 . 
Quadro 6 - Expectativa dos principais participantes na fase de pré-proposta

\begin{tabular}{|c|c|}
\hline Parte interessada & Expectativa (CFS) \\
\hline \multirow{10}{*}{$\begin{array}{c}\text { Patrocinadores e } \\
\text { potenciais interessados }\end{array}$} & Evitar ganhar contrato não rentável. \\
\hline & Lance em um valor competitivo que viabilize a vitória em um certame. \\
\hline & $\begin{array}{l}\text { Garantia de que o modelo financeiro reflita o projeto e os termos de } \\
\text { financiamento. }\end{array}$ \\
\hline & $\begin{array}{l}\text { Garantia de que o modelo financeiro possa ser usado para } \\
\text { determinar a classificação do projeto sob racionamento de capital. }\end{array}$ \\
\hline & Redução do tempo e custo de licitação. \\
\hline & Transparência do processo de adjudicação. \\
\hline & $\begin{array}{l}\text { Procedimentos de manifestação de interesse com inovações } \\
\text { importantes (por exemplo, um novo tipo de projeto, ou uma nova } \\
\text { solução para problemas conhecidos, ou ainda novas formas de } \\
\text { definir padrões de desempenho). }\end{array}$ \\
\hline & A TIR é superior à taxa de obstáculos corporativos. \\
\hline & $\begin{array}{l}\text { Preferência em submeter PMIs, pois proporcionam mais espaço para } \\
\text { participar na definição dos contornos técnicos e comerciais do } \\
\text { projeto. }\end{array}$ \\
\hline & $\begin{array}{l}\text { Envolver-se nas considerações de longo prazo para ter presença } \\
\text { comercial no país de aplicação. }\end{array}$ \\
\hline \multirow{4}{*}{$\begin{array}{l}\text { Autoridade } \\
\text { Governamental }\end{array}$} & Verificar a capacidade do projeto de entregar VfM. \\
\hline & $\begin{array}{l}\text { Celeridade no processo de adjudicação da PMI, em função da } \\
\text { demanda urgente de operacionalização/instalação do projeto, com } \\
\text { menor risco para o ente concedente. }\end{array}$ \\
\hline & $\begin{array}{l}\text { Experiência operacional robusta e solidez financeira do licitante } \\
\text { durante o processo de solicitação de qualificação. }\end{array}$ \\
\hline & Usar um modelo financeiro para avaliar as propostas. \\
\hline $\begin{array}{l}\text { Investidores / } \\
\text { Financiadores }\end{array}$ & $\begin{array}{l}\text { O projeto deve gerar fluxo de caixa suficiente para dar aos credores } \\
\text { uma margem de segurança em relação às suas obrigações de } \\
\text { serviço da dívida }\end{array}$ \\
\hline \multirow[t]{2}{*}{$\begin{array}{l}\text { Agência de Assessoria / } \\
\text { Consultoria }\end{array}$} & $\begin{array}{l}\text { Garantir o preço mais competitivo com base na taxa de retorno } \\
\text { necessária. }\end{array}$ \\
\hline & $\begin{array}{l}\text { Evitar que o patrocinador obtenha um projeto que cause perdas ao } \\
\text { ente público (exemplo: pagamento de parcela por serviço que não } \\
\text { atenda a comunidade orientada no projeto). }\end{array}$ \\
\hline
\end{tabular}

Fonte: Adaptado de Kurniawan (2015, p. 07).

Compreender tais condições por meio de fornecedores nacionais ou mesmo internacionais, para um determinado projeto, pode facilitar a realização da iniciativa e a oitiva de novos entrantes. As expectativas também devem ser consideradas, para mitigar obstáculos de forma a ampliar a competição entre os concorrentes, sejam entrantes ou consolidados no mercado.

As informações trazidas pelos fornecedores de crédito (bancos e agências de fomento de crédito locais e internacionais) devem ser consideradas, dada a apurada percepção de risco de solvência dos proponentes e do mercado. 
O diálogo com a iniciativa privada pode ser encorajado por meio de:

I. mecanismo eletrônicos de divulgação das informações do projeto, por exemplo sites e

II. enquetes com perguntas sobre os caminhos alternativos (também apresentados de forma amigável e sugestiva no mesmo ambiente eletrônico).

Finalmente, no âmbito da transparência do processo, essa pode ser assegurada tornando público todos os materiais levantados (TEO; BRIDGE, 2016) e os chamamentos dos proponentes para auditarem os dados coletados. Ademais, contratar-se-ia terceiro para auditar os trâmites (TSERNG et al., 2014).

\subsubsection{INOVAÇÃO}

A inovação, embora seja uma variável relevante de micro nível, traz consigo a dificuldade de aplicação justamente por sua irrelevância em alguns contextos e ambientes com baixa maturidade de projetos de PPP/PFI. Uma determinada tecnologia pode ser apresentada em um país e se caracterizar como inovação, mas, em outros países maduros em processo de PPP/PFIs, pode não ser interpretada como nova tendência.

\subsubsection{CAPACIDADE DE COBRIR CUSTOS TRANSACIONAIS}

O conceito de custos transacionais, cunhado por Ronald Coase, em 1937, com a obra "Teoria da Firma" pontua que os custos transacionais se referem aos de utilização de mecanismos de preço ou aos de realização de uma transação por meio de uma troca no mercado aberto. Todas as transações comerciais envolvem despesas ocultas, chamadas custos transacionais, baseadas na assunção de que todos os seres humanos agem com racionalidade limitada e, algumas vezes, adotam comportamentos oportunistas. Douma e Schreuder (2008) afirmam que a divisão do trabalho e especialização encoraja transações na sociedade.

De acordo com Ho e Tsui (2009), os custos transacionais envolvidos na modelagem de PMls podem ser correlacionados com fatores institucionais do ente concedente, influenciando diretamente na condução da proposta originária da 
PPP/PFI. Os custos transacionais se devem aos elevados gastos de negociação, contratação, e de despesas geradas com os mecanismos de monitoramento e regulação do serviço entregue à população (FOURIE; BURGER, 2000). O Quadro 7, a seguir, retrata a influência dos fatores institucionais sobre os fatores do projeto.

Quadro 7 - Fatores causadores de custos transacionais em PMls de PPP/PFls

\begin{tabular}{lll}
\hline \multirow{2}{*}{ Fatores Institucionais } & \multicolumn{1}{c}{ PPP/PFI } & \multicolumn{1}{c}{ PMI } \\
\cline { 2 - 3 } $\begin{array}{l}\text { Política de PPP/PFI imatura } \\
\text { e não efetiva }\end{array}$ & $\begin{array}{l}\text { Escala do Projeto muito } \\
\text { grande para falhar }\end{array}$ & $\begin{array}{l}\text { Interesses difusos envolvidos } \\
\text { no curso da modelagem }\end{array}$ \\
\hline $\begin{array}{l}\text { Administração da PPP/PFI } \\
\text { inexperiência e } \\
\text { incompetência }\end{array}$ & $\begin{array}{l}\text { Natureza do Projeto muito } \\
\text { grande para falhar }\end{array}$ & $\begin{array}{l}\text { Dificuldade de capturar todas } \\
\text { as variáveis necessárias para a } \\
\text { montagem do edital da }\end{array}$ \\
\hline PPP/PFI
\end{tabular}

Fonte: Adaptado de Schepper, Haezendonck e Dooms (2014).

Estabelecer um conjunto de requisitos mínimos e aplicados de forma compulsória pode reduzir significativamente os custos de transação desnecessários. Em cenário de concorrência perfeita, o custo de transacional de uma PMl é mais elevado se comparado a cenários não competitivos, muito embora haja a redução dos custos de diligências de risco. Segundo Portugal Ribeiro, (2014), diligenciar o processo livra o ente público de percalços em contratos Tradicionais de Compras Públicas - Traditional Public Procurement - TPP, pois medidas podem ser tomadas para reduzir as perdas econômicas do ente federativo e encurtar eventuais desacordos que pedem demandar tempo considerável para a resolução. 


\subsubsection{ALOCAÇÃO EFICIENTE DE RISCOS}

De acordo com Ameyaw e Chan (2015a), a urgência na apresentação de resultados tem conduzido entes públicos à contratação de projetos na forma de PPP/PFI pouco estruturados e mal redigidos. Os escopos destes projetos são resultados de curto prazo, desconsiderando responsabilidade futuras. Assim, compromete-se o grau de detalhamento e a forma de condução das PMls. Segundo $\mathrm{Xu}$ et al. (2015), para evitar que os contratos falhem, sejam renegociados ou interrompidos, é necessária minuciosa avaliação do risco de PPP/PFI.

Portanto, segundo Zou et al. (2014) quando termos de curto prazo se tornam a principal orientação de processos de PMls, fatores de longo prazo, como os econômicos, os técnicos e a racionalidade financeira dos projetos, não podem ser assegurados. Reforça a posição por meio de relatório da Eurostat (2016, p. 340) onde os riscos são divididos em três sub níveis:

1. Riscos de construção (atrasos, aumento do valor original, expropriações) transferidos para o parceiro privado da PPP/PFI;

2. Riscos de disponibilidade, por meio de exigências mínimas de desempenho estabelecidas nas diretrizes para o chamamento da PMI e

3. Risco de demanda, encontrados nos marcos regulatórios. O ente concedente assegura ao operador um valor mínimo fixo de remuneração pelo serviço prestado, a fim de garantir determinado nível de receita para a parte proponente. Essa ação independe do nível de demanda realizada no mercado. É necessário o preenchimento dos requisitos predefinidos do serviço a ser prestado ou obra a ser entregue.

Grimsey e Lewis (2002, p. 5) por sua vez, identificam nove áreas de risco associados a projetos de PPP/PFI que por sua vez resultam em reflexos na construção das PMls. (i) Risco técnico, atribuído a falhas de engenharia e design do projeto; (ii) Risco construtivo, pela adoção de técnica e materiais inadequados; (iii) Risco Operacional, em razão do alto custo operacional e de manutenção; (iv) Risco de receita, em razão da baixa demanda de usuários e volatilidade dos preços base do contrato, resultando em déficit receita, forçando o concessionário e o concedente a renegociarem ou interromperem a prestação do serviço (MARQUES; BERG, 2011); (v) Risco financeiro em função de hedge equivocado; (vi) risco de força maior, ocasionado por calamidades e catástrofes; (vii) risco político, dado pela ocasião de perda de apoio político ao projeto; (viii) risco ambiental, em razão dos impactos e ameaças geradas pelo projeto; (ix) risco de falência do projeto, resultado da combinação dos riscos anteriores. 
Ou seja, o desenho eficaz de uma PMI demanda a identificação e busca de alternativas de fatores de risco de longo prazo, como econômico, técnico e racionalidade financeira (ZOU et al., 2014).

KE et al. (2011), estruturam os fatores de riscos em duas categorias:

(i) riscos sistêmicos e

(ii) riscos específicos dos projetos.

Em que, os riscos sistêmicos são formados por:

- Grupo de risco político: corrupção governamental, intervenção governamental, expropriação, crédito público, processo público de tomada de decisão;

- Grupo de risco econômico: envolvendo volatilidade da taxa de juros, flutuação cambial, inflação, mercado de financiamento não desenvolvido, com baixa instrumentalização;

- Grupo de risco legal: mudança de legislação, lei imperfeita e sistema de supervisão, alterações nas regulamentações tributária; Grupo de risco social: objeção pública de poluição / taxa de pedágio;

- Grupo de risco natural: força maior, condições atmosféricas/ geotécnicas imprevistas, risco ambiental. Por sua vez, o risco específico de projetos figura em:

- Grupo de risco de construção: superação de custos de construção, atraso de tempo de construção, falta de disponibilidade de material/mão-de-obra, técnicas de engenharia não comprovadas;

- Grupo de risco de operação: mudanças de projeto/operação, superação de custo de operação, mudança de preço, risco de pagamento de despesas;

- Grupo de risco de mercado: concorrência no mercado, déficit de demanda;

- Grupo de risco de relacionamento: atraso/violação de terceiros, organização e risco de coordenação, incapacidade da concessionária; 
- Outros riscos: aquisição de terras, atraso nas aprovações e autorizações de projetos, contrato conflitante ou imperfeito, falta de infraestrutura de suporte, risco residual, concorrência inadequada para concurso.

\subsubsection{PROCESSO TRANSPARENTE}

O Relatório do PPIAF (2014) aponta para a carência de transparência e compliance adequados nas PMls, gerando desconfiança do mercado proponente, da sociedade civil e do Ministério Público. Interesses pessoais na condução das avaliações e poucas métricas padronizadas dão ampla liberdade para ações, mesmo com escopo estabelecido, externalidades podem influenciar no processo decisório, desviando da estrutura ideal concebida. De acordo com Hueskes, Verhoest e Block (2017) e Verhoest et al. (2015), a flexibilização das regras, a responsabilidade das partes e a baixa transparência no processo podem resultar em abusos e corrupção (EFFAH AMEYAW; CHAN, 2013; FARQUHARSON; YESCOMBE, 2011; ZOU et al., 2014).

Enfatiza-se que um mecanismo para a promoção da isonomia entre os partícipes seria a organização de portal eletrônico que permita a realização de imputação prévia dos dados qualificadores dos proponentes (pessoa física e jurídica) e posterior submissão das propostas vinculadas a número codificado. Assim, o processo de avaliação blind review das propostas seria essencial. Logo, a atribuição de métricas que contemplem para além das atribuições previstas em marcos legais supriria as expectativas da realidade local. Por outro lado, seria possível a adoção de auditorias independentes para fazer parte da composição da junta/núcleo de avaliação de projetos, assumindo o papel de avaliadores blind review. 


\section{METODOLOGIA DE PESQUISA}

A seção de metodologia narra os objetivos, hipóteses e etapas do trabalho.

\section{$5.1 \quad$ JUSTIFICATIVA}

Ismail e Harris (2014) realizaram um levantamento, por meio de 122 (cento e vinte e dois) questionários de especialistas e profissionais da área de gestão de $\mathrm{PPP} / \mathrm{PFI}$, e identificou o modo de influência das principais forças no processo de concretude de uma PPP/PFI no contexto da Malásia:

- Pressão de desenvolvimento econômico de exigir mais instalações;

- Pressão política (DEVKAR et al., 2013);

- Pressão social de Instalações Públicas pobres;

- Incentivo privado;

- Escassez de financiamento do Governo;

- Ineficiência por monopólio público e falta de concorrência;

- Alta qualidade dos serviços necessários;

- Restrição do investimento público e

- Falta de negócios e habilidades (geradoras de lucro no Setor Público).

As PPP/PFIs sofrem ainda com a falta de diretrizes e procedimentos governamentais (SCHEPPER; HAEZENDONCK; DOOMS, 2014), atrasos pelo debate político (ISMAIL; HARRIS, 2014; LI et al., 2005), atrasos em negociações (YUAN et al., 2015) e confusão sobre objetivos e avaliação.

Os procedimentos de manifestação de interesse, PMl, são um meio fundamental para garantir a qualidade e adequação do projeto de PPP. A PPP/PFI estabelece uma ponte entre a atenção ao lucro privado e a melhoria do serviço oferecido ao público. Modeladas de forma cooperativa (KOUWENHOVEN, 1993), com o objetivo de atender mutuamente os interesses de ambos os lados (LAM, 2005), poderiam resultar em projetos finais mais exitosos com a maximização do(s) lucro(s) privado(s) direto e indireto (resultante de receitas secundárias). A atribuição de escopos bem definidos, possibilita oferecer mais segurança e respaldo para 
governos e concessionários, serviços e modelos mais confiáveis, evitando conflitos e problemas.

O gráfico 1 apresenta o mercado brasileiro ilustrando a evolução dos projetos de PMI submetidos aos entes proponentes, onde verifica-se a inversão da quantidade de projetos de PMls submetidos a quantidade de PMls convertidas em contratos.

Gráfico 1 - Propostas apresentadas convertidas em contratos

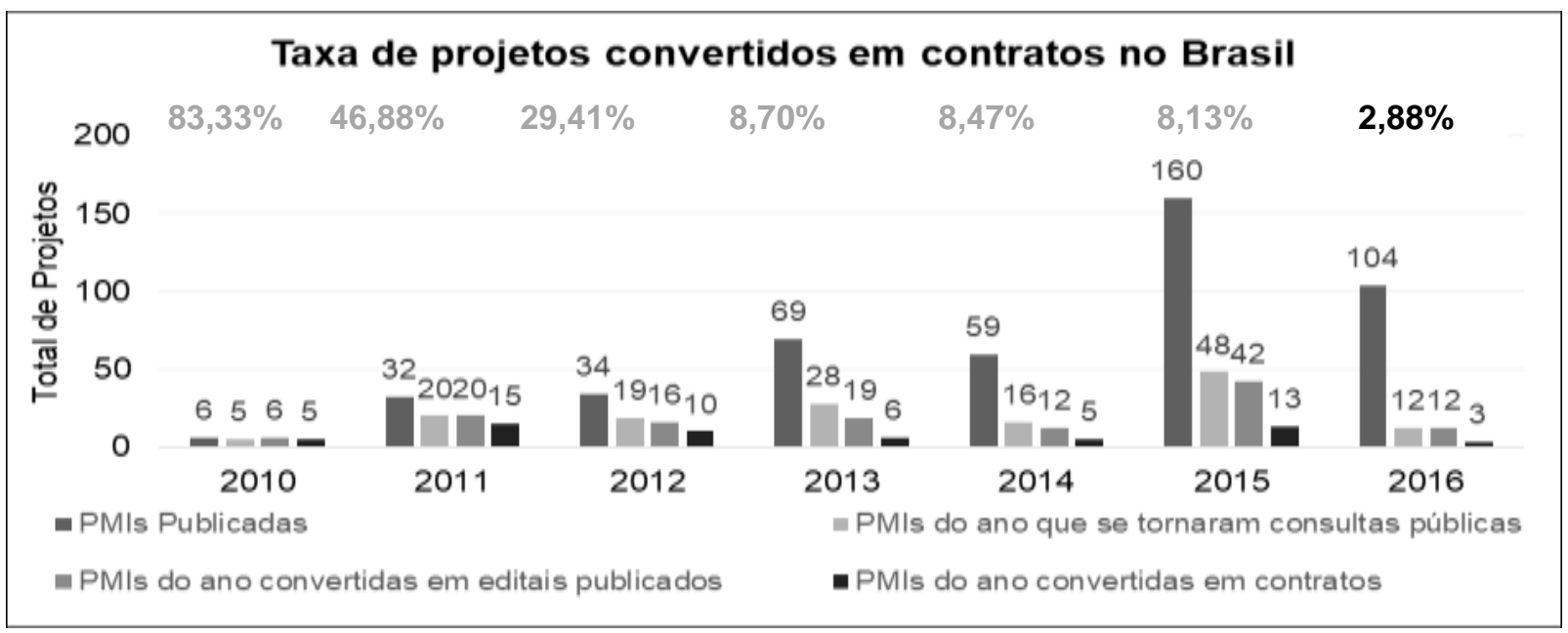

Fonte: Reis (2017).

Conforme apresentado na introdução e referencial teórico desta tese, capítulos 1, 2 e 3, o principal instrumento para a avaliação de propostas é o Value for Money (Zhang et al. 2016), em que a avaliação considera essencialmente aspectos capazes de serem representados quantitativamente. A falta de considerações de aspectos qualitativos é um problema complexo, que impede a consideração de aspectos mais abrangentes.

Uma alternativa seria procedimentos utilizados na esfera pública como o leilão score (NOBRE, 2014), uma forma que permite a utilização de critérios mais subjetivos por meio de notas. Neste caso, porém, é essencial a questão dos critérios, sendo importante a sistematização dos mesmos para o caso das Parcerias Público Privadas.

Neste trabalho investigou-se, no caso prático brasileiro, a opinião de especialistas quanto à adequação e problemas com o VfM, de forma a verificar se está crítica se faz presente. Além disso, buscou-se sistematizar os fatores críticos de sucesso de PPPs e PMIs para, em seguida, obter um modelo teórico que sirva de subsídio para a elaboração de critérios, fundamentando propostas práticas de 
avaliação. Por fim, este modelo teórico foi verificado em um caso específico por meio da sua aplicação no desenvolvimento de um número índice.

\subsection{OBJETIVO DO TRABALHO}

Esta pesquisa teve duas etapas e, portanto, dois objetivos principais seguidos de dois objetivos específicos.

A primeira teve dois objetivos:

(i) Estruturar indicadores capazes de mensurar às PMls submetidas a órgãos públicos, organizando, simplificando e sistematizando as variáveis presentes nos estudos realizados na etapa I;

(ii) Avaliar na percepção dos especialistas se a medida com o VfM é suficiente para a avaliação de PMls e identificar a sua efetividade;

Os objetivos específicos da segunda etapa são:

(i) Delimitar, conceitualmente, sistematizar e apresentar um modelo genérico de indicadores para avaliar PMIs

(ii) Verificar, na percepção dos especialistas, se o modelo proposto é viável de ser aplicado em situações reais, com um exemplo de criação de indicador.

\subsection{FASES, ETAPAS E MÉTODOS ESPECÍFICOS}

A natureza do estudo exigiu a aplicação conjunta de mais de um método, com adoção de técnicas qualitativas e quantitativas. A combinação de métodos encontra respaldo nas orientações de Babbie (2013) que recomenda a aplicação de mais de uma abordagem dada as forças e fraquezas de cada uma das técnicas. A pesquisa é apresentada em 7 (sete) etapas organizadas em 4 fases: 


\subsubsection{FASE 1 - IDENTIFICAÇÃo DE FCs SOBRE PMIs E PPP/PFIs DA LITERATURA}

\subsubsection{ETAPA I - EXPLORATÓRIA}

A etapa visa permitir compreensão dos conceitos e fenômenos que afetam os institutos PPP/PFI e "PMl", valendo-se do mecanismo de pesquisa exploratória e revisão bibliográfica. Foram consultados repositórios de pesquisa, livros, artigos indexados, compêndios, notas técnicas, relatórios de órgãos setoriais e seminários materiais que versassem sobre fatores de impacto nas PPP/PFIs.

Delimitados os termos e recorte do estudo, foram realizadas duas Revisões Bibliográficas. A primeira pode ser classificada como uma Revisão Bibliográfica Inicial, não estruturada, para verificação de disponibilidade de fontes de pesquisa, qualidade das referências, profundidade de tratamento do tema e verificação de ineditismo da abordagem esperada.

A segunda, trata-se de Revisão Bibliográfica Sistemática. O objetivo foi escrever os institutos PPP/PFI e PMI, bem como os Fatores Críticos para o Sucesso - FCSs Positivos e Negativos de ambos institutos.

Por fim, há a caracterização das Propriedades de Visão do Produto, alcançado por meio de protocolo de busca descrito no Apêndice $A$, com o detalhamento do método empregado, contornos limítrofes das fontes consultadas, idioma de pesquisa, chaves de pesquisa, com o respectivo detalhamento das strings utilizadas, abordagem do trabalho e amplitude do período das publicações. O quadro 8 lista as atividades realizadas e a indicação sobre como identificá-las no texto.

Quadro 8 - Descritivo de Atividades da Etapa I

\begin{tabular}{lll}
\hline No. & \multicolumn{1}{c}{ Descrição da Atividade } & \multicolumn{1}{c}{$\begin{array}{c}\text { Localização dos } \\
\text { Resultados }\end{array}$} \\
\hline 01 & $\begin{array}{l}\text { Definição de PPP/PFI, Origem das } \\
\text { PPP/PFIs, VfM, Desafios e FCSs das } \\
\text { PPP/PFIs. }\end{array}$ & $\begin{array}{l}\text { Seções: 2.1, 2.2, 2.3, } 2.4 \\
\text { e 2.5 do Capítulo 02. }\end{array}$ \\
\hline 02 & $\begin{array}{l}\text { Definição da Teoria de Gestão de } \\
\text { Projetos Públicos e Privados. }\end{array}$ & $\begin{array}{l}\text { Seções: 3.1, 3.2 e 3.3 do } \\
\text { Capítulo 03. }\end{array}$ \\
& $\begin{array}{l}\text { Definição de Teoria de: Escopo e } \\
\text { Visão do Produto, Descrição da Visão }\end{array}$ & $\begin{array}{l}\text { Seções: 3.3.1, 3.3.2, } \\
\text { em Projetos Públicos e FCSs de }\end{array}$ \\
& $\begin{array}{l}\text { PMls.2.3 e 3.4 do Capítulo } \\
\text { PMls. }\end{array}$ \\
\hline
\end{tabular}

Fonte: Elaborado pelo autor. 


\subsubsection{ETAPA II - IDENTIFICAÇÃO DAS VARIÁVEIS E FATORES}

Estabelecido os construtos do estudo, passa-se a fase de definição de fatores críticos e variáveis para avaliação comparativa de PMls. A Revisão Bibliográfica Sistemática permitiu identificar trabalhos que analisaram PMls ou propuseram variáveis para avaliá-las. $O$ resultado foi a identificação das variáveis alvo ${ }^{23}$ para a elaboração de uma PPP/PFI formatada nos termos do instituto PMI.

A eleição das variáveis foi suportada por meio de aplicação da Survey e pelo levantamento dos Fatores Críticos para o Sucesso - FCSs de PPP/PFls e de PMls. Relevante contribuição foi obtida por meio da lista de variáveis encontradas nos modelos de avaliação de propostas concebidas pela Source - WBG e UPPP/PFI/SP e pela análise textual das propriedades de Visão do Produto.

Quadro 9 - Descritivo de Atividades da Etapa II

\begin{tabular}{cll}
\hline No. $^{\prime}$ & \multicolumn{1}{c}{ Descrição da Atividade } & \multicolumn{1}{c}{$\begin{array}{c}\text { Localização dos } \\
\text { Resultados }\end{array}$} \\
\hline & Reconhecimento das variáveis latentes críticas & Seções: 3.2 e 3.4 \\
04 & $\begin{array}{l}\text { para a definição de uma PMI baseados em: } \\
\text { Relatório do PPIAF (2014) e artigos técnicos } \\
\text { consultados. }\end{array}$ & $\begin{array}{l}\text { dado por: 3.4.1 e 3.4.2 } \\
\text { do Capítulo 03. }\end{array}$
\end{tabular}

Fonte: Elaborado pelo autor.

\subsubsection{FASE 2 - SÍNTESE DOS FCSs PARA AVALIAÇÃO DE PMIS}

\subsubsection{ETAPA III - PREPARAÇÃO DOS INSTRUMENTOS DE COLETA}

Escolhidas as Propriedades de Visão do Produto e o conjunto de variáveis latentes e quantitativas adequadas a cada uma das dimensões, representadas por indicadores, foi realizada uma Survey.

De acordo com Kothari (2004), foi elaborado o instrumento de coleta da Survey, baseado nos resultados das etapas anteriores, em uma versão preliminar de questionário, integrando os conceitos de propriedade de visão aos FCSs de PMls e elementos necessários às propostas de PMls para grupo maior de especialistas.

A versão beta foi combinada com informações coletadas em entrevistas informais, tornando possível a concepção de um questionário estruturado. Buscouse, na modelagem do questionário, observar fatores cognitivos dos entrevistados

${ }^{23}$ Diz-se alvo ou latente pois eram as variáveis indicadas na literatura e, portanto, não verificadas. 
(TOURANGEAU, RIPS e RASINSKI, 2000; VANNETTE; KROSNICK, 2013) de forma a compreender como eles se sentiam ao responder questões delicadas (SMITH, 2017), como grau de corrupção e conflito de interesse nas PMls submetidas.

As variáveis encontradas nas bases referenciais consultadas foram agrupadas em 7 (sete) dimensões em razão da proximidade de impacto dentro dos escopos das propostas. A separação determinística considerou os elementos necessários, julgados mínimos, para a modelagem de uma proposta de PMI que cumprisse os requisitos para sua conversão em um edital de PPP/PFI viável.

Com a lista de variáveis agrupadas nas dimensões, procedeu-se o estudo das Propriedades de Visão do Produto. O eixo $x$ de uma matriz estruturada foi representado pelo conjunto total das variáveis latentes a serem julgadas em face do eixo $y$, representado pelas Propriedades de Visão do Produto. No cruzamento das variáveis, verificaram-se as Propriedades de Visão do Produto com maior aderência de julgamento às propriedades ${ }^{24}$. Os cruzamentos não óbvios foram submetidos ao escrutínio de especialistas. Tais julgamentos foram operacionalizados por meio de questionário empírico (Apêndice $\mathrm{C}$ ) que compôs a Survey do estudo.

$\mathrm{O}$ estudo piloto era composto de 2 (dois) profissionais do setor, com o intuito de validar a compreensão/clareza (vocabulário), adequação/assertividade (enquadramento ao objeto do estudo), fluidez (ordem das perguntas), extensão do questionário e reduzir falhas existentes, como inconsistências ou complexidade das questões (KROSNICK, 1999; MARCONI; LAKATOS, 2003), se estas apresentavam soluções imediatas ou não (KROSNICK, 1999) e se possuíam excessivo uso de jargões (VANNETTE; KROSNICK, 2013). As perguntas foram agrupadas por tipo (PINTO; PRESCOTT, 1988), iniciando por simples questionamentos e priorizando perguntas críticas logo nas primeiras arguições. O desafio de integração de variáveis aos entrevistados também foi proposto.

Em seguida, as perguntas foram estratificadas em sub níveis relativos ao grau de experiência do profissional em relação a projetos de PPP/PFI e PMI, nas fases de:

\footnotetext{
${ }^{24}$ Para o julgamento das variáveis relativas às dimensões as quais eram relacionadas, cada uma das Propriedades de Visão do Produto recebeu uma escala numérica de 0 (zero) a 10 (dez).
} 
- modelagem, avaliação e gerenciamento;

- correção e adequação semântica textual das perguntas às respostas, ajustando as variáveis para enquadramento escalar, nominal e ordinal frente às perguntas;

- reorganização das escalas atribuídas para melhor acurácia nas respostas perseguidas, variando de acordo com o grau de detalhe desejado para cada perspectiva estudada, com amplitude total das respostas de 4 (quatro) a 7 (sete).

Os polos das respostas foram alternados para evitar viés (SCHAEFFER; PRESSER, 2003). Por exemplo, na pergunta 19 (dezenove) e 21 (vinte e um), em que 1 (um) representa concordância total com o aduzido na assertiva e não 7 (sete), como normalmente encontrado na literatura.

O mesmo conceito de aleatoriedade foi aplicado no quadro de ranking para os postos de posições das questões: 23 (vinte e três), 24 (vinte e quatro) e 26 (vinte e seis) do questionário. Para as questões 23 (vinte e três) e 24 (vinte e quatro) foram estabelecidos números índices para os fatores de acordo com a frequência $(\delta)$, posto de posição $(n)$ e peso $(\rho)$ dado por: $I_{f}=\sum\left(\delta_{f n} X \rho_{n}\right)$.

O posto de posição $1^{\text {025 }}$ recebeu peso 5 (cinco), seguido sucessivamente dos 4 (quatro) postos de posições com peso de relevância inversamente proporcional a escala de posição atingida pelo fator. Para Best e Krueger (2008), os FCSs são examinados por seu grau individual de criticidade ao longo das diferentes fases do projeto.

Referente à questão 26 (vinte e seis) do questionário, o número do posto de posição foi atingido por meio da moda da matriz transposta das respostas, indicando a propriedade a uma determinada colocação no posto de posição.

A versão final totalizou 27 perguntas (estruturadas e abertas) e contou com uma descrição introdutória do objetivo do estudo. Essa foi elaborada com cinco seções:

(i) histórico profissional na área dos respondentes;

(ii) questionamentos abertos sobre PPP/PFls e PMls para evitar constrições e direcionamento das respostas,

${ }^{25}$ Primeiro FCS mais relevante na lista ordenada. 
(iii) percepção e experiência nas medidas avaliação de PMls;

(iv) FCS em PMls elencados e

(v) avaliação da integração dos conceitos (Visão do Produto e FCS em PMls).

Foi assegurado, no preenchimento do questionário, o sigilo de fonte para que houvesse pouco ruído nas devolutivas. Utilizou-se, como veículo de envio da Survey, o correio eletrônico (e-mail) e Mensageiro Instantâneo (Instant Message WhatsApp ${ }^{\circledR}$ ), por intermédio da ferramenta de produção de formulários desenvolvida pela Qualtrics.

As atividades desenvolvidas são listadas no Quadro 10.

Quadro 10 - Descritivo de Atividades da Etapa III

\begin{tabular}{|c|c|c|}
\hline $\mathbf{N}^{\circ}$. & Descrição da Atividade & $\begin{array}{l}\text { Localização dos } \\
\text { Resultados }\end{array}$ \\
\hline 05 & $\begin{array}{l}\text { Integração das variáveis escolhidas as } \\
\text { Propriedades de Visão de Produto para } \\
\text { reduzir o subjetivismo das avaliações das } \\
\text { propostas submetidas pelos proponentes } \\
\text { privados. }\end{array}$ & $\begin{array}{l}\text { Seções: } 3.3 .2 .2 \text { e } 3.4 \text {, do } \\
\text { Capítulo } 03 \text { e Apêndice C } \\
\text { Questão } 26 .\end{array}$ \\
\hline 06 & $\begin{array}{l}\text { Organização dos questionamentos em } \\
\text { perguntas para um questionário. }\end{array}$ & Seção: Apêndice C. \\
\hline 07 & $\begin{array}{l}\text { Entrevista com especialistas em PMls para } \\
\text { validação das perguntas do questionário. }\end{array}$ & $\begin{array}{l}\text { Seção: 4.4.3.1 do Capítulo } \\
04 .\end{array}$ \\
\hline 08 & $\begin{array}{l}\text { Ajustes e formatação da versão final do } \\
\text { questionário. }\end{array}$ & $\begin{array}{l}\text { Apêndice C (Versão final } \\
\text { do questionário). }\end{array}$ \\
\hline 09 & $\begin{array}{l}\text { Organização do Grupo de Especialistas } \\
\text { para a distribuição efetiva dos questionários. }\end{array}$ & $\begin{array}{l}\text { Contatados } 300 \text { (trezentos) } \\
\text { especialistas setoriais, } \\
\text { descritos na Seção: 4.4.3.3 } \\
\text { do Capítulo } 04 \text {. }\end{array}$ \\
\hline
\end{tabular}

Fonte: Elaborado pelo autor.

\subsubsection{ETAPA IV - COLETA DE DADOS PARA O SURVEY}

O método utilizado nesta etapa persiste no levantamento. 3 (três) contatos foram realizados ao longo de 14 (quatorze) dias seguidos de atividades. Na data inicial, foi encaminhado um pedido, descrevendo o pleito com o respectivo link de acesso às perguntas da Survey. 
Após o prazo de sete dias, foi reiterado o pedido para preenchimento do questionário e, em 10 (dez) dias, foi feito o último pedido para o preenchimento, buscando sensibilizar os respondentes que haviam iniciado o preenchimento, mas não encerrado. A essa ação, seguiu-se uma nota de agradecimento àqueles que concluíram o questionário. A taxa de resposta obtida foi de $49,66 \%$.

As atividades, desta etapa, encontram-se sistematizadas estão no Quadro 11.

Quadro 11 - Descritivo de Atividades da Etapa IV

\begin{tabular}{cll}
\hline N$^{\circ}$. & \multicolumn{1}{c}{ Descrição da Atividade } & \multicolumn{1}{c}{$\begin{array}{c}\text { Localização dos } \\
\text { Resultados }\end{array}$} \\
\hline & Aplicação do procedimento de & Descritos nas Seções: \\
10 & $\begin{array}{l}\text { cobrança de respostas dos } \\
\text { questionários submetidos. }\end{array}$ & $\begin{array}{l}\text { 4.4.2.2 e 4.4.2.3 do } \\
\text { Capítulo 04. }\end{array}$
\end{tabular}

Fonte: Elaborado pelo autor.

\subsubsection{ETAPA V - ANÁLISE DOS RESULTADOS DO SURVEY}

O método empregado na Survey valeu-se, inicialmente, da organização das respostas dos questionários em planilhas do Microsoft Excel. Posteriormente, os dados foram transferidos para uma base de dados única, no programa IBM/SPSS, versão 22. Adotados os testes de verificação de normalidade Kolmogorov-Smirnov (KS) e de Shapiro-Wilk, os resultados motivaram análises não paramétricas para o grupo amostral, detalhados no Capítulo 05.

Ao todo foram consolidadas 190 (cento e noventa) variáveis. Dessas, 09 (nove) variáveis foram classificadas como escalares, 152 (cento e cinquenta e duas) categóricas nominais e 27 (vinte e sete) variáveis categóricas ordinais.

A análise da confiabilidade das devolutivas do questionário foi aferida por meio da aplicação de métodos estatísticos. O coeficiente alfa de Cronbach, para a validação do grau de correlação entre as respostas dos respondentes e verificação de normalidade das respostas, foi utilizado. Por fim, este estudo considera análises estatísticas descritivas, de correlação e testes de hipóteses. Ressalta-se que o desenho envolveu o estudo de variáveis independentes unpair statistics.

O total de questionários encaminhados aos respondentes foi de 300 (trezentos), distribuídos em blocos de 100 (cem), dada as restrições da ferramenta de formulário à versão utilizada na pesquisa. Da quantidade total enviada, 149 (cento e quarenta e nove) questionários foram devolvidos e, somente, 78 (setenta e 
oito) se mostraram úteis para o estudo. Entretanto, para uma melhor definição dos resultados, foram considerados os questionários apenas dos profissionais com experiência em ambos os institutos - PPP/PFI e PMI, conjuntamente, por pelo menos mais de 1 (um) ano. Por fim, 45 (quarenta e cinco) questionários constituíram o corpus.

O conjunto total dos dados da amostra apresentou heterogeneidade significativa para parte das respostas e não foi possível comprovar estatisticamente a as hipóteses. Os dados indicaram, porém, que na percepção dos especialistas consultados há subjetivismo nas avaliações dos projetos de PMI.

As respostas se mostraram homogêneas, indicando uma carência do campo teórico sobre o tema e uma necessidade esperada pelo mercado e academia de buscar respostas para reduzir tal discrepância e aclarar situações envolvendo os institutos PPP/PFI e "PMI". Seguiu-se, então, para a próxima etapa, a saber Etapa V.

As atividades da etapa estão definidas no Quadro 12.

Quadro 12 - Descritivo de Atividades da Etapa V

\begin{tabular}{|c|c|c|}
\hline $\mathbf{N}^{\circ}$. & Descritivo da Atividade & $\begin{array}{l}\text { Localização dos } \\
\text { Resultados }\end{array}$ \\
\hline 11 & $\begin{array}{l}\text { Organização das devolutivas dos } \\
\text { questionários encaminhados e } \\
\text { tabulações das respostas. }\end{array}$ & $\begin{array}{l}\text { Seção: } 5.3,5.4 \text { e } 5.5 \text { do } \\
\text { Capítulo } 05 .\end{array}$ \\
\hline
\end{tabular}

Fonte: Elaborado pelo autor.

\subsubsection{ETAPA VI - PROPOSIÇÂO DE UM MODELO TEÒRICO DE DIMENSÔES PARA AVALIAÇÂO DE PMIS}

As fontes iniciais para a geração das dimensões, portanto, foram os artigos identificados na literatura com Fatores Críticos para Proposição de PMls e PPPs, bem como o os modelos propostos pela Source (WBG) e pela Unidade de PPP/PFI do Estado de São Paulo, Brasil. Estes trabalhos foram sintetizados e os fatores foram transformados em perguntas, orientadas para os profissionais que participaram do levantamento, tipo Survey.

O questionário adotado na Survey por intermédio da Questão 20 resultou em uma opinião dos respondentes sobre o nível de importância e priorização dos fatores críticos identificados na literatura. As Questões 23 e 24 da Survey, por exemplo, 
orientaram a ordem de posição dos 5 (cinco) Fatores Críticos - FCs positivos e negativos, que tiveram maior significância para o grupo amostral.

Os FCs foram agrupados em postos de posição. Uma vez realizado o ordenamento dos postos de posições de ambos os FCs positivos e negativos, a descrição de cada um foi comparada às variáveis presentes nos modelos da Source e na Unidade de PPP/PFI do Estado de São Paulo, Brasil, em conjunto com as variáveis apresentadas pelos especialistas encontradas na Questão 20 da Survey.

Como resultado, foram identificadas 7 (sete) dimensões.

\subsubsection{FASE 3 - VERIFICAÇÂO DAS DIMENSÕES PELA PROPOSIÇÂO DE NÚMERO ÍNDICE PARA AVALIAÇÃO DE PMIS}

\subsubsection{ETAPA VI - PROPOSIÇÃO DE INDICADORES BASEADO NO MODELO}

O modelo foi verificado por meio de um esforço de desdobramento de um indicador específico, utilizando o modelo conceitual gerado.

O resultado do conjunto formado pelos indicadores e pelo número índice "T" consolidam um Modelo para Avaliação de PMls, que considera ambos aspectos qualitativos e quantitativos. Portanto, não se restringe somente a perspectiva financeira do projeto, mas permite a qualificação, comparação das propostas e a sua prévia verificação pelos proponentes.

\subsubsection{ETAPA VII - PROPOSTA DE NÚMERO ÍNDICE BASEADO NO MODELO DE DIMENSÕES}

Os processos de proposição e validação de PPP/PFls, porém, possuem fases de qualificação e de comparação de propostas. Logo, um conjunto de indicadores distinto não é suficiente para apoiá-las. Justifica-se, assim, a necessidade de elaboração de uma síntese ou um indicador comparativo.

A solução foi a criação de um índice, denominado índice " $T$ " que combina o conjunto de indicadores a partir de um conjunto de pesos, oferecidos por especialistas. O índice "T" poderia ser utilizado como métrica objetiva para qualificação de propostas com o intuito de sua adoção, como referência, para processos de preparação ou avaliação. 
Esta etapa foi uma elaboração teórico do autor, de forma a verificar inicialmente a viabilidade de uso do modelo conceitual, considerando um conjunto simples de indicadores.

\subsubsection{ETAPA VII - PROPOSTA DE MÉTODO DE VALIDAÇÃO DO NÚMERO ÍNDICE}

Foi realizada uma busca por modelos e métodos de validação de indicadores, tendo sido verificado a proposta de Cloquell-Ballester et al. (2006), como a mais pertinente ao contexto desta tese. A metodologia empregada na validação seguiu, portanto, a proposta realizada pelos autores para indicadores de sustentabilidade (Apêndice E).

Ao todo, cada entrevista foi composta por 3 (três) perguntas divididas em medição do peso dos indicadores que constituem o índice "T" à luz do método Analytic Hierarchy Process - AHP ( WIND; SAATY, 1980), sob 3 (três) perspectivas: ente privado, ente público e cidadão;

2.A - Pergunta conduzida com a aplicação via AHP do método "3 S" proposto por Cloquell-Ballester et al. (2006). Por sua vez, esse foi ajustado e analisado de acordo com as necessidades da pesquisa, a saber:

- Coerência Conceitual,

- Coerência Operacional e

- Utilidade do índice "T".

2.B - Apurou-se o grau de concordância do especialista ao modelo de indicadores proposto com o índice "T", por meio de questionário de avaliação. A abordagem de conteúdo à última pergunta foi de conteúdo espontâneo. No entanto, para 0 arquivamento das palavras do respondente, com sua autorização, a sua fala foi gravada. Posteriormente, foram transcritas e sintetizadas. 
Na Etapa VI do estudo (Quadro 13), há as atividades 12, 13 e 14 descritas.

Quadro 13 - Descritivo de Atividades da Etapa VI

\begin{tabular}{|c|c|c|}
\hline $\mathrm{N}^{\circ}$. & Descrição da Atividade & $\begin{array}{l}\text { Localização dos } \\
\text { Resultados }\end{array}$ \\
\hline 12 & $\begin{array}{l}\text { Proposta de indicadores para a } \\
\text { avaliação de PMls. }\end{array}$ & $\begin{array}{l}\text { Seções: } 6.1,6.2 \text { e } 6.3 \\
\text { do Capítulo } 06 \quad \text { e } \\
\text { Apêndice F. }\end{array}$ \\
\hline 13 & $\begin{array}{l}\text { Proposta de índice para a } \\
\text { avaliação de PMls. }\end{array}$ & $\begin{array}{l}\text { Seções: } 6.3 \text { e } 6.4 \text { do } \\
\text { Capítulo } 06 .\end{array}$ \\
\hline 14 & Aplicação do Modelo. & $\begin{array}{l}\text { Seção: } 6.5 \text { do Capítulo } \\
06 .\end{array}$ \\
\hline
\end{tabular}

Fonte: Elaborado pelo autor.

\subsubsection{ETAPA VII - VERIFICAÇÂO DO NÚMERO ÍNDICE COM PROFISSIONAIS DO MERCADO}

Após a revisão bibliográfica e estruturação das variáveis com base nos FCSs, foram realizadas entrevistas com grupo de especialistas, iniciada com pedido formal (Apêndice D) do encontro. Essas, por sua vez, foram orientadas por protocolo que assegurasse a aplicação padronizada das perguntas (Apêndice E). Nas entrevistas, ocorreu a descrição individual de cada um dos indicadores nas respectivas dimensões que compuseram o índice "T" (Apêndice F).

Os entrevistados tiveram contato preliminar com as perguntas da entrevista e puderam se posicionar livremente sobre as questões postuladas. Foram realizadas ao todo 12 (doze) entrevistas, sendo 5 (cinco) presenciais e 7 (sete) nãopresenciais, por meio do Skype ${ }^{\circledR}$.

As atividades resultantes da Etapa VII da pesquisa são descritas pelo Quadro 14. 
Quadro 14 - Descritivo de Atividades da Etapa VII

\begin{tabular}{|c|c|c|}
\hline $\mathbf{N}^{\circ}$. & Descrição da Atividade & $\begin{array}{l}\text { Localização dos } \\
\text { Resultados }\end{array}$ \\
\hline 15 & $\begin{array}{l}\text { Validação do Modelo de Indicadores [índice “T”] } \\
\text { de avaliação com a descrição da Pesquisa de } \\
\text { Campo, adoção de } 4 \text { (quatro) perguntas } \\
\text { estruturadas e abertas a } 12 \text { (doze) } \\
\text { especialistas em PMls. }\end{array}$ & $\begin{array}{l}\text { Seções: } 7.1,7.2 \text { e } 7.3 \\
\text { do Capítulo } 07 \text { e } \\
\text { Apêndices D e. }\end{array}$ \\
\hline 16 & $\begin{array}{l}\text { Consolidação das respostas das perguntas e } \\
\text { tabulações dos resultados encontrados. }\end{array}$ & $\begin{array}{l}\text { Seção: } 7.2 \text { do Capítulo } \\
07 \text { e Apêndices G e H. }\end{array}$ \\
\hline 17 & $\begin{array}{l}\text { Reflexões sobre o índice proposto e desafios à } \\
\text { sua aplicação prática. }\end{array}$ & $\begin{array}{l}\text { Seções: } 7.3 \text { e } 7.4 \text { do } \\
\text { Capítulo } 07 .\end{array}$ \\
\hline
\end{tabular}

Fonte: Elaborado pelo autor. 


\section{DIMENSÕES PARA AVALIAÇÃO DE PMIS}

Este capítulo descreve um levantamento dos fatores críticos realizados com 84 especialistas e que permitiu a identificação de um conjunto de sete dimensões que podem ser utilizadas para a avaliação de PMls.

\subsection{INTEGRAÇÃO DOS FCSS DE PPP/PFIS E PMIS}

Inicia-se esta seção com a pergunta 1), a saber: Seria possível estabelecer por meio de similaridades a junção dos Fatores Críticos para o Sucesso - FCSs de PPP/PFIs e PMls, considerando que embora sejam ambos institutos distintos possuam efeitos diretos de um sob o outro no processo de contratação do serviço?

Com o intuito de respondê-las, é necessária a contextualização inicial dos Fatores Críticos para o Sucesso das PPP/PFls, dado que esses são processos anteriores e concomitantes com o rito das PMls. Além disso, o emprego de conceitos de linguística que justificassem o processo de agrupamento dos Fatores Críticos em conjuntos de impacto positivos e negativos foram explorados também.

O primeiro passo consiste na identificação do conjunto total de Fatores Críticos para o Sucesso disponíveis na literatura por meio de consulta às bases de dados com os strings previstos no Apêndice A. Posteriormente, organiza-se uma planilha envolvendo: (i) a orientação de aplicação do FCS previsto na publicação se PPP/PFI ou "PMl"; (ii) a descrição do objetivo do artigo; (iii) o enquadramento de aplicação do artigo expondo os limites da pesquisa; (iv) as responsáveis pela publicação; (v) a base de referência de autoria dos FCSs elencados; (vi) o enquadramento do FCSs a um dos 10 (dez) níveis de macro ou micro nível identificados pelo PPIAF (2014) - [arbitrado pelo autor] nos chamados "Grupos de Aplicação" e, por fim, (vii) a descrição dos Fatores Críticos para o Sucesso - FCSs em si.

Os documentos e materiais técnicos que conduzem as escolhas dos fatores relativos às PPP/PFIs da literatura ${ }^{26}$ foram: Chou e Pramudawardhani (2015), Hwang, Zhao e Gay (2013), Mota e Moreira (2015), Osei-Kyei e Chan (2015), Yun et

\footnotetext{
${ }^{26}$ A escolhas dos artigos indexados ocorreu de acordo com disponibilidade de acesso da USP e contou com uma revisão sistemática. A revisão foi elaborada de acordo com a data da publicação, em especial, publicações atuais que contemplem fatores críticos presentes nas obras clássicas e por estarem atualizados no contexto das PPP/PFIs e PMls. Ademais, considera-se a localidade territorial alvo da publicação e busca-se, assim, capturar o maior número possível de fatores críticos de sucesso.
} 
al. (2015) e Zou et al. (2014), e PMls dados por Yun et al. (2015) e pelo relatório produzido pelo Public-Private Infrastructure Advisory Facility - PPIAF (2014) para o World Bank Group - WBG. Os estudos indicaram que é possível, por meio de similaridades, a junção dos Fatores Críticos para o Sucesso - FCSs de PPP/PFIs e PMls.

A principal unidade de significado é chamada de "item lexical" e compreende uma palavra ou conjunto de termos inseridos em um contexto (SINCLAIR, 201). A definição "terminológica" é a busca da definição dos conceitos e a "lexiológica" é o significado (LARA, 2004) do conjunto de palavras dos FCSs. Nesta tese, as associações dos "itens lexicais" são dadas pelas sentenças que representam os FCSs de PPP/PFI e PMI associados a cada um dos 10 (dez) grupos propostos pelo PPIAF (2014), pautando-se no enquadramento terminológico dos fatores observados na literatura consultada aos "Grupos de Aplicação", considerando que a análise envolveu um primeiro entendimento terminológico e lexiológico dos FCSs.

O léxico temático configura-se como um componente linguístico a serviço de comunicações especializadas, transmitindo conteúdos próprios da área, ou seja, a dimensão cognitiva da sentença que representa o Fator Crítico ao conhecimento especializado por este representado. Sendo assim, os termos (dos FCSs) realizam duas funções essenciais: a representação e a transmissão do conhecimento especializado. A circunscrição do conteúdo específico auxilia a

Elidir ambiguidades e jogos polissêmicos, (...), contribuindo para uma desejada precisão conceitual, (...) considerando a monorreferencialidade (...) veiculando o significado específico de cada área, bem como estabelece uma única referência com o mundo exterior, sempre na ótica da área que a unidade lexical está inserida. (KRIEGER; FINATTO, 2004, p.17). 
Quadro 15 - Fatores críticos para o sucesso de PPP/PFls e PMls

\begin{tabular}{|c|c|c|c|c|c|c|}
\hline Orientação & Objetivo & Enquadramento & Fonte & Base de Referência & $\begin{array}{l}\text { Grupo de } \\
\text { Aplicação }\end{array}$ & $\begin{array}{l}\text { Fator Crítico para o } \\
\text { Sucesso }\end{array}$ \\
\hline \multirow{10}{*}{ PPP/PFI } & \multirow{10}{*}{$\begin{array}{c}\text { Análise } \\
\text { comparativa } \\
\text { da Austrália e } \\
\text { da China }\end{array}$} & \multirow{10}{*}{$\begin{array}{l}\text { Identificar fatores } \\
\text { críticos que afetam a } \\
\text { eficácia e eficiência } \\
\text { dos processos de } \\
\text { licitação em } \\
\text { Parcerias Público- } \\
\text { Privadas }\end{array}$} & \multirow{10}{*}{$\begin{array}{l}\text { Tingting Liu, Yan } \\
\text { Wang, Suzanne } \\
\text { Wilkinson (2016) }\end{array}$} & $\begin{array}{l}\text { KPMG (2010), Qiao et al. (2001), } \\
\text { Birnie (1999) e Mahalingam (2010). }\end{array}$ & \multirow{3}{*}{$\begin{array}{l}\text { Robustez do } \\
\text { desenvolvimento } \\
\text { de um caso de } \\
\text { negócio }\end{array}$} & $\begin{array}{l}\text { Existência de Serviços } \\
\text { Necessários }\end{array}$ \\
\hline & & & & $\begin{array}{l}\text { Zhang (2005), Tang and Shen (2013), } \\
\text { Chen and Doloi (2008). }\end{array}$ & & $\begin{array}{l}\text { Viabilidade econômica do } \\
\text { projeto }\end{array}$ \\
\hline & & & & $\begin{array}{l}\text { Infrastructure Australia (2008) e } \\
\text { Yescombe (2007). }\end{array}$ & & $\begin{array}{l}\text { Robustez da análise da } \\
\text { opção de compra }\end{array}$ \\
\hline & & & & $\begin{array}{l}\text { Li et al. (2005), Chan et al. (2010a), } \\
\text { Akintoye et al. (2003), KPMG (2010) e } \\
\text { Tang and Shen (2013). }\end{array}$ & $\begin{array}{l}\text { Qualidade dos } \\
\text { sumários } \\
\text { executivos }\end{array}$ & $\begin{array}{l}\text { Clareza do resumo do } \\
\text { projeto e requisitos do } \\
\text { cliente }\end{array}$ \\
\hline & & & & $\begin{array}{l}\text { Aziz (2007), Garvin (2010), } \\
\text { Mahalingam (2010) e Li et al. (2005). }\end{array}$ & \multirow{4}{*}{$\begin{array}{l}\text { Capacidade do } \\
\text { setor privado }\end{array}$} & $\begin{array}{l}\text { Disponibilidade de } \\
\text { diretrizes PPP/PFI e } \\
\text { documentação } \\
\text { padronizada }\end{array}$ \\
\hline & & & & $\begin{array}{l}\text { Jefferies et al. (2002), Dixon et al. } \\
\text { (2005) e Dulaimi et al. (2010). }\end{array}$ & & $\begin{array}{l}\text { Experiência e } \\
\text { conhecimento do setor } \\
\text { público }\end{array}$ \\
\hline & & & & $\begin{array}{l}\text { Chan et al. (2010a), Tiong (1996), } \\
\text { Chen (2009), Li et al. (2005) Chen } \\
\text { (2009), Qiao et al. (2001) e Garvin } \\
(2010) \text {. }\end{array}$ & & Suporte político \\
\hline & & & & $\begin{array}{l}\text { Chen (2009), Qiao et al. (2001) e } \\
\text { Garvin (2010). }\end{array}$ & & Liderança do setor público \\
\hline & & & & $\begin{array}{l}\text { Chan et al. (2010a), Chan et al. } \\
\text { (2010b), Liu e Wilkinson (2014) e } \\
\text { Martins et al. (2011). }\end{array}$ & $\begin{array}{l}\text { Estrutura de } \\
\text { governança }\end{array}$ & $\begin{array}{l}\text { Clareza e } \\
\text { responsabilidade da } \\
\text { estrutura de governo }\end{array}$ \\
\hline & & & & & & Continue \\
\hline
\end{tabular}


Quadro 20 - Fatores críticos para o sucesso de PPP/PFIs e PMls

Conclusão

\begin{tabular}{|c|c|c|c|c|c|c|}
\hline Orientação & Objetivo & Enquadramento & Fonte & Base de Referência & $\begin{array}{l}\text { Grupo de } \\
\text { Aplicação }\end{array}$ & $\begin{array}{l}\text { Fator Crítico para o } \\
\text { Sucesso }\end{array}$ \\
\hline & & & & $\begin{array}{l}\text { Zhang (2005), Kwak et al. (2009), } \\
\text { Jefferies et al. (2002), Li et al. (2005), } \\
\text { Birnie (1999) }\end{array}$ & $\begin{array}{l}\text { Nível de } \\
\text { competição nos } \\
\text { certames }\end{array}$ & $\begin{array}{l}\text { Competitividade nos } \\
\text { certames }\end{array}$ \\
\hline & & & & $\begin{array}{l}\text { Li et al. (2005), Yescombe (2007), } \\
\text { Chan et al. (2010a) }\end{array}$ & $\begin{array}{l}\text { Nível de } \\
\text { transparência nos } \\
\text { certames }\end{array}$ & $\begin{array}{l}\text { Transparência do sistema } \\
\text { de aquisição }\end{array}$ \\
\hline
\end{tabular}

Fonte: Organizado pelo Autor. 
Quadro 16 - Fatores críticos de sucesso de PPP/PFls e PMIs (a)

\begin{tabular}{|c|c|c|c|c|c|c|}
\hline Orientação & Objetivo & Enquadramento & Fonte & Base de Referência & $\begin{array}{l}\text { Grupo de } \\
\text { Aplicação }\end{array}$ & $\begin{array}{c}\text { Fator Crítico para o } \\
\text { Sucesso }\end{array}$ \\
\hline \multirow{7}{*}{ PPP/PFI } & \multirow{7}{*}{$\begin{array}{l}\text { Analisar as } \\
\text { parcerias } \\
\text { público- } \\
\text { privadas na } \\
\text { Europa }\end{array}$} & \multirow{7}{*}{$\begin{array}{l}\text { A importância dos } \\
\text { determinantes não } \\
\text { financeiros nas } \\
\text { parcerias público- } \\
\text { privadas }\end{array}$} & \multirow{7}{*}{$\begin{array}{l}\text { Mota e Moreira } \\
\qquad(2015)\end{array}$} & $\begin{array}{l}\text { Li et al. (2005), Zhang (2005a), Zhang } \\
\text { (2005b) }\end{array}$ & \multirow{3}{*}{$\begin{array}{l}\text { Fatores } \\
\text { extrínsecos }\end{array}$} & $\begin{array}{l}\text { Ambiente econômico } \\
\text { favorável }\end{array}$ \\
\hline & & & & Zhang (2005b), $\mathrm{Ng}$ et al. (2012) & & Ambiente legal \\
\hline & & & & $\mathrm{Ng}$ et al. (2012) & & Ambiente político \\
\hline & & & & $\begin{array}{l}\text { Li et al. (2005), Zhang (2005a), Zhang } \\
\text { (2005b), Ng et al. (2012) }\end{array}$ & \multirow{4}{*}{ Fatores intrínsecos } & $\begin{array}{l}\text { Viabilidade econômica do } \\
\text { projeto }\end{array}$ \\
\hline & & & & Li et al. (2005), Zhang (2005b) & & Confiança \\
\hline & & & & Zhang (2005a) & & Gerenciamento de risco \\
\hline & & & & Zhang (2005b) & & Aquisição \\
\hline \multirow{6}{*}{ PPP/PFI } & \multirow{6}{*}{$\begin{array}{l}\text { Comparações } \\
\text { entre países } \\
\text { de fatores } \\
\text { críticos para o } \\
\text { sucesso de } \\
\text { PPP/PFIs }\end{array}$} & \multirow{6}{*}{$\begin{array}{l}\text { Alocação de riscos } \\
\text { em PPP/PFls }\end{array}$} & \multirow{6}{*}{$\begin{array}{l}\text { Jui-Sheng Chou; } \\
\text { Dinar } \\
\text { Pramudawardhani } \\
\text { (2015) }\end{array}$} & \multirow{6}{*}{$\begin{array}{l}\text { Integralizado por todo o referencial } \\
\text { teórico adotado }\end{array}$} & \multirow{3}{*}{$\begin{array}{l}\text { Contexto Político - } \\
\text { alta relevância }\end{array}$} & $\begin{array}{l}\text { Aceitabilidade política do } \\
\text { modelo e apoio interno no } \\
\text { governo para a execução }\end{array}$ \\
\hline & & & & & & $\begin{array}{l}\text { Atitude positiva do ente } \\
\text { concedente ao agente } \\
\text { privado }\end{array}$ \\
\hline & & & & & & Estabilidade política \\
\hline & & & & & \multirow{3}{*}{$\begin{array}{l}\text { Contexto de baixa } \\
\text { relevância }\end{array}$} & Garantias \\
\hline & & & & & & $\begin{array}{l}\text { Competência da unidade } \\
\text { gestora }\end{array}$ \\
\hline & & & & & & Desconto de impostos \\
\hline
\end{tabular}


Quadro 16 - Fatores críticos de sucesso de PPP/PFls e PMls (b)

Conclusão

\begin{tabular}{|c|c|c|c|c|c|c|}
\hline Orientação & Objetivo & Enquadramento & Fonte & Base de Referência & $\begin{array}{l}\text { Grupo de } \\
\text { Aplicação }\end{array}$ & $\begin{array}{c}\text { Fator Crítico para o } \\
\text { Sucesso }\end{array}$ \\
\hline \multirow{6}{*}{ PPP/PFI } & \multirow{6}{*}{$\begin{array}{l}\text { Revisão de } \\
\text { estudos sobre } \\
\text { os Fatores } \\
\text { Críticos de } \\
\text { Sucesso para } \\
\text { Parcerias } \\
\text { Público- } \\
\text { Privadas } \\
\text { (PPP/PFI) }\end{array}$} & \multirow{6}{*}{$\begin{array}{l}\text { Período de } 1990 \text { a } \\
\qquad 2013\end{array}$} & \multirow{6}{*}{$\begin{array}{l}\text { Osei-Kyei e Chan } \\
\qquad(2015)\end{array}$} & \multirow{6}{*}{$\begin{array}{l}\text { Integralizado por todo o referencial } \\
\text { teórico adotado }\end{array}$} & $\begin{array}{c}\text { Número de } \\
\text { ocorrência do Fator } \\
\text { nas publicações } \\
(13)\end{array}$ & $\begin{array}{l}\text { Apropriada alocação e } \\
\text { compartilhamento de risco }\end{array}$ \\
\hline & & & & & $\begin{array}{c}\text { Número de } \\
\text { ocorrência do Fator } \\
\text { nas publicações } \\
\text { (13) }\end{array}$ & Consórcio privado robusto \\
\hline & & & & & $\begin{array}{c}\text { Número de } \\
\text { ocorrência do Fator } \\
\text { nas publicações } \\
(12)\end{array}$ & Suporte político \\
\hline & & & & & $\begin{array}{l}\text { Número de } \\
\text { ocorrência do Fator } \\
\text { nas publicações (9) }\end{array}$ & Suporte da comunidade \\
\hline & & & & & $\begin{array}{c}\text { Número de } \\
\text { ocorrência do Fator } \\
\text { nas publicações (8) }\end{array}$ & Certame transparente \\
\hline & & & & & $\begin{array}{l}\text { Número de } \\
\text { ocorrência do Fator } \\
\text { nas publicações (8) }\end{array}$ & Estrutura legal favorável \\
\hline
\end{tabular}

Fonte: Organizado pelo Autor. 
Quadro 17 - Fatores críticos de sucesso de PPP/PFls e PMIs (a)

\begin{tabular}{|c|c|c|c|c|c|c|}
\hline Orientação & Objetivo & Enquadramento & Fonte & Base de Referência & $\begin{array}{l}\text { Grupo de } \\
\text { Aplicação }\end{array}$ & $\begin{array}{c}\text { Fator Crítico para o } \\
\text { Sucesso }\end{array}$ \\
\hline \multirow{8}{*}{ PPP/PFI } & \multirow{8}{*}{$\begin{array}{l}\text { Revisão de } \\
\text { estudos sobre } \\
\text { os Fatores } \\
\text { Críticos de } \\
\text { Sucesso para } \\
\text { Parcerias } \\
\text { Público- } \\
\text { Privadas } \\
\text { (PPP/PFI) }\end{array}$} & \multirow{8}{*}{$\begin{array}{l}\text { Período de } 1990 \text { a } \\
2013\end{array}$} & \multirow{8}{*}{$\begin{array}{l}\text { Osei-Kyei e Chan } \\
\qquad(2015)\end{array}$} & \multirow{8}{*}{$\begin{array}{l}\text { Integralizado por todo o referencial } \\
\text { teórico adotado }\end{array}$} & $\begin{array}{l}\text { Número de } \\
\text { ocorrência do Fator } \\
\text { nas publicações (7) }\end{array}$ & $\begin{array}{l}\text { Condições } \\
\text { macroeconômicas estáveis }\end{array}$ \\
\hline & & & & & $\begin{array}{c}\text { Número de } \\
\text { ocorrência do Fator } \\
\text { nas publicações (7) }\end{array}$ & Certame competitivo \\
\hline & & & & & $\begin{array}{c}\text { Número de } \\
\text { ocorrência do Fator } \\
\text { nas publicações (6) }\end{array}$ & $\begin{array}{l}\text { Forte engajamento de } \\
\text { ambas as partes }\end{array}$ \\
\hline & & & & & $\begin{array}{c}\text { Número de } \\
\text { ocorrência do Fator } \\
\text { nas publicações (6) }\end{array}$ & $\begin{array}{l}\text { Clareza no papel e } \\
\text { responsabilidade das partes }\end{array}$ \\
\hline & & & & & $\begin{array}{c}\text { Número de } \\
\text { ocorrência do Fator } \\
\text { nas publicações (6) }\end{array}$ & $\begin{array}{l}\text { Habilidade financeira do } \\
\text { setor privado }\end{array}$ \\
\hline & & & & & $\begin{array}{l}\text { Número de } \\
\text { ocorrência do Fator } \\
\text { nas publicações (5) }\end{array}$ & Inovação tecnológica \\
\hline & & & & & $\begin{array}{l}\text { Número de } \\
\text { ocorrência do Fator } \\
\text { nas publicações (5) }\end{array}$ & $\begin{array}{l}\text { Estudo de viabilidade } \\
\text { plausível }\end{array}$ \\
\hline & & & & & $\begin{array}{l}\text { Número de } \\
\text { ocorrência do Fator } \\
\text { nas publicações (5) }\end{array}$ & $\begin{array}{l}\text { Comunicação aberta e } \\
\text { constante }\end{array}$ \\
\hline
\end{tabular}


Quadro 17 - Fatores críticos de sucesso de PPP/PFIs e PMIs (b)

Conclusão

\begin{tabular}{|c|c|c|c|c|c|c|}
\hline Orientação & Objetivo & Enquadramento & Fonte & Base de Referência & $\begin{array}{l}\text { Grupo de } \\
\text { Aplicação }\end{array}$ & $\begin{array}{c}\text { Fator Crítico para o } \\
\text { Sucesso }\end{array}$ \\
\hline & & & & & $\begin{array}{l}\text { Número de } \\
\text { ocorrência do Fator } \\
\text { nas publicações (5) }\end{array}$ & $\begin{array}{l}\text { Planejamento de projeto } \\
\text { detalhado }\end{array}$ \\
\hline & & & & & $\begin{array}{l}\text { Número de } \\
\text { ocorrência do Fator } \\
\text { nas publicações (5) }\end{array}$ & $\begin{array}{l}\text { Garantias providas pelo } \\
\text { ente concedente }\end{array}$ \\
\hline & & & & & $\begin{array}{l}\text { Número de } \\
\text { ocorrência do Fator } \\
\text { nas publicações (5) }\end{array}$ & Confiança \\
\hline & & & & & $\begin{array}{l}\text { Número de } \\
\text { ocorrência do Fator } \\
\text { nas publicações (4) }\end{array}$ & Seleção do projeto correto \\
\hline & & & & & $\begin{array}{l}\text { Número de } \\
\text { ocorrência do Fator } \\
\text { nas publicações (4) }\end{array}$ & $\begin{array}{l}\text { Demanda de longo prazo } \\
\text { para o projeto }\end{array}$ \\
\hline & & & & & $\begin{array}{c}\text { Número de } \\
\text { ocorrência do Fator } \\
\text { nas publicações (4) }\end{array}$ & $\begin{array}{l}\text { Descritivo de projeto claro e } \\
\text { desenvolvimento do design }\end{array}$ \\
\hline
\end{tabular}


Quadro 18 - Fatores críticos de sucesso de PPP/PFls e PMls (a)

\begin{tabular}{|c|c|c|c|c|c|c|}
\hline Orientação & Objetivo & Enquadramento & Fonte & Base de Referência & $\begin{array}{c}\text { Grupo de } \\
\text { Aplicação }\end{array}$ & $\begin{array}{c}\text { Fator Crítico para o } \\
\text { Sucesso } \\
\end{array}$ \\
\hline \multirow{6}{*}{ PPP/PFI } & \multirow{6}{*}{$\begin{array}{l}\text { Revisão de } \\
\text { estudos sobre } \\
\text { os Fatores } \\
\text { Críticos de } \\
\text { Sucesso para } \\
\text { Parcerias } \\
\text { Público- } \\
\text { Privadas } \\
\text { (PPP/PFI) }\end{array}$} & \multirow{6}{*}{$\begin{array}{l}\text { Período de } 1990 \text { a } \\
2013\end{array}$} & \multirow{6}{*}{$\begin{array}{l}\text { Osei-Kyei e Chan } \\
\quad(2015)\end{array}$} & \multirow{6}{*}{$\begin{array}{l}\text { Integralizado por todo o referencial } \\
\text { teórico adotado }\end{array}$} & $\begin{array}{c}\text { Número de } \\
\text { ocorrência do Fator } \\
\text { nas publicações (3) }\end{array}$ & $\begin{array}{l}\text { Maturidade e } \\
\text { disponibilidade do } \\
\text { mercado financeiro }\end{array}$ \\
\hline & & & & & $\begin{array}{c}\text { Número de } \\
\text { ocorrência do Fator } \\
\text { nas publicações (3) }\end{array}$ & $\begin{array}{l}\text { Tarifa em um nível } \\
\text { aceitável }\end{array}$ \\
\hline & & & & & $\begin{array}{c}\text { Número de } \\
\text { ocorrência do Fator } \\
\text { nas publicações (3) }\end{array}$ & $\begin{array}{l}\text { Processo de aprovação } \\
\text { simplificado }\end{array}$ \\
\hline & & & & & $\begin{array}{c}\text { Número de } \\
\text { ocorrência do Fator } \\
\text { nas publicações (3) }\end{array}$ & $\begin{array}{l}\text { Compatibilidade de } \\
\text { conhecimento de ambas } \\
\text { as partes }\end{array}$ \\
\hline & & & & & $\begin{array}{c}\text { Número de } \\
\text { ocorrência do Fator } \\
\text { nas publicações (2) }\end{array}$ & $\begin{array}{l}\text { Boas habilidades de } \\
\text { liderança e } \\
\text { empreendedorismo }\end{array}$ \\
\hline & & & & & $\begin{array}{c}\text { Número de } \\
\text { ocorrência do Fator } \\
\text { nas publicações (2) }\end{array}$ & Política econômica sólida \\
\hline
\end{tabular}




\begin{tabular}{|c|c|c|c|c|c|c|}
\hline Orientação & Objetivo & Enquadramento & Fonte & Base de Referência & $\begin{array}{l}\text { Grupo de } \\
\text { Aplicação }\end{array}$ & $\begin{array}{c}\text { Fator Crítico para o } \\
\text { Sucesso }\end{array}$ \\
\hline & & & & & $\begin{array}{c}\text { Número de } \\
\text { ocorrência do Fator } \\
\text { nas publicações (2) }\end{array}$ & $\begin{array}{l}\text { Órgão público bem } \\
\text { organizado e } \\
\text { comprometido }\end{array}$ \\
\hline & & & & & $\begin{array}{c}\text { Número de } \\
\text { ocorrência do Fator } \\
\text { nas publicações (2) }\end{array}$ & Boa governança \\
\hline & & & & & $\begin{array}{c}\text { Número de } \\
\text { ocorrência do Fator } \\
\text { nas publicações (2) }\end{array}$ & $\begin{array}{l}\text { Emprego de consultores } \\
\text { profissionais }\end{array}$ \\
\hline & & & & & $\begin{array}{c}\text { Número de } \\
\text { ocorrência do Fator } \\
\text { nas publicações (2) }\end{array}$ & $\begin{array}{l}\text { Responsabilidade } \\
\text { financeira }\end{array}$ \\
\hline
\end{tabular}


Quadro 19 - Fatores críticos de sucesso de PPP/PFls e PMls

\begin{tabular}{|c|c|c|c|c|c|c|}
\hline Orientação & Objetivo & Enquadramento & Fonte & Base de Referência & $\begin{array}{l}\text { Grupo de } \\
\text { Aplicação }\end{array}$ & $\begin{array}{c}\text { Fator Crítico para o } \\
\text { Sucesso }\end{array}$ \\
\hline \multirow{7}{*}{ PPP/PFI } & \multirow{2}{*}{$\begin{array}{c}\text { Revisão de } \\
\text { estudos sobre } \\
\text { os Fatores } \\
\text { Críticos de } \\
\text { Sucesso para } \\
\text { Parcerias } \\
\text { Público- } \\
\text { Privadas } \\
\text { (PPP/PFI) } \\
\end{array}$} & \multirow[b]{2}{*}{$\begin{array}{l}\text { Período de } 1990 \text { a } \\
\qquad 2013\end{array}$} & \multirow[b]{2}{*}{$\begin{array}{l}\text { Osei-Kyei e Chan } \\
\qquad(2015)\end{array}$} & \multirow[b]{2}{*}{$\begin{array}{l}\text { Integralizado por todo o referencial } \\
\text { teórico adotado }\end{array}$} & $\begin{array}{c}\text { Número de } \\
\text { ocorrência do Fator } \\
\text { nas publicações (2) }\end{array}$ & $\begin{array}{l}\text { Prestação de serviços } \\
\text { confiáveis }\end{array}$ \\
\hline & & & & & $\begin{array}{l}\text { Número de } \\
\text { ocorrência do Fator } \\
\text { nas publicações (2) }\end{array}$ & $\begin{array}{l}\text { Impacto ambiental do } \\
\text { projeto }\end{array}$ \\
\hline & \multirow{5}{*}{$\begin{array}{l}\text { Investigar as } \\
\text { percepções e } \\
\text { experiências } \\
\text { atuais de } \\
\text { gerenciamento } \\
\text { de risco em } \\
\text { projetos }\end{array}$} & \multirow{5}{*}{$\begin{array}{c}\text { Identificar os fatores } \\
\text { críticos de sucesso } \\
\text { para o } \\
\text { gerenciamento de } \\
\text { relacionamento em } \\
\text { projetos PPP/PFI }\end{array}$} & \multirow{5}{*}{$\begin{array}{l}\text { Weiwu Zou, } \\
\text { Mohan } \\
\text { Kumaraswamy, } \\
\text { Jacky Chung, } \\
\text { James Wong } \\
\text { (2014) }\end{array}$} & $\begin{array}{l}\text { Stanley et al. (2006), Briscoe et al. } \\
\text { (2001), Frankel et al. (1996), Burgess } \\
\text { (1998), Tailby et al. (2004), Zhang } \\
(2005)\end{array}$ & \multirow{3}{*}{$\begin{array}{l}\text { FCSs de alta } \\
\text { relevância }\end{array}$} & $\begin{array}{l}\text { Compromisso e } \\
\text { participação dos executivos } \\
\text { seniores }\end{array}$ \\
\hline & & & & $\begin{array}{l}\text { Kumaraswamy and Anvuur (2007), } \\
\text { Kumaraswamy et al. (2007a, 2007b), } \\
\text { Samii et al. (2002), Chen and } \\
\text { Popovich (2003) }\end{array}$ & & $\begin{array}{l}\text { Equipe multidisciplinar } \\
\text { responsável pela } \\
\text { implementação da Gestão } \\
\text { de Risco }\end{array}$ \\
\hline & & & & $\begin{array}{l}\text { Esteves and Pastor (2001), Mentzer et } \\
\text { al. (2001), Anvuur et al. (2011) }\end{array}$ & & $\begin{array}{l}\text { Definir os objetivos de valor } \\
\text { para serem alcançados com } \\
\text { a implementação da } \\
\text { estratégia / exercícios de } \\
\text { Gestão de Risco }\end{array}$ \\
\hline & & & & $\begin{array}{l}\text { Mentzer et al. (2001), Parvatiyar and } \\
\text { Sheth (2001), Kumaraswamy and } \\
\text { Anvuur (2007), Kumaraswamy et al. } \\
\text { (2007a, 2007b), Chen and Popovich } \\
\text { (2003), Anvuur et al. (2011) }\end{array}$ & \multirow[t]{2}{*}{$\begin{array}{l}\text { FCSs de média } \\
\text { relevância }\end{array}$} & $\begin{array}{l}\text { Integração das diferentes } \\
\text { divisões da organização de } \\
\text { forma a atender aos } \\
\text { objetivos gerais da empresa } \\
\text { e de cada uma das divisões } \\
\text { / grupos }\end{array}$ \\
\hline & & & & $\begin{array}{l}\text { Grönroos (1994), Mentzer et al. } \\
\text { (2001), Parvatiyar and Sheth (2001) }\end{array}$ & & $\begin{array}{l}\text { Publicar / divulgar os } \\
\text { objetivos, benefícios e } \\
\text { implicações do projeto para } \\
\text { todo o pessoal }\end{array}$ \\
\hline
\end{tabular}


Quadro 19 - Fatores críticos de sucesso de PPP/PFIs e PMIs (b)

Conclusão

Orientação

Objetivo

Enquadramento

Fonte

Base de Referência

Grupo de

Aplicação

Fator Crítico para o

Duncan and Moriarty (1998) Mentzer

et al. (2001), Chen and Popovich

(2003)

Compromisso da equipe

com à estratégia de gestão de risco

Fonte: Organizado pelo Autor. 
Quadro 20 - Fatores críticos de sucesso de PPP/PFls e PMls

\begin{tabular}{|c|c|c|c|c|c|c|}
\hline Orientação & Objetivo & Enquadramento & Fonte & Base de Referência & $\begin{array}{l}\text { Grupo de } \\
\text { Aplicação }\end{array}$ & $\begin{array}{c}\text { Fator Crítico para o } \\
\text { Sucesso }\end{array}$ \\
\hline \multirow{2}{*}{ PPP/PFI } & \multirow{2}{*}{$\begin{array}{l}\text { Investigar as } \\
\text { percepções e } \\
\text { experiências } \\
\text { atuais de } \\
\text { gerenciamento } \\
\text { de risco em } \\
\text { projetos }\end{array}$} & \multirow{2}{*}{$\begin{array}{c}\text { Identificar os fatores } \\
\text { críticos de sucesso } \\
\text { para o } \\
\text { gerenciamento de } \\
\text { relacionamento em } \\
\text { projetos PPP/PFI }\end{array}$} & \multirow{2}{*}{$\begin{array}{l}\text { Weiwu Zou, } \\
\text { Mohan } \\
\text { Kumaraswamy, } \\
\text { Jacky Chung, } \\
\text { James Wong } \\
\text { (2014) }\end{array}$} & $\begin{array}{l}\text { Mentzer et al. (2001), Chen and } \\
\text { Popovich (2003) }\end{array}$ & \multirow{2}{*}{$\begin{array}{l}\text { CSFs de média } \\
\text { relevância }\end{array}$} & $\begin{array}{l}\text { Integração de Sistemas de } \\
\text { Informação para consistência } \\
\text { e disponibilidade de } \\
\text { informação relacionada à } \\
\text { gerenciamento de risco na } \\
\text { organização }\end{array}$ \\
\hline & & & & $\begin{array}{l}\text { Grönroos (1994), Duncan and Moriarty } \\
\text { (1998), Kumaraswamy and Anvuur } \\
\text { (2007), Kumaraswamy et al. (2007a, } \\
\text { 2007b), Samii et al. (2002), Anvuur et } \\
\text { al. (2011) }\end{array}$ & & $\begin{array}{l}\text { Abordagens / canais de } \\
\text { comunicação eficazes entre } \\
\text { as principais partes do } \\
\text { PPP/PFI }\end{array}$ \\
\hline PPP/PFI & $\begin{array}{c}\text { Analisar os } \\
\text { fatores críticos } \\
\text { de sucesso, } \\
\text { aspectos } \\
\text { positivos e } \\
\text { negativos } \\
\text { destes que } \\
\text { influenciam a } \\
\text { atratividade de } \\
\text { PPP/PFIs }\end{array}$ & $\begin{array}{l}\text { Projetos em } \\
\text { Cingapura }\end{array}$ & $\begin{array}{l}\text { Bon-Gang } \\
\text { Hwang, Xianbo } \\
\text { Zhao, Mindy } \\
\text { Jiang Shu Gay } \\
\text { (2013) }\end{array}$ & $\begin{array}{l}\text { Grimsey and Lewis (2002); Estache et } \\
\text { al. (2007); Zou et al. (2008); Thomas } \\
\text { et al. (2003); Xu et al. (2010) }\end{array}$ & - & $\begin{array}{l}\text { Carência de suporte } \\
\text { governamental }\end{array}$ \\
\hline \multirow{3}{*}{ PPP/PFI } & \multirow{3}{*}{$\begin{array}{l}\text { Levantar os } \\
\text { fatores, riscos } \\
\text { críticos e } \\
\text { alocação de } \\
\text { risco } \\
\text { preferencial do } \\
\text { ponto de vista } \\
\text { dos } \\
\text { contratados }\end{array}$} & \multirow{3}{*}{$\begin{array}{l}\text { Projetos } \\
\text { desenvolvidos em } \\
\text { Cingapura }\end{array}$} & \multirow{3}{*}{$\begin{array}{l}\text { Bon-Gang } \\
\text { Hwang, Xianbo } \\
\text { Zhao, Mindy } \\
\text { Jiang Shu Gay } \\
\text { (2013) }\end{array}$} & Li et al. (2005); Zou et al. (2008) & \multirow{3}{*}{ Setor Público } & Instabilidade política \\
\hline & & & & $\begin{array}{l}\text { Kumaraswamy and Zhang (2001); Li et } \\
\text { al. (2005); Ng e Loosemore (2007); } \\
\text { Estache et al. (2007); Medda (2007); } \\
\text { Xu et al. (2010) }\end{array}$ & & Nacionalização/expropiação \\
\hline & & & & $\begin{array}{l}\text { Kumaraswamy and Zhang (2001); Li et } \\
\text { al. (2005); Shen et al. (2006); Ng e } \\
\text { Loosemore (2007); Medda (2007); Xu } \\
\text { et al. (2010) }\end{array}$ & & Interferência política \\
\hline
\end{tabular}

Fonte: Organizado pelo Autor. 
Quadro 21 - Fatores críticos de sucesso de PPP/PFls e PMls

\begin{tabular}{|c|c|c|c|c|c|c|}
\hline Orientação & Objetivo & Enquadramento & Fonte & Base de Referência & $\begin{array}{l}\text { Grupo de } \\
\text { Aplicação }\end{array}$ & $\begin{array}{l}\text { Fator Crítico para o } \\
\text { Sucesso }\end{array}$ \\
\hline \multirow{11}{*}{ PPP/PFI } & \multirow{11}{*}{$\begin{array}{l}\text { Levantar os } \\
\text { fatores, riscos } \\
\text { críticos e } \\
\text { alocação de } \\
\text { risco } \\
\text { preferencial } \\
\text { do ponto de } \\
\text { vista dos } \\
\text { contratados }\end{array}$} & \multirow{11}{*}{$\begin{array}{l}\text { Projetos } \\
\text { desenvolvidos em } \\
\text { Cingapura }\end{array}$} & \multirow{11}{*}{$\begin{array}{l}\text { Bon-Gang } \\
\text { Hwang, Xianbo } \\
\text { Zhao, Mindy } \\
\text { Jiang Shu Gay } \\
\text { (2013) }\end{array}$} & $\begin{array}{l}\text { Kumaraswamy and Zhang (2001); Li et } \\
\text { al. (2005); Shen et al. (2006); Ng e } \\
\text { Loosemore (2007); Estache et al. } \\
\text { (2007); Xu et al. (2010) }\end{array}$ & \multirow{3}{*}{ Setor Público } & $\begin{array}{l}\text { Inconsistência legal e } \\
\text { regulatória }\end{array}$ \\
\hline & & & & $\begin{array}{l}\text { Shen et al. (2006); Zou et al. (2008); } \\
\text { Xu et al. (2010) }\end{array}$ & & $\begin{array}{l}\text { Carência legal e estrutura } \\
\text { regulatória }\end{array}$ \\
\hline & & & & $\begin{array}{l}\text { Kumaraswamy and Zhang (2001); } \\
\text { Grimsey and Lewis (2002); Li et al. } \\
\text { (2005); Ng e Loosemore (2007); } \\
\text { Estache et al. (2007); Medda (2007); } \\
\text { Xu et al. (2010) }\end{array}$ & & $\begin{array}{l}\text { Mudança em regulação } \\
\text { tarifária }\end{array}$ \\
\hline & & & & $\begin{array}{l}\text { Grimsey and Lewis (2002); Li et al. } \\
\text { (2005); Ng e Loosemore (2007); Xu et } \\
\text { al. (2010) }\end{array}$ & \multirow{8}{*}{ Setor Privado } & Fatores climáticos \\
\hline & & & & $\begin{array}{l}\text { Li et al. (2005); Ng e Loosemore } \\
\text { (2007); Xu et al. (2010) }\end{array}$ & & Condições geológicas \\
\hline & & & & $\begin{array}{l}\text { Grimsey and Lewis (2002); Li et al. } \\
\text { (2005); Xu et al. (2010) }\end{array}$ & & Ambiente \\
\hline & & & & $\begin{array}{l}\text { Li et al. (2005); Shen et al. (2006); Ng } \\
\text { e Loosemore (2007); Xu et al. (2010) }\end{array}$ & & $\begin{array}{l}\text { Risco de comunicação e } \\
\text { organizacional }\end{array}$ \\
\hline & & & & Li et al. (2005); Zou et al. (2008) & & Mercado financeiro pobre \\
\hline & & & & $\begin{array}{l}\text { Li et al. (2005); Ng e Loosemore } \\
\text { (2007); Estache et al. (2007); Thomas } \\
\text { et al. (2003); Xu et al. (2010) }\end{array}$ & & $\begin{array}{l}\text { Atraso no cronograma } \\
\text { construtivo }\end{array}$ \\
\hline & & & & Li et al. (2005); Zou et al. (2008) & & $\begin{array}{l}\text { Segurança no local do } \\
\text { Projeto da PPP/PFI }\end{array}$ \\
\hline & & & & Li et al. (2005) & & $\begin{array}{l}\text { Qualidade pobre da força de } \\
\text { trabalho }\end{array}$ \\
\hline
\end{tabular}


Quadro 22 - Fatores críticos de sucesso de PPP/PFls e PMIs (a)

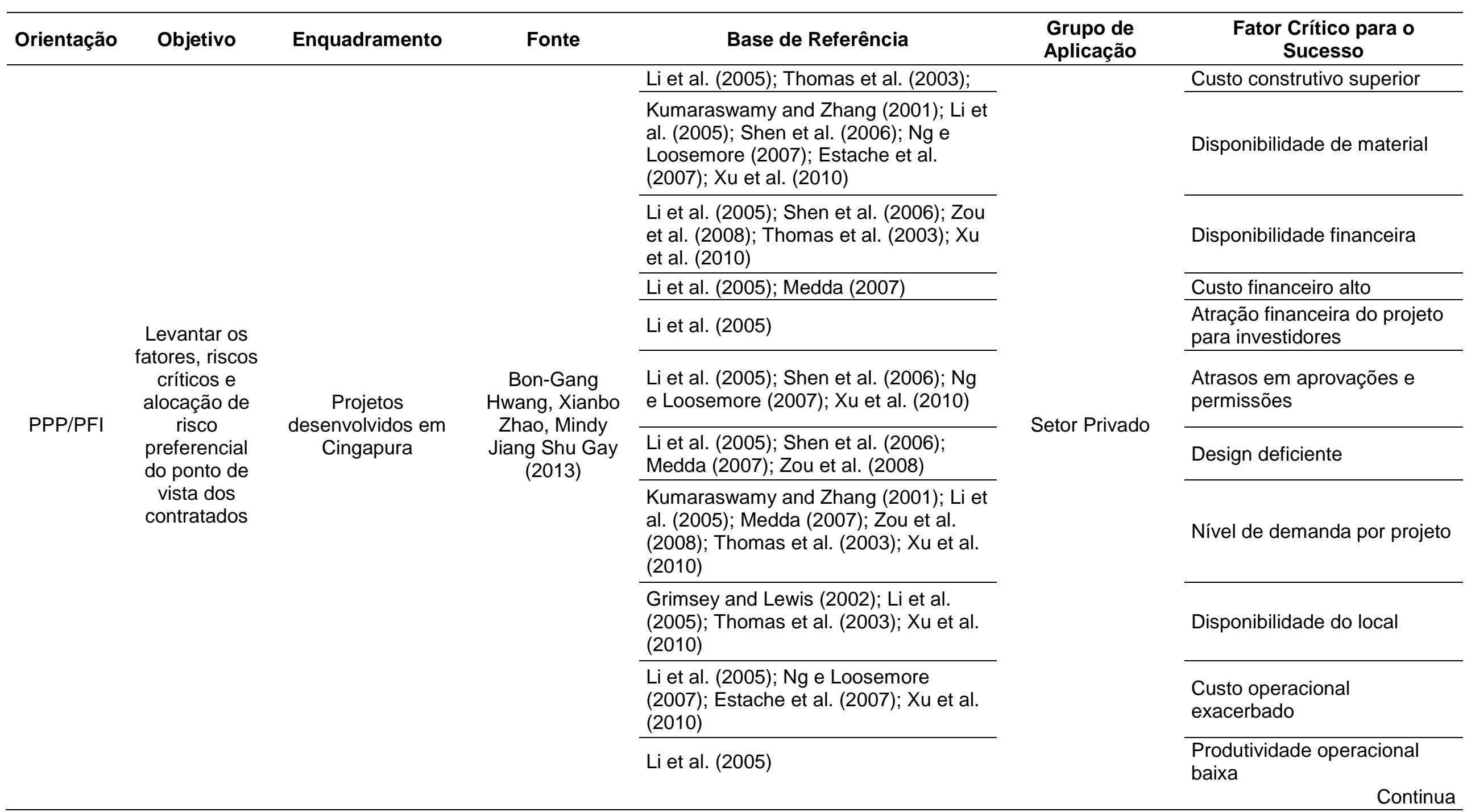


Quadro 22 - Fatores críticos de sucesso de PPP/PFls e PMIs (b)

Conclusão

Orientação

Objetivo

Enquadramento

Fonte

Base de Referência

Li et al. (2005)

Li et al. (2005)
Grupo de

Aplicação Sucesso

Custo de manutenção maior que o esperado

Manutenção mais frequente que esperada

Fonte: Organizado pelo Autor. 
Quadro 23 - Fatores críticos de sucesso de PPP/PFls e PMls

\begin{tabular}{|c|c|c|c|c|c|c|}
\hline Orientação & Objetivo & Enquadramento & Fonte & Base de Referência & $\begin{array}{l}\text { Grupo de } \\
\text { Aplicação }\end{array}$ & $\begin{array}{l}\text { Fator Crítico para o } \\
\text { Sucesso }\end{array}$ \\
\hline \multirow{11}{*}{ PPP/PFI } & \multirow{11}{*}{$\begin{array}{l}\text { Levantar os } \\
\text { fatores, riscos } \\
\text { críticos e } \\
\text { alocação de } \\
\text { risco } \\
\text { preferencial } \\
\text { do ponto de } \\
\text { vista dos } \\
\text { contratados }\end{array}$} & \multirow{11}{*}{$\begin{array}{c}\text { Projetos } \\
\text { desenvolvidos em } \\
\text { Cingapura }\end{array}$} & \multirow{11}{*}{$\begin{array}{c}\text { Bon-Gang } \\
\text { Hwang, Xianbo } \\
\text { Zhao, Mindy } \\
\text { Jiang Shu Gay } \\
\text { (2013) }\end{array}$} & $\begin{array}{l}\text { Kumaraswamy and Zhang (2001); Li et } \\
\text { al. (2005); Shen et al. (2006); Estache } \\
\text { et al. (2007); Zou et al. (2008); Xu et } \\
\text { al. (2010) }\end{array}$ & \multirow{11}{*}{ Compartilhado } & Inflação \\
\hline & & & & $\begin{array}{l}\text { Kumaraswamy and Zhang (2001); Li et } \\
\text { al. (2005); Ng e Loosemore (2007); } \\
\text { Estache et al. (2007); Medda (2007); } \\
\text { Zou et al. (2008); Xu et al. (2010) }\end{array}$ & & Taxa de juros \\
\hline & & & & $\begin{array}{l}\text { Kumaraswamy and Zhang (2001); } \\
\text { Grimsey and Lewis (2002); Li et al. } \\
\text { (2005); Ng e Loosemore (2007); } \\
\text { Estache et al. (2007); Xu et al. (2010) }\end{array}$ & & Força Maior \\
\hline & & & & $\begin{array}{l}\text { Kumaraswamy and Zhang (2001); Li et } \\
\text { al. (2005); Zou et al. (2008); Xu et al. } \\
(2010)\end{array}$ & & Corrupção e propina \\
\hline & & & & $\begin{array}{l}\text { Li et al. (2005); Ng e Loosemore } \\
\text { (2007); Xu et al. (2010) }\end{array}$ & & Risco residual do ativo \\
\hline & & & & Shen et al. (2006); Xu et al. (2010) & & Variação de escopo \\
\hline & & & & Li et al. (2005); Shen et al. (2006) & & $\begin{array}{l}\text { Experiência inadequada em } \\
\text { projetos desta natureza }\end{array}$ \\
\hline & & & & $\begin{array}{l}\text { Li et al. (2005); Shen et al. (2006); Ng } \\
\text { e Loosemore (2007); Medda (2007) }\end{array}$ & & $\begin{array}{l}\text { Distribuição inadequada de } \\
\text { responsabilidade }\end{array}$ \\
\hline & & & & Li et al. (2005) & & $\begin{array}{l}\text { Distribuição inadequada de } \\
\text { autoridade }\end{array}$ \\
\hline & & & & Li et al. (2005) & & $\begin{array}{l}\text { Diferenças no método de } \\
\text { trabalho }\end{array}$ \\
\hline & & & & $\begin{array}{l}\text { Li et al. (2005); Ng e Loosemore } \\
\text { (2007) }\end{array}$ & & $\begin{array}{l}\text { Falta de comprometimento } \\
\text { entre as partes }\end{array}$ \\
\hline
\end{tabular}

Fonte: Organizado pelo Autor. 
Quadro 24 - Fatores críticos de sucesso de PPP/PFls e PMIs (a)

\begin{tabular}{|c|c|c|c|c|c|c|}
\hline Orientação & Objetivo & Enquadramento & Fonte & Base de Referência & $\begin{array}{l}\text { Grupo de } \\
\text { Aplicação }\end{array}$ & $\begin{array}{l}\text { Fator Crítico para o } \\
\text { Sucesso }\end{array}$ \\
\hline \multirow{3}{*}{ PPP/PFI } & \multirow{3}{*}{$\begin{array}{l}\text { Levantar os } \\
\text { fatores, riscos } \\
\text { críticos e } \\
\text { alocação de } \\
\text { risco } \\
\text { preferencial } \\
\text { do ponto de } \\
\text { vista dos } \\
\text { contratados }\end{array}$} & \multirow{3}{*}{$\begin{array}{c}\text { Projetos } \\
\text { desenvolvidos em } \\
\text { Cingapura }\end{array}$} & \multirow{3}{*}{$\begin{array}{c}\text { Bon-Gang } \\
\text { Hwang, Xianbo } \\
\text { Zhao, Mindy } \\
\text { Jiang Shu Gay } \\
\text { (2013) }\end{array}$} & $\begin{array}{l}\text { Li et al. (2005); Estache et al. (2007); } \\
\text { Zou et al. (2008); Xu et al. (2010) }\end{array}$ & \multirow{3}{*}{$\begin{array}{l}\text { Negociado em } \\
\text { dadas } \\
\text { circunstâncias }\end{array}$} & $\begin{array}{l}\text { Nível de oposição pública } \\
\text { ao projeto }\end{array}$ \\
\hline & & & & $\begin{array}{l}\text { Grimsey and Lewis (2002); Li et al. } \\
\text { (2005); Ng e Loosemore (2007); } \\
\text { Estache et al. (2007); Xu et al. (2010) }\end{array}$ & & $\begin{array}{l}\text { Adoção de técnica de } \\
\text { engenharia não aprovada }\end{array}$ \\
\hline & & & & Li et al. (2005) & & $\begin{array}{l}\text { Variação excessiva no } \\
\text { contrato }\end{array}$ \\
\hline \multirow{6}{*}{ PMI } & \multirow{6}{*}{$\begin{array}{l}\text { Avaliar fatores } \\
\text { críticos em } \\
\text { PMI e MIP }\end{array}$} & \multirow{6}{*}{$\begin{array}{l}\text { Amostra colhida nos } \\
\text { EUA e Coréia do Sul }\end{array}$} & \multirow{6}{*}{$\begin{array}{l}\text { Yun, Jung, Han e } \\
\text { Park (2015) }\end{array}$} & \multirow{6}{*}{$\begin{array}{l}\text { Integralizado por todo o referencial } \\
\text { teórico adotado }\end{array}$} & \multirow{4}{*}{$\begin{array}{l}\text { Capacidade de } \\
\text { implantação de } \\
\text { projeto }\end{array}$} & $\begin{array}{l}\text { Concessão apropriada de } \\
\text { contratos e acordos }\end{array}$ \\
\hline & & & & & & $\begin{array}{l}\text { Alinhamento estratégico } \\
\text { de metas e objetivos }\end{array}$ \\
\hline & & & & & & $\begin{array}{l}\text { Definição clara e } \\
\text { documentada de escopo } \\
\text { do projeto }\end{array}$ \\
\hline & & & & & & $\begin{array}{l}\text { Papéis e } \\
\text { responsabilidades } \\
\text { claramente definidos dos } \\
\text { participantes do projeto }\end{array}$ \\
\hline & & & & & \multirow{2}{*}{$\begin{array}{l}\text { Coordenação inter- } \\
\text { organizacional }\end{array}$} & $\begin{array}{l}\text { Coordenação da } \\
\text { Sociedade de Propósito } \\
\text { Específico com o } \\
\text { construtor }\end{array}$ \\
\hline & & & & & & $\begin{array}{l}\text { Coordenação da } \\
\text { Sociedade de Propósito } \\
\text { Específico com } \\
\text { investidores financeiros } \\
\quad \text { Continua }\end{array}$ \\
\hline
\end{tabular}




\begin{tabular}{|c|c|c|c|c|c|c|}
\hline Orientação & Objetivo & Enquadramento & Fonte & Base de Referência & $\begin{array}{l}\text { Grupo de } \\
\text { Aplicação }\end{array}$ & $\begin{array}{c}\text { Fator Crítico para o } \\
\text { Sucesso }\end{array}$ \\
\hline & & & & & & $\begin{array}{l}\text { Coordenação da } \\
\text { Sociedade de Propósito } \\
\text { Específico com arquitetos } \\
\text { e engenheiros } \\
\text { Coordenação da } \\
\text { Sociedade de Propósito } \\
\text { Específico com } \\
\text { supervisores e inspetores } \\
\text { dos construtores }\end{array}$ \\
\hline & & & & & $\begin{array}{c}\text { Liderança e } \\
\text { cooperação } \\
\text { governamental }\end{array}$ & $\begin{array}{c}\text { Liderança da agência de } \\
\text { governo }\end{array}$ \\
\hline
\end{tabular}

Fonte: Organizado pelo Autor. 
Quadro 25 - Fatores críticos de sucesso de PPP/PFls e PMIs (a)

\begin{tabular}{|c|c|c|c|c|c|c|}
\hline Orientação & Objetivo & Enquadramento & Fonte & Base de Referência & $\begin{array}{l}\text { Grupo de } \\
\text { Aplicação }\end{array}$ & $\begin{array}{l}\text { Fator Crítico para o } \\
\text { Sucesso }\end{array}$ \\
\hline \multirow{8}{*}{ PMI } & \multirow{8}{*}{$\begin{array}{l}\text { Avaliar fatores } \\
\text { críticos em } \\
\text { PMI e MIP }\end{array}$} & \multirow{8}{*}{$\begin{array}{l}\text { Amostra colhida nos } \\
\text { EUA e Coréia do Sul }\end{array}$} & \multirow{8}{*}{$\begin{array}{c}\text { Sungmin Yun, } \\
\text { Wooyong Jung, } \\
\text { Seung Heon Han } \\
\text { e Heedae Park } \\
(2015)\end{array}$} & \multirow{8}{*}{$\begin{array}{l}\text { Integralizado por todo o referencial } \\
\text { teórico adotado }\end{array}$} & \multirow{3}{*}{$\begin{array}{l}\text { Liderança e } \\
\text { cooperação } \\
\text { governamental }\end{array}$} & $\begin{array}{l}\text { Evitar duplicações de } \\
\text { instalações similares }\end{array}$ \\
\hline & & & & & & Apoio a aquisição de terras \\
\hline & & & & & & $\begin{array}{l}\text { Atitude cooperativa da } \\
\text { agência governamental }\end{array}$ \\
\hline & & & & & \multirow{3}{*}{$\begin{array}{l}\text { Estratégia de } \\
\text { compartilhamento } \\
\text { de riscos e } \\
\text { mitigação }\end{array}$} & $\begin{array}{l}\text { Contramedida para evitar } \\
\text { queixas públicas }\end{array}$ \\
\hline & & & & & & $\begin{array}{l}\text { Aprovação e expedição de } \\
\text { permissões }\end{array}$ \\
\hline & & & & & & $\begin{array}{l}\text { Alocação apropriada de } \\
\text { risco entre o setor público e } \\
\text { privado }\end{array}$ \\
\hline & & & & & \multirow{2}{*}{$\begin{array}{l}\text { Suporte financeiro } \\
\text { governamental }\end{array}$} & $\begin{array}{l}\text { Rendimento mínimo } \\
\text { garantido }\end{array}$ \\
\hline & & & & & & Subsídios construtivos \\
\hline \multirow{11}{*}{ PMI } & \multirow{11}{*}{$\begin{array}{l}\text { Avaliar PMI } \\
\text { em projetos } \\
\text { de PPP/PFI }\end{array}$} & \multirow{11}{*}{$\begin{array}{l}\text { Amostras colhidas } \\
\text { em África, Ásia, } \\
\text { América Latina e } \\
\text { Caribe }\end{array}$} & \multirow{11}{*}{$\begin{array}{l}\text { Public-Private } \\
\text { Infrastructure } \\
\text { Advisory Facility } \\
\text { (2014) }\end{array}$} & \multirow{11}{*}{ Dados providos pelos entrevistados } & \multirow{5}{*}{ Macro nível } & Interesse do setor privado \\
\hline & & & & & & $\begin{array}{l}\text { Capacidade do setor } \\
\text { privado }\end{array}$ \\
\hline & & & & & & Capacidade do setor público \\
\hline & & & & & & $\begin{array}{l}\text { Coordenação do setor } \\
\text { público }\end{array}$ \\
\hline & & & & & & Clareza no procedimento \\
\hline & & & & & \multirow{6}{*}{ Micro nível } & Preço competitivo \\
\hline & & & & & & Inovação do setor privado \\
\hline & & & & & & Custo transacional \\
\hline & & & & & & Alocação eficiente de risco \\
\hline & & & & & & Transparência \\
\hline & & & & & & Continua \\
\hline
\end{tabular}


Quadro 25 - Fatores críticos de sucesso de PPP/PFls e PMIs (b)

Conclusão

Orientação

$$
\text { Objetivo }
$$

Enquadramento

Fonte

Base de Referência

Grupo de Aplicação

Fator Crítico para o

\begin{tabular}{|c|c|c|c|c|}
\hline PMI & $\begin{array}{c}\text { Avaliar PMls } \\
\text { em projetos } \\
\text { de } \\
\text { infraestrutura }\end{array}$ & $\begin{array}{l}\text { Como países } \\
\text { introduzem } \\
\text { competitividade e } \\
\text { transparência }\end{array}$ & $\begin{array}{c}\text { Hodges e } \\
\text { Dellacha (2007) }\end{array}$ & $\begin{array}{l}\text { Dados providos por meio dos materiais } \\
\text { levantados na pesquisa }\end{array}$ \\
\hline
\end{tabular}

Tempo de alocação projeto

Aprovação preliminar da

proposta

Negociação e finalização do

Publicação para licitação

Propostas contrárias

apresentadas

Valor do bônus

Concorrência

potencial

Estabelecimento do preço

ideal

Montante de tempo e

informação disponível

Fonte: Organizado pelo Autor.

Transparência do processo 
Apresentados os Fatores Críticos para o Sucesso - FCSs de PPP/PFIs e PMls, passou-se ao Enquadramento do FCSs (descrito nas planilhas 12 a 22) a um dos 10 (dez) níveis de Macro ou Micro nível identificados pelo PPIAF (2014) [arbitrado pelo autor] nos chamados "Grupos de Aplicação".

Convém ressaltar que, para enquadramento, há a possibilidade de compreensão polissêmica dos conteúdos, a análise sistematizada do corpora, a modelagem de um protocolo para análise de corpus, os resultados da Survey e das entrevistas com especialistas sustentam o posicionamento alegado nesta tese.

Para o enquadramento dos FCs aos "Grupos de Aplicação", busca-se regularidade nos tipos de associações entre as palavras e estruturas, as quais são normalmente utilizadas no setor das PPP/PFIs. Para que evidências de padrões lexicais sejam constatados, um conjunto de sentenças propostas por Sardinha (2004) foi adaptado e adotado com o intuito de determinar se haveria ou não possibilidade de inter-relacionar um dado FC a um determinado "Grupos de Aplicação". Os padrões de regularidade das palavras buscavam atender as seguintes sentenças:

- $\mathrm{A}(\mathrm{s})$ palavra(s) do(s) $\mathrm{FC}(\mathrm{s})$ se associa(m) regularmente com o sentido do "Grupo de Aplicação" de destino eleito;

- O padrão lexical do conjunto de palavras que compõem os FCs está de acordo com o nível (Macro ou Micro) do "Grupo de Aplicação";

- Há correlação entre o uso/sentido das palavras e estruturas dos FCs ao "Grupo de Aplicação" de destino.

Posteriormente a organização inicial dos FCSs, emprega-se o conceito de Prosódia Semântica, ou seja, uma "associação entre itens lexicais e conotações (negativas e positivas ou neutras) ou instância avaliativa" (SARDINHA, 2004, p. 40). Busca-se, assim, a generalização sobre o propósito comunicativo da unidade: o motivo da escolha e se está relacionado ao conceito de "força ilocucionária" (STUBBS, 2009), dado por uma fala completa, de um enunciado típico em que o autor afirma e sugere a interligação dos conceitos de FCSs, com isto é possível obter os FCSs de impacto positivo e os de impacto negativo nas propostas de PMI submetidas pelos entes privados ao ente público demandante.

Os substantivos observados nos FCSs tiveram seu campo lexical comparados e enquadrados aos Grupos de Aplicação propostos pelo PPIAF para o Banco 
Mundial por meio de aproximação semântica dos conteúdos ao contexto abordado, ou seja, buscou-se compreender o sentido das palavras e da interpretação das sentenças nos contextos propostos. O cruzamento, e respectivo enquadramento, pode ser observado nos Quadros 26 a 30, onde tem-se a orientação de enquadramento do FCS se constituído inicialmente para avaliar PPP ou PMI, autores dos respectivos FCSs e inserção destes em uma das 10 (dez) áreas de Macro ou Micro níveis propostas pelo PPIAF (2014). 
Quadro 26 - Integração [macro nível] dos FCSs de PPP/PFls e PMls

\begin{tabular}{|c|c|c|}
\hline Orientação & Referência & Autoria \\
\hline PPP & 1 & $\begin{array}{l}\text { Tingting Liu, Yan } \\
\text { Wang, Suzanne } \\
\text { Wilkinson (2016) }\end{array}$ \\
\hline PPP & 2 & $\begin{array}{l}\text { J. Mota, A.C. Moreira } \\
\text { (2015) }\end{array}$ \\
\hline PPP & 3 & $\begin{array}{c}\text { Jui-Sheng Chou; Dinar } \\
\text { Pramudawardhani } \\
(2015)\end{array}$ \\
\hline PPP & 4 & $\begin{array}{l}\text { Robert Osei-Kyei, } \\
\text { Albert P.C. Chan } \\
\text { (2015) }\end{array}$ \\
\hline PPP & 5 & $\begin{array}{c}\text { Weiwu Zou, Mohan } \\
\text { Kumaraswamy, Jacky } \\
\text { Chung, James Wong } \\
\text { (2014) }\end{array}$ \\
\hline PPP & 6 & $\begin{array}{l}\text { Bon-Gang Hwang, } \\
\text { Xianbo Zhao, Mindy } \\
\text { Jiang Shu Gay (2012) }\end{array}$ \\
\hline PPP & 7 & $\begin{array}{l}\text { Bon-Gang Hwang, } \\
\text { Xianbo Zhao, Mindy } \\
\text { Jiang Shu Gay (2012) }\end{array}$ \\
\hline PPP & 8 & $\begin{array}{l}\text { Bon-Gang Hwang, } \\
\text { Xianbo Zhao, Mindy } \\
\text { Jiang Shu Gay (2012) }\end{array}$ \\
\hline PMI & 9 & $\begin{array}{c}\text { Sungmin Yun, } \\
\text { Wooyong Jung, Seung } \\
\text { Heon Han e Heedae } \\
\text { Park (2015) }\end{array}$ \\
\hline PMI & 10 & $\begin{array}{l}\text { John T. Hodges, } \\
\text { Georgina Dellacha } \\
\text { (2007) }\end{array}$ \\
\hline
\end{tabular}

\begin{tabular}{|c|c|c|c|c|c|c|c|c|c|}
\hline \multicolumn{10}{|c|}{ Grupo de Aplicação } \\
\hline & & & & & Macro nível & & & & \\
\hline \multicolumn{10}{|c|}{ Fator Crítico para o Sucesso } \\
\hline Referência & $\begin{array}{l}\text { Interesse do setor } \\
\text { privado }\end{array}$ & Referência & $\begin{array}{c}\text { Capacidade do setor } \\
\text { privado }\end{array}$ & Referência & $\begin{array}{c}\text { Capacidade do setor } \\
\text { público }\end{array}$ & Referência & $\begin{array}{l}\text { Coordenação do } \\
\text { setor público }\end{array}$ & Referência & Clareza no procedimento \\
\hline 7 & $\begin{array}{l}\text { Atração financeira do } \\
\text { projeto para } \\
\text { investidores }\end{array}$ & 4 & $\begin{array}{l}\text { Consórcio privado } \\
\text { robusto }\end{array}$ & 1 & $\begin{array}{c}\text { Existência de Serviços } \\
\text { Necessários }\end{array}$ & 1 & Suporte político & 1 & $\begin{array}{l}\text { Disponibilidade de diretrizes } \\
\text { PPP e documentação } \\
\text { padronizada }\end{array}$ \\
\hline 7 & $\begin{array}{c}\text { Disponibilidade de } \\
\text { material }\end{array}$ & 4 & $\begin{array}{l}\text { Habilidade financeira } \\
\text { do setor privado }\end{array}$ & 1 & $\begin{array}{l}\text { Robustez da análise } \\
\text { da opção de compra }\end{array}$ & 1 & $\begin{array}{l}\text { Liderança do setor } \\
\text { público }\end{array}$ & 1 & $\begin{array}{l}\text { Clareza e responsabilidade } \\
\text { da estrutura de governo }\end{array}$ \\
\hline 7 & $\begin{array}{l}\text { Disponibilidade } \\
\text { financeira }\end{array}$ & 4 & $\begin{array}{l}\text { Boas habilidades de } \\
\text { liderança e } \\
\text { empreendedorismo }\end{array}$ & 1 & $\begin{array}{c}\text { Experiência e } \\
\text { conhecimento do setor } \\
\text { público }\end{array}$ & 2 & Ambiente político & 1 & $\begin{array}{l}\text { Clareza do resumo do } \\
\text { projeto e requisitos do } \\
\text { cliente }\end{array}$ \\
\hline 7 & Custo financeiro alto & 4 & $\begin{array}{l}\text { Maturidade e } \\
\text { disponibilidade do } \\
\text { mercado financeiro }\end{array}$ & 2 & Ambiente legal & 3 & $\begin{array}{l}\text { Atitude positiva do } \\
\text { ente concedente ao } \\
\text { agente privado }\end{array}$ & 4 & $\begin{array}{l}\text { Descritivo de projeto claro e } \\
\text { desenvolvimento do design }\end{array}$ \\
\hline \multirow[t]{3}{*}{10} & $\begin{array}{l}\text { Propostas contrárias } \\
\text { apresentadas }\end{array}$ & 5 & $\begin{array}{c}\text { Compromisso e } \\
\text { participação dos } \\
\text { executivos seniores }\end{array}$ & 3 & Desconto de impostos & 3 & Estabilidade política & 4 & $\begin{array}{l}\text { Clareza no papel e } \\
\text { responsabilidade das partes }\end{array}$ \\
\hline & & & \begin{tabular}{|c|} 
Integração das \\
diferentes divisōes da \\
organização de forma \\
a atender aos \\
objetivos gerais da \\
empresa ede cada \\
uma das divisōes / \\
grupos \\
\end{tabular} & 3 & $\begin{array}{l}\text { Competência da } \\
\text { unidade gestora }\end{array}$ & 4 & Suporte político & 7 & $\begin{array}{l}\text { Risco de comunicação e } \\
\text { organizacional }\end{array}$ \\
\hline & & & & 3 & \begin{tabular}{|} 
Aceitabilidade política \\
do modelo e apoio \\
interno no governo \\
para a execuçąo
\end{tabular} & 4 & Estabilidade política & 9 & $\begin{array}{l}\text { Concessão apropriada de } \\
\text { contratos e acordos }\end{array}$ \\
\hline
\end{tabular}

Fonte: Organizado pelo Autor. 
Quadro 27 - Integração [macro nível] dos FCSs de PPP/PFls e PMls

\begin{tabular}{|c|c|c|c|c|c|c|c|c|c|c|c|c|}
\hline Orientacão & Referência & Autoria & & & & & G & irupo de Aplicação & & & & \\
\hline PPP & 1 & $\begin{array}{l}\text { Tingting Liu, Yan } \\
\text { Wang, Suzanne } \\
\text { Wilkinson (2016) }\end{array}$ & \multicolumn{10}{|c|}{ Fator Crítico para o Sucesso } \\
\hline PPP & 2 & $\mid \begin{array}{l}\text { J. Mota, A.C. Moreira } \\
(2015)\end{array}$ & Referência & $\begin{array}{l}\text { Interesse do setor } \\
\text { privado }\end{array}$ & Referência & $\begin{array}{c}\text { Capacidade do setor } \\
\text { privado }\end{array}$ & Referência & $\begin{array}{c}\text { Capacidade do setor } \\
\text { público }\end{array}$ & Referência & $\begin{array}{l}\text { Coordenação do } \\
\text { setor público }\end{array}$ & Referência & Clareza no procedimento \\
\hline PPP & 3 & \begin{tabular}{|l} 
Jui-Sheng Chou; Dinar \\
Pramudawardhani \\
(2015)
\end{tabular} & & & 4 & \multicolumn{3}{|c|}{ Forte engajamento de ambas as partes } & 4 & Boa governança & 9 & $\begin{array}{l}\text { Alinhamento estratégico de } \\
\text { metas e objetivos }\end{array}$ \\
\hline PPP & 4 & $\begin{array}{l}\text { Robert Osei-Kyei, } \\
\text { Albert P.C. Chan } \\
\text { (2015) }\end{array}$ & & & 4 & \multicolumn{3}{|c|}{ Compatibilidade de conhecimento de ambas as partes } & 5 & $\begin{array}{l}\text { Publicar / divulgar os } \\
\text { objetivos, beneficios e } \\
\text { implicacoes do projeto } \\
\text { para todo o pessoal }\end{array}$ & 9 & $\begin{array}{c}\text { Definição clara e } \\
\text { documentada de escopo do } \\
\text { projeto }\end{array}$ \\
\hline PPP & 5 & \begin{tabular}{|} 
Weiwu Zou, Mohan \\
Kumaraswamy, Jacky \\
Chung, James Wong \\
(2014)
\end{tabular} & & & 7 & $\begin{array}{l}\text { Mercado financeiro } \\
\text { pobre }\end{array}$ & 4 & $\begin{array}{l}\text { Estudo de viabilidade } \\
\text { plausivel }\end{array}$ & 5 & \multicolumn{3}{|c|}{$\begin{array}{l}\text { Abordagens / canais de comunicação eficazes entre as principais } \\
\text { partes do PPP }\end{array}$} \\
\hline PPP & 6 & \begin{tabular}{|} 
Bon-Gang Hwang, \\
Xianbo Zhao, Mindy \\
Jiang Shu Gay (2012)
\end{tabular} & & & 7 & $\begin{array}{c}\text { Atraso no cronograma } \\
\text { construtivo }\end{array}$ & 4 & $\begin{array}{l}\text { Planejamento de } \\
\text { projeto detalhado }\end{array}$ & 7 & $\begin{array}{c}\text { [Reduzir a] } \\
\text { Instabilidade politica }\end{array}$ & 9 & $\begin{array}{l}\text { Papéis e responsabilidades } \\
\text { claramente definidos dos } \\
\text { participantes do projeto }\end{array}$ \\
\hline PPP & 7 & \begin{tabular}{|} 
Bon-Gang Hwang, \\
Xianbo Zhao, Mindy \\
Jiang Shu Gay (2012)
\end{tabular} & & & 7 & $\begin{array}{l}\text { Qualidade pobre da } \\
\text { força de trabalho }\end{array}$ & 4 & $\begin{array}{l}\text { Seleção do projeto } \\
\text { correto }\end{array}$ & 7 & $\begin{array}{c}\text { Nivel de demanda por } \\
\text { projeto }\end{array}$ & 10 & $\begin{array}{l}\text { Montante de tempo e } \\
\text { informação disponivel }\end{array}$ \\
\hline PPP & 8 & $\begin{array}{l}\text { Bon-Gang Hwang, } \\
\text { Xianbo Zhao, Mindy } \\
\text { Jiang Shu Gay (2012) }\end{array}$ & & & & & 4 & $\begin{array}{l}\text { Demanda de longo } \\
\text { prazo para o projeto }\end{array}$ & 8 & Inflação & 8 & Corrupção e propina \\
\hline PMI & 9 & \begin{tabular}{|c|} 
Sungmin Yun, \\
Wooyong Jung, Seung \\
Heon Han e Heedae \\
Park (2015)
\end{tabular} & & & & & 4 & $\begin{array}{c}\text { Escolhendo o parceiro } \\
\text { ideal }\end{array}$ & 8 & $\begin{array}{l}\text { Experiência } \\
\text { inadequada em } \\
\text { projetos desta } \\
\text { natureza }\end{array}$ & 8 & Variação de escopo \\
\hline PMI & 10 & $\begin{array}{l}\text { John T. Hodges, } \\
\text { Georgina Dellacha } \\
\text { (2007) }\end{array}$ & & & & & 4 & $\begin{array}{l}\text { Política econômica } \\
\text { sólida }\end{array}$ & 8 & $\begin{array}{l}\text { Distribuicicão } \\
\text { inadequada de } \\
\text { responsabilidade }\end{array}$ & & \\
\hline & & & & & & & 4 & $\begin{array}{l}\text { Órgão público bem } \\
\text { organizado e } \\
\text { comprometido }\end{array}$ & 8 & $\begin{array}{l}\text { Distribuicão } \\
\text { inadequadada de } \\
\text { autoridade }\end{array}$ & & \\
\hline & & & & & & & 4 & Objetivos claros & 8 & $\begin{array}{l}\text { Diferenças no método } \\
\text { de trabalho }\end{array}$ & & \\
\hline & & & & & & & 4 & $\begin{array}{l}\text { Emprego de } \\
\text { consultores } \\
\text { profissionais }\end{array}$ & 8 & $\begin{array}{l}\text { Falta de } \\
\text { comprometimento } \\
\text { entre as partes }\end{array}$ & & \\
\hline & & & & & & & 4 & $\begin{array}{c}\text { Responsabilidade } \\
\text { financeira }\end{array}$ & 8 & $\begin{array}{l}\text { Nivel de oposição } \\
\text { pública ao projeto }\end{array}$ & & \\
\hline
\end{tabular}


Quadro 28 - Integração [macro nível] dos FCSs de PPP/PFls e PMls

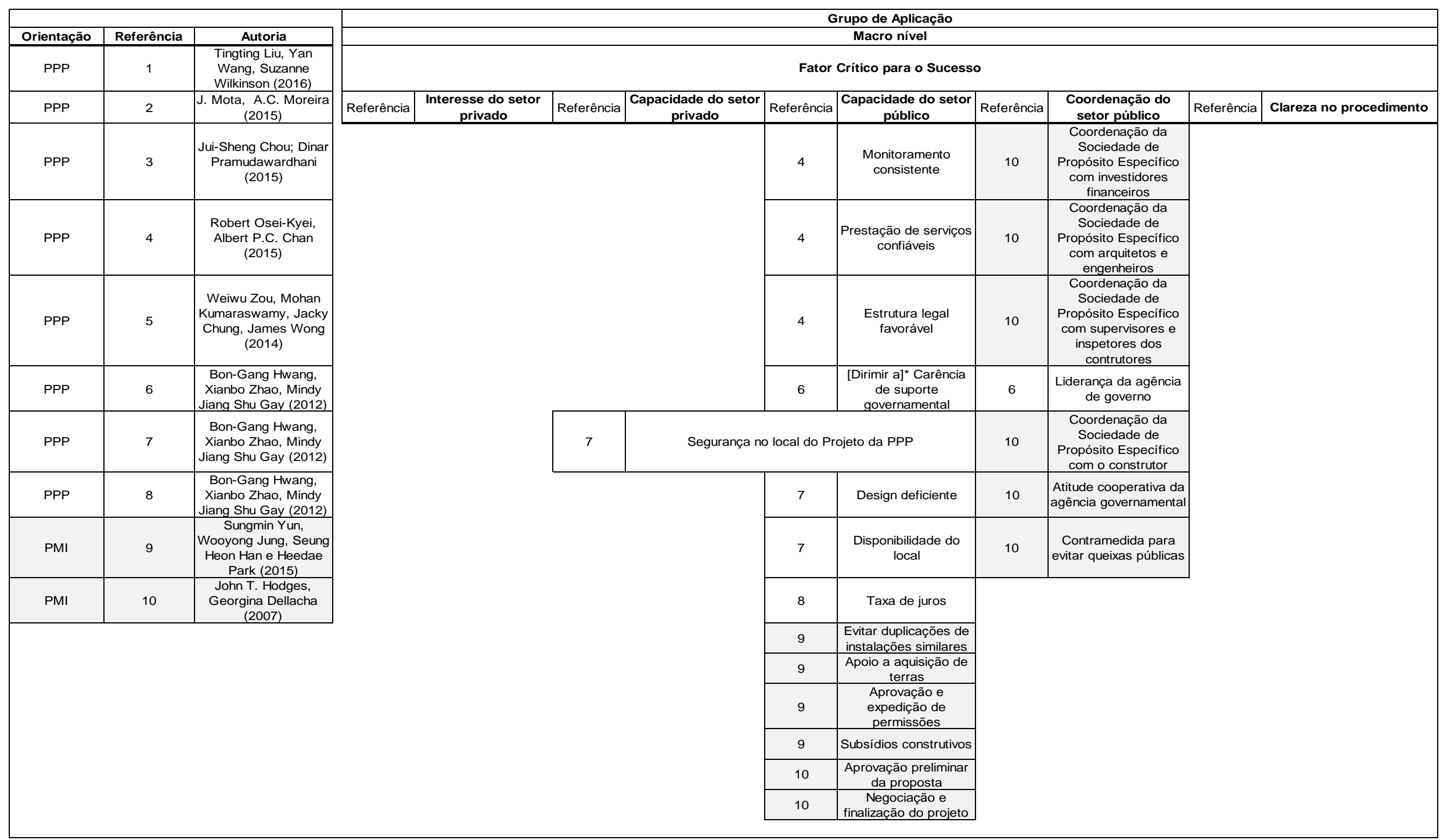

Fonte: Organizado pelo Autor. 
Quadro 29 - Integração [micro nível] dos FCSs de PPP/PFIs e PMls

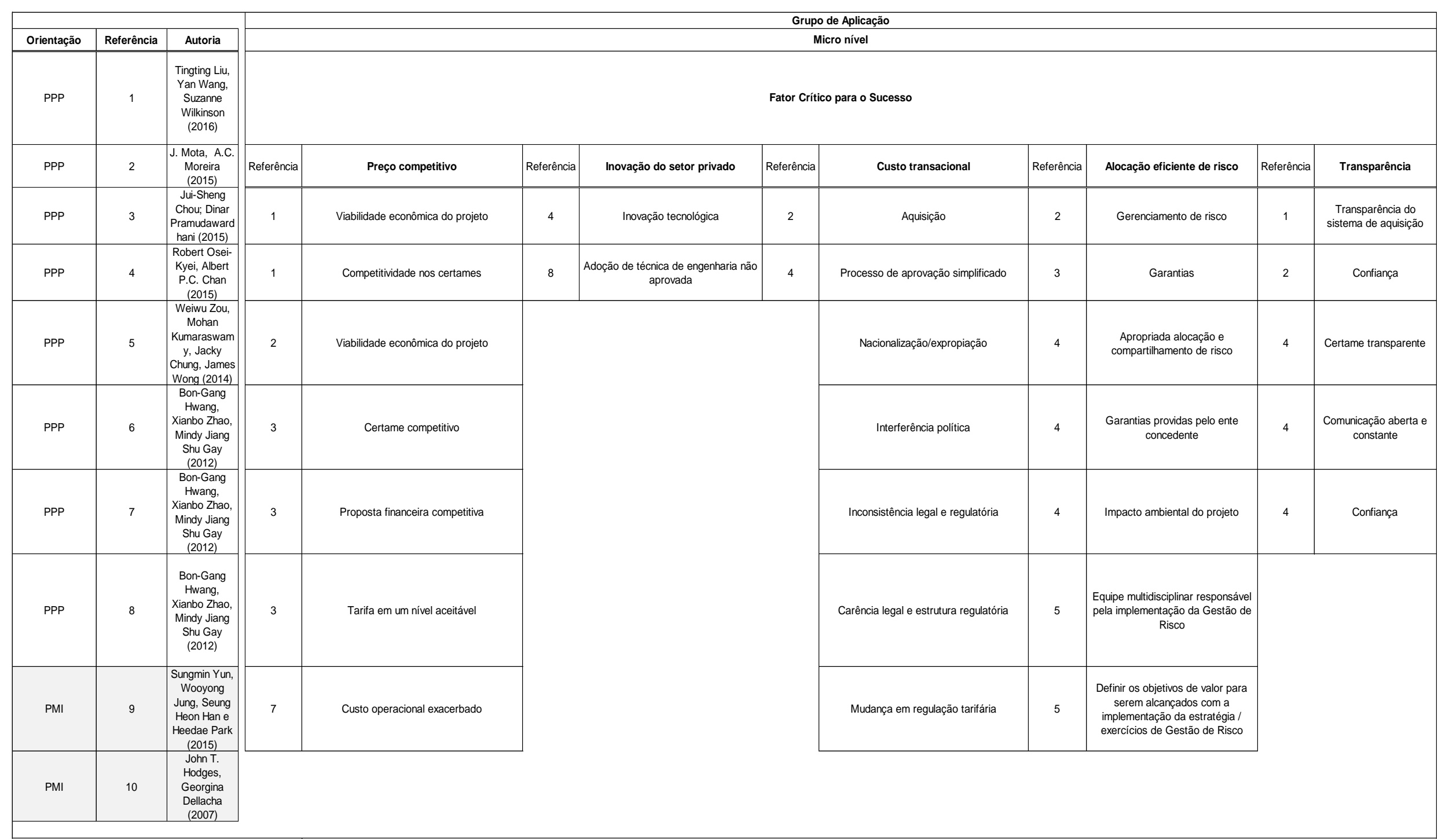

Fonte: Organizado pelo Autor. 
Quadro 30 - Integração [micro nível] dos FCSs de PPP/PFIs e PMls

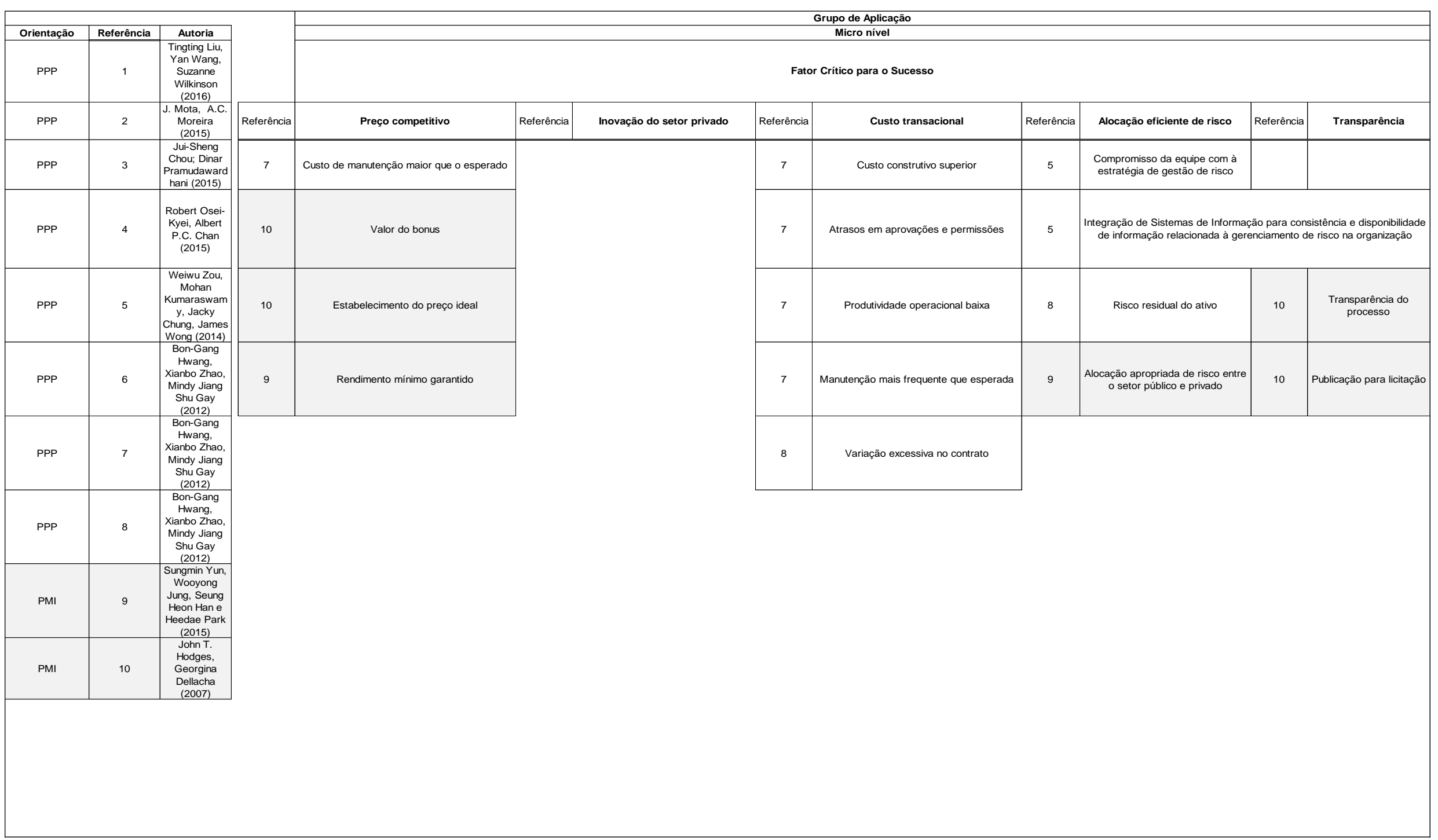

Fonte: Organizado pelo Autor. 
Os Fatores Críticos para o Sucesso uma vez integrados aos FCS de Macro e Micro níveis sugeridos pelo relatório do PPIAF 2014, resultam nos agrupamentos nos quadros supra expostos, contudo, 7 (sete) dos FCSs observados pelos autores empregados na revisão bibliográfica não tiveram enquadramento possíveis nos respectivos FCSs, sendo estes elencados na tabela 1.

Tabela 1 - Fatores críticos de sucesso de PPP/PFls e PMls não enquadrados

\begin{tabular}{cccc}
\hline Orientação & Referência & Autoria & Não enquadramento \\
\hline PPP/PFI & 2 & $\begin{array}{c}\text { J. Mota, A.C. Moreira } \\
(2015)\end{array}$ & $\begin{array}{c}\text { Ambiente econômico } \\
\text { favorável }\end{array}$ \\
\hline PPP/PFI & 4 & Osei-Kyei e Chan (2015) & $\begin{array}{c}\text { Suporte da } \\
\text { comunidade }\end{array}$ \\
\hline PPP/PFI & 4 & Osei-Kyei e Chan (2015) & $\begin{array}{c}\text { Condições } \\
\text { macroeconômicas } \\
\text { estáveis }\end{array}$ \\
\hline PPP/PFI & 7 & Hwang, Zhao e Gay & Fatores climáticos \\
\hline (2012) & $\begin{array}{c}\text { Hwang, Zhao e Gay } \\
(2012)\end{array}$ & Condições geológicas \\
\hline PPP/PFI & 7 & Hwang, Zhao e Gay \\
$(2012)$ & Ambiente \\
\hline PPP/PFI & 7 & $\begin{array}{c}\text { Hwang, Zhao e Gay } \\
(2012)\end{array}$ & Força Maior \\
\hline
\end{tabular}

Fonte: Organizado pelo Autor.

Para melhor visualização da sistemática e dos métodos linguísticos empregados para a junção dos FCSs em resposta à Questão 01 e 02, tem-se o organograma da Figura a seguir sequenciando as etapas que conduziram ao enquadramento dos FCSs Positivos e Negativos. 
Figura 14 - Metodologia para a organização dos FCSs

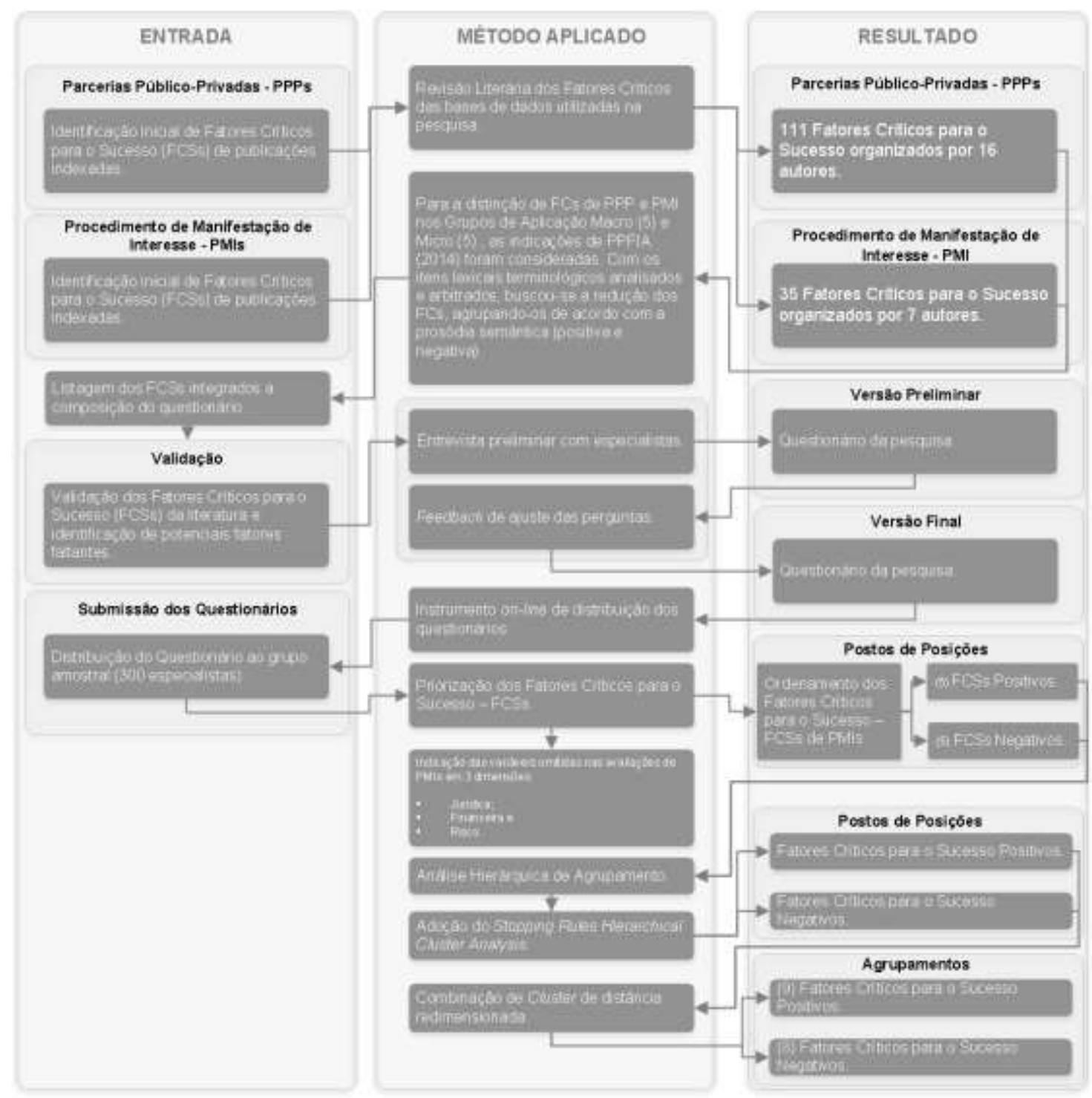

Fonte: Elaborado pelo Autor.

Ressalta-se que os FCSs são divididos em 2 (dois) grupos de conotação, Positiva ou Neutra (24 FCSs) e Negativa (21 FCSs). Os 45 (quarenta e cinco) FCSs são submetidos ao escrutínio de especialistas em PPP/PFls por meio da Survey, descrita na seção a seguir.

\subsection{APLICAÇÃO DA SURVEY}

A Survey, apresentada no apêndice C, disponibilizada por meio de um link encaminhado em uma mensagem eletrônica pelo mensageiro instantâneo WhatsApp ${ }^{\circledR}$, consiste em um questionário com perguntas. $O$ tamanho do grupo de 
perguntas busca maximizar a taxa de respostas e reduzir o erro amostral. Dos 300 (trezentos) especialistas (ou respondentes) que receberam a mensagem, obteve-se 149 (cento e quarenta e nove) questionários ${ }^{27}$ preenchidos, isto é, $49,6 \% 28$. Os questionários com respostas ${ }^{29}$ incompletas ou inconsistentes, 71 (setenta e um), foram eliminados, representando $47,65 \%$ do total de questionários recebidos, os dados foram tratados em pacote estatístico específico ${ }^{30}$.

Os questionários forneceram 180 (cento e oitenta) variáveis consolidadas de output, não confundidas aqui com os FCSs, separadas em quantitativas e qualitativas. O primeiro grupo é composto por 10 (dez) variáveis escalares, e o segundo por variáveis categóricas. Posteriormente, as variáveis foram separadas em 2 (dois) subgrupos: 146 (cento e quarenta e seis) variáveis e ordinais e 24 (vinte e quatro) variáveis.

A área territorial compreendida no estudo pautou-se em projetos desenvolvidos no Brasil, contudo os especialistas consultados possuíam experiência acadêmica e profissional no desenvolvimento de projetos desta natureza e condução executiva em África Lusófona (Moçambique e Angola), América do Sul, China e Território Autônomo de Hong Kong.

$\mathrm{Na}$ consolidação das informações e do nível de experiência exclusiva em apenas um dos institutos do estudo, PPP/PFI ou PMI, foram eliminados mais 33 (trinta e três) questionários, $22,15 \%$ do total de questionários respondidos. Por fim, 45 (quarenta e cinco) questionários de respondentes que preenchiam conhecimento em ambos os institutos PPP/PFI e PMI foram considerados, ou seja, tendo trabalhado na modelagem, avaliação e/ou gestão de PPP/PFIs por pelo menos 1 (um) ano e 1 (um) ano com a modelagem, avaliação e/ou gestão de PMls, representando $15 \%$ do total de questionários enviados e $30,20 \%$ do total de questionários devolvidos.

Quatro critérios para a seleção de especialistas foram definidos de forma ad hoc, a saber:

${ }^{27}$ Embora o questionário motive uma homogeneidade do universo de entrevistados no conhecimento da matéria, houve atenção em buscar visões múltiplas das partes interessadas que atuam neste mercado.

28 Porcentagem obtida pelo número de entrevistas completas/número de respondentes que confirmaram o recebimento do questionário.

29 Para melhorar a clareza das respostas, foram retirados do questionário os caracteres excêntricos (COHEN et al., 2013).

${ }^{30}$ O pacote estatístico SPSS, na versão 22, e o Excel 2016 foram adotados para a organização inicial das variáveis e para a realização das análises, respectivamente. 
(i) possuir real conhecimento e distinção dos institutos PPP/PFI e PMI,

(ii) ter experiência prática na modelagem de PPP/PFI e PMls;

(iii) ocupar cargos de liderança na condução de PPP/PFI [operação e/ou estruturação de estudos ${ }^{31}$ ] e

(iv) ter formação técnica suficiente para integrar os conceitos de visão de produto aos FCSs de PMls. A análise visou também compreender o nível de maturidade dos profissionais nos institutos, uma vez que se entende que o nível de maturidade em Projetos de PPP/PFI apresentaria médias estatísticas significativamente distintas das obtidas nas PMls. O meio adotado para a escolha dos especialistas ${ }^{32}$ derivou da rede de contatos setoriais do autor desta tese, ao longo de 8 (oito) anos trabalhando com gestão pública, e de uma pesquisa em grupos de interesse (SUDMAN; BRADBURN; SCHWARZ, 1996) de rede social profissional (Linkedln.com). ${ }^{33}$

Os respondentes indicaram o grau de experiência em anos em projetos de PPP/PFIs e PMIs. Em seguida, foram estratificados em 3 (três) grupos: Grupo 01 de 1 (um) a 4 (quatro) anos de experiência em ao menos um dos institutos; Grupo 02 - de 5 (cinco) a 8 (oito) anos e Grupo 03 - acima de 9 (nove) anos ${ }^{34}$. Outra perspectiva da abordagem foi conhecer o nível de experiência dos profissionais em quantidade e atividade desenvolvidas, sendo elas: modelagem, avaliação e gerenciamento de ambos institutos. O grau de experiência dos respondentes dos questionários da Survey em anos e número de Projetos de PPP/PFls conduzidos por meio do instituto "PMI" foi uma média de 4 (quatro) anos e 13 (treze) de experiência total.

\footnotetext{
31 Discute-se na literatura que o agrupamento das tarefas pode proporcionar ao contratante privado fortes incentivos para desenvolver um design flexível que seja particularmente rentável na fase de operação e que possa responder eficientemente às necessidades futuras e acompanhar a fronteira tecnológica (LITTLE; LINDENBERGER; NESSELROADE, 1999).

32 Não se considerou relevante a necessidade de estratificação de gênero dos profissionais consultados.

33 Salienta-se que, embora tenha sido cunhado na década de 70, o instituto PPP/PFI ganha força na Inglaterra a partir de 1992 (AKINTOYE; FITZGERALD; HARDCASTLE, 1999; POLLITT, 2002; COUTINHO; VELLUTINI; IVAN, 2014) em dois formatos de configuração: Design, Construção, Finanças e Operação (Design, Build, Finance and Operate - DBFO) ou Design, Construção, Gerenciamento e Finanças (Design Construct, Manage and Finance - DCMF) (RAYMOND, 2008). Na América do Sul, no início dos anos 2000, em especial no Brasil, ganha força com a criação da Lei Federal n. 11.079 em 30 de dezembro de 2004 (BRASIL).

${ }^{34}$ Os profissionais com menos de 1 (um) ano de experiência no tema foram eliminados do estudo.
} 
O recorte amostral é composto, então, por um grupo de indivíduos atuantes no segmento, ou seja, profissionais e acadêmicos com comprovada experiência na modelagem de PMls, advindos de ambos os setores: privado e público. Um prazo de 2 (duas) semanas foi estipulado para a devolutiva dos questionários.

Os questionários buscavam respostas a duas hipóteses objeto do estudo:

Hipótese Nula $\left(H_{0}\right)$ : não existe correlação entre experiência com Projetos de PPP/PFI e PMI (UNP) e a validação do Value for Money - VfM como critério para a seleção de Projetos;

Hipótese Alternativa $\left(H_{1}\right)$ : existe correlação entre experiência com Projetos de PPP/PFI e PMI (UNP) e a validação do Value for Money - VfM como critério para a seleção de Projetos.

Hipótese Nula $\left(H_{0}\right)$ : não existe correlação entre experiência com Projetos de PPP/PFI e PMI e reconhecimento de subjetivismo nas avaliações de PMls (UNPs);

Hipótese Alternativa $\left(H_{1}\right)$ : existe correlação entre experiência com Projetos de PPP/PFI e PMI e reconhecimento de subjetivismo nas avaliações de PMIs (UNPs).

As hipóteses foram testadas por meio de análise de correlação monotônica, uma vez que se admite que as variáveis tendem a mudar de direção conjuntamente, mas não necessariamente na mesma constância. Outrossim, verificou-se a relação entre as variáveis sem a possibilidade de assegurar a relação de causa e efeito (SPEARMAN, 1904), pois desejou-se motivar a lógica de coerência dos resultados e não somente a força preditiva dos níveis de correlação e significância.

As 180 variáveis foram agrupadas e testadas individualmente quanto à confiabilidade e viabilidade dos resultados. A consistência interna das variáveis qualitativas escalares resultou em Alfa de Cronbach ( $\alpha=0,884$, Número de itens 10 ), coeficiente que possui variabilidade entre 0 e 1. Contudo, não há restrição inferior ao coeficiente e quanto mais próxima de 1 (um) maior a consistência interna dos itens na escala. Com base da fórmula do coeficiente, dada por: $\mathrm{CC}=\mathrm{rk} /[1+(\mathrm{k}-1) \mathrm{r}]$, em que $k$ é o número de itens considerados e $r$ é a média das correlações entre os itens, o tamanho de alfa é determinado pelo número de itens em a escala e as 
correlações médias entre os itens. ${ }^{35}$ A intensidade das relações teve o seu grau medido pelo Coeficiente de Spearman considerando a característica das variáveis sendo "nominais" e "ordinais" (BOLBOACA; JÄNTSCHI, 2006) e foi obtida de dados brutos (KETCHEN; SHOOK, 1996).

George e Mallery (2003, p. 231) atribuem os parâmetros "CC > 0,9 Excelente; CC > 0,8 - Bom; CC > 0,7 - Aceitável; CC > 0,6 - Questionável; CC > 0,5 - Pobre; e CC < 0,5 - Inaceitável". Assim, o valor de alfa é parcialmente dependente do número de itens na escala, o incremento no valor do alfa, os retornos decrescem. A consistência interna dos itens na escala não implica que a escala seja unidimensional (IOSSA; MARTIMORT, 2015).

O grupo amostral apresentou "Consistência Boa" nas variáveis categóricas, sendo essas organizadas em Nominais e Binárias - testadas pelo teste de KuderRichardson 20 Test ( $\alpha=0,954$, Número de itens 141) e atingiu-se a "Consistência Alta". Por meio do teste, é possível medir a confiabilidade de consistência interna resultantes de variáveis que envolvam escolhas dicotômicas, dado pela equação

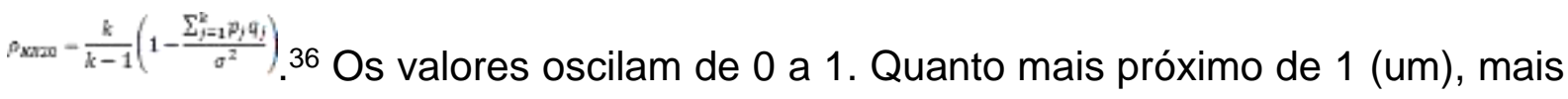
confiáveis são as variáveis. Todavia, um valor muito alto próximo a 1 indica um teste homogêneo. $\mathrm{O}$ comportamento das variáveis da amostra quanto à normalidade dos dados foi validado pelo teste Shapiro Wilks em razão do número de observações em teste $(n=45)$ (SMYTH; EDKINS, 2007). O resultado indicou comportamento não normal dos dados, levando os estudos para análises não-paramétricas.

O estudo valeu-se de análise de agrupamento, os clusters foram empregados para a redução do conjunto de FCS sob o ponto de impacto Positivo e Negativo, representado pelo posto de posição alcançado nas escolhas dos respondentes que compuseram a amostra.

Convém ressaltar que a metodologia de agrupamentos, muitas vezes referida na academia como Purdue Brewing, é originária de estudos nas organizações industriais em que grupos eram definidos em conjuntos estreitos de variáveis, muitas vezes apenas um ou dois (HATTEN; HATTEN, 1987) referenciando trabalhos de M.S. Hunt (1972) e Michael Porter (1973). Nessa perspectiva, há a restrição do

\footnotetext{
$35 \mathrm{O}$ emprego da estatística descritiva dos dados é realizado com o interesse de comprovar ou refutar a coerência das variáveis a serem indicadas no modelo de avaliação de Projetos de PMI. Pretendese compreender o grau de influência das PPP/PFI nas PMls.

36 Entende-se que ké 0 número de questões, pjé o número de indivíduos que responderam corretamente à questão, $\sigma$ é o desvio padrão das pontuações totais de todas as pessoas que tomaram o teste.
} 
número de dimensões e não se capturam os construtos de interesse estratégico para a compreensão dos institutos ou conceitos (KETCHEN; SHOOK, 1996). A posteriori, a técnica evolui e passa a incluir múltiplas variáveis, como fonte de definição de configuração. Por fim, entende-se que a variância entre os elementos dos grupos é mínima e é maximizada entre os agrupamentos.

Por esta técnica ser multivariada, um conjunto de características críticas para a existência de um dado projeto é reunido em classes de semelhança (ANDERBERG, 2014) e separado pela amplitude de suas diferenças. Essas ações (reunião e separação) propiciam a redução do total de fatores pesquisados na literatura para grupos menores adensados ${ }^{37}$.

O critério utilizado para a formação dos agrupamentos foi dado pelo grau de relevância do fator em ordem de impacto (BEALE, 1969) positivo [representando por $\mathrm{P}$ ] e negativo [representando por N], sendo esses alocados nos 5 (cinco) primeiros postos de relevância pelos especialistas entrevistados, de duas matrizes individuais [M] dadas por: $M P$ e $M N$, $[N x p]$ em que $N$ para MP: 24 Fatores e $N$ para $M N$ : 21

Fatores. O agrupamento de cluster foi o armazenamento nos centroides (SHAPIRO; WILK, 1965) (vetor da média amostral) do número de fatores (UPGMC) e o espaçamento entre grupos fatoriais foi obtido por meio da distância euclidiana (GLIEM; GLIEM, 2003).

A análise dos dados aponta para uma amplitude total da variável "Anos de experiência em PPP/PFIs" que alcançou 13 (treze) anos, sendo sua média 6 (seis) anos (Tabela 30). No subgrupo número de projetos de PPP/PFI modelados, 4 (quatro) projetos em moda foram observados. Em relação à perspectiva de avaliação de PPP/PFIs, a moda de anos de experiência foi de 2 (dois) a 3 (três) anos e a média de 3 (três).

A variável "Número total de PPP/PFI gerenciadas" obteve os resultados menores, apresentando 1 (um) projeto em média. Aventam-se duas hipóteses para o resultado obtido: (i) o instituto não é consolidado ou (ii) a longevidade dos contratos e escopos dos projetos inviabilizam as ações de gestores em mais de um projeto ao mesmo tempo.

37 O número de ordem de classes estabelecidas respeitou a heurística semântica dos fatores, tendo por base homogeneidade entre os fatores internos do agrupamento e heterogeneidade entre eles (HADZIKADIC et al., 2007). 
Tabela 2 - Experiência em projetos de Parcerias Público-Privadas (PPP/PFI)

\begin{tabular}{|c|c|c|c|c|c|}
\hline \multirow{3}{*}{$\mathrm{N}$} & & $\begin{array}{c}\text { Anos de } \\
\text { Experiência } \\
\text { em PPP/PFI }\end{array}$ & $\begin{array}{l}\text { N. Total de } \\
\text { PPP/PFI } \\
\text { Modeladas }\end{array}$ & $\begin{array}{c}\text { N. Total } \\
\text { de } \\
\text { PPP/PFI } \\
\text { Avaliadas }\end{array}$ & $\begin{array}{l}\text { N. Total de } \\
\text { PPP/PFI } \\
\text { Gerenciadas }\end{array}$ \\
\hline & Válido & 45 & 45 & 45 & 45 \\
\hline & Ausente & 0 & 0 & 0 & 0 \\
\hline \multicolumn{2}{|c|}{ Média } & 6,2 & 6,7 & 5,5 & 3,3 \\
\hline \multicolumn{2}{|c|}{ Mediana } & 6 & 4 & 3 & 1 \\
\hline \multicolumn{2}{|c|}{ Moda } & 6 & 4 & $2^{a}$ & 0 \\
\hline \multicolumn{2}{|c|}{ Desvio Padrão } & 3,7 & 6,3 & 6,4 & 5,4 \\
\hline \multicolumn{2}{|c|}{ Variância } & 13,6 & 39,6 & 41,1 & 29,4 \\
\hline \multicolumn{2}{|c|}{ Mínimo } & 1 & 0 & 0 & 0 \\
\hline \multicolumn{2}{|c|}{ Máximo } & 13 & 20 & 20 & 20 \\
\hline \multirow{3}{*}{ Percentis } & 25 & 3,5 & 2 & 1,5 & 0 \\
\hline & 50 & 6 & 4 & 3 & 1 \\
\hline & 75 & 10 & 10 & 7 & 3,5 \\
\hline
\end{tabular}

a - Há várias modas. O menor valor é mostrado.

Fonte: Elaborado pelo Autor.

Diante dos resultados advindos dos dados coletados e parametrizados, afirma-se que os profissionais, desde a criação de regulamentação do instituto "PMl", no caso brasileiro, já se preocupavam com a operacionalização de atividades derivadas do marco legal das PPP/PFIs e com o modelo derivado de concessões públicas. Contudo, quando a amostra é estratificada em grupos de experiências, os extremos do gráfico (Gráfico 2) se destacam. Tem-se uma elevação para 25 (vinte e cinco) profissionais enquadrados em "pouca experiência em Projetos de PMI" (de 1 a 4 anos) e 11 (onze) profissionais constituem item "experiência alta em Projetos de PMI". O grupo de profissionais com "experiência moderada" (de 5 a 8 anos) foi o de menor incidência. Tal variação indica sinais de que, desde 2010 a 2015, o instituto tenha sido preterido a modelagens alternativas das PPP/PFIs e a outras formas de contratação pelos órgãos públicos, como licitações diretas, com objetos previamente definidos em estudos pré contratados e concessões diretas. 
Gráfico 2 - Experiência na condução de projetos de PPP/PFIs e PMIs

\begin{tabular}{|c|c|c|c|c|c|}
\hline \multicolumn{6}{|c|}{ Estatistica Descritiva } \\
\hline \multicolumn{3}{|c|}{$\begin{array}{l}\text { Anos de Experiencia no } \\
\text { Instiuto PPP }\end{array}$} & \multicolumn{3}{|c|}{$\begin{array}{c}\text { Anos de Experiencia no } \\
\text { Insitiuto PMal }\end{array}$} \\
\hline \multirow{2}{*}{$\mathrm{N}$} & Valido & 45 & \multirow{2}{*}{$\mathrm{N}$} & Vatido & 45 \\
\hline & Ausente & 0 & & Aussente & 0 \\
\hline \multicolumn{2}{|l|}{ Media } & 6.20 & \multicolumn{2}{|l|}{ Media } & 5.49 \\
\hline \multicolumn{2}{|l|}{ Mediane } & 6,00 & \multicolumn{2}{|l|}{ Mediana } & 4,00 \\
\hline \multicolumn{2}{|l|}{ Modo } & 6 & \multicolumn{2}{|l|}{ Modo } & 4 \\
\hline \multicolumn{2}{|l|}{ Varidnelia } & 13.57 & \multicolumn{2}{|l|}{ Varidncia } & 12.07 \\
\hline \multicolumn{2}{|l|}{ Minimo } & 1 & \multicolumn{2}{|l|}{ Minimo } & 1 \\
\hline \multicolumn{2}{|l|}{ Matcimo } & 13 & \multicolumn{2}{|l|}{ Madime } & 13 \\
\hline \multirow{3}{*}{ Percentis } & 25 & 3,50 & \multirow{3}{*}{ Percentis } & 25 & 3.00 \\
\hline & 50 & 6,00 & & 50 & 4.00 \\
\hline & 75 & 10,00 & & 75 & 8.60 \\
\hline
\end{tabular}

Fonte: Elaborado pelo Autor.

\section{Experiência Comparada}

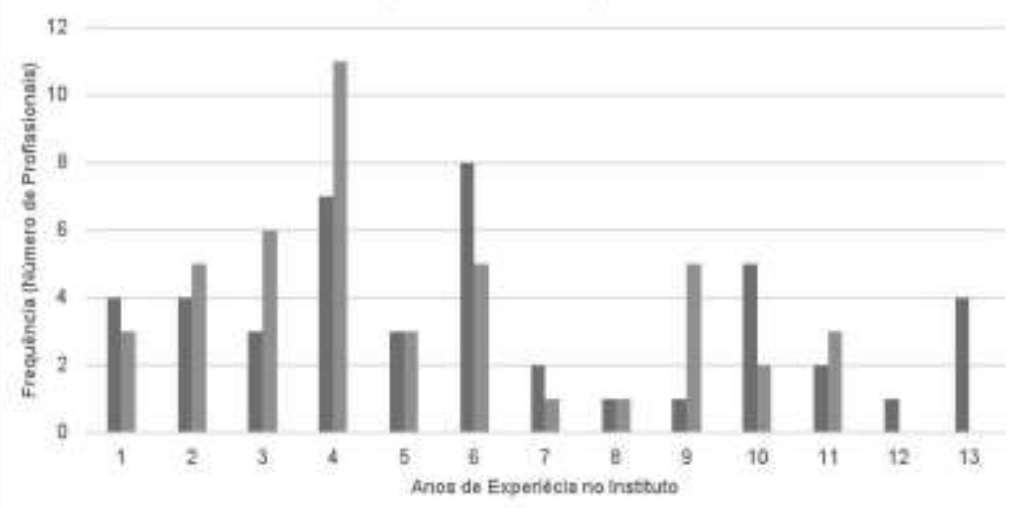

- Anos de Experiencia no Inattuto PPP =Anos de Expanéncia no instituto PMI

Do grupo amostral, 15 (quinze) áreas de projetos $^{38}$ foram identificadas (Tabela 29). As áreas com maiores incidências são Mobilidade Urbana (sistemas viários), Saneamento (urbano e rural), lluminação, Saúde e Habitação. Esse resultado indica a utilização das PPP/PFIs em projetos mais voltados para infraestrutura do que para a prestação de serviços como educação (1) e meioambiente (2). Ademais, é possível verificar que os resultados sinalizam as demandas emergentes dos mercados aos quais os profissionais estão inseridos ${ }^{39}$.

Tabela 3 - Áreas de atuação e projetos de interesse

\begin{tabular}{lc}
\hline \multicolumn{1}{c}{ Área dos Projetos } & $\begin{array}{c}\text { Número de } \\
\text { Incidência }\end{array}$ \\
\hline Mobilidade Urbana (vias) & 23 \\
\hline Saneamento & 15 \\
\hline Iluminação & 9 \\
\hline Saúde & 7 \\
\hline Habitação & 3 \\
\hline Centro Administrativo & 2 \\
\hline Estádio de Futebol (e arena esportiva) & 2 \\
\hline Meio-ambiente & 2 \\
\hline Prisional & 2 \\
\hline Rede de Fibra Ótica & 2 \\
\hline RSU & 2 \\
\hline Cemitério & 1 \\
\hline Centro de Exposições & 1 \\
\hline
\end{tabular}

${ }^{38}$ Conduzidas por meio dos institutos PPP/PFI e PMI. 


\begin{tabular}{ll}
\hline Desalinização & 1 \\
\hline Educação & 1 \\
\hline
\end{tabular}

Fonte: Elaborado pelo Autor.

Dos resultados dos questionários e validações estatísticas, surgem novos questionamentos quanto a: (i) efetividade do Value for Money - VfM como instrumento de avaliação de Procedimentos de Manifestação de Interesse - PMls (UNPs); (ii) a existência/grau de subjetividade nos Procedimentos de Manifestação de Interesse - PMIs (UNPs); (iii) quais seriam os Fatores Críticos de Sucesso FCSs mais relevantes positivos e negativos de Procedimentos de Manifestação de Interesse - PMls (UNPs) e (iv) possibilidade de mensuração da influência das Propriedades de Visão de Produto em Variáveis Qualitativas em Projetos de Procedimentos de Manifestação de Interesse - PMI (UNP).

\subsection{PERCEPÇÃO DOS ESPECIALISTAS SOBRE A PROPOSIÇÃO DE PMIS}

Com o intuito de refletir sobre a percepção dos especialistas sobre a proposição de $\mathrm{PMI}$, questionou-se aos respondentes qual seria o número ideal de projetos submetidos. A média adquirida foi de 3 (três) propostas de PMls. A respeito de o número ideal de concorrentes nos certames de PPP/PFI, não pode ser obtida uma uniformidade nas respostas advindas dos respondentes. Para melhor visualização da situação descrita, tem-se o Gráfico $3^{40}$.

\footnotetext{
40 O Gráfico 3 traz frutíferas provocações na continuação e ampliação do tema estudado nesta tese. A primeira possível seria a consideração de que, não necessariamente, mais projetos oferecem a melhor gama de escolhas, pois um número alto de projetos submetidos pode reduzir a celeridade da marcha de contratação da PPP/PFI em função da necessidade de avaliação de projetos por parte do órgão contratante. A segunda, diz respeito aos contratantes. Eles, não necessariamente também, estão preparados para a avaliação dos projetos de forma técnica e imparcial, em função de propostas de PMI possuírem alta complexidade (FROUD, 2003; PPIAF, 2014; MANSOR; RASHID, 2016; SASTOQUE et al., 2016) e deve-se exigir um corpo técnico especializado em conteúdos muito pontuais. No entanto, neste momento, não as aprofundaremos e deixaremo-nas para verificação de pesquisas futuras.
} 
Gráfico 3 - Número Ideal de submissões

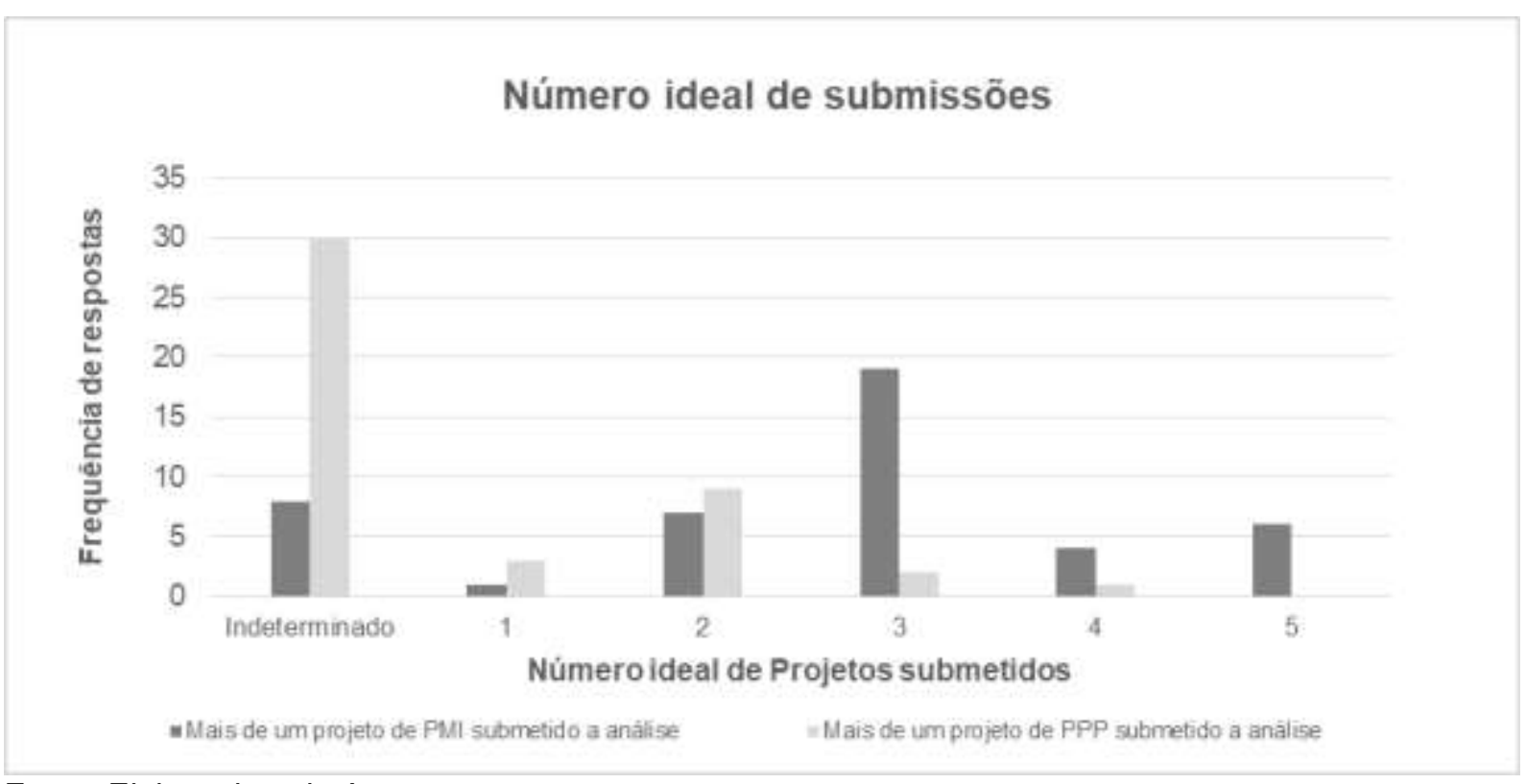

Fonte: Elaborado pelo Autor.

Os respondentes brasileiros indicaram que a expectativa para a celebração de contratos é a mesma de anos anteriores. Todavia, considerando a análise dos dados, a expectativa de $69 \%$ dos entrevistados é de aumento, $20 \%$ de níveis equivalentes aos anos anteriores e $11 \%$ em decréscimo.

No intuito de compreender qual modelo de relação jurídica entre as partes interessadas seria o mais aderente para a formatação do edital final proposto para a PPP/PFI (GURGUN; TOURAN, 2014), sendo questionado aos participantes da Survey o número ideal de competidores em um dado certame e sob quais regras este deveria ser vigido.

Os resultados presentes no Gráfico 5 indicam que $47 \%$ dos entrevistados relataram que os projetos finais conjugam atributos advindos de mais de um projeto de PMI, $18 \%$ sinalizaram que os projetos deveriam vir exclusivamente de instituições terceiras especialistas contratadas pelos órgãos solicitantes, $11 \%$ não souberam informar e $11 \%$ àqueles que elegeram apenas as características de um único projeto a ser selecionado. Todavia, $9 \%$ julgaram que o conjunto de variáveis a constituir 0 edital final deveria ser obtido por meio de consultas públicas e $4 \%$, por grupo de especialistas individuais não pertencentes a grupos de interesse específico do certame a ser estruturado. 


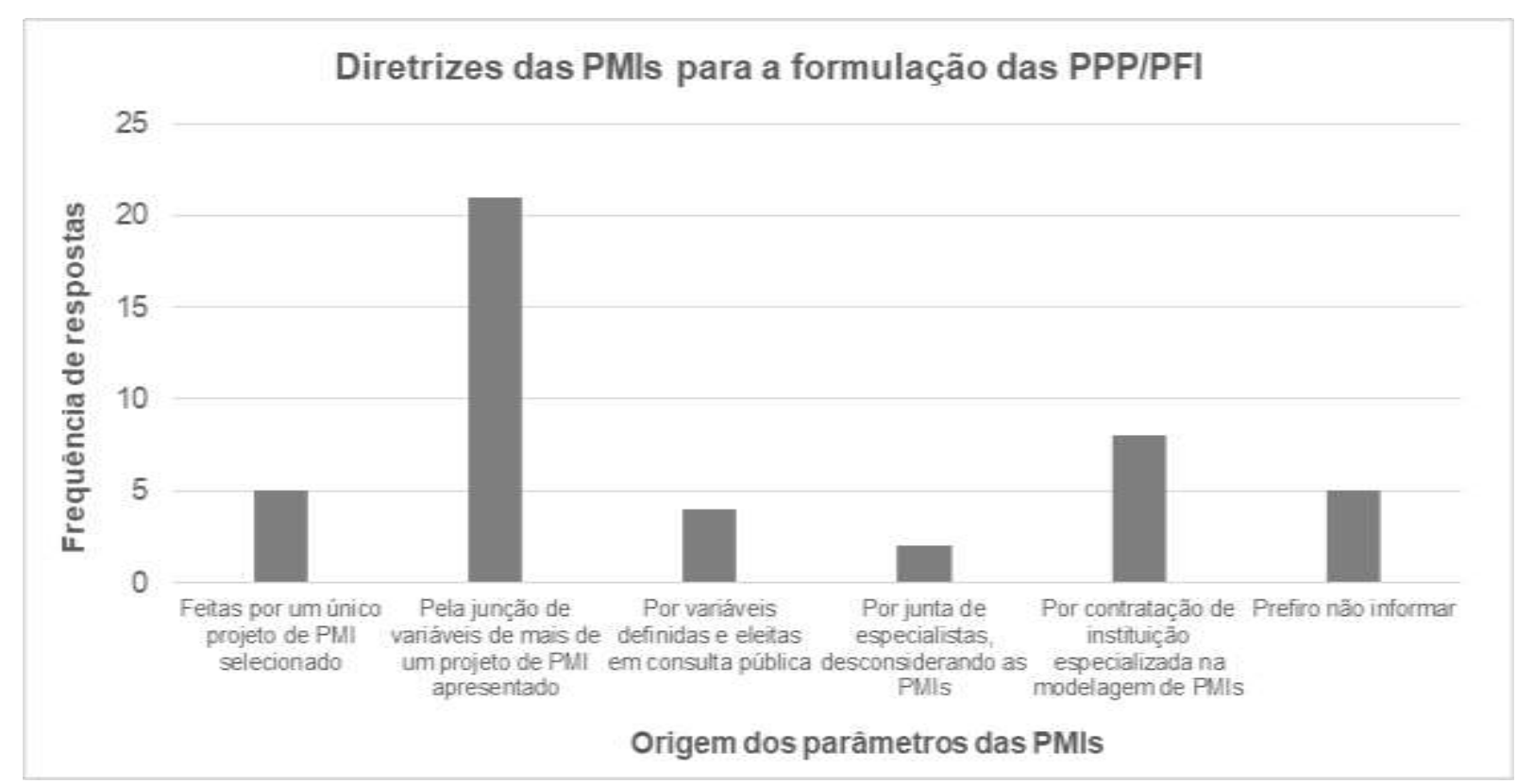

Fonte: Elaborado pelo Autor.

A qualidade do marco regulatório vigente no Brasil foi também questionada (Gráfico 5). Dentre os respondentes, 53\% sinalizaram que a regulamentação das PMls no Brasil precisa de melhorias, embora não inviabilizem o processo, 16\% julgaram como adequada a regulamentação vigente, $16 \%$ relataram que, embora 0 processo não cesse, traz dificuldades significativas para a marcha processual de contratação, 7\% consideraram que a atual regulamentação não é causa geradora de efeito na contratação das PMls, $2 \%$ alegaram que a atual situação torna quase impeditivo o rito de contratação e 7\% optaram por não apresentarem posição sobre o tema.

Devkar et al. (2013), em seus trabalhos, também, ilustraram a seara legal, como o terceiro fator mais crítico para projetos desta natureza. Kweun, Wheeler e Gifford (2017) entendem que a regulamentação deve ser estabelecida ou melhorada em decorrência da natureza dinâmica dos requisitos de um país, variando de acordo com as características do local. 


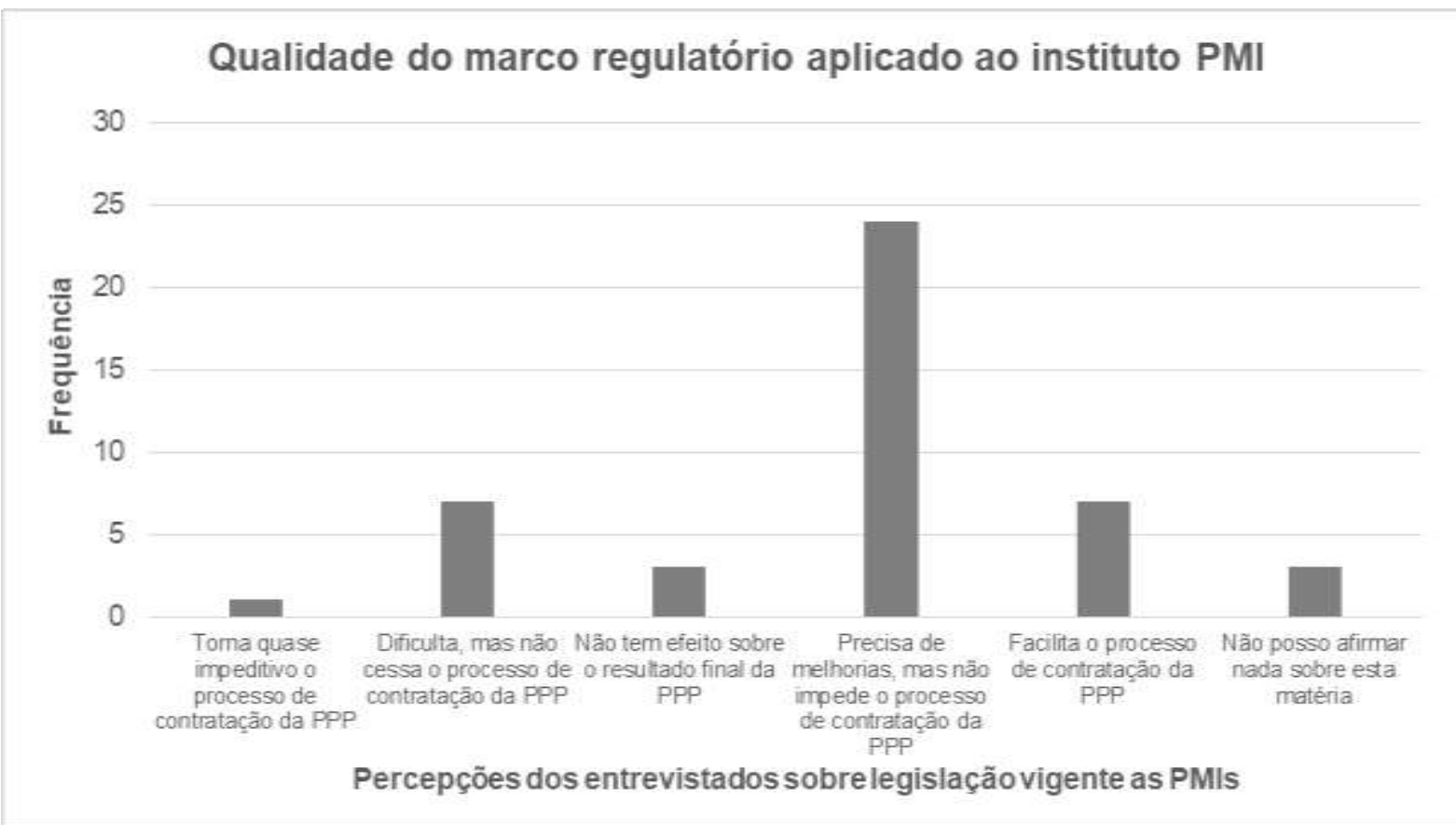

Fonte: Elaborado pelo Autor.

Xiong et al., (2017) destacam investimentos por meio do instituto das PPP/PFIs, tanto em países com economia desenvolvidas quanto em nações em desenvolvimento, dentre os entrevistados consultados, os países com legislação e a regulamentação mais próxima do ideal para garantir robustez técnica e celeridade processual, sendo indicado em parênteses o número de incidências: Inglaterra (4), Austrália (1), EUA (1), Canadá (1), Portugal (1), Coréia do Sul (1), Chile (1) e Colômbia $(1)^{41}$.

\subsection{PERCEPÇÃO DOS RESPONDENTES QUANTO AO GRAU DE SUBJETIVIDADE}

Avaliado o aspecto jurídico em face legal e regulamentar das PMls buscou-se averiguar a percepção dos especialistas sobre o grau de subjetivismo nas avaliações de PMls submetidas aos órgãos demandantes dos projetos que participaram. Atribuída escala de ordem de concordância de: "Concordo Totalmente" a "Discordo Totalmente", obteve-se que somados os resultados dos respondentes indicando a existência de algum grau de subjetivismo nas avaliações dos projetos alcançou 93,3\% da amostra segredada em "Concordo Totalmente" (24,4\%), "Concordo" (22,2\%), "Concordo Parcialmente" (46,7\%). Somente 6,7\% optaram por neutralidade de resposta e nenhum respondente alegou a inexistência de

${ }^{41}$ Ressalta-se que o Brasil foi excluído como opção de resposta pelos respondentes. 
obscuridade no processo de avaliação dos projetos de PMl por parte do órgão demandante, reforçando a tese de subjetivismo no processo de avaliação de projetos desta natureza e a clara necessidade de métricas mais consistentes para a avaliação destes projetos.

O estudo incluiu questionamento sobre quais variáveis atualmente são atualmente preteridas nas avaliações dos projetos de PMI submetidos, sob três pilares, jurídico, financeiro e riscos. Levantamento atribuído ao PPIAF (2014), vinculado ao Banco Mundial estabelece conjunto de fatores chave para o sucesso destas no Macro nível [Interesse do Setor Privado, Capacidade do Setor Privado, Capacidade Pública, Coordenação Pública e Clareza nos Procedimentos e Avaliações] e Micro nível [Preço Competitivo, Inovação, Capacidade de Cobertura de Custos Transacionais, Alocação Eficiente de Riscos e Processo Transparente]. Tomando por base estes fatores e reduzindo em 5 (cinco) categorias de conhecimento por proximidade semântica definida pelo autor, com fulcro nas devolutivas dos questionários, tem-se:

Quadro 31 - Variáveis omitidas nas avaliações de PMls

\begin{tabular}{lll}
\hline \multicolumn{1}{c}{ Jurídico } & \multicolumn{1}{c}{ Financeiro } & \multicolumn{1}{c}{ Riscos } \\
\hline Modelagem Jurídica & $\begin{array}{l}\text { Aderência ao interesse público, } \\
\text { na relação impacto social/ônus } \\
\text { decorrente }\end{array}$ & Riscos e avaliação de cenários \\
\hline $\begin{array}{l}\text { Marco regulatório } \\
\text { questionável }\end{array}$ & Garantias e financiamento & $\begin{array}{l}\text { Avaliação Quantitativa dos } \\
\text { Riscos e Avaliação da } \\
\text { Financiabilidade do Projeto }\end{array}$ \\
\hline & $\begin{array}{l}\text { Economicidade gerado com a } \\
\text { PPP/PFI }\end{array}$ & $\begin{array}{l}\text { Capacidade técnica da } \\
\text { empresa privada }\end{array}$ \\
\hline & $\begin{array}{l}\text { Impactos futuros, dado a custos } \\
\text { mal mensurados }\end{array}$ & Histórico de compliance \\
\hline & $\begin{array}{l}\text { Equilíbrio financeiro (BEP) } \\
\text { (BOYER et al., 2016) }\end{array}$ & $\begin{array}{l}\text { Análise de alocação de riscos } \\
\text { do empreendimento }\end{array}$ \\
\hline & Viabilidade econômica & \\
\hline & $\begin{array}{l}\text { Impacto orçamentário de longo } \\
\text { prazo, flexibilidade contratual } \\
\text { em caso de frustração de }\end{array}$ & \\
\hline & financiamento & \\
\hline Onteresses dos stakeholders & Operacional & \\
\hline Demanda & Mistura de partes de projetos & \\
\hline
\end{tabular}




\begin{tabular}{ll}
\hline \multicolumn{1}{c}{ Jurídico } & \multicolumn{1}{c}{ Financeiro } \\
\hline Participação popular & $\begin{array}{l}\text { capacidade de atualização da } \\
\text { tecnologia ao longo da PPP/PFI }\end{array}$ \\
\hline Expertise para execução & $\begin{array}{l}\text { Critérios de Julgamento pré- } \\
\text { estabelecidos no edital. Para } \\
\text { tentar objetivar a avaliação }\end{array}$ \\
\hline $\begin{array}{l}\text { critérios de transparência na } \\
\text { relação Poder Público - }\end{array}$ & Capacidade técnica para avaliar \\
\hline $\begin{array}{l}\text { PMlstas } \\
\text { Interesses difusos, como } \\
\text { conservação e } \\
\text { ambiente }\end{array}$ & $\begin{array}{l}\text { Racionalidade e exposição } \\
\text { previa do que será avaliado }\end{array}$ \\
\hline $\begin{array}{l}\text { Maximização do interesse } \\
\text { do benefício à população }\end{array}$ & Experiência com o tema \\
\hline & PMI mais fundamentadas \\
\hline & A visão geral do projeto \\
\hline & $\begin{array}{l}\text { Que as licitantes tenham } \\
\text { certificados com notas técnicas } \\
\text { de agencias de saneamento, } \\
\text { antes de participarem do } \\
\text { processo. }\end{array}$ \\
\hline
\end{tabular}

Fonte: Organizado pelo Autor.

Um dos objetivos da pesquisa era verificar quão adequado, ou não, o Value for Money - VfM seria como critério de suficiência para garantir que o melhor projeto seja escolhido na fase de eleição da PMI cuja estrutura moldará o edital da PPP/PFI. Comprovando assim a lacuna de pesquisa.

A análise VfM pode ser utilizada durante todas as fases do desenvolvimento do projeto, entretanto, atualmente é usada principalmente durante o período ex ante a elaboração física do projeto (PODANI; SCHMERA, 2006) e essencialmente sob o viés financeiro. 60\% da amostra discordam (11,1\% "Discorda Totalmente" e 48,9\% "Discorda") da suficiência deste critério para a escolha do melhor projeto. Contra, 17,8\% que "Concorda" e 6,7\% "Concorda Totalmente" na suficiência deste. 15,6\% dos questionados optaram por posicionamento neutro.

A Survey avaliou o grau de detalhe e clareza dos escopos dos projetos de PMI. As respostas foram ordenadas por grau de clareza na definição do escopo e flexibilidade. Grekousis (2013) enfatiza como fator chave de impacto em projetos de PPP/PFI a definição do escopo de projetos. $62,2 \%$ entendem que os escopos das PMI são mal elaborados, contra 4,4\% que julgam estes como bem definidos. 6,7\% optaram por não opinar neste quesito. $26,7 \%$ dos especialistas consultados consideram que os escopos dos projetos aos quais tiveram acesso mostraram-se flexíveis e ajustáveis as inovações tecnológicas e as necessidades não observadas 
a priori ao tempo da contratação, sendo estes ajustados ao longo do curso do contrato.

\subsection{FATORES CRÍTICOS E PROPRIEDADES DE PMIS IDENTIFICADAS}

Uma das questões avaliadas e elencadas na revisão bibliográfica foram os Fatores Críticos para o Sucesso - FCS de projetos de PMIs e os reflexos destes nos FCS de PPP/PFI. Partiu-se da premissa de interdependência dos FCSs, sendo estes organizados e agrupados ${ }^{42}$ em 24 características de impacto positivo e 21 características de impacto negativo.

Quadro 32 - Fatores críticos para o sucesso - FCSs (a)

\begin{tabular}{|c|c|c|c|}
\hline Posição & Positivos & Posição & Negativos \\
\hline 1 & $\begin{array}{l}\text { Propostas contrárias } \\
\text { apresentadas }\end{array}$ & 1 & $\begin{array}{l}\text { Propostas contrárias } \\
\text { apresentadas }\end{array}$ \\
\hline 2 & $\begin{array}{l}\text { Montante de tempo e } \\
\text { informação disponível }\end{array}$ & 2 & $\begin{array}{l}\text { Aprovação preliminar da } \\
\text { proposta }\end{array}$ \\
\hline 3 & $\begin{array}{l}\text { Aprovação preliminar da } \\
\text { proposta }\end{array}$ & 3 & $\begin{array}{l}\text { Negociação e finalização do } \\
\text { projeto }\end{array}$ \\
\hline 4 & $\begin{array}{l}\text { Negociação e finalização do } \\
\text { projeto }\end{array}$ & 4 & Valor do bônus \\
\hline 5 & Valor do bônus & 5 & $\begin{array}{l}\text { Estabelecimento do preço } \\
\text { ideal }\end{array}$ \\
\hline 6 & $\begin{array}{l}\text { Estabelecimento do preço } \\
\text { ideal }\end{array}$ & 6 & Transparência do processo \\
\hline 7 & Transparência do processo & 7 & Publicação para licitação \\
\hline 8 & Publicação para licitação & 8 & $\begin{array}{l}\text { Concessão apropriada de } \\
\text { contratos e acordos }\end{array}$ \\
\hline 9 & $\begin{array}{l}\text { Concessão apropriada de } \\
\text { contratos e acordos }\end{array}$ & 9 & $\begin{array}{l}\text { Alinhamento estratégico de } \\
\text { metas e objetivos }\end{array}$ \\
\hline 10 & $\begin{array}{l}\text { Alinhamento estratégico de } \\
\text { metas e objetivos }\end{array}$ & 10 & $\begin{array}{l}\text { Papéis e responsabilidades } \\
\text { claramente definidos dos } \\
\text { participantes do projeto }\end{array}$ \\
\hline 11 & $\begin{array}{l}\text { Definição clara e } \\
\text { documentada de escopo do } \\
\text { projeto }\end{array}$ & 11 & $\begin{array}{l}\text { Evitar duplicações de } \\
\text { instalações similares }\end{array}$ \\
\hline 12 & $\begin{array}{l}\text { Papéis e responsabilidades } \\
\text { claramente definidos dos } \\
\text { participantes do projeto }\end{array}$ & 12 & Apoio à aquisição de terras \\
\hline 13 & $\begin{array}{l}\text { Evitar duplicações de } \\
\text { instalações similares }\end{array}$ & 13 & $\begin{array}{l}\text { Aprovação e expedição de } \\
\text { permissões }\end{array}$ \\
\hline
\end{tabular}

Continua

Conclusão

42 Decorrente das integrações dos FCSs de PPP/PFI e PMI que convergiram nas categorias de Micro e Macro nível (tabelas 23 a 28). 


\begin{tabular}{|c|c|c|c|}
\hline Posição & Positivos & Posição & Negativos \\
\hline 14 & Apoio a aquisição de terras & 14 & Subsídios construtivos \\
\hline 15 & $\begin{array}{l}\text { Aprovação e expedição de } \\
\text { permissões }\end{array}$ & 15 & $\begin{array}{l}\text { Coordenação da Sociedade } \\
\text { de Propósito Específico } \\
\text { com investidores } \\
\text { financeiros }\end{array}$ \\
\hline 16 & Subsídios construtivos & 16 & $\begin{array}{l}\text { Coordenação da Sociedade } \\
\text { de Propósito Específico } \\
\text { com arquitetos e } \\
\text { engenheiros }\end{array}$ \\
\hline 17 & $\begin{array}{l}\text { Coordenação da Sociedade } \\
\text { de Propósito Específico com } \\
\text { investidores financeiros }\end{array}$ & 17 & $\begin{array}{l}\text { Coordenação da Sociedade } \\
\text { de Propósito Específico } \\
\text { com supervisores e } \\
\text { inspetores dos construtores }\end{array}$ \\
\hline 18 & $\begin{array}{l}\text { Coordenação da Sociedade } \\
\text { de Propósito Específico com } \\
\text { arquitetos e engenheiros }\end{array}$ & 18 & $\begin{array}{l}\text { Coordenação da Sociedade } \\
\text { de Propósito Específico } \\
\text { com o construtor }\end{array}$ \\
\hline 19 & $\begin{array}{l}\text { Coordenação da Sociedade } \\
\text { de Propósito Específico com } \\
\text { supervisores e inspetores } \\
\text { dos construtores }\end{array}$ & 19 & $\begin{array}{l}\text { Contramedida para evitar } \\
\text { queixas públicas }\end{array}$ \\
\hline 20 & Boa governança & 20 & $\begin{array}{l}\text { Rendimento mínimo } \\
\text { garantido }\end{array}$ \\
\hline 21 & $\begin{array}{l}\text { Coordenação da Sociedade } \\
\text { de Propósito Específico com } \\
\text { o construtor }\end{array}$ & 21 & $\begin{array}{l}\text { Informações disponíveis } \\
\text { inconsistentes }\end{array}$ \\
\hline 22 & $\begin{array}{l}\text { Contramedida para evitar } \\
\text { queixas públicas }\end{array}$ & & \\
\hline 23 & $\begin{array}{l}\text { Rendimento mínimo } \\
\text { garantido }\end{array}$ & & \\
\hline 24 & $\begin{array}{l}\text { Alocação apropriada de risco } \\
\text { entre o setor público e } \\
\text { privado }\end{array}$ & & \\
\hline
\end{tabular}

Fonte: Elaborado pelo Autor.

Apresentada a relação de FCSs aos avaliadores, foi pedido para que os 5 (cinco) mais críticos tanto positivos como negativos fossem ranqueados, atribuindo o grau de relevância do primeiro ao quinto colocado. Os FCSs foram ordenados em postos de posição encontrando os seguintes resultados do grupo amostral. 


\begin{tabular}{|c|c|c|c|}
\hline $\begin{array}{l}\text { Posto de } \\
\text { Posição }\end{array}$ & Freq. & $\%$ & Descrição \\
\hline 1 & 14 & 31,1 & Transparência do processo \\
\hline 2 & 7 & 15,6 & $\begin{array}{l}\text { Definição clara e documentada de escopo do } \\
\text { projeto }\end{array}$ \\
\hline 3 & 6 & 13,3 & Montante de tempo e informação disponível \\
\hline 4 & 6 & 13,3 & $\begin{array}{l}\text { Alocação apropriada de risco entre o setor público } \\
\text { e privado }\end{array}$ \\
\hline \multirow[t]{2}{*}{5} & 5 & 11,1 & Propostas contrárias apresentadas \\
\hline & \multicolumn{3}{|r|}{ 2 FCS Positivo } \\
\hline $\begin{array}{l}\text { Posto de } \\
\text { Posição }\end{array}$ & Freq. & $\%$ & Descrição \\
\hline 1 & 8 & 17,8 & $\begin{array}{l}\text { Alocação apropriada de risco entre o setor } \\
\text { público e privado }\end{array}$ \\
\hline 2 & 6 & 13,3 & $\begin{array}{l}\text { Papéis e responsabilidades claramente definidos } \\
\text { dos participantes do projeto }\end{array}$ \\
\hline 3 & 5 & 11,1 & Montante de tempo e informação disponível \\
\hline 4 & 4 & 8,9 & Transparência do processo \\
\hline \multirow[t]{2}{*}{5} & 4 & 8,9 & Alinhamento estratégico de metas e objetivos \\
\hline & \multicolumn{3}{|r|}{ 3o FCS Positivo } \\
\hline $\begin{array}{l}\text { Posto de } \\
\text { Posição }\end{array}$ & Freq. & $\%$ & Descrição \\
\hline 1 & 8 & 17,8 & $\begin{array}{l}\text { Papéis e responsabilidades claramente } \\
\text { definidos dos participantes do projeto }\end{array}$ \\
\hline 2 & 6 & 13,3 & $\begin{array}{l}\text { Definição clara e documentada de escopo do } \\
\text { projeto }\end{array}$ \\
\hline 3 & 5 & 11,1 & Montante de tempo e informação disponível \\
\hline 4 & 5 & 11,1 & Aprovação preliminar da proposta \\
\hline \multirow[t]{2}{*}{5} & 5 & 11,1 & Transparência do processo \\
\hline & \multicolumn{3}{|r|}{ 4으 FCS Positivo } \\
\hline $\begin{array}{l}\text { Posto de } \\
\text { Posição }\end{array}$ & Freq. & $\%$ & Descrição \\
\hline 1 & 8 & 17,8 & Transparência do processo \\
\hline 2 & 7 & 15,6 & $\begin{array}{l}\text { Alocação apropriada de risco entre o setor público } \\
\text { e privado }\end{array}$ \\
\hline 3 & 4 & 8,9 & Propostas contrárias apresentadas \\
\hline 4 & 4 & 8,9 & Montante de tempo e informação disponível \\
\hline \multirow[t]{2}{*}{5} & 4 & 8,9 & Publicação para licitação \\
\hline & \multicolumn{3}{|r|}{ 5o FCS Positivo } \\
\hline $\begin{array}{l}\text { Posto de } \\
\text { Posição }\end{array}$ & Freq. & $\%$ & Descrição \\
\hline 1 & 7 & 15,6 & Boa governança \\
\hline 2 & 6 & 13,3 & Montante de tempo e informação disponível \\
\hline 3 & 6 & 13,3 & $\begin{array}{l}\text { Papéis e responsabilidades claramente } \\
\text { definidos dos participantes do projeto }\end{array}$ \\
\hline 4 & 4 & 8,9 & Publicação para licitação \\
\hline 5 & 3 & 6,7 & Aprovação preliminar da proposta \\
\hline
\end{tabular}

Fonte: Elaborado pelo Autor.

Os Fatores Críticos para o sucesso Negativos tiveram o mesmo tipo de abordagem sendo ordenados também por escala de relevância. Daquele que 
causaria o efeito mais nefasto no projeto de PMI se não fosse observado ao quinto mais prejudicial para a evolução da PPP/PFI.

Tabela 5 - Postos de posição FCSs negativos

\begin{tabular}{|c|c|c|c|c|}
\hline \multicolumn{5}{|r|}{ 1 FCS Negativo } \\
\hline $\begin{array}{l}\text { Posto de } \\
\text { Posição }\end{array}$ & \multicolumn{2}{|c|}{ Freq. $\%$} & \multicolumn{2}{|r|}{ Descrição } \\
\hline 1 & \multicolumn{2}{|c|}{18} & \multicolumn{2}{|c|}{ Informações disponíveis inconsistentes } \\
\hline 2 & \multicolumn{2}{|c|}{14} & \multicolumn{2}{|c|}{ Propostas contrárias apresentadas } \\
\hline 3 & \multicolumn{2}{|c|}{5} & \multicolumn{2}{|c|}{ Apoio a aquisição de terras } \\
\hline 4 & 2 & 4,4 & \multicolumn{2}{|c|}{ Estabelecimento do preço ideal } \\
\hline 5 & 2 & 4,4 & \multicolumn{2}{|c|}{ Rendimento mínimo garantido } \\
\hline \multicolumn{5}{|r|}{ 2 FCS Negativo } \\
\hline $\begin{array}{l}\text { Posto de } \\
\text { Posição }\end{array}$ & Freq. & q. $\%$ & \multicolumn{2}{|r|}{ Descrição } \\
\hline 1 & 8 & 18 & \multicolumn{2}{|r|}{ Propostas contrárias apresentadas } \\
\hline 2 & 7 & 16 & \multicolumn{2}{|c|}{ Aprovação preliminar da proposta } \\
\hline 3 & 5 & 11 & \multicolumn{2}{|c|}{ Rendimento mínimo garantido } \\
\hline 4 & 4 & 8,9 & \multicolumn{2}{|c|}{ Valor do bônus } \\
\hline 5 & 4 & $8,9 \mathrm{~T}$ & \multicolumn{2}{|c|}{ Transparência do processo } \\
\hline \multicolumn{5}{|r|}{ 3ํFCS Negativo } \\
\hline $\begin{array}{l}\text { Posto de } \\
\text { Posição }\end{array}$ & Freq. & $\%$ & \multicolumn{2}{|r|}{ Descrição } \\
\hline 1 & 7 & 15,6 & \multicolumn{2}{|r|}{ Negociação e finalização do projeto } \\
\hline 2 & 6 & 13,3 & Esta & oelecimento do preço ideal \\
\hline 3 & 5 & 11,1 & Prop & ostas contrárias apresentadas \\
\hline 4 & 4 & 8,9 & $\begin{array}{l}\text { Coor } \\
\text { com }\end{array}$ & $\begin{array}{l}\text { denação da Sociedade de Propósito Específico } \\
\text { investidores financeiros }\end{array}$ \\
\hline 5 & 3 & 6,7 & Valo & do bônus \\
\hline & & & & 4ํ FCS Negativo \\
\hline $\begin{array}{l}\text { Posto de } \\
\text { Posição }\end{array}$ & Freq. & $\%$ & & Descrição \\
\hline 1 & 9 & 20 & & Valor do bônus \\
\hline 2 & 7 & 15,6 & Apro & vação preliminar da proposta \\
\hline 3 & 4 & 8,9 & Prop & ostas contrárias apresentadas \\
\hline 4 & 3 & 6,7 & Neg & ciação e finalização do projeto \\
\hline 5 & 3 & 6,7 & Apoi & a aquisição de terras \\
\hline & & & & 5 FCS Negativo \\
\hline $\begin{array}{l}\text { Posto } \\
\text { Posiçã }\end{array}$ & & Freq. & $\%$ & Descrição \\
\hline 1 & & 10 & 22,2 & Estabelecimento do preço ideal \\
\hline 2 & & 9 & 20 & Aprovação preliminar da proposta \\
\hline 3 & & 7 & 15,6 & Negociação e finalização do projeto \\
\hline 4 & & 4 & 8,9 & Valor do bônus \\
\hline 5 & & 4 & 8,9 & Subsídios construtivos \\
\hline
\end{tabular}

Fonte: Elaborado pelo Autor.

Posterior à análise das posições, os 24 FCSs positivos e 21 FCSs negativos foram submetidos a Análise Hierárquica de Clusters [Agrupamento], organizados e 
interpretados foram estabelecidos 09 agrupamentos e armazenamento nos respectivos centroides (tomando por intervalo a distância euclidiana quadrática), sem a transformação de valores considerando que estes já estão padronizados em números naturais e inteiros.

Os FCSs positivos plotados no gráfico 6 resultaram na aglomeração de coeficientes por meio da Stopping Rules Hierarchical Cluster Analysis (PHIPPS, 1971), representando o montante de heterogeneidade encontrada na solução de cluster, em que as barras significam o grau de alteração dos coeficientes na tabela de aglomeração, com o respectivo estágio de parada.

\section{Gráfico 6 - Stopping rule analysis FCSs positivos}

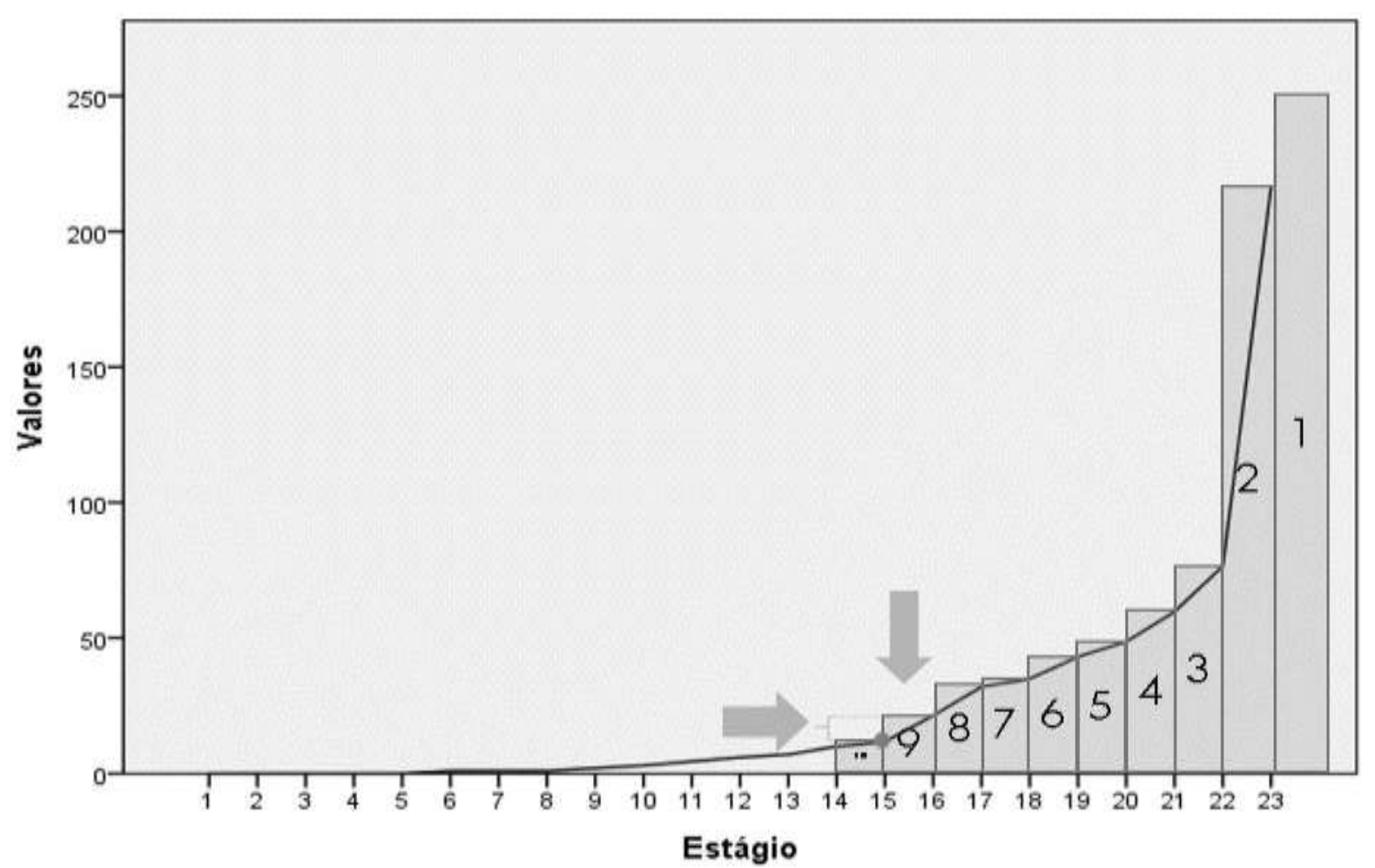

Fonte: Elaborado pelo Autor.

Observada a melhor solução de heterogeneidade, 9 (nove) agrupamentos clusters com soluções distintas foram encontradas, a numeração que antecede o fator crítico indica a ordem na lista apresentada aos entrevistados: 
Figura 15 - Agrupamento de FCSs positivos

\begin{tabular}{|}
\hline 1 - Cluster: Transparência \\
\hline 7 & Transparência do processo \\
\hline 2 - Cluster: Risco \\
\hline 24 & $\begin{array}{l}\text { Alocação apropriada de risco entre o } \\
\text { setor público e privado }\end{array}$ \\
\hline
\end{tabular}

\begin{tabular}{|c|l|}
\hline 3 - Cluster: Responsabilidade \\
\hline 12 & $\begin{array}{l}\text { Papéis e responsabilidades } \\
\text { claramente definidos dos } \\
\text { participantes do projeto }\end{array}$ \\
\hline
\end{tabular}

\begin{tabular}{|c|l|}
\hline 4 - Cluster: Informações \\
\hline 2 & $\begin{array}{l}\text { Montante de tempo e informação } \\
\text { disponível }\end{array}$ \\
\hline
\end{tabular}

\section{5 - Cluster: Escopo}

11 Definição clara e documentada de escopo do projeto

\section{6 - Cluster: Concorrência \\ 1 Propostas contrárias apresentadas}

\begin{tabular}{|c|l|}
\hline 7 - Cluster: Governança \\
\hline 20 & Boa governança \\
\hline
\end{tabular}

\begin{tabular}{|c|l|}
\hline \multicolumn{2}{|l|}{ - Cluster: Atos Jurídicos } \\
\hline 8 & Publicação para licitação \\
\hline 9 & Concessão apropriada de contratos e acordos \\
\hline 3 & Aprovação preliminar da proposta \\
\hline 10 & Alinhamento estratégico de metas e objetivos \\
\hline
\end{tabular}

\begin{tabular}{|c|l|}
\hline 9 - Cluster: Coordenação de Stakeholders \\
\hline 21 & $\begin{array}{l}\text { Coordenação da Sociedade de Propósito } \\
\text { Específico com o construtor }\end{array}$ \\
\hline 22 & Contramedida para evitar queixas públicas \\
\hline 14 & Apoio a aquisição de terras \\
\hline 18 & $\begin{array}{l}\text { Coordenação da Sociedade de Propósito } \\
\text { Específico com arquitetos e engenheiros }\end{array}$ \\
\hline 19 & $\begin{array}{l}\text { Coordenação da Sociedade de Propósito } \\
\text { Específico com supervisores e inspetores dos } \\
\text { construtores }\end{array}$ \\
\hline 17 & $\begin{array}{l}\text { Coordenação da Sociedade de Propósito } \\
\text { Específico com investidores financeiros }\end{array}$ \\
\hline 16 & Subsídios construtivos \\
\hline 15 & Aprovação e expedição de permissões \\
\hline 13 & Evitar duplicações de instalações similares \\
\hline 6 & Estabelecimento do preço ideal \\
\hline 23 & Rendimento mínimo garantido \\
\hline 5 & Valor do bônus \\
\hline 4 & Negociação e finalização do projeto \\
\hline
\end{tabular}

Fonte: Elaborado pelo Autor.

A análise de cluster das matrizes de distância (dissimilaridade) tem sido 0 procedimento mais utilizado para exibir estruturas de distância em termos de árvores (MASON et al., 2005) cuja topologia é definida como a relação de padrão de ramificação entre os fatores (MOUCHET et al., 2008).

Os resultados mostraram que o comprimento do dendograma exposto a seguir e o número da FCSs estão positivamente correlacionados. Em geral, os valores de diversidade funcional provenientes de diferentes números de FCSs só podem ser comparados se alguma normalização for utilizada para explicar o efeito do número de Fatores Críticos subjacente (CRUZ; MARQUES, 2013) não sendo estes objetos enquadrados no recorte do trabalho. Tal verificação analítica é ensejo para projetos futuros. 
Gráfico 7 - Dendograma agrupamentos positivos

\section{Dendrograma usando ligação de centroide}

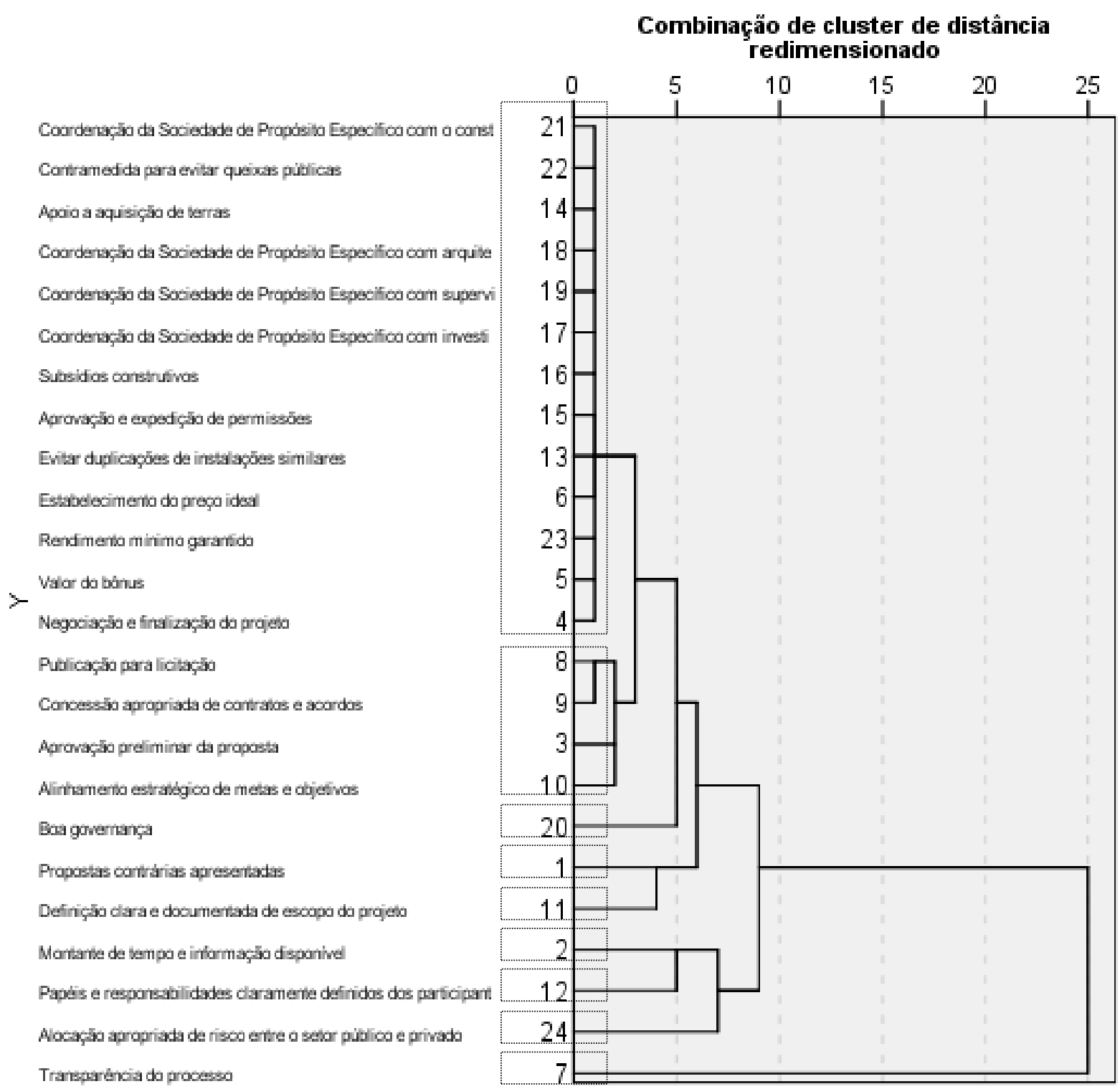

Fonte: Elaborado pelo Autor.

Outro recorte foi a análise dos FCS - Negativos, pela Stopping Rules Hierarchical Cluster Analysis que resultou em 8 (oito) agrupamentos clusters, conforme observado no Gráfico 8. 


\section{Planejamento de aglomeração Coeficientes}

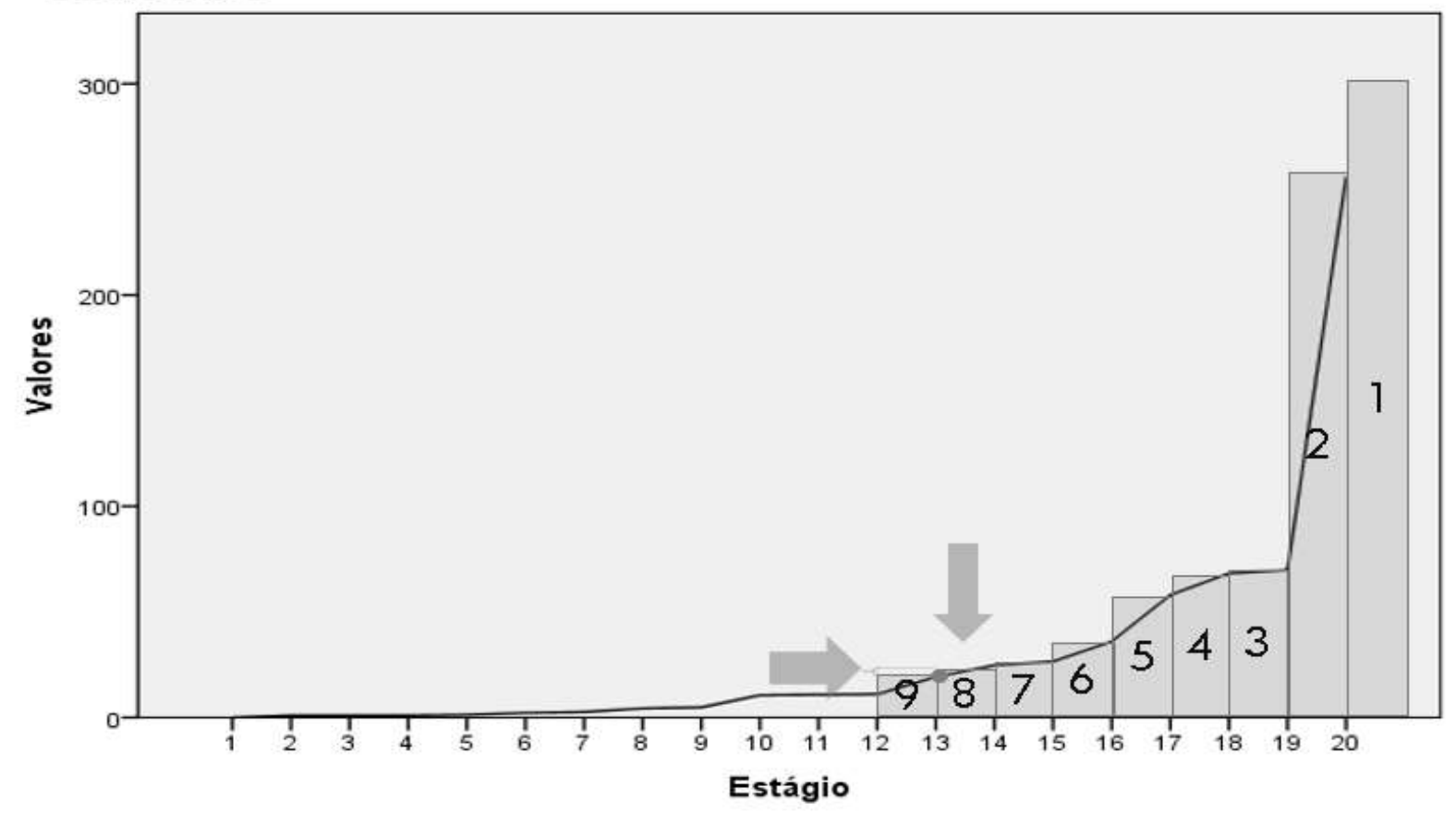

Fonte: Elaborado pelo Autor.

A melhor solução de heterogeneidade para os FCSs - Negativos foi com 8 (oito) agrupamentos clusters, conforme observado na figura 16, seguindo o mesmo princípio dos FCSs - positivos.

Figura 16 - Agrupamento de FCSs negativos

\section{1 - Cluster: Informações Inconsistentes}

21 Informações disponíveis inconsistentes

\begin{tabular}{|c|l|}
\hline 2 - & Cluster: Concorrência \\
\hline 1 & Propostas contrárias apresentadas \\
\hline
\end{tabular}

\section{3 - Cluster: Bônus}

4 Valor do Bônus

\section{4 - Cluster: Aprovação preliminar da proposta \\ 2 Aprovação preliminar da proposta}

\section{5 - Cluster: Negociação do Valor}

3 Negociação e finalização do projeto

4 Estabelecimento do preço ideal

\section{6 - Cluster: Aquisições}

12 Apoio a aquisição de terras

Fonte: Elaborado pelo Autor.

\section{7 - Cluster: Rendimentos Mínimos}

20 Rendimento mínimo garantido

\begin{tabular}{|c|l|}
\hline 8 - & Cluster: Coordenação de Stakeholder (Partes Interessadas) \\
\hline 10 & $\begin{array}{l}\text { Papéis e responsabilidades claramente definidos dos } \\
\text { participantes do projeto }\end{array}$ \\
\hline 19 & Contramedida para evitar queixas públicas \\
\hline 9 & Alinhamento estratégico de metas e objetivos \\
\hline 8 & Concessão apropriada de contratos e acordos \\
\hline 17 & $\begin{array}{l}\text { Coordenação da Sociedade de Propósito Específico com } \\
\text { supervisores e inspetores dos construtores }\end{array}$ \\
\hline 11 & Evitar duplicações de instalações similares \\
\hline 18 & $\begin{array}{l}\text { Coordenação da Sociedade de Propósito Específico com o } \\
\text { construtor }\end{array}$ \\
\hline 16 & $\begin{array}{l}\text { Coordenação da Sociedade de Propósito Específico com } \\
\text { arquitetos e engenheiros }\end{array}$ \\
\hline 13 & Aprovação e expedição de permissões \\
\hline 7 & Pubicação para a licitação \\
\hline 6 & Transparência do processo \\
\hline 15 & $\begin{array}{l}\text { Coordenação da Sociedade de Propósito Específico com } \\
\text { investidores financeiros }\end{array}$ \\
\hline 14 & Subsídios construtivos \\
\hline
\end{tabular}


Os Fatores Críticos Negativos identicamente ao processo anterior, tiveram as distâncias euclidianas redimensionadas possibilitando a observação dos núcleos agrupados.

\section{Gráfico 9 - Dendograma agrupamentos negativos}

\section{Dendrograma usando ligação de centroide}

Papeis e responsabilidades daramente dofinidas das parfoipant:

Contramedida para enitar quasas püblicas

Airnamento estrakgioo de metas a cojefivos

Concessajo apropriata de contralos e acordas

Coordersaja da Sociedade de Proposito Espection com supervi

Evitar duplicapóes de instajapojes similares

Coordaraça da Sociedade de Propásito Espacifico com a corrst

Coardaraciaja da Sociedade de Proposito Espocifoo com arquibe

Aprovaçẵo e expedçẵo de permissóes

Publicaçăo para licitaçă:

- Transparáncia da processo

Coordaração da Sociedade de Propasito Espocifico com imves?

Subsidas construfivos

Rendmerto minimo gararido

Apoio a aquisiçăo da verras

Negociacajo e finalizacão do proieto

Estabelecimerto do prepo ides

Agrovaça prelimina da proposta

Valar da bánus

Propostas contráias aresentatas

Irormapöes dsponives inconsistertes

Combinação de cluster de distância redimensionado

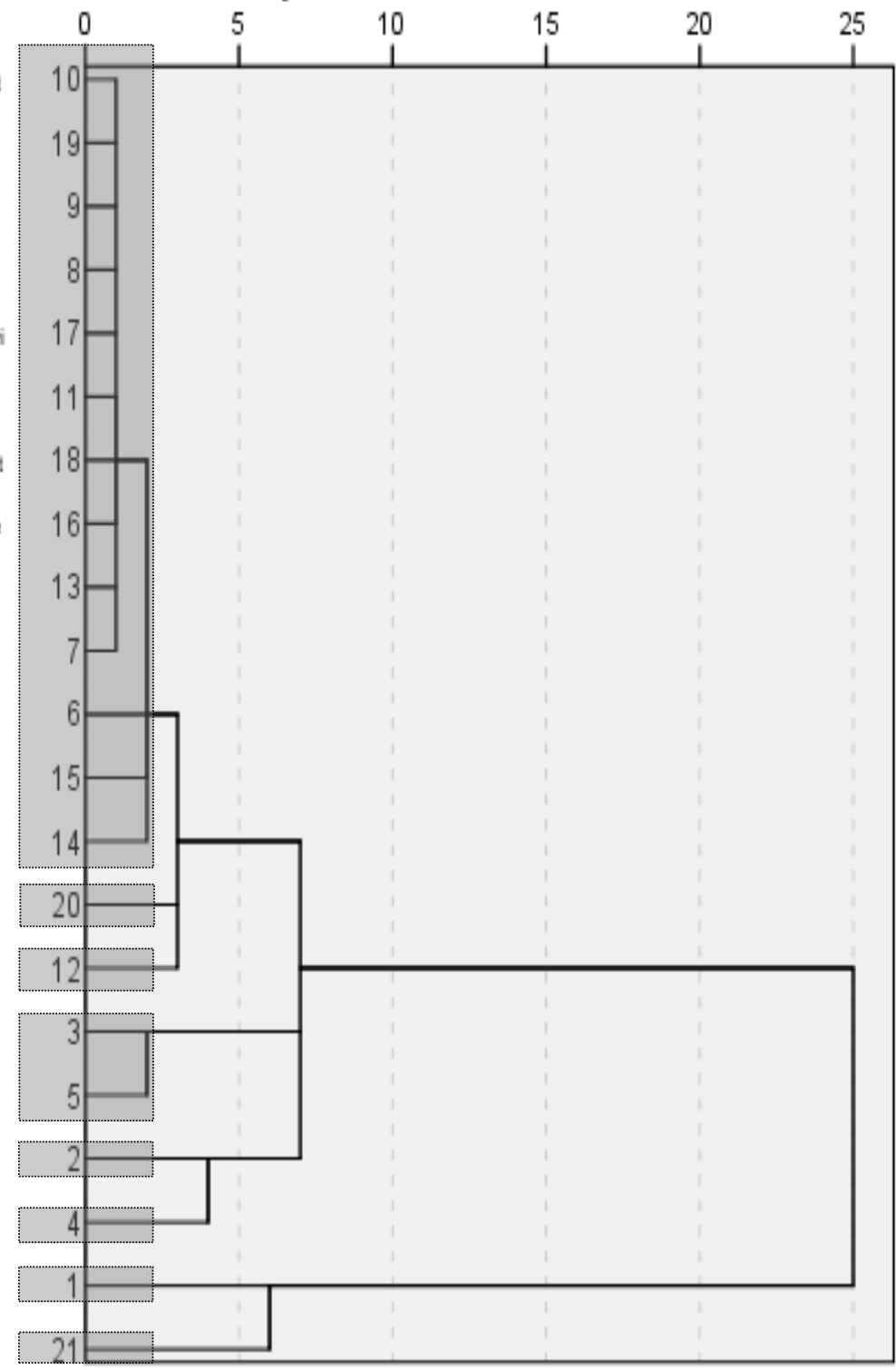

Fonte: Elaborado pelo Autor.

O conjunto de dados que compõe as variáveis "Presença de Subjetivismo nas PMIs", "Número total de PPP/PFI Gerenciadas" e "Número total de PPP/PFI Gerenciadas" foram testadas por meio da Correlação de Spearman (YUAN et al., 2009), com $P$-value $(\alpha=5 \%)$ significativo e encontrada relação monotônica descendente não linear entre as variáveis. Tal comportamento resultou em uma correlação negativa fraca, reforçando o obtido na comparação de médias e mediana, 
sendo possível rejeitar a Hipótese Nula $\left(H_{0}\right)$ : Não existe correlação entre experiência com Projetos de PPP/PFI e PMI e reconhecimento de subjetivismo nas avaliações de PMls (UNPs), mas suscitando a reflexão sob quais seriam os fatores que impactam no subjetivismo das PMls (UNPs).

Tabela 6 - Coeficiente de correlação de Spearman

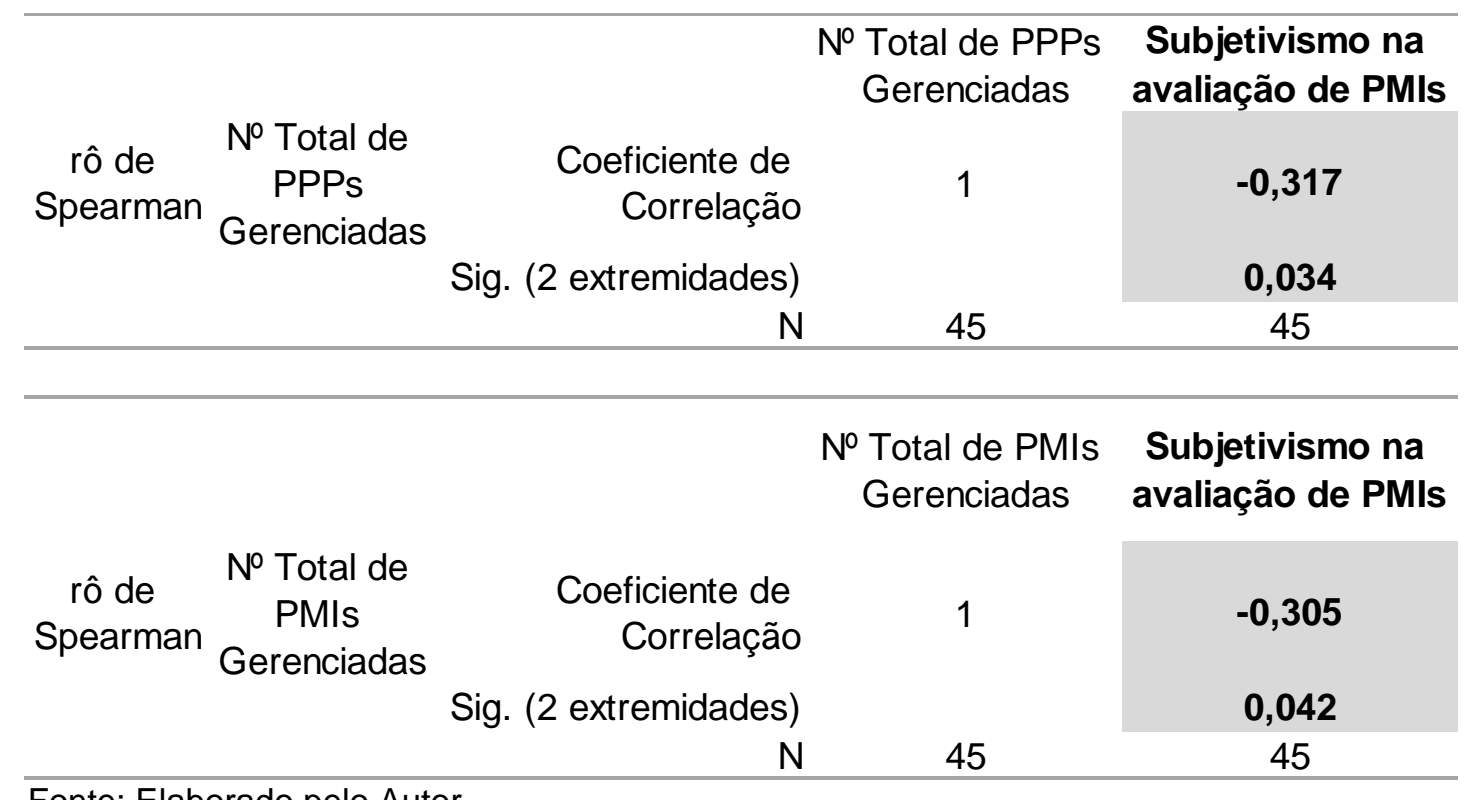

Fonte: Elaborado pelo Autor.

Outra análise contemplada no estudo foi a verificação da existência ou não de correlação entre a percepção dos respondentes sobre o atual desenho dos escopos das PMls por meio do Coeficiente de Correlação Tau b de Kendall. Neste contexto as variáveis alvo são: "Subjetivismo nas Avaliações de Projetos de PMIs" e "Escopo de PMIs".

Por meio do Coeficiente de Correlação de Tau b de Kendall, a correlação de postos de posições entre duas quantidades medidas, na qual é possível verificar a semelhança entre as ordens das observações quando classificadas por cada uma das quantidades. O índice de correlação entre as variáveis testadas será alto se as observações tiverem postos de posições semelhantes, ou seja, classificações equiparadas. Inversamente a correlação de Kendall, será baixa se a comparação dos postos de posições das variáveis comparadas apresentarem classificações distintas. Onde o coeficiente Tau b de Kendall é dado pela equação 2. 
Equação 2:

$\tau=\frac{n c-n d}{\sqrt{\left(n_{0}-n_{1}\right) *\left(n_{0}-n_{2}\right)}}$, em que:

$n$ é o número de observações da amostra,

$n c=$ Quantidade de pares concordantes e

$n d=$ Quantidade de pares discordantes.

$n_{0}$ é $n(n-1) / 2 ; n_{1}=\sum_{i} \frac{t_{i}\left(t_{i}-1\right)}{2}$ e $n_{2}=\sum_{j} \frac{w_{j}\left(u_{j}-1\right)}{2}$.

$t_{i}$ representa o número de valores empatados $i$-ésimo conjunto de empates para a primeira variável " $E$ ";

$u_{j}$ representa o número de valores empatados $i$-ésimo conjunto de empates para a segunda variável " $S$ "; Respeitando as propriedades: (i) intervalo do coeficiente $\tau,-1$ $<\tau<+1$, (ii) quanto coeficiente $=1$, indica equivalência padrão dos postos de posições das variáveis, ou seja, concordância entre os ranks das variáveis, (iii) quanto mais próximo de -1, maior será a discordância entre os postos de posições e (iv) quanto mais próximo de 0 (zero), presentará independência entre as variáveis comparadas.

O teste de hipótese do coeficiente indica se duas variáveis podem ser estatisticamente dependentes ou não se levando em conta distribuição não paramétrica e amostra relativamente pequena $(\mathrm{n}<=50$, no estudo $\mathrm{n}=45$ ) e $P$-Value $(\alpha$ $=5 \%)$, traçando como Hipótese $(H o): \nexists$ correlação entre as variáveis “( $E)$ - Escopo de PMIs" e "(S) - Subjetivismo nas Avaliações de Projetos de PMls".

Tabela 7 - Correlação tau b de Kendall

\begin{tabular}{|c|c|c|c|c|}
\hline \multirow{3}{*}{$\begin{array}{r}\text { tau_b de } \\
\text { Kendall }\end{array}$} & \multirow{3}{*}{$\begin{array}{l}\text { Escopo } \\
\text { de PMls }\end{array}$} & & $\begin{array}{c}\text { Escopo de } \\
\text { PMls }\end{array}$ & $\begin{array}{c}\text { Subjetivismo nas } \\
\text { Avaliações de Projetos } \\
\text { de PMls }\end{array}$ \\
\hline & & $\begin{array}{r}\text { Coeficiente de } \\
\text { Correlação } \\
\text { Sig. (2 extremidades) }\end{array}$ & $\begin{array}{l}1 \\
-\end{array}$ & $\begin{array}{c}0,267 \\
0,04759\end{array}$ \\
\hline & & $\mathrm{N}$ & 45 & 45 \\
\hline
\end{tabular}

Fonte: Elaborado pelo Autor.

Resultando em correlação fraca e $P$-Value significativo, reforçando o obtido na tabela de referência cruzada, sendo possível rejeitar $\left(H_{0}\right)$ apontando o grau de 
definição do escopo $(E)$ fator de impacto no $(S)$ subjetivismo das PMls (UNPs), sendo este um dos fatores preditivos, mas não determinante.

A tabela de referência cruzada da argumentação relativa a mensuração do grau de subjetivismo de avaliação dos escopos do projeto e o grau de clareza destes resultou em respostas centradas em concordância forte para o grau de subjetivismo nas avaliações e escopos poucos definidos.

Tabela 8 - Referência cruzada de subjetivismo ${ }^{43}$

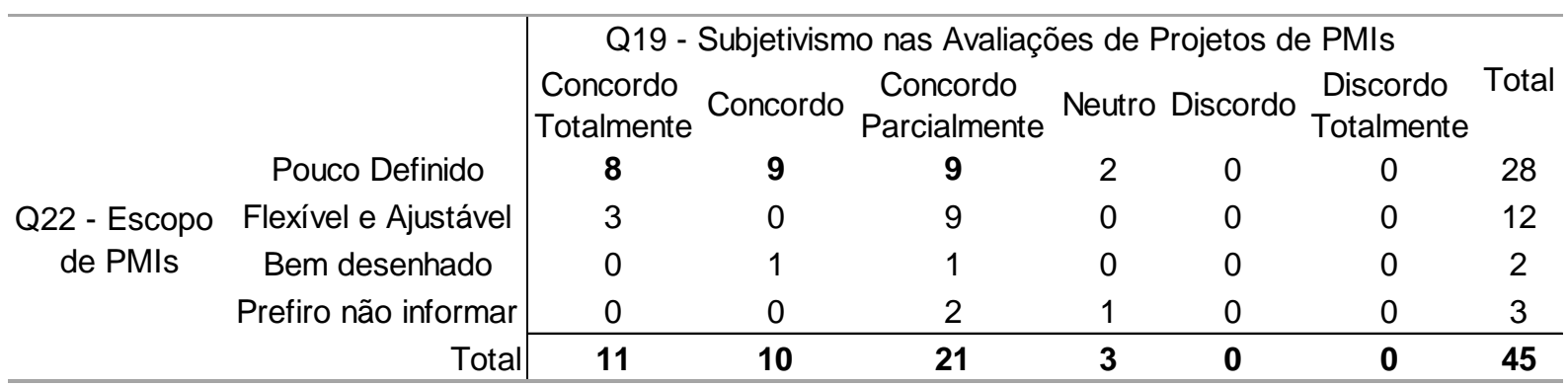

Fonte: Elaborado pelo Autor.

As Propriedades de Visão de Produto foram organizadas nas tabelas 9 e 10 e ilustradas pelos respectivos gráficos 10 e 11, com os postos de posições de acordo com o grau de relevância atribuído pelos respondentes a melhoraria identificada nos procedimentos de avaliação dos Projetos de PMI (UNP) submetidos aos entes concedentes. É possível observar notadamente a forte tendência dos respondentes as propriedades Clareza e Concisão, no primeiro e segundo posto de posição e um acentuado preterimento as posições finais as propriedades relacionadas a flexibilidade e acessibilidade.

${ }^{43}$ Nas Avaliações de PMls e Escopo de PMls. 
Tabela $9-1^{\circ}$ ao $5^{\circ}$ Posto de relevância das propriedades de visão do produto

\begin{tabular}{|c|c|c|c|c|c|}
\hline \multirow[b]{2}{*}{ Propriedade } & \multicolumn{5}{|c|}{ Número de Incidência ao Posto de Posição } \\
\hline & $\begin{array}{l}1^{\circ} \text { Posto de } \\
\text { Posição }\end{array}$ & $\begin{array}{l}2^{\circ} \text { Posto de } \\
\text { Posição }\end{array}$ & $\begin{array}{l}3^{\circ} \text { Posto de } \\
\text { Posição }\end{array}$ & $\begin{array}{l}4^{\circ} \text { Posto de } \\
\text { Posição }\end{array}$ & $\begin{array}{l}5^{\circ} \text { Posto de } \\
\text { Posição }\end{array}$ \\
\hline Clareza & 28 & 13 & 5 & 2 & 1 \\
\hline Concisão & 2 & 15 & 12 & 4 & 5 \\
\hline Priorizadora & 2 & 7 & 10 & 13 & 4 \\
\hline Comunicadora & 0 & 2 & 2 & 9 & 16 \\
\hline Antecipadora & 0 & 0 & 3 & 2 & 9 \\
\hline Alinhado com a estratégia & 12 & 6 & 2 & 6 & 4 \\
\hline $\begin{array}{l}\text { Metafórica [Compreensão } \\
\text { intuitiva de objetos] }\end{array}$ & 0 & 0 & 0 & 0 & 0 \\
\hline $\begin{array}{l}\text { Análoga [Que converta o } \\
\text { intuitivo em explícito] }\end{array}$ & 0 & 0 & 5 & 1 & 2 \\
\hline Acessível & 1 & 1 & 3 & 5 & 3 \\
\hline Flexível & 0 & 1 & 3 & 3 & 1 \\
\hline
\end{tabular}

Fonte: Elaborado pelo Autor.

Gráfico $10-1$ ao 5을 Posto de relevância das propriedades de visão do produto

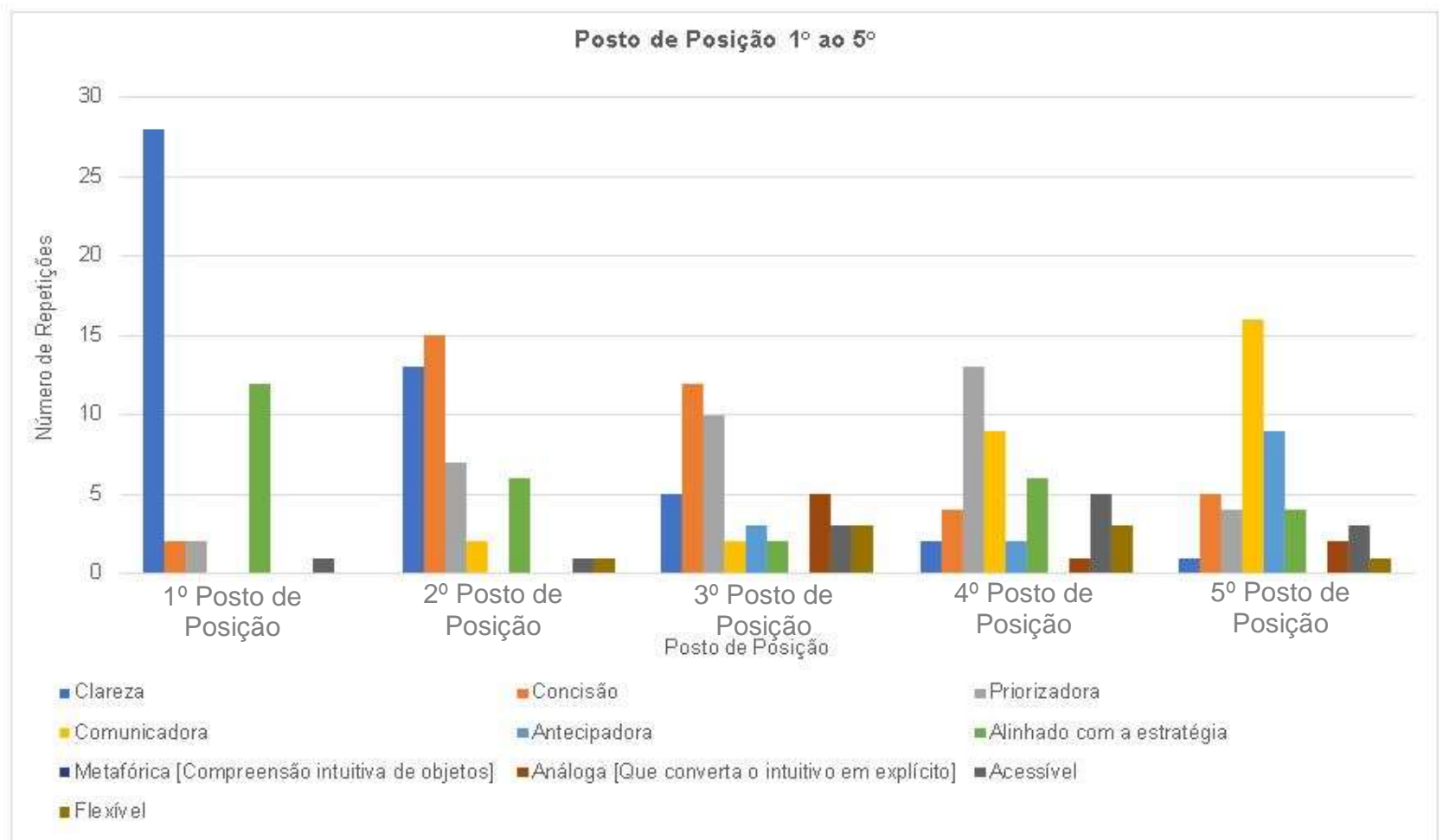

Fonte: Elaborado pelo Autor. 
Tabela $10-6^{\circ}$ ao $10^{\circ}$ Posto de relevância das propriedades de visão do produto

\begin{tabular}{|c|c|c|c|c|c|}
\hline \multirow[b]{2}{*}{ Propriedade } & \multicolumn{5}{|c|}{ Número de Incidência ao Posto de Posição } \\
\hline & $\begin{array}{l}6^{\circ} \text { Posto de } \\
\text { Posição }\end{array}$ & $\begin{array}{l}7^{\circ} \text { Posto de } \\
\text { Posição }\end{array}$ & $\begin{array}{l}8^{\circ} \text { Posto de } \\
\text { Posição }\end{array}$ & $\begin{array}{l}9^{\circ} \text { Posto de } \\
\text { Posição }\end{array}$ & $\begin{array}{l}10^{\circ} \text { Posto de } \\
\text { Posição }\end{array}$ \\
\hline Clareza & 1 & 1 & 1 & 1 & 1 \\
\hline Concisão & 3 & 0 & 1 & 2 & 0 \\
\hline Priorizadora & 5 & 3 & 1 & 0 & 0 \\
\hline Comunicadora & 5 & 8 & 2 & 0 & 0 \\
\hline Antecipadora & 10 & 11 & 6 & 2 & 1 \\
\hline Alinhado com a estratégia & 7 & 3 & 3 & 0 & 0 \\
\hline $\begin{array}{l}\text { Metafórica [Compreensão } \\
\text { intuitiva de objetos] }\end{array}$ & 2 & 11 & 11 & 10 & 9 \\
\hline $\begin{array}{l}\text { Análoga [Que converta o } \\
\text { intuitivo em explícito] }\end{array}$ & 2 & 3 & 13 & 12 & 7 \\
\hline Acessível & 6 & 2 & 3 & 14 & 7 \\
\hline Flexível & 4 & 3 & 4 & 4 & 20 \\
\hline
\end{tabular}

Fonte: Elaborado pelo Autor.

Gráfico $11-6^{\circ}$ ao $10^{\circ}$ Posto de relevância das propriedades de visão do produto

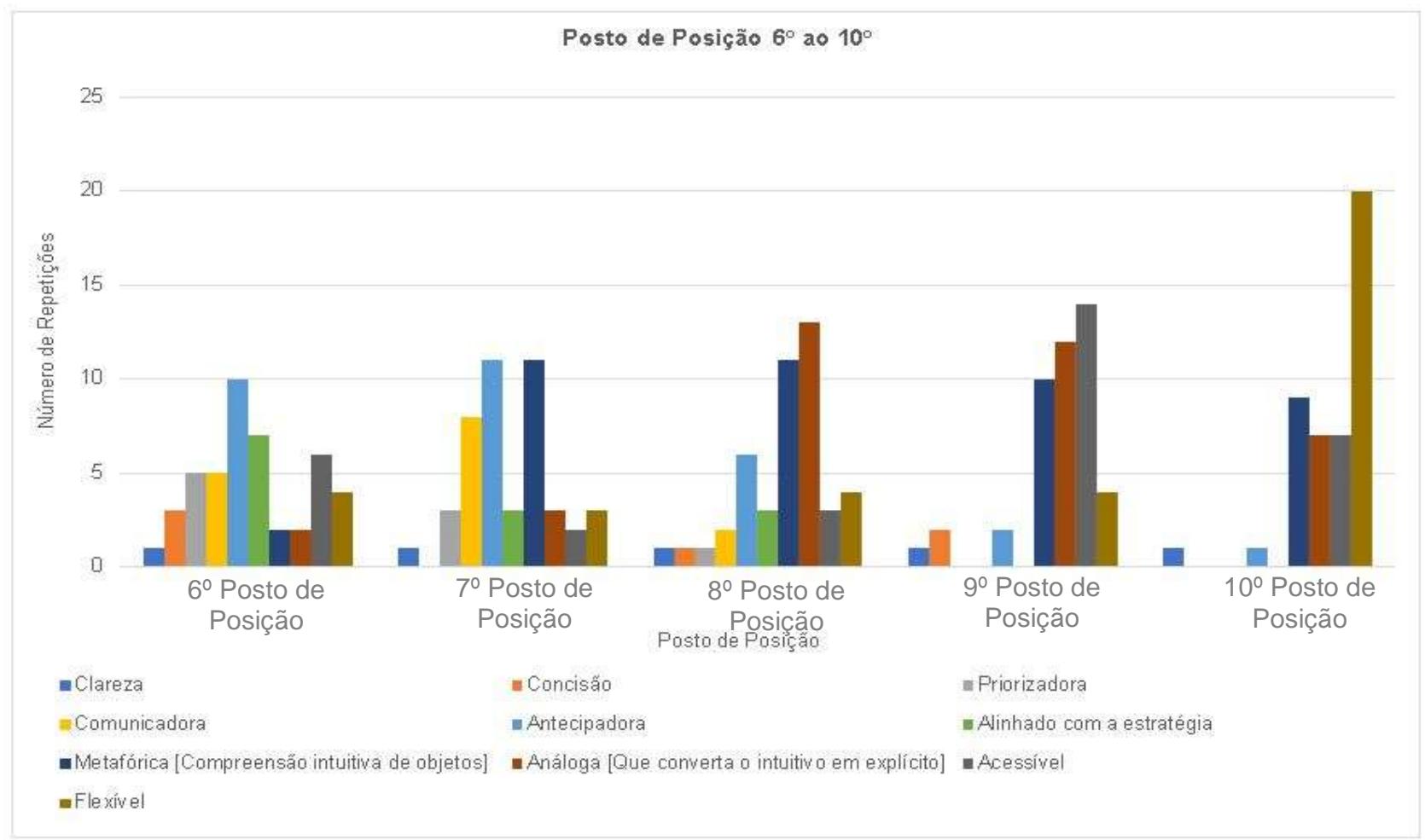

Fonte: Elaborado pelo Autor.

Cabe destacar que o coeficiente de Kuder-Richardson 20 Test $(\alpha=-0,155$, Número de itens 10), apontou para Consistência Inexistente, colocando em questionamento a viabilidade de utilização dos dados. A pouca familiaridade dos entrevistados com as Propriedades pode ter conduzido a indicação de inconsistência. Contudo, quando instruídos sobre a forma de aplicação para a avaliação das variáveis qualitativas das propostas de PMls, os resultados alcançam 
consistência alta, o teste Kuder-Richardson 20 Test, atingiu $\alpha=0,954$, segundo parâmetro estabelecido pelo autor do teste.

Os dados obtidos são também indícios de que as observações teóricas realizadas e suposições iniciais de que as propriedades relacionadas às figuras de linguagem Análoga, Acessível e Flexível são mais difíceis de serem aplicadas ao contexto das PMls, conforme identificado no Capítulo 3.

Consolidando os resultados dos especialistas em uma matriz indicada na tabela 11: (i $)$ variável qualitativa de projetos de PMls (UNPs) $\times(\boldsymbol{j})$ Propriedade de Visão, definidos por: $\sum_{i, j=1}^{n} \boldsymbol{X}_{i, j}$ os resultados dos cruzamentos dos eixos conduziram à criação do modelo proposto.

O conjunto de variáveis qualitativas inicialmente organizadas em 26 (vinte e seis), após agrupamento inicial alcança 13 (variáveis qualitativas críticas), derivadas do agrupamento inicial, sendo estas:

Descrição do Objeto, Justificativa do objeto, Relevância social, Governança, Justificativa do PPA, Descritivo da Inovação tecnológica, Justificativa da demanda do projeto, Descrição, Responsabilidade [Setor Público], Descrição Responsabilidade [Setor Privado], Descrição Risco, [Setor Público], Descrição Risco [Setor Privado], Aspectos jurídicos relevantes, Indicador de desempenho do Projeto, Capacidade máximo de oferta do serviço, Descritivo dos custos operacionais dos serviços ofertados, Previsão de demanda, Metas ambientais, Atividades ambientais, Impactos ambientais e por fim Beneficiados. 


\begin{tabular}{|c|c|c|c|c|c|c|c|c|c|c|c|}
\hline & Clareza & Concisão & Priorizadora & Comunicadora & Antecipadora & $\begin{array}{l}\text { Alinhada com a } \\
\text { estratégia }\end{array}$ & Metafórica & Análoga & Acessível & Flexível & Não Aplicável \\
\hline Objetivo do Projeto & 61 & 32 & 21 & 16 & 6 & 37 & 2 & 14 & 15 & 6 & 5 \\
\hline Relevância Social & 35 & 8 & 28 & 30 & 6 & 26 & 2 & 9 & 13 & 5 & 6 \\
\hline Governança & 45 & 16 & 20 & 23 & 9 & 40 & 2 & 6 & 13 & 12 & 6 \\
\hline Inovação Tecnológica & 24 & 10 & 15 & 11 & 17 & 28 & 3 & 10 & 17 & 20 & 11 \\
\hline Responsabilidade & 50 & 13 & 18 & 18 & 16 & 26 & 3 & 6 & 12 & 9 & 5 \\
\hline Risco & 52 & 16 & 18 & 12 & 20 & 32 & 3 & 9 & 10 & 7 & 6 \\
\hline $\begin{array}{c}\text { Aspectos Jurídicos } \\
\text { Relevantes } \\
\text { Indicador de }\end{array}$ & 56 & 21 & 12 & 16 & 22 & 21 & 2 & 8 & 13 & 6 & 5 \\
\hline $\begin{array}{l}\text { Desempenho do } \\
\text { Projeto }\end{array}$ & 49 & 27 & 22 & 17 & 16 & 29 & 2 & 13 & 19 & 9 & 6 \\
\hline Investimento & 40 & 14 & 23 & 12 & 11 & 35 & 1 & 6 & 15 & 16 & 10 \\
\hline $\begin{array}{l}\text { Capacidade Máxima } \\
\text { de Oferta do Serviço }\end{array}$ & 37 & 13 & 26 & 19 & 9 & 28 & 2 & 5 & 12 & 13 & 10 \\
\hline $\begin{array}{c}\text { Custos Operacional } \\
\text { dos Serviços } \\
\text { Ofertados }\end{array}$ & 38 & 20 & 24 & 14 & 11 & 23 & 2 & 8 & 18 & 14 & 7 \\
\hline $\begin{array}{c}\text { Metas e Impactos } \\
\text { Ambientais }\end{array}$ & 50 & 17 & 21 & 17 & 21 & 31 & 3 & 9 & 10 & 14 & 5 \\
\hline Beneficiados & 40 & 15 & 22 & 31 & 11 & 26 & 4 & 9 & 21 & 10 & 7 \\
\hline
\end{tabular}

Fonte: Elaborado pelo Autor. 
A consolidação dos resultados estatísticos levou à proposição de um modelo conceitual integrado de Variáveis Qualitativas de Projetos de PMls (UNPs) a propriedade de Visão de Produto. A próxima seção apresenta as dimensões que subsidiaram a geração do modelo de avaliação.

\subsection{SÍNTESE DAS DIMENSÕES PARA AVALIAÇÃO DE PMIS}

O passo seguinte da pesquisa foi organizar os Clusters dos FCSs em áreas de conhecimento que pudessem reunir quantidade suficiente de dados para o desenho final das propostas de PMI submetidas.

Tais conjuntos de áreas do conhecimento foram nomeadas de "dimensões" e tiveram origem no referencial bibliográfico consultado e modelos provenientes da Source do WBG e da Unidade de PPP/PFIs do Estado de São Paulo/Brasil.

Os resultados obtidos do levantamento (Survey) apresentados nas seções anteriores levaram a estratificação de 7 (sete) dimensões, ou seja, 7 (sete) vértices de forças que atuam no desenho de Propostas apresentadas por proponentes privados.

Os agrupamentos - Clusters foram organizados e cada um recebeu um código de representação, onde: um numeral indica a ordem de prioridade do cluster segundo o levantamento da Survey, em que "1" representa o Fator Crítico mais relevante e "8" o FC Negativo menos relevante e "9" para o FC Positivo menos relevante, seguidos pela indicação de impacto no projeto, se Positivos representado pela letra "P" e os Negativos, representados por "N".

O reduzido número de Clusters e dimensões isentou a necessidade de emprego de WordSmith Tools - WST (TAGNIN, 2013) para os agrupamentos dos FCSs, sendo os Clusters imputados às dimensões correspondentes de acordo com semelhança terminológica e contextual. 
Quadro 33 - Associação dos agrupamentos às dimensões

\begin{tabular}{|c|c|c|c|c|c|}
\hline \multicolumn{2}{|c|}{ Código } & \multirow{2}{*}{$\begin{array}{c}\text { FCSs Positivos } \\
1 \text { - Cluster: Transparência }\end{array}$} & \multicolumn{2}{|c|}{ Código } & \multirow{2}{*}{\begin{tabular}{l}
\multicolumn{1}{c}{ FCSs Negativos } \\
$1-$ Cluster: Informações \\
Inconsistentes
\end{tabular}} \\
\hline 1 & $P$ & & 1 & $\mathrm{~N}$ & \\
\hline 2 & $\mathrm{P}$ & 2 - Cluster: Risco & 2 & $\mathrm{~N}$ & 2 - Cluster: Concorrência \\
\hline 3 & $P$ & $\begin{array}{l}\text { 3- Cluster: } \\
\text { Responsabilidade }\end{array}$ & 3 & $\mathrm{~N}$ & 3 - Cluster: Bônus \\
\hline 4 & $P$ & 4 - Cluster: Informações & 4 & $\mathrm{~N}$ & $\begin{array}{l}4 \text { - Cluster: Aprovação } \\
\text { preliminar da proposta }\end{array}$ \\
\hline 5 & $P$ & 5 - Cluster: Escopo & 5 & $\mathrm{~N}$ & $\begin{array}{l}5 \text { - Cluster: Negociação } \\
\text { do Valor }\end{array}$ \\
\hline 6 & $\mathrm{P}$ & 6 - Cluster: Concorrência & 6 & $\mathrm{~N}$ & 6 - Cluster: Aquisições \\
\hline 7 & $P$ & 7 - Cluster: Governança & 7 & $\mathrm{~N}$ & $\begin{array}{l}7 \text { - Cluster: Rendimentos } \\
\text { Mínimos }\end{array}$ \\
\hline 8 & $P$ & 8 - Cluster: Atos Jurídicos & 8 & $\mathrm{~N}$ & $\begin{array}{l}8 \text { - Cluster: Coordenação } \\
\text { de Stakeholders (Partes } \\
\text { Interessadas) }\end{array}$ \\
\hline 9 & $P$ & $\begin{array}{l}9 \text { - Cluster: Coordenação } \\
\text { de Stakeholders }\end{array}$ & & & \\
\hline
\end{tabular}

\begin{tabular}{ll}
\hline Dimensão & \multicolumn{1}{c}{ Códigos } \\
\hline Qualificação & 1.P, 4.P, 6.P, 1.N, \\
& $4 . \mathrm{N}$ \\
\hline Governança & 7.P, 9.P, $2 . \mathrm{N}, 8 . \mathrm{N}$ \\
\hline Técnico/Operacional & $5 . \mathrm{P}, 8 . \mathrm{P}$ \\
\hline Econômico & $3 . \mathrm{N}, 5 . \mathrm{N}$ \\
\hline Financeiro & $6 . \mathrm{N}, 7 . \mathrm{N}$ \\
\hline Ambiental & 2.P, 3.P \\
\hline Social & $9 . \mathrm{P}, 8 . \mathrm{N}$ \\
\hline Fonte: Elaborado pelo Autor.
\end{tabular}

As dimensões organizadas tiveram os nomes atribuídos de acordo com 0 conjunto de FCSs envolvidos, e ao conjunto de variáveis previstas nas propostas a serem analisadas, sendo estas: Dimensão Qualificação: Definida pelo conjunto de elementos que rotulem os componentes de descrição dos objetos a serem alvo do certame futuro da PPP/PFI; Dimensão Governança: llustra o conjunto de partes interessadas na modelagem operacional da proposta, bem como associa as unidades responsáveis por quais áreas do projeto; Dimensão Técnico/Operacional: Dado pelo conjunto de responsabilidades e riscos de ambos envolvidos na negociação, contratante e contratado(s); Dimensão Econômica: Estabelece o conjunto de elementos do investimento do projeto e o descritivo dos custos operacionais do projeto; Dimensão Financeira: Estabelece a previsão de demanda do serviço a ser desenvolvimento que ensejará a contraprestação; 
Dimensão Ambiental: Inicia-se com a compreensão do potencial passivo decorrente da(s) prática(s) adotadas com a(s) operação(ões) do serviço e condiciona a demonstração de mecanismo e metas de mitigação e Dimensão Social: Metas, impactos e público beneficiado, esta dimensão aproxima-se do entendimento do VfM, convertendo este em critérios qualitativos com métricas quantificáveis. 


\section{APLICAÇÃO DAS DIMENSÕES NO DESENVOLVIMENTO DE UM NÚMERO ÍNDICE PARA AVALIAÇÃO DE PMIS}

Nesta seção, apresenta-se o modelo de indicadores para a avaliação de PMls, formado por indicadores em 7 (sete) dimensões, e um número índice que provê a síntese geral para comparação.

\subsection{REQUISITOS PARA O DESENVOLVIMENTO DE PMIS}

Segundo Schnetzler (2012) um modelo de indicadores para avaliar PMls precisa estar aderente a 3 (três) princípios, a saber:

Ser de fácil aplicação: não conter dupla interpretação de entendimento das variáveis por parte do jurado - avaliador das propostas, não exigindo assim grau de expertise nos conceitos. Assim, torna-se escusável a necessidade de consultor externo ao processo ou pesquisador profissional;

Prover interpretação direta: mitigar a necessidade de estudos analíticos dos dados, baseado em termos com heurística simples e direta. O formato deve ser por notas atribuídas por árbitros (especialistas) de fácil interpretação e comutáveis em gráficos de todas as variáveis integradas às Propriedades de Visão eleitas para as respectivas avaliações, permitindo clareza nas escolhas e resultados mais diretos e

Possibilitar replicação: desde que os objetivos cumpram a mesma natureza, a mesma métrica tem que ser atendida para projetos que tenham o mesmo objeto nas propostas submetidas, sendo possível a comparação, por sua vez, por "múltiplos" desses projetos.

Importante considerar que o modelo não deve se limitar a aspectos quantitativos, como os encontrados nas avaliações de propostas por meio do VfM, mas qualitativos também.

\subsection{PROPOSTA DE INDICADOR}

Utilizando as dimensões da seção 5 estabelece-se um indicador para cada uma das dimensões específicas para avaliação das PPP/PFIs. Logo, foi possível avaliar todos os aspectos da proposta. Ao conjunto de indicadores foi adicionado um 
número índice, denominado de índice "T", um acrônimo para "totalizante", cujo objetivo é gerar uma métrica única e sintética para efeitos de comparação. O modelo serve para:

1 - Prover subsídios métricos para os avaliadores de Projetos de PMls;

2 - Auxiliar no processo de tomada de decisão do melhor projeto a ser escolhido e

3 - Servir de suporte para os tomadores de decisão integralizarem conceitos apresentados pelos proponentes com o intuito de busca de projetos mais aderentes à realidade fática e ao contexto evolutivo de uma comunidade ou ambiente de inserção.

O índice "T" tem, como público alvo, as equipes de gestores públicos envolvidos no processo de seleção de projetos de PMI que resultem na modelagem final de Editais de PPP/PFIs, os consultores de gestão de projetos em três nível, a modelagem, a avaliação, gerenciamento de projetos de PMls e PPP/PFls e os grupos de interesse para a melhor adequação das propostas submetidas a órgãos demandantes. Ademais, o índice serve como instrumento de comparação de propostas de projetos de departamentos consulares de fomento econômico, oferece - para órgãos internacionais - uma alternativa para a avaliação de métricas qualitativas não observadas em projetos que se valem de institutos PPP/PFI e, especialmente, PMls.

O índice pode ter sua aplicação adaptada e estendida para outras formas de contratação por órgãos públicos, como concessões e licitações. Nesse contexto deve ser enquadrado sob o julgamento de critérios técnicos mais objetivos, outrora vistos como subjetivos, permitindo a homogeneização das avaliações e servindo para agências internacionais com o objetivo de estudos comparativos, por meio de avaliações ex post.

\subsubsection{INDICADORES POR DIMENSÃO}

Os indicadores foram organizados com base nas 7 (sete) dimensões, resultando em 7 (sete) indicadores a compor um número índice para medir o conjunto de variáveis necessárias para a composição de um projeto de PMI. Os conjuntos de informações foram sistematizados por meio do método sugerido por 
Cloquell-Ballester et al. (2006). Os indicadores de "Qualificação", "Governança", "Técnico/Operacional", "Econômico", "Financeiro", "Ambiental" e "Social" foram contextualizados aos critérios definidos por Cloquell-Ballester et al. (2006). Os critérios de cada um dos indicadores estão concentrados no Apêndice $F$.

\subsection{2 ÍNDICE "T” PARA AVALIAÇÃO DE PMIS}

A proposta do índice "T" para avaliação de PMls consiste na consolidação das dimensões das propostas de PMls convertidas em indicadores. Cada indicador representa uma única dimensão da proposta de projeto e exige-se a integração das dimensões para uma melhor interpretação desta como um todo.

Para solucionar o problema da avaliação subjetiva das propostas de PMI recepcionadas pelos entes públicos demandantes dos serviços, propõe-se o uso de um índice Totalizante dos indicadores, nomeado índice "T", segundo Adamiecki et al. (2003) a técnica de desenvolvimento de ferramentas de medição envolve um processo de quatro estágios:

(a) Desenvolvimento de conceitos;

(b) Especificação das dimensões do conceito;

(c) Seleção de indicadores; e

(d) Formação do índice ${ }^{44}$.

A modelagem do índice "T" seguiu a proposta de Cloquell-Ballester et al. (2006) para a validação de indicadores. Um conjunto de 7 (sete) indicadores a luz das 7 (sete) dimensões observadas nas propostas foi estruturado na equação 03.

Equação 03:

$T_{i}=\left[I_{Q_{i}}+I_{G_{i}}+I_{O_{i}}+I_{E_{i}}+I_{F_{i}}+I_{A_{i}}+I_{S_{i}}\right]$

Lê se:

$$
I_{Q_{i}}=\text { Indicador de Qualificação da Proposta } i
$$

${ }^{44} \mathrm{~A}$ etapa (a) foi desenvolvida nas seções 02 e 03 , desta tese, a etapa (b) no 05 , as etapas (c) e (d) são relatadas ao longo desta seção. 


$$
\begin{aligned}
& I_{G_{i}}=\text { Indicador de Governança da Proposta } i ; \\
& I_{O_{i}}=\text { Indicador Técnico/Operacional da Proposta } i ; \\
& I_{E_{\bar{i}}}=\text { Indicador Econômico da Proposta } i ; \\
& I_{F_{\bar{i}}}=\text { Indicador Financeiro da Proposta } i ; \\
& I_{A_{\bar{i}}}=\text { Indicador Ambiental da Proposta } i \mathrm{e} \\
& I_{S_{\bar{i}}}=\text { Indicador Social da Proposta. }
\end{aligned}
$$

A nota final de uma Proposta da PMI, seja de origem Motivada ou Provocada, é obtida pela soma ponderada dos indicadores que compõem o índice "T".

Apresenta-se em perspectiva o índice "T", na Figura 17 que, também, contempla o conjunto de variáveis agrupadas de cada um dos indicadores presentes nos escopos das propostas de PMls. 
Figura 17 - Variáveis de análise do índice "T"

Perspectiva (ii)

Perspectiva (iii)

Escopo da PMI (Procedimento de Manifestação de Interesse)

Avaliação das Propostas submetidas sob a égide de Propriedades Chave

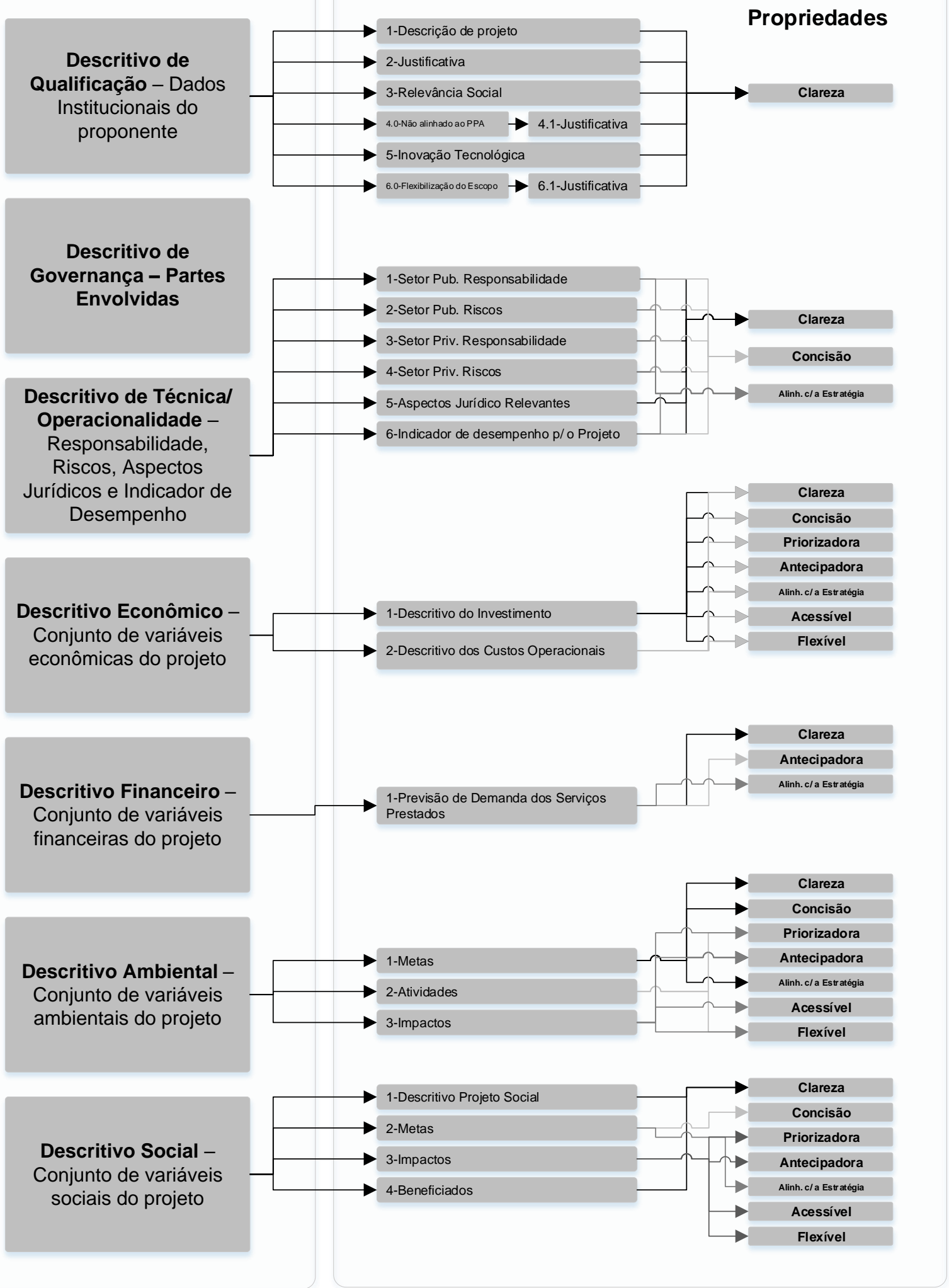

Fonte: Elaborado pelo Autor. 
A Figura 17, agrupa o conjunto de dimensões das variáveis a saber: descrição: Define a PMI que melhor preencher os requisitos estabelecidos nas diretrizes iniciais apresentadas pelo órgão demandante a otimizar o interesse público. O usuário (Stakeholders): Reúne todas as partes envolvidas no processo, proponente, concedente, órgãos fiscais e sociedade civil beneficiada. Além disso, essa categoria contém a descrição de ambiente de aplicação: é dado pelas 7 (sete) dimensões que compõe o conjunto de indicadores a integrar o índice "T": Qualificação; Governança; Técnico/Operacional; Econômico; Financeiro; Ambiental e Social.

A categoria definição conceitual apresenta o índice "T" e reúne em 7 (sete) dimensões nomeadas de "indicadores" (conjunto de variáveis latentes e quantitativas relativas a propostas de projetos de PMIs). As variáveis recebem notas atribuídas à luz do conceito de Propriedades de Visão do Produtos (conceito cunhado pelo Design de Produto) por considerar individualmente únicas as características de cada proposta submetida ao ente público demandante.

Em descrição do dado e da unidade, há variáveis quantitativas, representadas por dados numéricos e variáveis latentes - qualitativas, as quais apresentam coerência textual nos campos Ihes são atribuídas nota (1). Tem-se, então, uma avaliação binária $(0 ; 1)$ de coerência textual.

O mero preenchimento da variável com texto desconexo ou conteúdo diverso do definido pelas diretrizes do ente demandante não tornam automaticamente aceitas as variáveis. Após cumprido o primeiro requisito de conexão textual, todas as variáveis latentes são avaliadas de acordo com as Propriedades de Visão do Produto. Nas propriedades, as variáveis recebem uma nota de 0 a 10 pelo grau de aderência da descrição da variável à propriedade de visão em análise, pelo árbitro membro da(s) Câmara(s) Técnica(s).

A nota do árbitro à propriedade é multiplicada pela nota de existência de nexo textual da variável. Por fim, o resultado da multiplicação é mais uma vez multiplicado pelo peso ponderado da variável às outras variáveis que compõem a dimensão do indicador. O peso atribuído entre as variáveis que compõem o indicador é definido pela Câmara técnica de acordo com as características do projeto e contexto de aplicação. 
$\mathrm{Na}$ categoria de Definição de Layout ${ }^{45}$, há o layout sugerido para o formulário de inserção das variáveis das Propostas e Propriedade(s) de Visão do Produto utilizada(s) como critério(s) de avaliação(ões) a cada uma das dimensões dos indicadores.

No Método de Medida é possível encontrar o preenchimento integral dos campos das variáveis quantitativas e qualitativas de acordo com as características requisitadas pelo ente demandante do serviço a ser entregue. Considera-se o texto das variáveis de acordo com o porte do projeto, onde é possível em projetos com escopos mais amplos a aceitação de anexos complementares de forma assessoria ao processo de tomada de decisão dos membros da(s) Câmaras Técnica(s).

A próxima categoria a ser detalhada é a Justificativa (Interpretação/significado). Trata-se na nota unitária dos indicadores refletida na nota final que representa o número índice "T" de uma dada proposta de PMI. Entretanto, em razão da flexibilidade do peso ponderado das variáveis dos indicadores definidas pelos membros das Câmara(s) Técnica(s), por intermédio de diretivas do conselho administrativo do ente demandante, notas relativas (por indicador) menores não necessariamente condicionam o projeto não ser aceito em função do peso atribuído entre os indicadores pelos membros das Câmara(s) Técnica(s) (também cumprindo deliberação do conselho administrativo do ente demandante).

Em relação à exatidão desse indicador, pode-se dizer que três fatores (i, ii e iii em sequência) condicionam a precisão das informações capturadas pelas variáveis. Ademais, esses influenciam a sensibilidade do indicador que compõe o Índice final (Alocação de pesos dados aos "indicadores") e as variáveis que compõem cada um dos indicadores para a constituição final do índice "T". Para limitar o subjetivismo, os membros das Câmaras Técnicas poderiam adotar o (i) método AHP para tal ponderação (PIERE; MANTESE, 2017), capturando assim a percepção dos árbitros, dos indicadores e variáveis que demandariam maior peso de acordo com o Planejamento Estratégico da instituição demandante do serviço. Outrossim, (ii) a avaliação correta dos indicadores, ou seja, a avaliação do serviço a ser entregue condiciona a inter-relação entre as variáveis do próprio indicador e seu grau de concordância e interação com as variáveis de outros indicadores para a composição de um número índice robusto se faz importante. Convém ressaltar que não pode haver discrepância entre essas, pois inviabilizaria o indicador em si e

${ }^{45}$ Para detalhes, consultar o Apêndice F. 
comprometeria o valor observado no índice, pesando negativamente no resultado final da proposta avaliada. Imprescindível também é (iii) medir a capacidade real de serviço entregue e não potencial. Tem-se um dado direto, atribuído somente à variável que está sendo preenchida no indicador $I x$. Por fim, considerando os mecanismos definidos e detalhados, poderá ocorrer a exatidão de todos os indicadores que compõem a avaliação de PMls, sendo o mesmo representado por $\varepsilon$ (no Apêndice F).

Por fim, tem-se a categoria de relevância. As PPP/PFls têm se mostrado como instituto apto a preencher o binômio "escassez e resultado". Entende-se "escassez", em razão da dificuldade do Estado em demandar dos contribuintes mais recursos financeiros, oriundos de sua fonte de receitas (tributos), impactando na sensível relação de confiança e respaldo político de gestores públicos com a população. Por sua vez, "resultado" deve ser compreendido como algo que advém da entrega desse ao cidadão, por meio de serviços remunerados ao ente privado atrelados a métricas do serviço realizado, validados por terceira parte ou pelo próprio ente contratante. Esse pode, também, variar de acordo com a qualidade e medida verificada do serviço fornecido (CLOQUELL-BALLESTER et al., 2006). Ressalta-se que a flexibilidade da iniciativa privada aos marcos regulatórios contratuais cíveis e trabalhistas resultam em maior capacidade de entrega de resultados mais céleres.

A modelagem do conjunto de dados teve sua origem fundamentada nas fontes Source - World Bank Group (WBG), na Unidade de Parceria Público-Privada da Secretaria Estadual de Governo do Estado de São Paulo, na bibliografia acadêmica consultada e nos FCSs de PPP/PFls e PMls utilizados como recorte nos estudos desta tese. Há o mesmo conjunto de fontes consultadas para o desenho dos indicadores representadas por $\kappa$ (no Apêndice F).

\subsubsection{PROCESSO DE APLICAÇÃO DO MODELO}

A implantação prática do índice " $T$ " como política pública poderá servir como instrumento de organização e classificação do conjunto de propostas de PMls submetidas ao órgão demandante, de forma a estabelecer um mesmo padrão de comparação entre os projetos apresentados pela iniciativa privada e entidades do terceiro setor. $\mathrm{O}$ objetivo é reduzir as avaliações subjetivas dos escopos de projetos 
apresentados em relação à análise do conjunto de variáveis qualitativas envolvidas. Consequentemente, o processo de transparência na construção do edital da PPP/PFI e enquadramento dos requisitos descritos nas diretrizes apresentadas para a elaboração dos projetos de PMls melhorarão.

O índice de avaliação de PMls agrupa o total de descrições de funcionalidades de cada proposta submetida ao ente demandante e está segmentado em 4 (quatro) perspectivas, de acordo com Wang (2013, tradução do autor):

1. Solicitante do serviço objeto do descritivo da PMI que resultará na composição do edital do certame final PPP/PFI;

2. Avaliadores dos projetos submetidos (Câmara Técnica, com subordinação ao Conselho Gestor);

3. Interessados privados em submeter projetos para o órgão demandante e

4. Órgãos de compliance e transparência, isto é, Ouvidorias, TCU, TCEs, Ministério Público, Associações Civis Públicas e Privadas, Câmaras e Assembleias e Mídia em todos os formatos.

O Índice de avaliação segue a tendência do NPM de compliance (conformidade) e transparência. Ademais, esse atende o terceiro requisito proposto por Oliveira, Ribeiro e Macário (2016), isto é, permite replicação, como ampla utilização, considerando um grupo de variáveis padronizadas e a simetria nas análises por parte dos especialistas membros das câmaras técnicas avaliadoras.

$\mathrm{Na}$ Figura 18, apresentam-se as 4 (quatro) perspectivas em conjunto totais de dados distintos e inseridas de forma sequencial (cumprindo ritos legais e regulamentares).

Figura 18 - Macro sequenciamento dos ritos da PMI no processo de avaliação

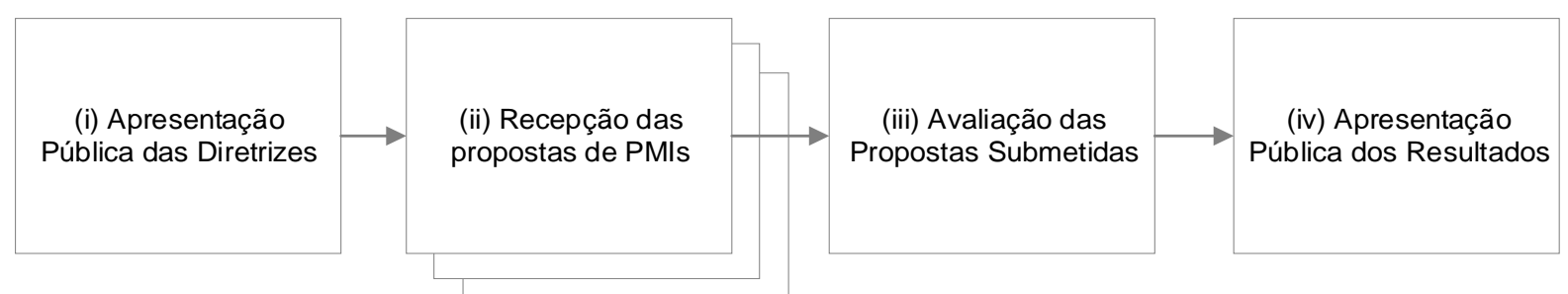

Fonte: Elaborado pelo Autor. 
Entende-se desta:

(i) Apresentação Pública das Diretrizes, estabelecidas pelos órgãos concedentes;

(ii) Recepção das propostas de PMls, por parte dos empreendedores interessados na PPP/PFI;

(iii) Avaliação das Propostas Submetidas, composta por grupo de especialistas internos ou externos ao órgão demandante $\mathrm{e}$ subordinados ao conselho gestor de PPP/PFls da instituição;

(iv) Escrutínio público dos resultados para abertura de consultas e audiências públicas. Buscando reduzir as armadilhas decorrentes dos desvios entre a demanda esperada para a demanda realizada (Georgakopoulos, Hornick e Sheth, 1995). 
Figura 19 - Sequenciamento dos critérios de avaliação de proposta de PMI

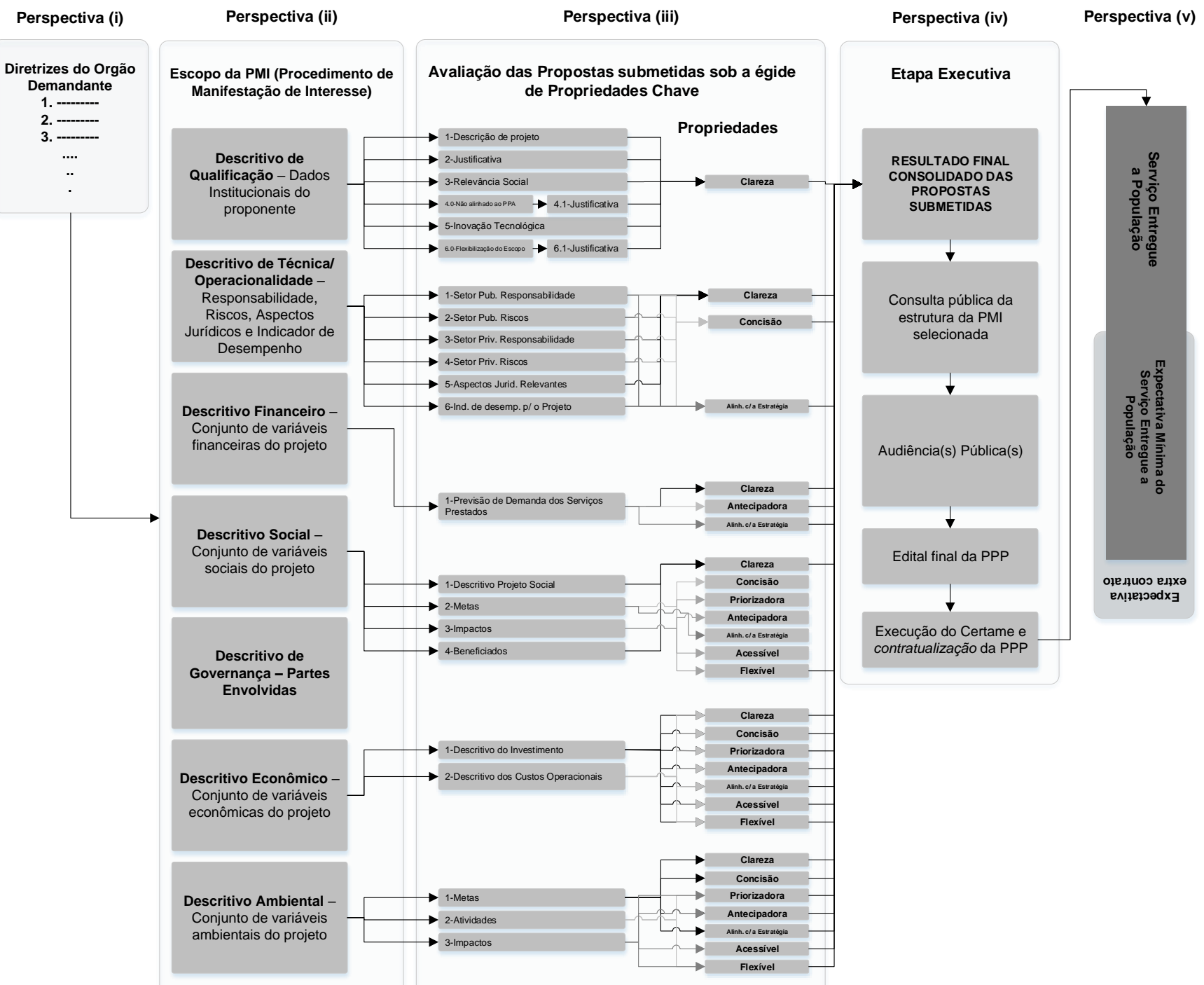

Fonte: Elaborado pelo Autor. 
Deste modo, a marcha processual de recepção das propostas pelo ente público demandante, segue a sequência exposta na Figura 20.

Figura 20 - Sequência de etapas operacionais de avaliação das PMls

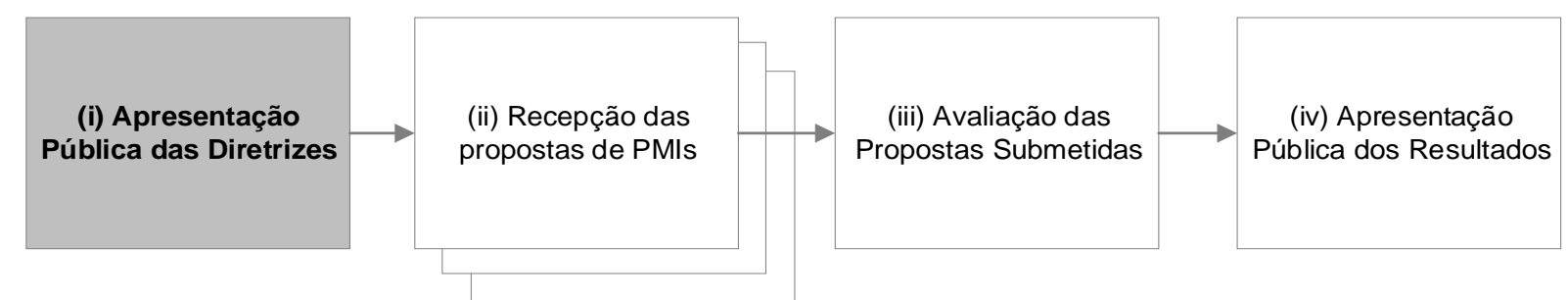

Fonte: Elaborado pelo Autor.

Entende-se:

Apresentação pública das diretrizes que nortearão o projeto a ser desenvolvido com as regras e dispositivos legais a serem seguidos. Tais informações são publicadas nos respectivos $\mathrm{DO}^{46}$ competentes e expostas em área específica do site on-line do órgão demandante. Uma vez despertado o interesse pela iniciativa privada, essa é orientada a como proceder na inserção dos dados e documentos comprobatórios de habilitação para a participação no certame.

A etapa (ii) está ilustrada na Figura 21.

Figura 21 - Sequência de etapas operacionais de avaliação das PMIs

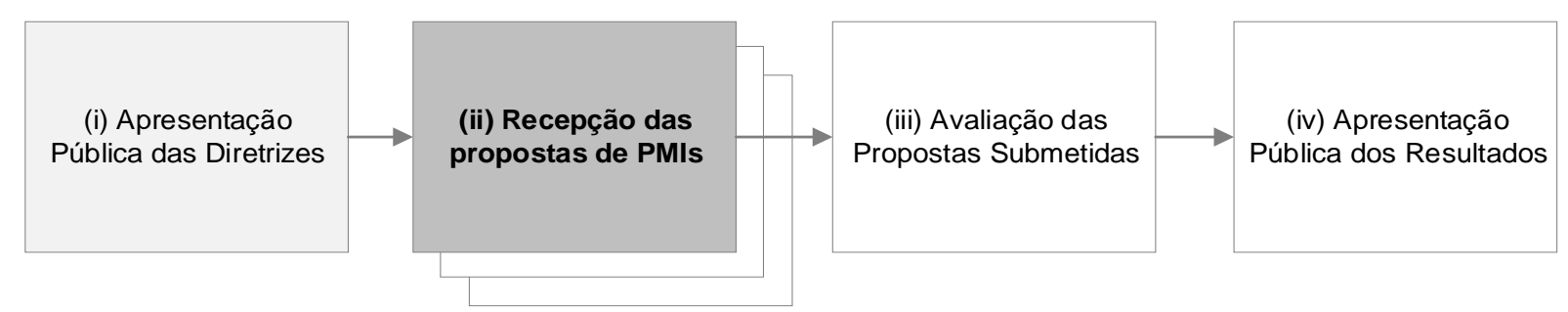

Fonte: Elaborado pelo Autor.

\section{Entende-se:}

(i) Sequencialmente, o ente privado inicia o seu cadastramento no órgão demandante. Ativado o seu cadastro, o proponente é remetido à formulário de inserção da(s) proposta(s) de PMls ao objeto das diretrizes

${ }^{46}$ DO - Diários Oficiais. 
publicadas no Diário Oficial - DO órgão proponente do certame ou veículo de publicidade dos atos a serem realizados.

As informações são agrupadas em conjuntos de formulários de atividades a serem executadas, de acordo com a atribuição das partes interessadas no processo:

1. Propostas - reúne o detalhamento do escopo do projeto de PMI proposto, contemplando proposta executiva e conjunto total identificado de variáveis qualitativas e quantitativas;

2. Partes Interessadas - reúne dados individuais dos representantes ou pessoas jurídicas interessadas;

3. Quadro institucional do conselho gestor e câmara técnica;

4. Matriz RACl - Responsible, Accountable, Consulted and Informed, tratase do detalhamento dos cargos e atribuições dos executivos do certame da PPP/PFI;

5. Avaliação, formulários com marcadores de interpretação por especialistas da(s) câmara(s), atribuindo pontuações as sessões cruzadas das variáveis qualitativas às propriedades, quando aplicadas segundo proposta do modelo e

6. Resultados consolidados dos árbitros das Câmaras técnicas para referendo do conselho gestor de PPP/PFI, ou para a suspensão rito, ou ainda para a escolha da proposta e sequencial prosseguimento do curso de contratação da PPP/PFI com a feitura do edital.

Na fase "1", a parte interessada cadastra "Nome do Projeto" e "Imagem relativa ao projeto", os quais são ocultados no formulário e codificados posteriormente, para que na etapa de avaliação dos projetos, a Câmara Técnica não tenha acesso à identificação da parte interessada, mitigando condutas adversas e conduzindo a favorecimentos de determinados players.

Posteriormente, é realizado o processo de qualificação completa do proponente. Indica-se "qualificação documental" ou "Tipo do Projeto" e se é uma iniciativa de natureza nova ou uma expansão de projeto já realizado pela administração do órgão.

No campo grupo de trabalho, insere-se a informação sobre a possibilidade ou não de composição de algum consórcio ou proposição individual do proponente. 
Projetos dessa natureza, normalmente, envolvem um conjunto de especialistas de inúmeras áreas em razão da complexidade de operacionalização (HARDCASTLE et al., 2005), motivando a formação de consórcios de empreendedores e especialistas desde a etapa de concepção do projeto (COHEN; BAILEY, 1997). Inserido o grupo de trabalho, os nomes dos componentes são agrupados por setor e subsetor de atuação. Com o agrupamento, mais homogeneidade funcional e coesão do processo de trabalho são originadas (DURSUN; STOY, 2011; HARRISON et al., 2002).

Outro elemento da qualificação da proposta é a localização geodésica do projeto. Consideram-se projetos localizados em múltiplos sites. Sobre as diretrizes apresentadas pelo órgão demandante do serviço, essas podem desconhecer o melhor local de implantação do serviço e dispositivos acessórios para a viabilização.

De acordo com Kušljić, Čengija e Marenjak (2009), a informação sobre o desconhecimento das diretrizes é considerada crítica para os órgãos de fiscalização centrais em países com escala continental e para os executores do projeto final. A sua não precisão pode impactar no custo construtivo e no prazo de entrega do projeto, atingindo diretamente o escopo do projeto em razão de interferências decorrentes das cercanias do site (ASENOVA; BECK, 2009) e de características suigeneres do projeto (MANSOR; RASHID, 2014). Tais incongruências podem gerar incertezas e insegurança nas partes interessadas, deteriorando os indicadores de expectativa de retorno do projeto (MANSOR; RASHID, 2014).

Definida a localização, é inserida a descrição do objeto premissa maior das diretrizes previamente apresentadas e a apresentação do "Plano de Negócio". Este é modelado externamente e contempla dados não parametrizáveis pelo indicador de Qualificação.

A indicação do "Custo de Capital Estimado" e do "Prazo em anos" constituem a próxima etapa. Essa orienta o órgão proponente sobre a curva esperada de desembolso ao longo do ciclo de vida da PPP/PFI e é seguida pelas informações relativas à "Relevância Social" da proposta do projeto.

Posteriormente, informa-se, caso haja, o desalinhamento com macro estratégias de governo (Plano Plurianual - PPA, contexto Brasil, por exemplo). Submete-se a justificativa técnica para o projeto dissociado a essa, indica-se a qualificação adicional para o projeto ou exclui-se, imediatamente, o pleito postulado.

No âmbito do indicador de Governança, há os rótulos das partes envolvidas na concepção dos estudos que compõe a proposta $e$ as respectivas responsabilidades na fase do projeto. Já no indicador Técnico/Operacional, segundo 
Ashley ${ }^{47}$ (1977, p.19 apud EXPER, 2015), cada elemento de risco deve ser apresentado e distribuído de modo que o efeito total do custo esperado seja minimizado. Contempla-se, ademais, os "aspectos jurídicos relevantes" e o "indicador de desempenho do projeto", sob qual unidade de medida atribuída para efeito de auditoria do projeto, caso venha a ser a proposta escolhida e posta em prática.

O indicador Econômico reúne as seguintes informações:

- "Prazo do início da operação" - relativa ao lead time esperado; da aprovação da proposta ao início da operação, considerando a inexistência de fatores exógenos (como recursos processuais ou embargos ao certame). A essa categoria, segue-se a "expectativa de início da operação";

- "Prazo da Concessão";

- "Descritivo de investimento", anexos acessórios;

- "Capacidade Máxima do Serviço" e

- "Descritivo dos Custos Operacionais".

O indicador Financeiro, demanda a inserção das variáveis:

- "Custo Total do EVTEFA";

- "Previsão de Custos Operacionais e Despesas";

- "Previsão de demandas dos serviços prestados";

- "Tributação [Direta e Indireta]";

- "TIR estimada do projeto";

- "Transferência de tecnologia48";

- "Grau de depreciação do bem";

- "Investimento total previsto" e

- "Aporte Público49".

\footnotetext{
${ }^{47}$ Ashley, D.B. (1977) Construction Risk Sharing. Technical Report No.220, Dept of Civil Engineering, Stanford University.

48 Considera-se se há ou não transferência de tecnologia do ente privado para o público após o término da concessão.

${ }^{49}$ Considera-se a previsão de aporte público de capital antecipado para a realização da PPP/PFI. Em caso positivo, é questionado a natureza do aporte [com informe da fonte de recurso] e o montante.
} 
O indicador Ambiental recorre à descrição do manejo ambiental do passivo potencial gerado pelo projeto, seja na fase de estudo, implantação e operação. Nele, há "Metas", "Atividades" e "Cronograma". Outrossim, apura-se a existência de necessidade de licenciamentos sobre a atividade pleiteada. No caso de afirmativa, isto é, há a necessidade de licenciamento, aponta-se o "âmbito" da licença e sua natureza.

Por fim, o indicador Social exige o cumprimento do "descritivo do projeto social", "Metas", "Impactos", "Beneficiados (estimativa de beneficiados direto e indiretos)" e "Postos de trabalho gerados com a implantação e operação (empregos diretos e indiretos)".

Todos os aspectos apresentados detalhamento acima constituem a etapa (ii) no contexto da Sequência de etapas operacionais de avaliação das PMls, ilustrada na Figura 21. Com o intuito de dar prosseguimento, apresenta-se a etapa (iii), ilustrada na Figura 22.

Após o cadastramento das propostas, avalia-se cada grupo de variáveis latentes sob a égide das Propriedades da Visão de Produto, que foram eleitas para as validações, por meio de uma escala Likert de 0 (zero) a 10 (dez) atribuída ao modelo.

Figura 22 - Sequência de etapas operacionais de avaliação das PMls

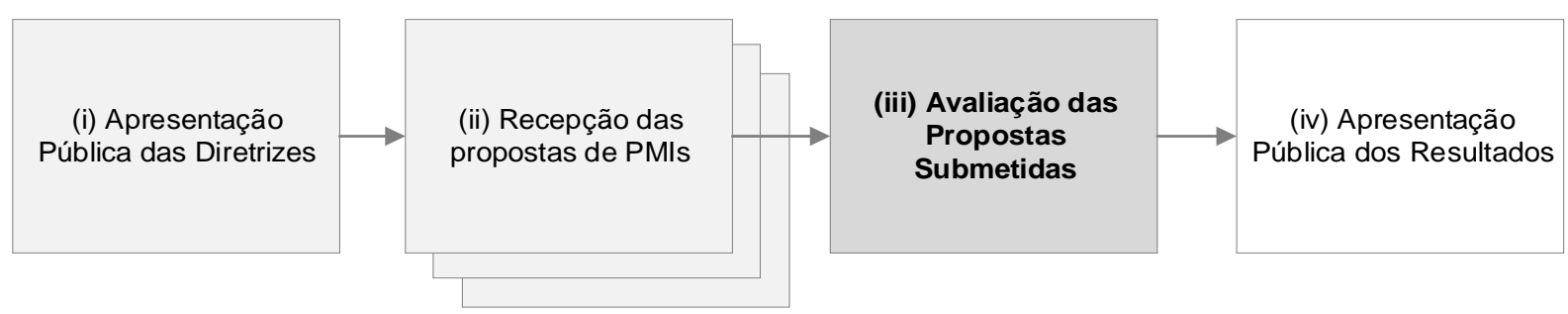

Fonte: Elaborado pelo Autor.

O conjunto de variáveis está estruturada matricialmente e os pesos dos indicadores são ponderados de acordo com a característica e natureza do projeto. Cada um dos árbitros membros da(s) Câmara(s) Técnicas conceitua as variáveis das propostas submetidas, de acordo com a aderências das respostas à luz da(s) propriedade(s) de Visão do Produto a essa relacionada conforme apresenta a matriz de relacionamentos apresentada no Quadro 34. 
Quadro 34 - Matriz de relacionamentos ${ }^{50}$ do índice "T"

\begin{tabular}{|c|c|c|c|c|c|c|c|c|c|}
\hline & & & \multicolumn{7}{|c|}{ Propriedade } \\
\hline Dimensão & Indicador & Variável & Clareza & Concisão & Priorizadora & Antecipadora & $\begin{array}{c}\text { Alinhamento } \\
\text { Estratégico }\end{array}$ & Acessível & Flexível \\
\hline \multirow{7}{*}{ Qualificação } & \multirow{7}{*}{ Qualificação } & 1-Descrição de projeto & $\square$ & & & & & & \\
\hline & & 2-Justificativa & $\square$ & & & & & & \\
\hline & & 3-Relevância Social & $\mathbf{a}$ & & & & & & \\
\hline & & 4.0-Não alinhado ao PPA & $\square$ & & & & & & \\
\hline & & 4.1-Justificativa & $\boldsymbol{\square}$ & & & & & & \\
\hline & & 6.0-Flexibilização do Escopo & $\mathbf{\square}$ & & & & & & \\
\hline & & 6.1-Justificativa & $\mathbf{\square}$ & & & & & & \\
\hline Governança & Governança & - & & & & & & & \\
\hline \multirow{5}{*}{ Técnico/Operacional } & \multirow{5}{*}{ Técnico/Operacional } & 1-Setor Pub. Responsabilidade & $\mathbf{a}$ & $\mathbf{\square}$ & & & $\mathbf{\square}$ & & \\
\hline & & 2-Setor Pub. Riscos & $\square$ & $\mathbf{\square}$ & & & $\boldsymbol{\square}$ & & \\
\hline & & 3-Setor Priv. Responsabilidade & $\square$ & $\mathbf{D}$ & & & $\mathbf{\square}$ & & \\
\hline & & 4-Setor Priv. Riscos & $\mathbf{\square}$ & $\mathbf{\square}$ & & & $\mathbf{\square}$ & & \\
\hline & & 6-Indicador de desempenho $\mathrm{p} / \mathrm{o}$ Projeto & $\mathbf{a}$ & $\mathbf{\square}$ & & & $\mathbf{\square}$ & & \\
\hline \multirow{2}{*}{ Econômico } & \multirow{2}{*}{ Econômico } & 1-Descritivo do Investimento & $\square$ & $\mathbf{\square}$ & $\mathbf{\square}$ & $\boldsymbol{\square}$ & $\mathbf{\square}$ & $\square$ & $\mathbf{\square}$ \\
\hline & & 2-Descritivo dos Custos Operacionais & $\mathbf{\square}$ & $\mathbf{a}$ & $\mathbf{\square}$ & $\mathbf{a}$ & $\mathbf{\square}$ & $\mathbf{a}$ & $\mathbf{\square}$ \\
\hline Financeiro & Financeiro & 1-Previsão de Demanda dos Serviços Prestados & $\mathbf{a}$ & & & $\mathbf{\square}$ & $\mathbf{a}$ & & \\
\hline \multirow{3}{*}{ Ambiental } & \multirow{3}{*}{ Ambiental } & 1-Metas & $\mathbf{\square}$ & $\mathbf{\square}$ & & $\mathbf{\square}$ & $\boldsymbol{\square}$ & & \\
\hline & & 2-Atividades & & & $\mathbf{\square}$ & & & & $\boldsymbol{\square}$ \\
\hline & & 3-Impactos & & & $\mathbf{\square}$ & $\boldsymbol{\square}$ & & $\boldsymbol{E}$ & $\mathbf{\square}$ \\
\hline \multirow{4}{*}{ Social } & \multirow{4}{*}{ Social } & 1-Descritivo Projeto Social & $\square$ & & & & & & \\
\hline & & 2-Metas & & $\mathbf{\square}$ & & & $\square$ & & \\
\hline & & 3-Impactos & & & $\boldsymbol{\square}$ & $\boldsymbol{\square}$ & & $\boldsymbol{\square}$ & $\boldsymbol{\square}$ \\
\hline & & 4-Beneficiados & $\mathbf{\square}$ & & & & & & \\
\hline
\end{tabular}

Fonte: Elaborado pelo Autor.

${ }^{50}$ Variáveis dos indicadores e Propriedades de Visão do Produto. 
Por fim, na Figura 23, tem-se a etapa (iv) da Sequência de etapas operacionais de avaliação das PMls:

A fase de apresentação pública dos resultados encerra o papel funcional do índice "T" junto ao rito de contratação das PPP/PFIs, pois fornece ao gestor público a ordem de classificação das propostas submetidos.

Figura 23 - Sequência de etapas operacionais de avaliação das PMls

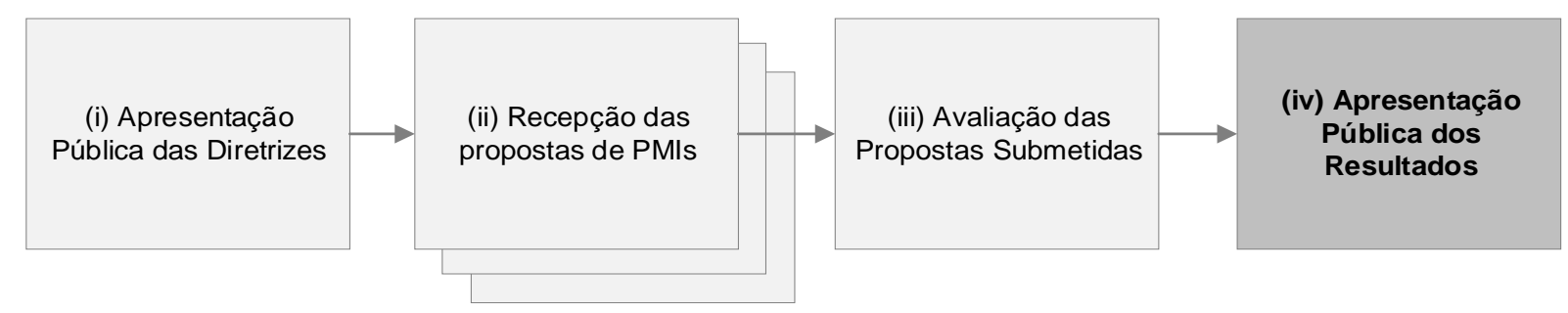

Fonte: Elaborado pelo Autor.

\subsection{VERIFICAÇÃO DO MODELO DE AVALIAÇÃO DE PMIS}

Nesta seção, apresentam-se uma avaliação do indicador proposto. Descrevese uma pesquisa de campo do grupo de especialistas com o intuito de cumprir dois objetivos: (a) obter o valor de pesos para a cada um dos indicadores sob critérios previamente definidos e (b) refletir sobre a percepção desses em relação às vantagens do índice "T", sobre as vantagens do modelo de indicadores e sobre as possíveis dificuldades para a sua aplicação no campo prático.

O índice "T" foi apresentado a um grupo de 12 (doze) especialistas em PPP/PFI e PMI. O critério de escolha do especialista pautou-se no conhecimento teórico e prático dos mesmos sobre os institutos PPP/PFI e PMI em vias de modelar, gerenciar, avaliar e/ou julgar propostas nas três esferas, bem como a realização de auditoria em projetos desta natureza, sem limite de tamanho e objeto do projeto a ser contratado. Consideram-se projetos entre $R \$ 20.000 .000,00^{51}$ (vinte milhões de reais) a $\mathrm{R} \$ 900.000 .000,00$ (novecentos milhões de reais).

Conforme descrito na seção 4.6, Etapa VII, e no Apêndice E (Protocolo das entrevistas), a apresentação foi conduzida por meio de entrevistas com duração média de 80 minutos cada uma. Ao final de cada ciclo de perguntas, resultados discutidos e apontamentos recolhidos para a melhoria do índice proposto.

51 O valor mínimo proposto, nesta tese, segue o limite mínimo versado na Lei Federal Brasileira, no 11.079 , de 30 de dezembro de 2004. Posteriormente, essa foi alterada pelo Decreto Lei Federal Brasileiro no 13.529 , de 4 de dezembro de 2017 , que dispõe no artigo $6^{\circ} \S 4^{\circ}$, Inciso I, o limite mínimo dos projetos em 10 (dez) milhões de reais. 
As entrevistas foram realizadas no período de 11 de dezembro de 2017 a 22 de dezembro, totalizando 2 (duas) semanas úteis. Para a operacionalização efetiva das entrevistas, em razão da logística dos entrevistados/entrevistador e a busca de resultados satisfatórios, houve uma fase preliminar preparatória formada por: (i) formalização do pedido de entrevista (Apêndice 04), (ii) organização de agenda adequada a todos os entrevistados, (iii) disponibilização do protocolo da entrevista para melhor familiarização dos entrevistados com o tema central da pesquisa, (iv) apresentação de descritivo dos indicadores e do índice "T", (v) montagem de apresentação em PowerPoint, direcionada para as entrevistas, (vi) plotagem em dobro (formato 4) da figura "Sequenciamento dos Critérios de Avaliação de Proposta de PMI" para manuseio e entendimento imediato da proposta, (vii) estruturação de régua de atribuição de pesos, para questões envolvendo o método $\mathrm{AHP}$, e (viii) modelagem de perguntas no software Super Decisions - versão 2.6.0-RC1 (Aplicação do AHP). Ademais, as entrevistas foram divididas em 3 (três) momentos:

Primeiro momento: agradecimentos protocolares e apresentação da proposta da pesquisa;

Segundo momento: apresentação das perguntas (1-3) e

Terceiro momento: composto pela arguição da pergunta $4^{52}$.

Como descrito na seção 4.4.4.2, Etapa VII e no Apêndice E (Protocolo das entrevistas), 5 (cinco) das entrevistas foram conduzidas presencialmente e 7 (sete) virtualmente. A título de esclarecimento, assegura-se o anonimato das respostas individuais ${ }^{53}$.

Para os critérios adotados nas perguntas, adaptou-se o método proposto por Cloquell-Ballester et al. (2006), a saber: a metodologia 3S. A metodologia 3S de validação de indicadores visa tornar o indicador acreditável (validado), uma vez que há o problema de tomada de decisão multicritério a multi especialistas. Outrossim, propõe a alocação binária dos pesos dos critérios em uma escala (WIND; SAATY, 1980) e o range da escala não apresenta limite. Contudo, convencionou-se, neste

\footnotetext{
52 A pergunta 4 consiste em áudio gravado com autorização do entrevistado, uma vez que se trata de pergunta aberta sobre a percepção final do entrevistado em relação ao índice " $T$ " e às implicações deste para a teoria e prática do conhecimento.

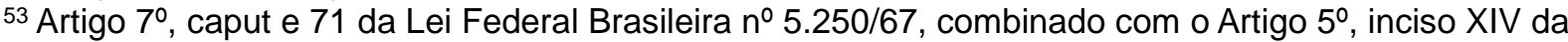
CFRB/88.
} 
trabalho, a adoção de escala limite em 9 (nove) para cada um dos critérios em análise.

Dado que valores acima de 9 (nove) poderiam gerar distorções na matriz de inconsistência, dificultando o processo de decisão do entrevistado na segunda rodada de arguições, tais premissas foram apresentadas aos entrevistados, não havendo questionamentos contrários à restrição de limite da escala. A adaptação do método consistiu, também, em considerar o grau de especificidade da matéria de difícil compreensão de público em geral. Logo, foi descartado o nível 3 (aplicação da pesquisa com público em geral) da análise, em razão da potencial baixa aderência das informações obtidas e por economia processual.

Segundo Piere e Mantese (2017, p. 09)

o cálculo das 3 Classes de Critérios, [sic] deve ser utilizada a técnica da média ponderada (EUROPEAN COMMISSION*, 1999, pp. 20; CANTER, 1996 apud CLOQUELL-BALLESTER et al. 2006), na qual [sic] são utilizados os valores das médias obtidas em cada Critério [sic] avaliado pelos especialistas na etapa anterior (Avaliação pelos Especialistas) e os pesos referentes a cada um dos critérios avaliados. ${ }^{54}$

$\mathrm{Na}$ esteira de Pierre e Mantese (2017), elaboraram-se as perguntas do questionário. Essas foram conduzidas de forma recursiva e após a segunda rodada os resultados eram apresentados ao entrevistado (WRIGHT; GIOVINAZZO, 2000) e as informações primárias recolhidas nas entrevistas lançadas no software Super Decisions - versão 2.6.0-RC1, para a aplicação da técnica do AHP, sob os critérios de avaliação de indicadores propostos por Cloquell-Ballester et al. (2006). Em seguida, os resultados foram tratados em planilhas Excel.

Importa dizer que a fase preparatória, associada ao grau técnico dos entrevistados e material compartilhado, permitiu nível satisfatório de consistência das respostas, com a maioria dos entrevistados ${ }^{55}$, em apenas uma rodada.

\footnotetext{
${ }^{54}$ Lê-se: Para o cálculo das 3 Classes de Critérios deve ser utilizada a técnica da média ponderada, apresentada na Comissão Europeia (European Commission, 1999). A perspectiva técnica consiste em 1) utilização dos valores das médias, avaliados na etapa de Avaliação pelos Especialistas, e em 2) pesos referentes a cada um dos critérios avaliados.

${ }^{55}$ Apenas duas sentenças se mostraram inconsistentes em toda a amostra.
} 
7 (sete) dimensões de análise de propostas de PMI. O conjunto total de indicadores resultou no índice "T" testados sob os critérios de (C1), (C2) e (C3), a saber:

- Coerência Conceitual (C1), nos sub níveis a), b) e c):
a) Definição (C1.1);
b) Relevância (C1.2) e
c) Interpretação/Significado (C1.3).

- Coerência Operacional (C2), nos sub níveis a), b), c) e d):
a) Formulação (C2.1);
b) Dado e Unidade (C2.2);
c) Método de Medida (C2.3) e
d) Exatidão/Sensibilidade (C2.4).

- Utilidade (C3), nos sub níveis a), b) e c):

a) Confiabilidade (C3.1) - segundo sub nível: Indicador (C3.1.1) e Fonte (C3.1.2);

b) Disponibilidade (C3.2) e

c)Informação (C3.3), nos sub níveis:

Segurança (C3.3.1) e Custo (C3.3.2).

No teste AHP, 3 (três) perspectivas de interpretação dos indicadores, foram adotadas para cada entrevistado, independentemente de sua atividade (profissional ou acadêmica). $O$ intuito versou em colocar o entrevistado no contexto de outro Stakeholder do processo.

Destaca-se que 3 (três) partes interessadas foram utilizadas no estudo, a saber: (i) a iniciativa privada (representada pelo critério "Custo"), (ii) ente público, (representado pelo critério "Qualidade do Serviço Entregue") e por fim, (iii) o cidadão beneficiário do serviço decorrente da PPP/PFI (sob o critério "Satisfação do Cidadão").

Os 7 (sete) indicadores que compõem o índice foram contrapostos em escala de importância ${ }^{56}$ sob as 3 partes interessadas. Posteriormente, o grau de

\footnotetext{
56 Tendo escala de 1 (importância equivalente) até 9 (extremamente mais importante) com a utilização números inteiros e de valores pares no estudo, para escolhas extremas fossem evitadas.
} 
inconsistência das respostas dos entrevistados dos indicadores ${ }^{57}$ foi medido via teste AHP.

Os pesos relativos de cada um dos critérios foram normalizados e o vetor de prioridades $^{58}$ foi obtido por meio da média aritmética, determinando assim a participação dos critérios na meta global.

O índice de inconsistência é dado pela Equação 04.

Equação 04: $C I=\frac{\lambda_{\max }-n}{n-1}$,

Em que $\lambda_{\max }$ é dado pelo $\Sigma$ (vetor de prioridade ${ }_{n} *$ total $_{n}$ ).

Segundo Wind e Saaty (1980) matrizes de ordem 3 (três) possuem inconsistência máxima tolerável de $5 \%$, matrizes de ordem 5 , inconsistência máxima tolerável de $8 \%$ e matrizes de ordem superior a 5 , inconsistência máxima tolerável de $10 \%$.

A condução da primeira rodada resultou em inconsistência de respostas acima do aceitável $(<0,1)$ para o critério "Custo" em 8/12 entrevistas. Todavia, após esclarecimentos e argumentação individual a cada um dos entrevistados do critério de análise e comparação entre os indicadores, obtiveram-se novos resultados: inconsistência de respostas acima do aceitável $(<0,1)$ para o critério "Custo" em 0/12 entrevistas.

Para o critério "Qualidade do serviço entregue", em 7/12 entrevistas, superaram o limite aceitável de $10 \%$. Após esclarecimentos e argumentação individual a cada um dos entrevistados do critério de análise e comparação entre os indicadores, os resultados foram inconsistência de respostas acima do aceitável $(<0,1)$, em $0 / 12$ entrevistas.

Por fim, para o critério "Satisfação do Cidadão", em 8/12 entrevistas, extrapolaram o limite de $10 \%$. Contudo, após esclarecimentos e argumentação individual a cada um dos entrevistados do critério de análise e comparação entre os indicadores, os resultados foram inconsistência de respostas acima do aceitável $(<0,1)$, em $0 / 12$ entrevistas.

O estudo não buscou aplicar a técnica de multicritérios para reduzir o conjunto de dimensões a exemplo do proposto por Bernand Roy (1968) com o Electre. ${ }^{59}$

\footnotetext{
57 Indicadores: Ambiental, Econômico, Financeiro, Governança, Qualificação, Social e Técnico/Operacional.

58 Vetor de Eigen.
} 
Pretendeu-se observar o grau de importância atribuído aos indicadores, de acordo com o critério de teste, por meio da média dos resultados normalizados obtidos nas entrevistas e ponderados para a validação.

Infere-se que os resultados se mostraram consistentes para a atribuição de relevância do indicador aos critérios em análise. Impende destacar que, quando questionados os entrevistados para o julgamento sob o critério de "Satisfação do Cidadão", Tabela "C", notou-se forte peso atribuído ao indicador de "Governança". Possivelmente, a motivação para tal impacto deve-se ao fato de a ampla experiência do grupo entrevistado na compreensão das dificuldades e dos desafios de se colocar em prática projetos dessa natureza, no contexto de grande público, direta ou indiretamente, beneficiado com o serviço a ser provido.

\begin{tabular}{|c|c|c|c|c|c|}
\hline \multirow{2}{*}{\multicolumn{2}{|c|}{ A }} & \multicolumn{4}{|c|}{ Estatística } \\
\hline & & \multicolumn{2}{|c|}{$\begin{array}{c}\text { Média } \\
\text { normalizada }\end{array}$} & \multicolumn{2}{|c|}{$\begin{array}{l}\text { Desvio- } \\
\text { padrão }\end{array}$} \\
\hline Critério & Rodada & $1^{\mathrm{a}}$ & $2^{\mathbf{a}}$ & $1^{\mathrm{a} a}$ & $2^{\mathrm{a}}$ \\
\hline \multirow{11}{*}{ Custo } & INDICADOR & & & & \\
\hline & Ambiental & 0,05 & 0,05 & 0,03 & 0,03 \\
\hline & Econômico & 0,24 & 0,21 & 0,12 & 0,09 \\
\hline & Financeiro & 0,23 & 0,22 & 0,10 & 0,10 \\
\hline & Governança & 0,13 & 0,13 & 0,08 & 0,08 \\
\hline & Qualificação & 0,11 & 0,12 & 0,06 & 0,07 \\
\hline & Social & 0,08 & 0,09 & 0,05 & 0,06 \\
\hline & Técnico/Operacional & 0,16 & 0,18 & 0,05 & 0,07 \\
\hline & Total & 1,00 & 1,00 & & \\
\hline & \multirow[b]{2}{*}{ B } & \multicolumn{4}{|c|}{ Estatística } \\
\hline & & \multicolumn{2}{|c|}{$\begin{array}{c}\text { Média } \\
\text { normalizada }\end{array}$} & \multicolumn{2}{|c|}{$\begin{array}{l}\text { Desvio- } \\
\text { padrão }\end{array}$} \\
\hline \multirow{10}{*}{$\begin{array}{c}\text { Critério } \\
\text { Qualidade } \\
\text { do Serviço } \\
\text { Entregue }\end{array}$} & Rodada & $1^{a}$ & $2^{a}$ & $1^{\mathrm{a}}$ & $2^{a}$ \\
\hline & INDICADOR & & & & \\
\hline & Ambiental & 0,08 & 0,08 & 0,05 & 0,04 \\
\hline & Econômico & 0,12 & 0,12 & 0,10 & 0,08 \\
\hline & Financeiro & 0,14 & 0,14 & 0,11 & 0,09 \\
\hline & Governança & 0,14 & 0,15 & 0,11 & 0,11 \\
\hline & Qualificação & 0,15 & 0,15 & 0,07 & 0,07 \\
\hline & Social & 0,19 & 0,18 & 0,13 & 0,11 \\
\hline & Técnico/Operacional & 0,18 & 0,18 & 0,10 & 0,10 \\
\hline & Total & 1,00 & 1,00 & & \\
\hline
\end{tabular}

Continua

Estatística

${ }^{59}$ As derivações e evoluções desta técnica concebidas por outros autores, no julgamento de critérios e pseudos-critérios.

${ }^{60}$ CQS - Custo; Qualidade do Serviço Prestado e Satisfação do Cidadão. 


\begin{tabular}{|c|c|c|c|c|c|}
\hline \multicolumn{2}{|r|}{ C } & \multicolumn{2}{|c|}{$\begin{array}{c}\text { Média } \\
\text { normalizada }\end{array}$} & \multicolumn{2}{|c|}{$\begin{array}{l}\text { Desvio- } \\
\text { padrão }\end{array}$} \\
\hline Critério & Rodada & $\mathbf{1}^{\mathbf{a}}$ & $2^{\mathbf{a}}$ & $1^{a}$ & $2^{\mathbf{a}}$ \\
\hline \multirow{9}{*}{$\begin{array}{l}\text { Satisfação } \\
\text { do Cidadão }\end{array}$} & INDICADOR & & & & \\
\hline & Ambiental & 0,14 & 0,15 & 0,09 & 0,09 \\
\hline & Econômico & 0,11 & 0,12 & 0,08 & 0,08 \\
\hline & Financeiro & 0,11 & 0,11 & 0,09 & 0,09 \\
\hline & Governança & 0,14 & 0,16 & 0,10 & 0,10 \\
\hline & Qualificação & 0,13 & 0,13 & 0,06 & 0,06 \\
\hline & Social & 0,26 & 0,23 & 0,09 & 0,07 \\
\hline & Técnico/Operacional & 0,11 & 0,11 & 0,06 & 0,05 \\
\hline & Total & 1,00 & 1,00 & & \\
\hline
\end{tabular}

Fonte: Elaborado pelo Autor.

O grau de inconsistência das respostas dos entrevistados às perguntas estruturadas por meio do AHP, após 2 (duas) rodadas de arguição, ficaram dentro dos limites de tolerância à ordem das matrizes encontrados na literatura, ou seja, próximo de 0 (zero) e do total amostral. Ademais, foram observados 2 (dois) outliers, representando coerência dos pesos atribuídos pelos entrevistados aos critérios testados.

Após a verificação dos pesos atribuídos aos indicadores com base nos 3 (três) critérios de julgamento, foi realizado, junto aos entrevistados, o julgamento de Coerência Conceitual, Coerência Operacional e Utilidade. Na Tabela 43, seguem as médias dos resultados das entrevistas.

Tabela 13 - Pesos das entrevistas aos critérios CCCOU61

\begin{tabular}{|c|c|c|c|c|c|}
\hline \multirow{2}{*}{\multicolumn{2}{|c|}{ A }} & \multicolumn{4}{|c|}{ Estatística } \\
\hline & & \multicolumn{2}{|c|}{ Média normalizada } & \multicolumn{2}{|c|}{ Desvio-padrão } \\
\hline Critério & $\begin{array}{l}\text { Rodada } \\
\text { INDICADOR }\end{array}$ & $1^{a}$ & $2^{\underline{a}}$ & $1^{\underline{a}}$ & $2^{\mathrm{a}}$ \\
\hline \multirow{4}{*}{$\begin{array}{l}\text { Coerência } \\
\text { Conceitual }\end{array}$} & Definição & 0,35 & 0,28 & 0,28 & 0,20 \\
\hline & $\begin{array}{l}\text { Interpretação } \\
\text { Significado }\end{array}$ & 0,27 & 0,30 & 0,23 & 0,25 \\
\hline & Relevância & 0,38 & 0,42 & 0,27 & 0,26 \\
\hline & & 1,00 & 1,00 & & \\
\hline \multirow{2}{*}{\multicolumn{2}{|c|}{ B }} & \multicolumn{4}{|c|}{ Estatística } \\
\hline & & Média & Ializada & Desvi & padrão \\
\hline \multirow[t]{2}{*}{ Critério } & $\begin{array}{l}\text { Rodada } \\
\text { INDICADOR }\end{array}$ & $1^{\mathrm{a}}$ & $2^{\mathrm{a}}$ & $1^{\underline{a}}$ & $2^{\mathrm{a}}$ \\
\hline & Dados e unidades & 0,25 & 0,22 & 0,25 & 0,22 \\
\hline Coerência & Formulação & 0,22 & 0,23 & 0,22 & 0,23 \\
\hline \multirow[t]{4}{*}{ Operacional } & Método de Medida & 0,31 & 0,29 & 0,31 & 0,29 \\
\hline & $\begin{array}{l}\text { Precisão da } \\
\text { Sensibilidade }\end{array}$ & 0,22 & 0,25 & 0,22 & 0,25 \\
\hline & & 1,00 & 1,00 & & \\
\hline & & \multicolumn{3}{|c|}{ Estatística } & Continua \\
\hline
\end{tabular}

${ }^{61}$ CCCOU - Coerência Conceitual, Coerência Operacional e Utilidade. 


\begin{tabular}{|c|c|c|c|c|c|}
\hline \multirow[b]{2}{*}{ Critério } & \multirow[b]{2}{*}{ Rodada } & \multicolumn{2}{|c|}{ Média normalizada } & \multicolumn{2}{|c|}{ Desvio-padrão } \\
\hline & & $1^{\mathrm{a}}$ & $2^{\mathrm{a}}$ & $1^{\underline{a}}$ & $2^{\mathrm{a}}$ \\
\hline \multirow{7}{*}{ Utilidade } & INDICADOR & & & & \\
\hline & $\begin{array}{c}\text { Confiança na Fonte do } \\
\text { Îndice }\end{array}$ & 0,25 & 0,25 & 0,25 & 0,25 \\
\hline & Confiança no índice & 0,18 & 0,17 & 0,18 & 0,17 \\
\hline & Custo da Informação & 0,13 & 0,13 & 0,13 & 0,13 \\
\hline & $\begin{array}{l}\text { Disponibilidade e } \\
\text { Aplicabilidade }\end{array}$ & 0,22 & 0,20 & 0,22 & 0,20 \\
\hline & $\begin{array}{l}\text { Segurança do Dado } \\
\text { Informado }\end{array}$ & 0,23 & 0,25 & 0,23 & 0,25 \\
\hline & Total & 1,00 & 1,00 & & \\
\hline
\end{tabular}

Fonte: Elaborado pelo Autor.

Finalmente, atribui-se a média ponderada para a obtenção da nota de Avaliação Agregada do índice "T", para a confirmação, revisão (simples ou completa) ou refutação ${ }^{62}$.

Tabela 14 - Avaliação agregada do índice "T"

\begin{tabular}{lccc}
\hline \multicolumn{4}{c}{ Valor da Classe de Critério } \\
& $\begin{array}{c}\text { Peso } \\
\text { atribuído }\end{array}$ & $1^{\mathrm{a}}$ & \multicolumn{2}{c}{ Rodada } \\
Coerência Conceitual & 0,33 & 4,034752 & 4,166667 \\
Coerência Operacional & 0,33 & 4,231079 & 4,327408 \\
Utilidade do índice & 0,33 & 4,061864 & 4,07145 \\
$\begin{array}{l}\text { Nota de Avaliação } \\
\text { Agregada }\end{array}$ & $\mathbf{1 , 0 0}$ & $\mathbf{4 , 1 0 9 2 3 2}$ & $\mathbf{4 , 1 8 8 5 0 8}$ \\
\hline
\end{tabular}

Fonte: Elaborado pelo Autor.

Os cálculos utilizados para o alcance das respectivas Notas de Avaliações Agregadas encontram-se no Apêndice $H$. Segundo a classe de enquadramento do índice, de acordo com a proposta de Cloquell-Ballester et al. (2006), o resultado condiciona a ajustes no índice "T". Muito embora a primeira rodada de arguições com os entrevistados não tenha resultado em significativa alteração da nota final, a segunda rodada mostrou consistência dos indicadores às dimensões sugeridas de análise.

${ }^{62}$ De acordo com Cloquell-Ballester et al.(2006), a Avaliação Agregada deve ser classifica em quatro categorias:

- Maior que 4,5: validado;

- Entre 3,5 e 4,5: necessidade de uma breve revisão;

- Entre 2,5 e 3,5: necessidade de uma revisão completa;

- Menor que 2,5: inaceitável, redefinir. 
Cumpre salientar que o ajuste no índice exigiria novas pesquisas para 0 entendimento de outras dimensões não observadas ou mesmo conjunto de variáveis exógenas e incertas. Contudo, os resultados sustentam a relevância da proposta para o processo de tomada de decisão para os gestores de unidades de PPP/PFIs e partes interessadas na proposição de PMls.

\subsubsection{AVALIAÇÕES DOS ESPECIALISTAS SOBRE O ÍNDICE "T”}

Com a adoção do modelo de estatística descritivo, foi possível constatar nas 12 sentenças formuladas, em relação ao índice "T", que apenas 2 (duas) apresentaram desvio-padrão superior a 1 (um), apenas uma pergunta manteve desvio-padrão superior a 1 (um), após arguição recursiva, e a resposta divergente permitiu reflexões sobre as limitações do índice (seção 8.1). Os dados coletados com os respectivos gráficos encontram-se no Apêndice G.

Os entrevistados foram motivados a problematizar os pontos críticos do índice "T". A discussão pautou-se em trazer maior segurança para a validação do índice com base na prática de mercado e conceitos da academia. A complexidade e volume financeiro, envolvidos em projetos de PPP/PFIs, exigiriam maior tempo de pesquisa para a aplicação experimental do índice "T". É possível constatar, por meio das colocações dos profissionais entrevistados, as virtudes e desafios que o índice possui. No quadro 35, têm-se as citações ${ }^{63}$ advindas dos respondentes organizadas por tema central abordado, as constatações elaboradas pelo autor desta tese e as evidências consideradas.

${ }^{63}$ Salienta-se que as citações advindas dos respondentes foram transcritas fielmente. Logo, estão presentes marcas de oralidade e aspectos linguísticos característico da língua falada. 
Quadro 35 - Pontos fortes do índice proposto (a)

\section{Constatação}

Processo de Avaliação de Propostas Realizados com grande subjetividade.

Necessidade de busca de conhecimento externo dos quadros da iniciativa pública.

Necessidade de um framework para a avaliação das propostas.

Dificuldades de órgãos de controle elaborarem pareceres consistentes sobre certames de PPP/PFIs realizado sob a égide das PMIs, ocasionando a suspensão dos Processos.

\section{Evidência}

Carência no mercado de editais com regras claras sob quais critérios serão julgadas as propostas submetidas.

Não é comum encontrar unidades de PPP/PFI em cidades de pequeno e médio porte, seja em países desenvolvidos ou em desenvolvimento.

Os mecanismos de recepção de PMls atuais não apresentam sistemáticas para a avaliação das propostas recepcionadas.
"(...) inexistência de mecanismo arregimentados para a avaliação dos estudos que são recebidos e comparação dos estudos para ressarcimento e aproveitamento. Em vista da dificuldade de comparabilidade dos estudos (...)"

"(...) tira as incertezas e as interpretações errôneas na hora de avaliação do melhor projeto para a população (...)"

"(...) o processo de tomada de decisão tem sido feito na base do feeling na base do eu acho. (...)"

"(...) qualquer instrumento que tem como objetivo atacar o mal da subjetividade é um instrumento válido."

"(...) buscar sair da subjetividade das percepções pessoais para algo que tenha um significado prático."

"(...) reduzir custos da gestão pública, (do poder público) no médio prazo dado a necessidade de uma equipe interna menor."

"(...) o PMI tem se tornado o principal instrumento de estruturação de projeto nos munícipios e nos estados [Brasil] (...) e como principal ferramenta de estruturação de projetos a definição de critérios objetivos [para a avaliação de projetos], (...) é

possível dizer que qualquer esforço de sistematização robusto ... é benéfico para o

mercado de PPP/PFI, (...) a criação dos indicadores de análise [a compor o índice

"T"] com as macro dimensões em 7 grupos definidos e a criação de [validadores] a

luz de propriedades específicas de análise parece ser um framework de trabalho de avaliação possível de extrapolar e genérico o suficiente para abarcar diferentes setores e projetos, portanto bem adequado para a avaliação de projetos de PPP/PFI e concessão estruturados por meio do PMI."

"(...) sintetizar a valoração de diferentes projetos com diferentes perfis."

Entrevistado 10

Recorrente informe de cancelamento de e editais. Fonte: Portal PPP/PFI.

Referencial

Entrevistado 01

Entrevistado 04

Entrevistado 05

Entrevistado 06

Entrevistado 11

Entrevistado 02

Entrevistado 03

"(...) viabilizando também maior controle dos órgãos fiscais."

Entrevistado 07 
Quadro 36 - Pontos fortes do índice proposto (b)

Conclusão

Evidência

Relatório da empresa Radar PPP/PFI para o caso brasileiro.

Os marcos regulatórios consultados, somente disciplinam as regras de submissão, mas não de como serão avaliadas as propostas, sob quais

critérios.
Constatação

\section{Citação}

Referencia

"(...) Existência de carência de ferramentas e instrumentos que norteiem os poderes concedentes no processo de elaboração de PMls, e observa-se no mercado elevada taxa de insucesso de projetos desta natureza, gerando uma ideia

Entrevistado 09 negativa do instituto dos PMls."

"por meio de um processo único e racional de todas as propostas."

Entrevistado 08 maior competição.

"(...) relevante para que se possa escolher os melhores pontos de cada uma das propostas submetidas."

Fonte: Organizado pelo Autor 


\subsubsection{POTENCIAIS DIFICULDADES PARA A APLICAÇÃO DO ÍNDICE "T”}

Os especialistas pontuaram possíveis dificuldades para a aplicação do índice "T". Para eles, um dos desafios será a qualificação específica dos operadores, tanto os operadores públicos quanto privados, em função da curva individual de aprendizado de cada um, ou seja, em razão da baixa familiaridade dos gestores de projetos com os conceitos de Propriedade de Visão do Produto. Ademais, de acordo com o Entrevistado 07, "Podendo inclusive ocasionar aumento dos custos transacionais dos projetos".

Outro desafio consiste na interpretação dos conjuntos de variáveis das propostas pelos representantes do ente concedente. Do lado da iniciativa privada, haverá a necessidade de calibrar as informações das variáveis a serem inseridas nos indicadores que compõem o índice para a menor incidência de erro possível. É necessário, também, evitar que o índice oculte processos de seleção adversa de proponentes.

Considerando os desafios pontuados, corrobora-se a afirmação do Entrevistado 09 sobre a "necessidade de criação de um passo a passo (simples e detalhada) ${ }^{64}$ de orientação para a análise do índice."

Convém pôr em relevo que a diversidade de objetos, que possam ser passíveis de estudos via PMI, pode ser um limitador de aplicação prática do índice, por exemplo: serviços de educação, serviços hospitalares, serviços prisionais, uma rodovia ou habitação. Em outras palavras, o grande desafio de implantação do índice será criar uma parametrização uniforme que considere a diversidade de objetos do mercado. Outrossim, é necessário considerar que haverá um parâmetro que pesará mais e outros que pesarão menos. A variabilidade de escopo dos serviços a serem contratados poderá ocasionar uma deformidade nas medições das variáveis.

Merece atenção, também, a ausência de dimensão jurídica exclusiva no índice, em razão dos entes federativos, em especial os municípios de médio e pequeno porte, não possuírem corpo técnico específico para a articulação das matérias por meio das procuradorias locais. Em contrapartida, o preenchimento do requisito, por meio da variável "aspectos jurídicos relevantes", poderia abarcar a captura de anexos para as peças modelos. Consequentemente, a execução do processo tornar-se-ia mais célere.

\footnotetext{
${ }^{64}$ Não foi relatado na entrevista a existência de seção do corpo da tese que aborde esta demanda.
} 
Outra potencial dificuldade identificada é do escopo do conjunto de variáveis. De acordo com o Entrevistado 03,

pode tornar a avaliação do setor público complexa, embora haja uma simplificação das definições em critérios objetivos, o tempo necessário para que esta análise seja rodada é algo a se avaliar, porém difícil de dizer com base no framework teórico, sendo necessário aplicação prática (...) duas limitações importantes [foram notadas]: tempo e a clareza do tratamento dos critérios do ponto de vista estatístico para que a resposta seja válida." Entrevistado 03.

O questionamento sobre a redução da análise de 7 (sete) indicadores fez-se preocupante. Essa seria suficiente para a o processo de tomada de decisão do gestor público? Tal questionamento ocasionou um sentimento de desconfiança a respeito da metodologia proposta. Alguns entrevistados entenderam que, talvez, a metodologia não fosse explicativa para projetos complexos ou ainda para que os membros do executivo e do legislativo fossem persuadidos. Logo, seria um fator a dificultar a adoção do índice. A esse respeito, os Entrevistados 05 e 09 refletem:

"a comunicação é um desafio comum relativamente grande para a viabilização do índice como política pública". Entrevistado 05.

A captura de subjetividade de demandas populares também foi relatada como um desafio de implantação do índice: "fatores intangíveis e existem fatores relativos [as demandas sociais das ruas] e não é índice algum capaz de quantificar alguns destes "sentimentos" e clamores [fatores subjetivos]." Entrevistado 06.

De acordo com o Entrevistado 08, tem-se outro desafio: a grande variação de propostas:

"A variância muito grande entre propostas pode representar um problema, pois estas podem ter elementos que dificultem a comparação entre as propostas, gerando resultados mais incertos se os indicadores resultarem em pesos mais dissonantes." Entrevistado 08.

Por fim, foram indicadas duas dificuldades: o índice não contempla garantias e não pode ser um fato decisório. 
"O índice não pode ser o único fator decisório para um processo de escolha de projeto, ele não pode único e exclusivo." Entrevistado 12.

Em lógica decorrência os desafios apontados, há o entendimento que tais variáveis estejam contempladas no corpo da descrição das variáveis do indicador Técnico/Operacional. Entretanto, tal apontamento, sinaliza a necessidade de melhor clareza, podendo ser objeto de análise para a versão 2.0 do índice. 


\section{CONCLUSÕES E DISCUSSÕES}

Nesta pesquisa foram investigadas questões relacionadas ao desafio de avaliação de PMls. A análise da literatura e um levantamento com especialistas demonstram que há uma predominância no uso de indicadores quantitativos, e que o VfM se destaca como instrumento principal para a seleção de propostas de PMls. Contudo, segundo os especialistas consultados, o VfM possui características que o tornam insuficiente para a escolha da proposta mais adequada a necessidade do ente federado a um dado público.

Este levantamento confirmou as evidências de limitação da visão mais quantitativa e financeira e sobre a importância de fatores qualitativos, a saber: descritivo de riscos e responsabilidades, relevância social do projeto, inovações tecnológicas, previsão de demanda do serviço, metas e impactos contemplados.

O levantamento realizado com a devolutiva de 45 (quarenta e cinco) especialistas, descrito no Capítulo 5, permitiu gerar uma lista de Fatores Críticos de Sucesso, positivos e negativos, capazes de serem aplicados na avaliação de PPP/PFIs e PMls. Uma análise hierárquica dos dados indicou ainda que os aspectos críticos podem ser reunidos em 7 (sete) dimensões: "Qualificação"; "Governança"; "Técnico/Operacional"; "Econômico"; "Financeiro"; "Ambiental" e "Social".

As dimensões identificadas são uma contribuição para a análise de PMIs pois indicam um caminho que pode ser seguido. Juntamente com os instrumentos de pesquisa desenvolvidos, baseados no levantamento da literatura e com especialistas, servem como indicação de meios para a avaliação de PMls em geral.

Um exemplo de aplicação das dimensões foi apresentado, indicando como se pode realizar a sua aplicação. As dimensões serviram de referência para a proposição de 7 (sete) indicadores descritos no anexo da pesquisa, que reúnem conjunto de variáveis atreladas a cada uma das dimensões, associados a um número índice nomeado de índice "T", constituíram uma proposta de modelo para avaliação de PMIs. O conjunto de dimensões permite análises sob múltiplos parâmetros das propostas apresentadas, reduzindo o grau de subjetividade dos árbitros no processo de avaliação das propostas e a respectiva comparação e hierarquização das escolhas.

$O$ conjunto de indicadores fruto da primeira parte da pesquisa foi testado com 12 (doze) especialistas. A primeira contribuição deste teste foi permitir a identificação de pesos capazes de serem utilizados para "equilibrar" os indicadores. 
Este procedimento de definição de pesos permite uma análise multicritério mais apropriada do que a simples aplicação de indicadores distintos para cada dimensão. E o procedimento desenvolvido, incluindo artefatos para aplicação, servem como referência para interessados em fazer uso das dimensões e indicadores propostos.

Os especialistas foram questionados também sobre a utilidade e aplicabilidade das dimensões, frente aos benefícios para o cidadão. As dimensões representadas pelos indicadores foram testadas por meio do método " $3 \mathrm{~S}$ " proposto por Cloquell-Ballester et al. (2006), uma vez que se trata da realidade contextual do estudo proposto, isto é, ocorre a impossibilidade de consulta populacional em razão da especificidade temática não ser de domínio público.

Os especialistas foram confrontados aos diferentes papéis de atuação em projetos de PMI, no de empresa proponente, no de órgão interessado e por fim no papel de cidadão beneficiado pelo projeto a ser constituído pela PPP via PMI. Tais papéis resultaram em perguntas e respostas via método AHP, com alto grau de consistência das arguições.

O resultado indicou que na opinião dos entrevistados, a proposta de dimensões e do indicador permitiria uma classificação dos projetos submetidos, o que serve como primeira avaliação da viabilidade de uso da proposta. Há, portanto, potencial para que a aplicação de indicadores conforme proposto possam produzir propostas mais concisas e aderentes às diretrizes versadas nos editais públicos.

A avaliação agregada do índice "T" ocorreu pela verificação dos pesos dos indicadores com base nos critérios de julgamento: Coerência Conceitual, Coerência Operacional e Utilidade, bem como para corroborar com a assertiva anterior de que os indicadores desta proposta são instrumentos válidos capazes de medir as Propostas de PMI sob diferentes aspectos, atingindo assim o objetivo da tese de estruturação dos indicadores e consolidação no índice "T". Somados, resultaram no valor 4,18, indicando necessidade de breve revisão, segundo Cloquell-Ballester et al. (2006), valores acima de 4,5 indicam irrestrita aprovação do indicador proposto. Contudo, no caso em tela fruto do estudo, a partir da primeira rodada, observa-se consistência nos indicadores às dimensões sugeridas, sugerindo familiaridade dos profissionais com os problemas vivenciados no setor e/ou fácil compreensão de perguntas elaboradas pelo estudo.

Um aspecto positivo da proposta, ressaltado pelos entrevistados, foi a possibilidade de redução dos custos de preparação das propostas pela iniciativa privada e o aumento dos custos de avaliação das propostas em razão dos técnicos 
necessitarem de familiarização com o procedimento de atribuição dos pesos e das notas das variáveis dos indicadores que compõem o índice "T". Logo, necessita-se de treinamento direcionado para a ampliação teórica do conhecimento de design de produto (Propriedades de Visão de Produto).

\subsection{LIMITAÇÕES DA PESQUISA}

A pouca maturidade do instituto PMI e o entendimento semântico plural do mercado e do meio acadêmico a esse são índices que apontam para a necessidade de estudos neste campo de conhecimento. Certamente, carecem de referências teóricas sólidas. Ademais, há a inexistência de uma base de dados central que congregue todas as informações relativas a PMls nos países dificulta o aprimoramento de pesquisas mais aprofundadas. As bases disponíveis, muitas vezes, não são consistentes dada a sobreposição de marcos legais, tornando a averiguação das informações uma tarefa árdua em um terreno árido.

Nesta tese, uma limitação foi o procedimento adotado na síntese das dimensões a partir dos fatores críticos, sendo pautada na experiência do autor. A aplicação de técnica mais sofisticadas de análise semântica poderiam resultar em maior precisão dos agrupamentos dos FCSs Positivos e Negativos e influenciar no conjunto de variáveis do modelo de indicadores.

Foi também observado no estudo limitações relacionadas às possíveis variáveis não observadas no modelo de aplicação, em razão do contexto, do escopo, da natureza e da extensão dos projetos a serem avaliados. Uma possibilidade de solução seria a busca de novas dimensões e conjunto de variáveis, sendo indicado por parte dos especialistas entrevistados o risco político de projetos desta natureza. Entende-se que esse seja apresentado pelo indicador Técnico/Operacional com a medição das variáveis Riscos e Responsabilidades. Entretanto, cabe a reflexão se não seria significativa a elaboração de uma dimensão específica para o estudo do impacto político no curso do projeto.

A temporalidade foi outro fator limitador para a definição dos indicadores e o índice em si, uma vez que os Fatores Críticos para o Sucesso das PPP/PFIs e PMls são diretamente influenciados pelos marcos jurídicos vigentes no contexto de estudo. Dessa forma, exige-se parcimônia dos operadores do índice à sua aplicação intertemporal, isto é, sem atenção a mudanças nas legislações e normativas que regem os institutos PPP/PFI e PMI. 
Pautado na percepção dos especialistas entrevistados, optou-se na pesquisa pela não atribuição de notas vinculadas as Propriedades de Visão do Produto ao Indicador Governança da Dimensão de mesmo nome. Segundo os especialistas cada projeto possui características abstratas e únicas que refletirão nos escopos e tecnologias adotadas. Tal singularidade das propostas pode resultar em necessidades distintas quanto ao número total de profissionais envolvidos e as respectivas atribuições de responsabilidades, o que pode impactar na forma de comparação das propostas, induzindo os avaliadores a julgamentos equivocados.

\subsection{PROPOSTAS E PERSPECTIVAS FUTURAS}

Sugere-se, como proposta futura, expandir a base de aplicação da pesquisa para outros grupos de interesse, por meio da submissão de novas entrevistas com novos atores do mercado, para observar as perspectivas sob tais prismas e verificar aderência ao modelo. A identificação das demandas não capturadas na pesquisa e os requisitos que por ventura também não tenham sido qualificados poderiam fazer parte da metodologia. Outrossim, as entrevistas e aplicações poderiam ser realizadas com legisladores e representantes do executivo na esfera Federal.

Outra abordagem possível seria a realização da aplicação dos questionários e entrevistas em países que adotam as PMls dentro de seus ordenamentos jurídicos, como prática de viabilização de projetos de PPP/PFI. Deve-se testar o grau de similaridade de julgamento das variáveis latentes nas propriedades de Visão do Produto, sob escala determinada, confrontando assim os resultados obtidos com a amostra realizada neste estudo (ou seja, em território brasileiro). Por sua vez, os resultados poderiam conduzir grupos de representatividade social e política a se mobilizarem para a formulação de procedimentos práticos e operacionais para a modernização de políticas públicas relativas à aquisição de contratações públicas. Assim, essas desempenhariam um mecanismo de celeridade processual, transparência e competitividade no processo de aquisições (Lopes and Carvalho 2012), deixando no passado a característica de mero instrumento burocrático.

Surge como oportunidade para projetos futuros a aplicações das dimensões em casos reais e pesquisas mais profundas para se estabelecer os limites de alcance da proposta desenvolvida, incluindo dimensões, artefatos para o seu desdobramento em indicadores e os próprios indicadores e pesos. 
Por fim, elencam-se 4 (quatro) possibilidades de ampliação e aprofundamento da pesquisa:

1. Validação das dimensões em casos reais de avaliação de PMls, o que poderia ampliar o modelo atual, por exemplo, conforme apontado por um dos entrevistados que sentiu falta da dimensão "Garantias", e que parece pertinente.

2. Estudo mais profundo sobre a derivação de indicadores a partir das dimensões identificadas. Seria possível tanto explorar propostas de novos indicadores como a de números índices, inclusive por meio do aprofundamento sobre variáveis específicas por tipo de projeto de PPP.

3. Análise estatística da interação e influência de um indicador sobre os outros e o detalhamento unitário das variáveis, com o intuito de que o modelo conceitual avance para um modelo determinístico de valores parametrizados e que satisfaça condições inicialmente encontradas no ambiente a ser desenvolvida a PPP/PFI. Os objetivos principais seriam capturar e eliminar variações aleatórias das variáveis que resultem na necessidade de realinhamento de preços e/ou alteração dos escopos dos projetos.

4. A quarta e última seria a medição do grau de eficiência e eficácia do índice no custo final das propostas submetidas. Esta seria uma etapa avançada pois dependeria da existência de aplicação da proposta em vários casos reais, permitindo assim uma avaliação sobre o impacto no sucesso, diminuição de risco ou mesmo na eficiência das propostas. 


\section{REFERÊNCIAS}

ABEDNEGO, M.P.; OGUNLANA, S.O. Good project governance for proper risk allocation in public-private partnerships in Indonesia. International Journal of Project Management, v. 24, n. 7, p. 622-634, 2006. Disponível em:<http://www.sciencedirect.com/science/article/pii/S0263786306000974>. Acesso em: 16 jan. 2018.

ACT GOVERNMENT. Guidelines for public private partnerships. $2^{\text {nd }} e d$. Camberra: ACT Government, 2016.

ADAMIECKI, K. et al. 9 th International Conference (2003) "Public and Private Sector Partnerships: Sustainable Success" By PhD candidate, Department of Public Policy Correspondence please to both Christos Apostolakis and Lawson Smith at the above addresses Public-Privat., n. May, p. 1-21, 2003.

APOSTOLAKIS, C.; SMITH, L. Public private partnerships: a new form institutionalism. In INTERNATIONAL CONFERENCE PUBLIC AND PRIVATE SECTOR PARTNESRSHIPS: sustainable success, 9., 2003, Katowice. Disponível em:<https://www.academia.edu/1145447/Public-

private_Partnerships_A_New_Form_of_Institutionalism>. Acesso em: 03 nov. 2017.

AKBIYIKLI, R.; EATON, D. A Value for money (VFM) framework proposal for PFI road projects. In: SUSTAINABILITY AND VALUE THROUGH CONSTRUCTION PROCUREMENT, 2006, Salford. Proceedings... [S.I.s.n.], 2006. p.18-35.

Disponível em:<https://www.irbnet.de/daten/iconda/CIB1848.pdf >. Acesso em: 03 jan. 2018.

AKINTOYE, A.; FITZGERALD, E.; HARDCASTLE, C. Risk management for local authorities' private finance initiative projects. New York: RICS Research Foundation; Cobra 1999.

Disponívelem:<https://scholar.googleusercontent.com/scholar?q=cache:hFAQjpOW mGYJ:scholar.google.com/+\%22Risk+Management+for+Local+Authorities\%E2\%80 $\% 99+$ Private+Finance+Initiative+Projects.+RICS+Research+Foundation,+Cobra+19 $99,+,+$ n. + December $,+1999 \% 22 \& h l=p t-B R \& \mid r=\& a s \_s d t=0,5 \& a s \_v i s=1>$. Acesso em: 17 mar. 2017.

ALBANO, G.L.; CESI, B.; IOZZI, A. Public procurement with unverifiable quality: the case for discriminatory competitive procedures. Journal of Public Economics, v. 145, p. 14-26, 2017. DOI: http://dx.doi.org/10.1016/j.jpubeco.2016.11.004.

AMBERG, M.; FISCHL, F.; WIENER, M. Background of critical success factor research. Evolution, v. 17, n. 2, p. 12, 2005. Disponível

em:<http://www.international-outsourcing.de/CSF-

Tool/docs/WorkingPaper_BackgroundCSF_Ambergetal._FINAL.pdf>. Acesso em: 08 mar. 2017.

AMEYAW, E.E.; CHAN, A.P. Risk ranking and analysis in PPP water supply infrastructure projects. Facilities, v. 33, n. 7/8, p. 428-453, 2015a. DOI: http://www.emeraldinsight.com/doi/10.1108/F-12-2013-0091. 
AMEYAW, E.E.; CHAN, A.P.C. Evaluation and ranking of risk factors in publicprivate partnership water supply projects in developing countries using fuzzy synthetic evaluation approach. Expert Systems with Applications, v. 42, n. 12, p. 5102-5116, 2015b. Disponível em:<http://linkinghub.elsevier.com/retrieve/pii/S0957417415001487>. Acesso em: 31 out. 2017.

AMSTER, R.; BÖHM, C. Improving intercultural competency in global IT projects through recognition of culture-based behaviors. International Journal of Information Systems and Project Management, v.4, n.2, p.5-20, 2016. DOI: $10.12821 /$ ijispm040201.

ANDERBERG, M.R. Cluster analysis for applications. New York: Academic Press; Amsterdã: Elsevier Science, 2014.

ANDRES, L.A.; GUASCH, J.L. Negotiating and renegotiating PPPs and concessions. In: SCHWARTZ, G.; CORBACHO, A.; FUNKE, K. (Ed.). Public investment and public-private partnerships. Berlin: Springer, 2008. p.197-227.

ARATA, M.; PETRANGELI, M.; LONGO, F. Innovative approaches to implement road infrastructure concession through public-private partnership (PPP) initiatives: a case study. Transportation Research Procedia, v. 14, p. 343-352, 2016. DOI: http://dx.doi.org/10.1016/j.trpro.2016.05.086.

ASENOVA, D.; BECK, M. Obstacles to accountability in PFI projects. In: AKINTOYE, A.; BECK, M. Policy, finance \& management for public-private partnerships. New York: Wiley-Blackwell, 2009. Cap.3, p.47-63.

ASKER, J.; CANTILLON, E. "Properties of Scoring Auctions." RAND Journal of Economics 39(1): 69-85, 2008.

ASSOCIATION PPP SUISSE. Paternariat public-privé (PPP): guide pratique bâtiment. Suisse, 2016.

ATKINSON, R.; CRAWFORD, L.; WARD, S. Fundamental uncertainties in projects and the scope of project management. International Journal of Project Management, v. 24, n. 8, p. 687-698, 2006. Disponível em:<http://linkinghub.elsevier.com/retrieve/pii/S0263786306001438>. Acesso em: 04 fev. 2017.

AURIOL, E.; PICARD, P.M. A Theory of BOT concession contracts. Journal of Economic Behavior and Organization, v. 89, p. 187-209, 2013. DOI: http://dx.doi.org/10.1016/j.jebo.2011.10.003.

BABBIE, E.R. The Basics of social research. $6^{\text {th }}$ ed. Belmont: Wadsworth Cengage Learning, 2013.

BADI, S. Public sustainable-energy requirements and innovation in UK PFI school projects. Construction Management and Economics, v.35, n.4, p.218-238, 2016. DOI: https://www.tandfonline.com/doi/full/10.1080/01446193.2016.1237034. 
BAUR, A. et al. Partenariat public-privé (PPP) guide pratique bâtiment. Zurich: Association PPP Suisse, 2016.

BEALE, E.M.L. Euclidean cluster analysis. Wavendon: Scientific Control Systems, 1969.

BEL, G.; BROWN, T.; MARQUES, R.C. Public-private partnerships: infrastructure, transportation and local services. Local Government Studies, v. 39, n. 3, p. 303311, 2013. Disponível

em:<http://www.tandfonline.com/doi/abs/10.1080/03003930.2013.775125>. Acesso em: 31 out. 2017.

BENASSI, J.L.G.; AMARAL, D.C. Método para a descrição da visão do produto no contexto do gerenciamento ágil de projetos. Produção, v. 21, n. 3, p. 392-403, 2011. Disponível em:<http://www.scielo.br/scielo.php?script=sci_arttext\&pid=S0103$65132011000300004 \&$ Ing=pt\&nrm=iso\&tlng=en>. Acesso em: 07 jan. 2016.

BENASSI, João Luís Guilherme. Proposta de método para a criação da visão no gerenciamento ágil de projetos de desenvolvimento de produtos. 2013. Tese (Doutorado em Processos e Gestão de Operações) - Escola de Engenharia de São Carlos, Universidade de São Paulo, São Carlos, 2013. doi:10.11606/T.18.2013.tde15102013-085611. Acesso em: 2018-02-26.

BENASSI, J.L.G.; AMARAL, D.C.; FERREIRA, L.D. Towards a conceptual framework for product vision. International Journal of Operations \& Production Management, v. 36, n. 2, p. 200-219, 2016. DOI:

http://www.emeraldinsight.com/doi/10.1108/IJOPM-11-2013-0511.

BENASSI, J.L.G.; FERREIRA JUNIOR, L.D.; AMARAL, D.C. Identificação das propriedades da visão do produto no gerenciamento ágil de projetos de produtos manufaturados. Produto \& Produção, v.13, n.1, Mar. 2012. Disponível em:<http://www.seer.ufrgs.br/index.php/ProdutoProducao/article/view/24355>. Acesso em: 7 fev. 2016.

BEST, S.J.; KRUEGER, B.S. Internet Survey design. In: FIELDING, N.G. The Sage handbook of online research methods. London: Sage, 2008. p.217-235.

BIMBER, B. The Internet and citizen communication with government: does the medium matter?. Political Communication, v. 16, n. 4, p. 409-428, 1999.

BING, L.; AKINTOYE, A.; EDWARDS, P. J. The Allocation of risk in PPP / PFI construction projects in the UK. International Journal of Project Management, v.23, n.1, p.25-35, Jan. 2005.

BLAND, R.L.; OVERTON, M. Assessing the contributions of collaborators in publicprivate partnerships: evidence from tax increment financing. American Review of Public Administration, v. 46, n. 4, p. 418-435, 2014.

BOLBOACA, S.-D.; JÄNTSCHI, L. Pearson versus Spearman, Kendall's tau correlation analysis on structure-activity relationships of biologic active compounds. Leonardo Journal of Sciences, v. 5, n. 9, p. 179-200, 2006. 
BOYER, E.J.; VAN SLYKE, D.M.; ROGERS, J.D. An Empirical examination of public involvement in public-private partnerships: qualifying the benefits of public involvement in PPPs. Journal of Public Administration Research and Theory, v. 26, n. 1, p. 45-61, Jan. 2016. Disponível em:<https://academic.oup.com/jpart/articlelookup/doi/10.1093/jopart/muv008>. Acesso em: 6 nov. 2017.

BRASIL. Decreto no 8428, de 2 de abril de 2015. Dispõe sobre o Procedimento de Manifestação de Interesse a ser observado na apresentação de projetos, levantamentos, investigações ou estudos, por pessoa física ou jurídica de direito privado, a serem utilizados pela administração pública. Disponível em:<http://www.planalto.gov.br/ccivil_03/_ato2015-2018/2015/decreto/d8428.htm>. Acesso em: 18 maio 2017.

BRASIL. Decreto Lei Federal No 13.529, de 4 de dezembro de 2017. Dispõe sobre a participação da União em fundo de apoio à estruturação e ao desenvolvimento de projetos de concessões e parcerias público-privadas; altera a Lei no 11.079, de 30 de dezembro de 2004, que institui normas gerais para licitação e contratação de parceria público-privada na administração pública, a Lei no 11.578, de 26 de novembro de 2007, que dispõe sobre a transferência obrigatória de recursos financeiros para a execução pelos Estados, Distrito Federal e Municípios de ações do Programa de Aceleração do Crescimento (PAC), e a Lei no 12.712, de 30 de agosto de 2012, que autoriza o Poder Executivo a criar a Agência Brasileira Gestora de Fundos Garantidores e Garantias S.A. (ABGF). Disponível em:<http://www.planalto.gov.br/ccivil_03/_ato2015-2018/2017/lei/L13529.htm>. Acesso em: 7 fev. 2018.

BRASIL. Lei no 11.079, de 30 de dezembro de 2004. Institui normas gerais para licitação e contratação de parceria público-privada no âmbito da administração pública. Disponível em:<http://www.planalto.gov.br/ccivil_03/_ato20042006/2004/lei/l11079.htm>. Acesso em: 18 maio 2017.

BRYMAN, A.; BELL, E. Business research methods. Oxford: Oxford University Press, 2015.

BULMAN, D.; KOLKMA, W.; KRAAY, A. Good countries or good projects? Comparing macro and micro correlates of World Bank and Asian Development Bank project performance. The Review of International Organizations, v. 12, n. 3, p. 335-363, 2017.

BUSO, M.; MARTY, F.; TRA, T. Public private partnership from budget constraints: looking for debt hiding?. 2014. ("Marco Fanno" Working paper n. 189). Disponível em:<https://halshs.archives-ouvertes.fr/halshs-01091725>. Acesso em: 06 abr. 2017.

CAMBRIDGE advanced learner's dictionary. $3^{\text {rd }}$ ed. Cambridge: Cambridge University Press, 2008.

CAMPBELL, D.T.; BAUM, J.A.C.; MCKELVEY, B. Variations in organization science: in honor of Donald T. Campbell. London: Sage, 1999. 
CAPITAL markets in PPP financing: where we were and where are we going?. Luxembourg: European PPP Expertise Centre, 2010.

CARALLI, R.A. et al. The Critical success factor method: establishing a foundation for enterprise security management. Pittsburgh: Software Engineering Institute, 2004. (CMU/SEI - 2004 - TR - 010).

CARBONARA, N.; COSTANTINO, N.; PELLEGRINO, R. Concession period for PPPs: a win-win model for a fair risk sharing. International Journal of Project Management, v. 32, n. 7, p. 1223-1232, 2014. DOI:

http://dx.doi.org/10.1016/j.ijproman.2014.01.007.

CARRILLO, P. et al. Participation, barriers, and opportunities in PFI: the united kingdom experience. Journal of Management in Engineering, v. 24, n. 3, p. 138145, 2008.

CHANG, C.-Y. The Economics of public-private partnerships: a basic guide.

Construction Management and Economics, v. 33, n. 3, p. 233-238, 2015.

Disponível

em:<http://www.tandfonline.com/doi/full/10.1080/01446193.2015.1050965>. Acesso em: 18 dez. 2016.

CHANG, M.; IMURA, H. Developing private finance initiatives (PFI)/public-private partnerships (PPP) for urban environmental infrastructure in Asia. Environmental Systems Research, v. 30, p. 143-152, 2002.

CHO, C.-S.; GIBSON JR., G.E. Building project scope definition using project definition rating index. Journal of Architectural Engineering, v. 7, n. 4, p. 115125, Dec. 2001. Disponível

em:<http://ascelibrary.org/doi/10.1061/\%28ASCE\%291076-

0431\%282001\%297\%3A4\%28115\%29>. Acesso em: 28 out. 2017.

CHOU, J.-S.; LEATEMIA, G.T. Critical process and factors for ex-post evaluation of public-private partnership infrastructure projects in Indonesia. Journal of

Management in Engineering, v. 32, n. 5, p. 5016011-1-5016011-14, 2016. DOI: http://ascelibrary.org/doi/10.1061/\%28ASCE\%29ME.1943-5479.0000436.

CHOU, J.-S.; PRAMUDAWARDHANI, D. Cross-country comparisons of key drivers, critical success factors and risk allocation for public-private partnership projects.

International Journal of Project Management, v. 33, n. 5, p. 1136-1150, 2015.

Disponível

em:<http://www.sciencedirect.com/science/article/pii/S0263786314002117>. Acesso em: 11 abr. 2017.

CLARK, G.L.; ROOT, A. Infrastructure shortfall in the United Kingdom: the private finance initiative and government policy. Political Geography, v. 18, n. 3, p. 341365, 1999. Disponível

em:<http://www.ingentaconnect.com/content/els/09626298/1999/00000018/0000000 3/art00109>. Acesso em: 7 fev. 2016.

CLARK, K.B.; WHEELWRIGHT, S.C. Managing new product and process development: text and cases. New York: Free Press, 1993. 
CLOQUELL-BALLESTER, V.-A. et al. Indicators validation for the improvement of environmental and social impact quantitative assessment. Environmental Impact Assessment Review, v. 26, n. 1, p. 79-105, 2006.

COHEN, J. et al. Applied multiple regression/correlation analysis for the behavioral sciences. London: Routledge, 2013.

COHEN, S.G.; BAILEY, D.E. What makes teams work: group effectiveness research from the shop floor to the executive suite. Journal of Management, v. 23, n. 3, p. 239-290, 1997.

CONFORTO, E.C.; AMARAL, D.C.; SILVA, S.L. Roteiro para revisão bibliográfica sistemática : aplicação no desenvolvimento de produtos e gerenciamento de projetos. In: CONGRESSO BRASILEIRO DE GESTÃO DE DESENVOLVIEMNTO DE PRODUTO, 8., Porto Alegre, 2011. Anais... Disponível em:<http://www.ufrgs.br/cbgdp2011/downloads/9149.pdf>. Acesso em: 13 nov. 2015.

COUTINHO, L. et al. Parcerias público-privadas no Brasil. Cadernos FGV Projetos, ano 9, n.23, jan. 2014.

CRESWELL, J.W.; CLARK, V.L.P. Designing and conducting mixed methods research. London: Sage, 2010.

CRUZ, C.O.; MARQUES, R.C. Flexible contracts to cope with uncertainty in publicprivate partnerships. International Journal of Project Management, v. 31, n. 3, p. 473-483, 2013. DOI: http://dx.doi.org/10.1016/j.jproman.2012.09.006.

DALKIR, K.; BEAULIEU, M. Knowledge management in theory and practice. Cambridge: MIT, 2017.

DeCORLA-SOUZA; P.; HAM, M.; TIMOTHY, D. Illustration of a Framework for Benefit-Cost Evaluation of Highway Concession Proposals. Transportation Research Record: journal of the transportation research board, n. 2597, p. 52-59, 2016. DOI: http://trrjournalonline.trb.org/doi/pdf/10.3141/2597-07.

DeDAD, M. Risk aversion in lending following the financial crisis. In: ANNUAL INDIANA UNIVERSITY DEPARTMENT OF ECONOMICS' JORDAN RIVER ECONOMICS CONFERENCE, 13., Bloomington, 2017. Proceedings... Bloomington: Indiana University, 2017.

DENG, Z.; SONG, S.; CHEN, Y. Private participation in infrastructure project and its impact on the project cost. China Economic Review, v. 39, p. 63-76, 2016. DOI: http://dx.doi.org/10.1016/j.chieco.2016.04.004.

DEVKAR, G.A. et al. Impact of private sector participation on access and quality in provision of electricity, telecom and water services in developing countries: a systematic review. Utilities Policy, v. 27, p. 65-81, 2013. Disponível em:<http://linkinghub.elsevier.com/retrieve/pii/S0957178713000404>. Acesso em: 31 out. 2017. 
DOUMA, S.W.; SCHREUDER, H. Economic approaches to organizations. $4^{\text {th }}$ ed. Harlow: Prentice Hall, 2008.

DURSUN, O.; STOY, C. Time-cost relationship of building projects: statistical adequacy of categorization with respect to project location. Construction Management and Economics, v. 29, n. 1, p. 97-106, 2011.

DYUSSENOV, M. The Increasing role of the kazakhstan private-public partnership center JSC in promoting PPP projects. London: GRIN, 2017.

EFFAH AMEYAW, E.; CHAN, A.P.C. Identifying public-private partnership (PPP) risks in managing water supply projects in Ghana. Journal of Facilities Management, v. 11, n. 2, p. 152-182, 2013. DOI: http://www.emeraldinsight.com/doi/10.1108/14725961311314651.

EMEK, U. Turkish experience with public private partnerships in infrastructure: opportunities and challenges. Utilities Policy, v. 37, p. 120-129, Dec. 2015.

ENGEL, E.; FISCHER, R.; GALATOVIC, A. The Basic public finance of publicprivate partnerships. New Haven: Economic Growth Center; Yale University, 2007. (Center Discussion Paper, n.957).

ENGWALL, M.; JERBRANT, A. The Resource allocation syndrome: the prime challenge of multi-project management?. International Journal of Project Management, v. 21, n. 6, p. 403-409, 2003.

EUROSTAT clarification note the statistical treatment of ppp contracts. 2016. Disponível em:<http://ec.europa.eu/eurostat/documents/1015035/7204121/Clarification-noteStatistical-treatment-of-PPP-contracts-accompanying-2016-MGDD.pdf/ed12cf33f8eb-4e7e-aa58-29a5fbc3f978>. Acesso em: 6 fev. 2018.

FARQUHARSON, E. et al. How to engage with the private sector in publicprivate partnerships in emerging markets. Washington, DC: World Bank Publications, 2011.

FAY, M.; MORRISON, M. Infrastructure in Latin America and the Caribbean: recent developments and key challenges. Washington, DC: World Bank Publications, 2007.

FELLOWS, R.F.; LIU, A.M.M. Research methods for construction. New York: John Wiley, 2015.

FOURIE, F.; BURGER, P. An Economic analysis and assessment of public-private partnerships (PPPs). South African Journal of Economics, v. 68, n. 4, p. 305316, 2000.

FROUD, J. The Private finance initiative. Accounting, Organizations and Society, v. 28 , n. 6 , p. 567-589, 2003. Disponível em:<http://www.sciencedirect.com/science/article/pii/S0361368202000119>. Acesso em: 12 mar. 2017. 
GEORGAKOPOULOS, D.; HORNICK, M.; SHETH, A. An Overview of workflow management: from process modeling to workflow automation infrastructure.

Distributed and Parallel Databases, v. 3, n. 2, p. 119-153, 1995. Disponível em:<http://link.springer.com/10.1007/BF01277643>. Acesso em: 3 nov. 2017.

GEORGE, D.; MALLERY, M. Using SPSS for Windows step by step: a simple guide and reference. Boston, MA: Allyn \& Bacon, 2003.

GLIEM, J.A.; GLIEM, R.R. Calculating, interpreting, and reporting cronbach's alpha reliability coefficient for likert-type scales. In: MIDWEST RESEARCH TO PRACTICE CONFERENCE IN ADULT, CONTINUING, AND COMMUNITY EDUCATION, Columbus, 2003. p. 82-88. Disponível em:<https://scholarworks.iupui.edu/handle/1805/344>. Acesso em: 10 set. 2017.

GOMES, A.R.G. A Gestão de contratos na administração pública. Id on Line Revista Multidisciplinar e de Psicologia, v. 10, n. 29, p. 100-110, 2016.

Disponível em:<https://idonline.emnuvens.com.br/id/issue/archive>. Acesso em: 07 fev. 2017.

GREKOUSIS, G. Giving fuzziness to spatial clusters: a new index for choosing the optimal number of clusters. International Journal on Artificial Intelligence Tools, v. 22, n. 3, p. 1350009, June 2013.

GRILO, L.M. Modelo de análise da qualidade do investimento em projetos de parceria público-privada ( Ppp ). 2008. 471p. Tese (Doutorado) - Escola Politécnica, Universidade de São Paulo, São Paulo, 2008.

GRIMSEY, D.; LEWIS, M.K. Evaluating the risks of public private partnerships for infrastructure projects. International Journal of Project Management, v. 20, n. 2, p. 107-118, 2002.

Developing a framework for procurement options analysis. In: AKINTOYE, A.; BECK, M. (Ed.). Policy, finance and management for public-private partnerships. Chichester: Wiley-Blackwell, 2009. p. 398-413.

GROUT, P. The Economics of the private finance initiative. Oxford Review of Economic Policy, v. 13, n. 4, p. 53-66, 1997. Disponível em:<http://oxrep.oxfordjournals.org/content/13/4/53.short\%5Cnhttp://oxrep.oupjourna Is.org/cgi/doi/10.1093/oxrep/13.4.53>. Acesso em: 09 abr. 2016.

GUERRA, E.M.; D'AMATO, M.C. Terceirização na administração pública. Revista do Tribunal de Contas do Estado de Minas Gerais, v. 34, n. 4, p.27-41, out./dez. 2016.

UM GUIA do conhecimento em gerenciamento de projetos: guia PMBOK®. 5.ed. Newton Square: Project Management Institute, 2013. Disponível em:<https://mail.google.com/mail/u/0/\#inbox/161d482fef8de670?projector=1\&messa gePartld=0.2>. Acesso em: 07 jan. 2016. 
GURGUN, A.P.; TOURAN, A. Public-private partnership experience in the international arena: case of Turkey. Journal of Management in Engineering, v. 30, n. 6, p. 4014029-1-4014029-14, 2014. Disponível em:<http://ascelibrary.org/doi/10.1061/\%28ASCE\%29ME.1943-5479.0000213>. Acesso em: 31 out. 2017.

GUY, M.E.; NEWMAN, M.A.; MASTRACCI, S.H. Emotional labor: putting the service in public service. London: Routledge, 2014.

HADZIKADIC, M.; BOHREN, B.F.; EICHELBERGER, C.N. Incremental clustering classifier and predictor. 1 May 2007. Google Patents. Disponível em:<https://www.google.com/patents/US7213023>. Acesso em: 17 out. 2017.

HAMMAMI, M.; RUHASHYANKIKO, J.-F.; YEHOUE, E.B. Determinants of publicprivate partnerships in infrastructure. Washington: International monetary Fund, 2006. (IMF Working Paper, wp/06/99). Disponível

em:<http://papers.ssrn.com/sol3/papers.cfm?abstract_id=902765\%5Cnhttp://poseido n01.ssrn.com/delivery.php?ID=0891191050640071140970201050670911240540460 3902104205506404600900912504101011109901008509203403408410510209311 80300990171200941101231041251110010830051 >. Acesso em: 18 mai. 2017.

HARDCASTLE, C. et al. Critical success factors for PPP/PFI projects in the UK construction industry: a factor analysis approach. Construction management and economics, v. 23, n. 5, p. 459-471, 2005.

HARRISON, D.A. et al. Time, teams, and task performance: changing effects of surface-and deep-level diversity on group functioning. Academy of Management Journal, v. 45, n. 5, p. 1029-1045, 2002.

HATTEN, K.J.; HATTEN, M.L. Strategic groups, asymmetrical mobility barriers and contestability. Strategic Management Journal, v. 8, n. 4, p. 329-342, 1987.

HERMAN, M. Technical translation style: clarity, concision, correctness. In: WRIGHT, S.E.; WRIGHT JR., L.D. Scientific and Technical Translation. Amsterdam: John Benjamins, 1993. p. 11-19. (American Translators Association Scholarly Monograph Series, VI).

HIGGINS, C.D.; HUQUE, A.S. Public money and Mickey Mouse: evaluating performance and accountability in the Hong Kong Disneyland joint venture publicprivate partnership. Public Management Review, v. 17, n. 8, p. 1103-1123, 2015. DOI: http://dx.doi.org/10.1080/14719037.2014.881533.

HO, S.P.; TSUI, C.W. The Transaction costs of public-private partnerships: implications on PPP governance design. In: LEAD 2009 SPECIALTY CONFERENCE: global governmance in project organiations, South Lake Tahoe, 2009. Disponível em:<http://www.academiceventplanner.com/LEAD2009/papers/Ho_Tsui.pdf $>$. Acesso em: 07 mar. 2017.

HODGES, J.T.; DELLACHA, G. Unsolicited infrastructure proposals: how some contries introduce competition and transparence. Washington, DC: The World Bank, 2007. (GridLines, n.19, Public Private Insfraestructure Advsory Facility). 
HONG KONG INSTITUTE OF SURVEYORS. Practical guide to public private partnership (PPP) projects. Hong Kong, 2009.

HOOD, C.; JAMES, O.; SCOTT, C. Regulation of government: has it increased, is it increasing, should it be diminished?. Public Administration, v. 78, n. 2, p. 283304, 2000. Disponível em:<http://doi.wiley.com/10.1111/1467-9299.00206>. Acesso em: 9 fev. 2016.

HOPPE, E.I.; SCHMITZ, P.W. Public-private partnerships versus traditional procurement: Innovation incentives and information gathering. The RAND Journal of Economics, v. 44, n. 1, p. 56-74, 2013. Disponível em:<http://doi.wiley.com/10.1111/1756-2171.12010>. Acesso em: 24 abr. 2017.

HOUAISS, A. Dicionário Houaiss da língua portuguesa. Lisboa: Temas \& Debates, 2003.

HUESKES, M.; VERHOEST, K.; BLOCK, T. Governing public-private partnerships for sustainability: an analysis of procurement and governance practices of PPP infrastructure projects. International Journal of Project Management, v. 35, n. 6, p. 1184-1195, 2017. DOI: http://dx.doi.org/10.1016/j.ijproman.2017.02.020.

HUNT, M.S. Competition in the major home appliance industry 1960-1970. Dissertation (Doctoral) - Harvard University, Cambridge, 1972.

HUNTER, K.; KELLY, J.; TRUFIL, G. Whole life costing of sustainable design. [S.I.:S.n.], 2006.

HWANG, B.G.; ZHAO, X.; GAY, M.J.S. Public private partnership projects in Singapore: factors, critical risks and preferred risk allocation from the perspective of contractors. International Journal of Project Management, v. 31, n. 3, p. 424-433, 2013. DOI: http://dx.doi.org/10.1016/j.ijproman.2012.08.003.

IOSSA, E.; MARTIMORT, D. The Simple microeconomics of public-private partnerships. Journal of Public Economic Theory, v. 17, n. 1, p. 4-48, 2015. Disponível em:<http://doi.wiley.com/10.1111/jpet.12114>. Acesso em: 31 out. 2017.

ISEKI, H.; HOUTMAN, R. Research in transportation economics evaluation of progress in contractual terms : two case studies of recent DBFO PPP projects in North America. RETREC, v. 36, n. 1, p. 73-84, 2012. DOI:

http://dx.doi.org/10.1016/j.retrec.2012.03.004.

ISMAIL, S. Critical success factors of public private partnership (PPP) implementation in Malaysia. Asia-Pacific Journal of Business Administration, v. 5, n. 1, p. 6-19, 2013. DOI: http://www.emeraldinsight.com/doi/10.1108/17574321311304503.

ISMAIL, S. Driving forces for implementation of public private partnerships (PPP) in Malaysia and a comparison with the United Kingdom. Journal of Economic and Administrative Sciences, v. 30, n. 2, p. 82-95, 2014. DOI: http://www.emeraldinsight.com/doi/10.1108/JEAS-06-2013-0019. 
ISMAIL, S.; AZZAHRA HARIS, F. Constraints in implementing public private partnership (PPP) in Malaysia. Built Environment Project and Asset

Management, v. 4, n. 3, p. 238-250, 2014.

ISMAIL, S.; HARRIS, F.A. Challenges in implementing public private partnership ( PPP ) in Malaysia. Procedia - social and behavioral sciences, v. 164, p. 5-10, Aug. 2014. DOI: http://dx.doi.org/10.1016/j.sbspro.2014.11.044.

ITTMANN, H.W. Private-public partnerships: a mechanism for freight transport infrastructure delivery?. Journal of Transport and Supply Chain Management, v. 11, n. 1, p. 1-13, 2017.

JANEIRO, P.R. Guia suplementar para avaliações de value for money preparado pelo município do Rio de Janeiro. 2013. Disponível

em:<http://www.rio.rj.gov.br/dlstatic/10112/5305003/4138533/GuiaSuplementarparaA valiacoesdeValueforMoney.pdf>. Acesso em: 19 jan. 2018.

JEFFERIES, M.; MCGEORGE, W.D. Using public-private partnerships (PPPs) to procure social infrastructure in Australia. Engineering, Construction and

Architectural Management, v. 16, n. 5, p. 415-437, 2009. Disponível em:<http://dx.doi.org/10.1108/09699980910988348>. Acesso em: 27 maio 2017.

JENSEN, M.C. Agency costs of free cash flow, corporate finance, and takeovers. The American Economic Review, v. 76, n. 2, p. 323-329, 1986.

JICK, T.D. Mixing qualitative and quantitative methods : triangulation in action. Administrative Science Quarterly - qualitative methodology, v. 24 , n.4 , p.602-611, dec. 1979. DOI: $10.2307 / 2392366$.

JOHANNISSE, S.; COENEN, G. A Textbook Case for the Use of PPP. The Hague: PPP Knowledge Centre, 2000.

KÄRNÄ, S.; JUNNONEN, J.-M. Designers' performance evaluation in construction projects. Engineering, Construction and Architectural Management, v. 24, n. 1, p. 154-169, 2017. Disponível

em:<http://www.emeraldinsight.com/doi/10.1108/ECAM-06-2015-0101>. Acesso em: 30 mar. 2017.

KE, Y. et al. Preferred risk allocation in China's public-private partnership (PPP) projects. International Journal of Project Management, v. 28, n. 5, p. 482-492, 2010. DOI: http://dx.doi.org/10.1016/j.ijproman.2009.08.007.

. Understanding the risks in China's PPP projects: ranking of their probability and consequence. Engineering, Construction and Architectural Management, v. 18, n. 5, p. 481-496, 2011. DOI:

http://www.emeraldinsight.com/doi/10.1108/09699981111165176.

KELMAN, S. Discussion paper on procurement issues in South Africa that affect growth and development. Cambridge: Harward Kennedy School, 2008.

KENSING, F.; MADSEN, K.H. Generating visions: future workshops and metaphorical design. Nova Jersey: L.Erlbaum, 1992. 
KETCHEN, D.J.; SHOOK, C.L. The Application of cluster analysis in strategic management research: an analysis and the application of cluster analysis in strategic management research: an analysis and critique strategic management research focuses on the. Source: strategic management journal strategic management journal, v. 17, n. 17, p. 441-458, 1996. Disponível em:<http://www.jstor.org/stable/2486927>. Acesso em: 27 out. 2017.

KHMEL, V.; ZHAO, S. Arrangement of financing for highway infrastructure projects under the conditions of public-private partnership. IATSS Research, v. 39, n. 2, p. 138-145, 2016. DOI: http://dx.doi.org/10.1016/j.iatssr.2015.05.002.

KIPLI, K.; ABDULLAH, F.; MUSTAFA, F.D. The Missing point of knowledge management in PFI projects. MATEC Web of Conferences, v. 66, p. 1-11, 2016.

KOG, F. et al. A Multi-agent systems-based contractor pre-qualification model. Engineering, Construction and Architectural Management, v. 23, n. 6, p. 709726, 2016.

KOTHARI, C.R. Research methodology: methods and techniques. India: New Age International, 2004.

KOUWENHOVEN, V. The Rise of the public private partnership: a model for the management of public-private cooperation. In: KOOIMAN, J. Modern governance: new government-society interactions. Rotterdam: SAGE, 1993. p. 119-130.

KRIEGER, M.G.; FINATTO, M.J.B. Introdução à terminologia: teoria e prática. São Paulo: Contexto, 2004.

KROSNICK, J.A. Survey Research. Annual Review of Psychology, v.50, p.537567, Feb. 1999.

KURNIAWAN, F. A Review: exploring stakeholders ' expectations from PFI financial modelling at different stages. In: PROJECT MANAGEMENT CONFERENCE, India, 2010. Proccedings... New Square, 2010.

KURNIAWAN, F.; MUDJANARKO, S.W.; OGUNLANA, S. Best practice for financial models of PPP projects. Procedia Engineering, v. 125, p. 124-132, 2015. DOI: http://dx.doi.org/10.1016/j.proeng.2015.11.019.

KUŠLJIĆ, D.; MARENJAK, S. Critical PPP/PFI project success criteria for public sector clients. Tehnicki Vjesmik, v. 20, n. 6, p.945-954, Aug. 2013. Disponível em:<http://search.ebscohost.com/login.aspx?direct=true\&profile=ehost\&scope=site \& authtype $=$ crawler \&jrnl $=13303651 \& A N=93360301 \& \mathrm{~h}=5 \mathrm{~L}+\mathrm{ySM} / \mathrm{tAeFTRkXSg1EXKdiw}$ WYRBwRLaa2V8gnpt1OZMIfdMyYAvlsD7z6e5tflXq0I/qCjrVJs9oO4X0+gmvw==\&crl $=$ C>. Acesso em: 15 out. 2017 .

KUŠLJIĆ, D.; ČENGIJA, J.; MARENJAK, S. Factors affecting output specification in PPP projects. In: INTERNATIONAL WORKSHOP ON "COMPUTATIONAL AND INTEGRATIVE BIOLOGY”, Hangzhou, 2009. Proceedings... Gatersleben: IPK, 2009. 
KWEUN, J.Y.; WHEELER, P.K.; GIFFORD, J.L. Evaluating highway public-private partnerships: evidence from U.S. value for money studies. Transport Policy, 2017. Disponível em:<http://www.sciencedirect.com/science/article/pii/S0967070X17300999?via\%3Di hub>. Acesso em: 26 out. 2017.

LAITINEN, J. et al. Visionary concept: combining scenario methodology with concept development. In: WAGNER, C.G. (Ed.). Seeing the future through new eyes. Washington, DC: World Future Society, 2008.

LAM, C.L. PPP - Opportunities for the private sector. In: ANNUAL CONFERENCE ON PUBLIC PRIVATE PARTNERSHIPS, 13., 2005, Toronto. Proceedings... Toronto: Canadian Council for Public Partnerships, 2005. p.32-34

LAM, P.T. et al. Use of output specifications in PFI housing projects-How they differ from prescriptive specifications. Journal of Construction Engineering and Project Management, v. 1, n. 2, p. 43-48, 2011.

LANE, J.-E. New public management. Routledege: Taylor \& Francis, 2000.

LARA, M.L.G. Diferenças conceituais sobre termos e definições e implicações na organização da linguagem documentária. Ciência da Informação, v. 33, n. 2, p. 91-96, 2004. Disponível em:<http://revista.ibict.br/index.php/ciinf/article/view/266/234>. Acesso em: 2011 2017.

LEIDECKER, J.K.; BRUNO, A.V. Identifying and using critical success factors. Long Range Planning, v. 17, n. 1, p. 23-32, 1984.

LEVITT, R.E.; ERIKSSON, K. Funding streams of design-build-finance-operatemitigating PPP governance challenges: lessons from eastern Australia to focus future PPP mitigating PPP governance challenges. [S.I.ss.n.], 2016.

LI, B. et al. Perceptions of positive and negative factors influencing the attractiveness of PPP/PFI procurement for construction projects in the UK: findings from a questionnaire Survey. Engineering, Construction and Architectural Management, v. 12, n. 2, p. 125-148, 2005.

LINDER, S.H. Coming to TERMS WITH THE PUBLIC-PRIVATE PARTNERSHIP: A GRAMMAR OF MULTIPLE MEANINgs. American Behavioral Scientist, v. 43, n. 1, p. 35-51, 1999. DOI: http://abs.sagepub.com/cgi/doi/10.1177/00027649921955146.

LITTLE, T.D.; LINDENBERGER, U.; NESSELROADE, J.R. On Selecting indicators for multivariate measurement and modeling with latent variables: when" good" indicators are bad and "bad" indicators are good. Psychological Methods, v. 4, n. 2, p. 192, 1999.

LIU, B.F.; HORSLEY, J.S. The Government communication decision wheel: toward a public relations model for the public sector. Journal of Public Relations Research, v. 19, n. 4, p. 377-393, 2007.

LIU, J. et al. Incentive mechanism for inhibiting investors' opportunistic behavior in 
PPP projects. International Journal of Project Management, v. 34, n. 7, p. 11021111, 2016. Disponível

em:<http://www.sciencedirect.com/science/article/pii/S0263786316300308>. Acesso em: 24 abr. 2017.

LOOSEMORE, M.; CHEUNG, E. Implementing systems thinking to manage risk in public private partnership projects. International Journal of Project Management, v. 33, n. 6, p. 1325-1334, 2015. Disponível

em:<http://www.sciencedirect.com/science/article/pii/S0263786315000381>. Acesso em: 24 abr. 2017.

LOPES, A.P.V.B.V.; CARVALHO, M.M. Evolução da literatura de inovação em relações de cooperação: um estudo bibliométrico num período de vinte anos.

Gestão \& Produção, v. 19, n. 1, p. 203-217, 2012. Disponível

em:<http://www.scielo.br/scielo.php?script=sci_arttext\&pid=S0104-

530X2012000100014\&Ing=en\&nrm=iso\&tlng=pt>. Acesso em: 8 fev. 2016.

LOVE, P.E.D. et al. Future proofing PPPs: life-cycle performance measurement and building information modelling. Automation in Construction, v. 56, p. 26-35, 2015. DOI: http://dx.doi.org/10.1016/j.autcon.2015.04.008.

LYNCH, D.P.; BERTOLINO, S.; CLOUTIER, E. How to scope DMAIC projects. Quality progress, v. 36, n. 1, p. 37-41, 2003.

MAHAMA, P. Government is committed to PPPs. [S.I.:s.n.], 2014. p.1-16.

MANSOR, N.S.B.; RASHID, K.A. Identifying the presence of incomplete contract in pfi contracts. In: MANAGEMENT IN CONSTRUCTION RESEARCH ASSOCIATION CONFERENCE GENERAL MEETING, 13., 2014, Kuala Lumper. Proceedings... Kuala lumpur: MICRA, 2014.

Incomplete contract in private finance initiative (PFI) contracts: causes, implications and strategies. Procedia - Social and Behavioral Sciences, v. 222, p. 93-102, 2016. DOI: http://dx.doi.org/10.1016/j.sbspro.2016.05.193.

MANSOR, N.S.; AYOB, M.F.; RASHID, K.A. Incomplete contract in private finance initiative (PFI): a modified delphi study. Advanced Science Letters, v. 23, n. 1, p. 227-231, 2017.

MARCONI, M.; LAKATOS, E. Fundamentos de metodologia científica. 5.ed. São Paulo: Atlas, 2003.

MARQUES, R.C.; BERG, S. Risks, contracts, and private-sector participation in infrastructure. Journal of Construction Engineering and Management, v.137, n. 11, p. 925-932, 2011.

MARTINS, J.; MARQUES, R.C.; CRUZ, C.O. Maximizing the Value for Money of PPP arrangements through flexibility: an application to airports. Journal of Air Transport Management, v. 39, p. 72-80, 2014. DOI:

http://dx.doi.org/10.1016/j.jairtraman.2014.04.003. 
MASON, N.W.H. et al. Functional richness, functional and functional evenness divergence: the primary of functional components diversity. Oikos, v. 111, n. 1, p. 112-118, 2005.

MATESANZ, D.; ORTEGA, G.J. Sovereign public debt crisis in Europe. A network analysis. Physica A: statistical mechanics and its applications, v. 436, p. 756-766, 2015. Disponível em:<http://www.sciencedirect.com/science/article/pii/S0378437115004677>. Acesso em: 17 jun. 2017.

MCKEVITT, D.; DAVIS, P. Value for money: a broken piñata?. Public Money \& Management, v. 36, n. 4, p. 257-264, 2016. DOI: http://www.tandfonline.com/doi/full/10.1080/09540962.2016.1162591.

MD LASA, Y.; AHMAD, N.; TAKIM, R. Financing preference behaviour for private finance initiative $(\mathrm{PFI})$ projects. Environment-Behaviour Proceedings Journal, v. 1, n. 1, p. 11, 2016. Disponível em:<http://ebpj.eiph.co.uk/index.php/EBProceedings/article/view/188>. Acesso em: 13 set. 2017.

MERGEL, I. Opening government: designing open innovation processes to collaborate with external problem solvers. Social Science Computer Review, v. 33, n. 5, p. 599-612, 2014. Disponível em:<http://papers.ssrn.com/sol3/papers.cfm?abstract_id=2012489\%5Cnhttp://ssc.sa gepub.com/cgi/doi/10.1177/0894439314560847>. Acesso em: 17 dez. 2015.

MLADENOVIC, G. et al. Use of key performance indicators for PPP transport projects to meet stakeholders' performance objectives. Built Environment Project and Asset Management, v. 3, n. 2, p. 228-249, 2013. DOI: http://www.emeraldinsight.com/doi/10.1108/BEPAM-05-2012-0026.

MORALLOS, D.; AMEKUDZI, A. The State of the practice of value for money analysis in comparing public private partnerships to traditional procurements. Public Works Management \& Policy, v.13 , n. 2, p. 114-125, Oct. 2008.

MORLEDGE, R.; OWEN, K. Critical success factors in PFI projects. In: ANNUAL ARCOM CONFERENCE, 14., 1998, Cambridge. Proceedings... Sheffiel: ARCOM, 1998. p. 565-574. Disponível

em:<http://www.arcom.ac.uk/publications/procs/ar1998-565-

574_Morledge_and_Owen.pdf>. 15052017.

MOTA, J.; MOREIRA, A.C. The Importance of non-financial determinants on publicprivate partnerships in Europe. International Journal of Project Management, v. 33, n. 7, p. 1563-1575, 2015. DOI: http://dx.doi.org/10.1016/j.ijproman.2015.04.005.

MOTT, M. Review of large public procurement in the UK. London: HM Treasury, 2002. (Report HM Treasury).

MOUCHET, M. et al. Towards a consensus for calculating dendrogram-based functional diversity indices. Oikos, v. 117, n. 5, p. 794-800, 2008. Disponível em:<http://doi.wiley.com/10.1111/j.0030-1299.2008.16594.x>. Acesso em: 25 out. 2017. 
MÜLLER-TSCHUMI, T. Contractual framework of infrastructure PPPs under

Swiss law. Disponível em:<https://content.next.westlaw.com/8-519-

2090? IrTS=20170422200445276\&transitionType=Default\&contextData=(sc. Defaul t)\&firstPage=true\&bhcp=1>. Acesso em: 22 abr. 2017.

MY, T. et al. An Exploratory study on policy of the public-private partnership to develop seaport in Vietnam. International Journal of Applied Business and Economic Research, v. 15, n. 3, p. 57-68, 2017.

NASIR, T.M. Value for money drivers in public private scheme. International Journal of Public Sector Management, v. 20, n. 2, p. 147-156, 2007.

NATIONAL INFRASTRUCTURE UNIT. Guidance for public private partnerships (PPPs) in New Zealand. Wellington, 2009.

NEDERHAND, J.; KLIJN, E.H. Stakeholder involvement in public-private partnerships: its influence on the innovative character of projects and on project performance. Administration \& Society, 2014. DOI: 10.1177/0095399716684887.

NG, A.; LOOSEMORE, M. Risk allocation in the private provision of public infrastructure. International Journal of Project Management, v. 25, n. 1, p. 66-76, 2007.

NG, S.T.; WONG, Y.M.W; WONG, J.M.W. Factors influencing the success of PPP at feasibility stage-A tripartite comparison study in Hong Kong. Habitat International, v. 36, n. 4, p. 423-432, 2012.

NG, S.T.; WONG, J.M.W.; WONG, K.K.W. A Public private people partnerships (P4) process framework for infrastructure development in Hong Kong. Cities, v. 31, p. 370-381, 2013. Disponível

em:<http://www.sciencedirect.com/science/article/pii/S0264275112002156>. Acesso em: 24 abr. 2017.

NISAR, T.M. Implementation constraints in social enterprise and community public private partnerships. International Journal of Project Management, v. 31, n. 4, p. 638-651, 2013. DOI: http://dx.doi.org/10.1016/j.jproman.2012.08.004.

NOBRE, L.R.G. Modelagem de Leilões Multidimensionais Aplicada a Concessão de Serviços Públicos. Dissertação de Mestrado: PUC - Rio de Janeiro/RJ. 60, 2014.

NONAKA, I. The knowledge-creating company. Harvard Business Review, nov-dez, 1991.

NOORDHOEK, P.; SANER, R. Beyond new public management. answering the claims of both politics and society. Public Organization Review, v. 5, n. 1, p. 3553, 2005.

OAK, V.J.; LAGHATE, K. Analysis of project management issues in information technology industry: an overview of literature. International Journal of System Assurance Engineering and Management, v. 7, n. 4, p. 418-426, 2016. DOI: http://link.springer.com/10.1007/s13198-016-0469-4. 
OLIVEIRA, M.; RIBEIRO, J.; MACÁRIO, R. Are we planning investments to fail? Consequences of traffic forecast effects on PPP contracts: portuguese and Brazilian cases. Research in Transportation Economics, v. 59, p. 167-174, 2016.

OLUSOLA BABATUNDE, S.; OPAWOLE, A.; EMMANUEL AKINSIKU, O. Critical success factors in public-private partnership (PPP) on infrastructure delivery in Nigeria. Journal of Facilities Management, v. 10, n. 3, p. 212-225, 2012.

OPAWOLE, A.; JAGBORO, G.O. Factors affecting the performance of private party in concession-based PPP projects in Nigeria. Journal of Engineering, Design and Technology, v. 15, n. 1, p. 44-57, 2017.

ORGANISATION FOR ECONOMIC CO-OPERATION AND DEVELOPMENT. Public-private partnerships: in pursuit of risk sharing and value for money. Paris: OECD, 2008.

OSEI-KYEI, R.; CHAN, A.P.C. Review of studies on the critical success factors for public-private partnership (PPP) projects from 1990 to 2013. International Journal of Project Management, v. 33, n. 6, p. 1335-1346, 2015. DOI:

http://dx.doi.org/10.1016/j.jproman.2015.02.008.

OTAIRU, A.G. et al. Slow adoption of PPPs in developing countries: Survey of nigerian construction professionals. Procedia Engineering, v. 77, p. 188-195, 2014. DOI: http://dx.doi.org/10.1016/j.proeng.2014.07.014.

PALMA, A.; PRUNIER, G.; LERUTH, L.E. Towards a principal-agent based typology of risks in public-private partnerships. Bulgaria: International Monetary Fund, 2009. (Working Paper, 09/177).

PAPAKONSTANTINOU, A.; BOGETOFT, P. "Multi-Dimensional Procurement Auction under Uncertain and Asymmetric Information." European Journal of Operational Research 258(3): 1171-80, 2017.

PEREIRA, B. PMI e insegurança jurídica. PPP Brasil, 2013. Disponível em:<http://www.pppbrasil.com.br/portal/content/artigo-pmi-e-inseguranç-jurídica>. Acesso em: 8 fev. 2016.

PHIPPS, J.B. Dendrogram topology. Systematic Zoology, v. 20, n. 3, p. 306-308, 1971.

PIERE, B.A.; MANTESE, G.C. Aplicação da metodologia 3S para validação de indicadores de simbiose industrial. [S.I.:S.n.]: 2017.

PINTO, J.K.; PRESCOTT, J.E. Variations in critical success factors over the stages in the project life cycle. Journal of Management, v. 14, n. 1, p. 5-18, 1988.

Disponível em:<http://journals.sagepub.com/doi/10.1177/014920638801400102>. Acesso em: 26 out. 2017.

PODANI, J.; SCHMERA, D. On Dendrogram-based measures of functional diversity. Oikos, v. 115, n. 1, p. 179-185, 2006. Disponível em:<http://doi.wiley.com/10.1111/j.2006.0030-1299.15048.x>. Acesso em: 25 out. 
2017.

POLLITT, M.G. The Declining role of the state in infrastructure investments in the UK. In: BERG, S.V.; POLLITT, M.G.; TSUJI, M. (Ed.). Private initiatives in infrastructure: priorities, incentives and performance. Cheltenham Glos: Edward Elgar, 2002. p. 67-100.

PORTER, M.E. Consumer behavior, retailer power, and manufacturer strategy in consumer goods industries. Dissertation (Doctoral) - Harvard University, Cambridge, 1973.

PORTUGAL RIBEIRO, M. 10 Anos da lei de PPP 20 anos da lei de concessões: viabilizando a implantação e melhoria de infraestruturas para o desenvolvimento econômico-social. [S.I.]: Simplíssimo, 2014. Disponível em:< https://pt.slideshare.net/portugalribeiro/10-anos-da-lei-de-ppp-20-anos-da-lei-deconcesses>. Acesso em: 10 set. 2017.

PPP for cities case studies cases quick facts and PPP learned lessons. Madrid: IESE Business School, 2016. Disponível em:<http://www.pppcities.org/wpcontent/uploads/2016/11/7.-PPP-for-Cities.pdf>. Acesso em: 8 ago. 2017.

PPP motivations and challenges for the public sector: why (not ) and how. Luxembourg: European PPP Expertise Centre, 2015.

PPP UNIT SOUTH AFRICA. Public Private Partnership - Republic of South Africa. Disponível em: <http://www.ppp.gov.za/Pages/About.aspx>. Acesso em: 13/4/2017.

THE PRIVATE finance iniciative: value for money. (Select Committee on Treasury Fourth Report). Disponível em:<https://publications.parliament.uk/pa/cm199900/cmselect/cmtreasy/147/14704.h tm>. Acesso em: 6 fev. 2018.

PROCEDIMENTOS para aproveitamento de estudos de PPP apresentados pela iniciativa privada (PMI e MIP). 2016. Disponível em:<https://pt.slideshare.net/priromanopinheiro/pmi-e-mip-conceitos-bsicos38831587>. Acesso em: 14 dez. 2016.

PUBLIC-PRIVATE INFRASTRUCTURE ADVISORY FACILITY. Main types of PPP. In: TOOLKIT for Public-private Partnerships in Roads \& Highways. Module 1: overview and diagnosis. Asia: PPIAF, 2009. p. 12-21.

PUBLIC-PRIVATE INFRASTRUCTURE ADVISORY FACILITY. Unsolicited proposals - an exception to public initiation of infrastructure PPPs an analysis of global trends and lessons learned. Asia: PPIAF, 2014.

PUBLIC private partnership policy statement. Ministry of Economic Development, Financial Services and Corporate Affairs, 2003. Disponível em:<http://unpan1.un.org/intradoc/groups/public/documents/CPSI/UNPAN027786.pd f>. Acesso em: 05 dez. 2016. 
QUALTRICS. Calculating sample size. 2010. Disponível

em:<https://www.qualtrics.com/blog/calculating-sample-size/>. Acesso em: 25 out. 2017.

QUEIROZ, C.; REDDEL, P. Transparency and good governance as success factors in public private partnerships. In: DELL'ACQUA, G.; WEGMAN, F. (Ed.). Transport infrastructure and systems: proceedings of the AllT international congress on transport infrastructure and systems (Rome, Italy, 10-12 April 2017). London: CRC Press, 2017. p. 39-46.

RAYMOND, J. Benchmarking in public procurement. Benchmarking: an international journal, v. 15, n. 6, p. 782-793, 2008. DOI: http://www.emeraldinsight.com/doi/10.1108/14635770810915940.

REAVIS, C. The Global financial crisis of 2008-2009: the role of greed, fear and oligarchs. Cambridge: Massachusetts Institute of Technology, 2009. Disponível em:<https://mitsloan.mit.edu/mstir/world-economy/crisis-2008-2009/documents/09093 the financial crisis of 2008-2009.pdf>. Acesso em: 06 ago. 2017.

REEVES, E. et al. The Determinants of tendering periods for PPP procurement in the UK: an empirical analysis. Applied Economics, v. 49, n. 11, p. 1071-1082, 2017. DOI: http://dx.doi.org/10.1080/00036846.2016.1210779.

REGAN, M.; SMITH, J.; LOVE, P.E.D. Impact of the capital market collapse on public private partnership infrastructure projects. Journal of Construction

Engineering and Management, v. 137, n. 1, p. 6-16, 2011.

REINHART, C.M.; ROGOFF, K.S. Is the 2007 U.S. sub-prime financial crisis so different? An International historical comparison. The American Economic Review, v. 98, n. 2, p. 339-344, 2009.

REIS, R. Panorama do mercado brasileiro de PPPs. Nova Lima: Radar PPP, 2017. Disponível

em:<https://mail.google.com/mail/u/0/\#inbox/161d482fef8de670?projector=1\&messa gePartld=0.4>. Acesso em: 04 dez. 2017.

RICHARDSON, R.J. et al. Pesquisa social - métodos e técnicas. 3.ed.rev. São Paulo: Atlas, 1999.

RIO DE JANEIRO (Cidade). Prefeitura do Rio de Janeiro. Guia suplementar para avaliações de value for money: preparado pelo município do Rio de Janeiro.

Disponível em:<https://mail-

attachment.googleusercontent.com/attachment/u/0/?ui=2\&ik=98b55919c1\&view=att\& th $=161 \mathrm{~d} 482$ fef8de670\&attid=0.3\&disp=inline\&safe $=1 \& z w \&$ saddbat $=$ ANGjdJ_AhpP44 63Hf0G0zie_eCHviGSAa-

nwTcVHA0A3fktvggeO92/6ouzx3uEStWsrYZA70RrBRg3CcqNfmIVeetK49jC0pY12kl bnbYa1H9d8HPatVryOhD0qLr6Gh4lsG2IxVA4tXlyqJvdMIY6xyJrKLwhGJJjc6nTxd_u p8qagCEABtO0R 8Get2QH9XCDz3Q-

CunolEOn34bi7PWAWVKExDMfpDES8fCCmqeraE4CXtFyopm4fHoyTUo83QwJsbi EXoRDr1KsKX4HSmdFMtJNDdbCpQB8eWcJSs5XyYlustRyJvXSkCr4MbJvzcpnb_b L5FhH8gO8hMWkpEmrZ4uf_oiUGSqEWXPJ6abjDGEHe2OALWPOgMgEicmf1 hvrl9 buZQrX8eb14iC-IUtLfIGtM5SqQPdzwoQvxOYKmsghxaQs71MP1RyntgLihnDhjwmXpvednMw_rJQxDQyhiBP2XMGG3F7M2ZCnldbCF9|8wnngz4B4- 
gF0kApzU8Q47obRCFcoq-HcHXyp-gcRInWa7la-

nJDDtZF5dEVvKjJyHhoD2XOICcVfJi5GUSbtk07kAWN5wZBqpylmSadAcfYnoGC-

VMOolU2Uw>. Acesso em: 27 dez. 2017.

ROCKART, J.F. Chief executives define their own data needs. Harvard Business Review, v. 57, n. 2, p. 81-93, 1979.

ROEHRICH, J.K.; LEWIS, M.A.; GEORGE, G. Are publiceprivate partnerships a healthy option? A systematic literature review. Social Science \& Medicine, v. 113, p. 110-119, 2014. Disponível em:<http://creativecommons.org/licenses/by/3.0/>. Acesso em: 24 abr. 2017.

ROUMBOUTSOS, A.; PANTELIAS, A. Allocating revenue risk in transport infrastructure public private partnership projects: how it matters. Transport Reviews, v. 35, n. 2, p. 183-203, 2015. DOI: http://dx.doi.org/10.1080/01441647.2014.988306.

ROY, B. Classement et choix en presence de points de vue multiples. Revue Française d'Informatique et de Recherche Opérationnelle, v. 2, n. 8, p. 57-75, 1968. Disponível em:<http://www.numdam.org/article/RO_1968_2_1_57_0.pdf>. Acesso em: 7 fev. 2018.

SAATY, T.L. Decision making with the analytic hierarchy process. International Journal of Services Sciences, v. 1, n. 1, p. 83-98, 2008.

SANDELOWSKI, M. Whatever happened to qualitative description?. Research in Nursing \& Health, v. 23, n. 4, p. 334-340, 2000. DOI:

http://doi.wiley.com/10.1002/1098-

240X\%28200008\%2923\%3A4\%3C334\%3A\%3AAID-NUR9\%3E3.0.CO\%3B2-G.

SANTANDREA, M. et al. Concentration risk and internal rate of return: evidence from the infrastructure equity market. International Journal of Project

Management, v. 35, n. 3, p. 241-251, 2017. Disponível em:<http://www.sciencedirect.com/science/article/pii/S0263786316302915>. Acesso em: 11 abr. 2017.

SARDINHA, T.B. Lingüística de corpus. São Paulo: Manole, 2004.

SASTOQUE, L.M.; ARBOLEDA, C.A.; PONZ, J.L. A Proposal for risk allocation in social infrastructure projects applying PPP in Colombia. Procedia Engineering, v. 145, p. 1354-1361, 2016. DOI: http://dx.doi.org/10.1016/j.proeng.2016.04.174.

SCHAEFER, M.; VOLAND, T. Germany: public private partnership in germany - an overview. 2009. Disponível

em:<http://www.mondaq.com/germany/x/87762/Government+Contracts+Procuremen t+PPP/Public+Private+Partnerships+In+Germany+An+Overview>. Acesso em: 16 set. 2017.

SCHAEFFER, N.C.; PRESSER, S. The Science of asking questions. Annual Review of Sociology, v.29, p. 65-88, Aug. 2003. 
SCHAPPER, P.R.; VEIGA MALTA, J.N.; GILBERT, D.L. An Analytical framework for the management and reform of public procurement. Journal of Public Procurement, v. 6, n.1/3, p.1-26, 2006.

SCHEPPER, S.; HAEZENDONCK, E.; DOOMS, M. Understanding pre-contractual transaction costs for public-private partnership infrastructure projects. International Journal of Project Management, v. 33, n. 4, p. 932-946, 2014. Disponível em:<http://linkinghub.elsevier.com/retrieve/pii/S0263786314001720\%5Cnhttp://www. sciencedirect.com/science/article/pii/S0263786314001720>. Acesso em: 16 set. 2017.

SCHNETZLER, J.P. Práticas de gerenciamento de projetos: proposta de um modelo para diagnóstico do gerenciamento ágil de projetos. São Carlos:

EESC/USP, 2012.

SCHWABER, K.; BEEDLE, M. Agile software development with scrum. New York: Pearson, 2001. (Series in Agile Software Development).

SCOTTISH GOVERNMENT RIAGNALTAS NA h-ALBA GOV.SCOT. Scottish public finance manual. 2016. Disponível

em:<http://www.gov.scot/Publications/2006/05/spdpolicymanual\#6>. Acesso em: 27 dez. 2017.

SHAOUL, J. A Critical financial analysis of the private finance initiative: selecting a financing method or allocating economic wealth?. Critical Perspectives on

Accounting, v. 16, n. 4, p. 441-471, 2005. Disponível em:<http://linkinghub.elsevier.com/retrieve/pii/S1045235403001254>. Acesso em: 18 set. 2017.

SHAPIRO, A.S.S.; WILK, M.B. An Analysis of variance test for normality (complete samples). Biometrika, v.52, n.3/4, p.591-611, Dec. 1965. DOI: 10.2307/2333709.

SHEPHERD, G.; VALENCIA, S. Modernizando a administração pública na América Latina : problemas comuns sem soluções fáceis. Revista do Serviço Público, v. 120, n. 3, p. 103-129, 1996.

SINCLAIR, J. Meaning in the framework of corpus linguistics.Lexicographica, v.20, p.2032, 2004.

SIQUEIRA MORAES, M.; REYES-TAGLE, G. Os Impactos fiscais dos contratos de parceria público-privada: estudo de caso do ambiente institucional e da prática no Brasil. Brasília: BID, 2017. (Notas Técnicas, IDB-TN-1246). Disponível em:<https://publications.iadb.org/handle/11319/8142>. Acesso em: 17 nov. 2017.

SKIETRYS, E.; RAIPA, A.; BARTKUS, E.V. Dimensions of the efficiency of publicprivate partnership. Engineering Economics, v. 58, n. 3, 2015.

SMITH, S.M. 7 Tips for Writing Surveys. 2017. Disponível em:<http://success.qualtrics.com/rs/qualtrics/images/7-Tips-for-Writing-Surveys.pdf>. Acesso em: 28 maio 2017.

SMYTH, H.; EDKINS, A. Relationship management in the management of PFI/PPP 
projects in the UK. International Journal of Project Management, v. 25, n. 3, p. 232-240, 2007.

SPEARMAN, C. The Proof and measurement of association between two things. The American journal of psychology, v. 15, n. 1, p. 72-101, 1904.

STUBBS, M. Memorial article: John Sinclair (1933-2007). Applied Linguistics, v. 30, n. 1, p. 115-137, 2009. Disponível em:<https://academic.oup.com/applij/articlelookup/doi/10.1093/applin/amn052>. Acesso em: 26 jan. 2018.

SUDMAN, S.; BRADBURN, N.M.; SCHWARZ, N. Thinking about answers: the application of cognitive processes to Survey methodology. New York: Jossey-Bass, 1996.

SUNDARAJ, G.; EATON, D. Quantifying robustness in PFIs. Journal of Financial Management of Property and Construction, v. 18, n. 1, p. 26-52, 2013. DOI: http://dx.doi.org/10.1108/13664381311305069.

TAGNIN, S.E.O. O Jeito que a gente diz. São Paulo: Disal, 2013.

TANG, L. et al. Ranked critical factors in PPP briefings. Journal of Management in Engineering, v. 29, n. 2, p. 164-171, 2013. DOI:

http://ascelibrary.org/doi/10.1061/\%28ASCE\%29ME.1943-5479.0000131.

TCE/SC - dotc-e2012-09-20. Diário Oficial Eletrônico, Curitiba, SC, ano 5, n.1073, 2012.

TEICHER, J.; ALAM, Q.; VAN GRAMBERG, B. Managing trust and relationships in PPPs: some Australian experiences. International Review of Administrative Sciences, v. 72, n. 1, p. 85-100, 2006. Doi:

http://journals.sagepub.com/doi/10.1177/0020852306061624.

TEO, P.; BRIDGE, A.J. Crafting an efficient bundle of property rights to determine the suitability of a public-private partnership: a new theoretical framework.

International Journal of Project Management, v. 35, n. 3, p. 269-279, 2016. DOI: http://dx.doi.org/10.1016/j.ijproman.2016.10.008.

THOMPSON, G. et al. New public management. Key Concepts in Governance, v. 12 , p. 141, 2008.

TOURANGEAU, R.; RIPS, L.J.; RASINSKI, K. The Psychology of Survey response. Cambridge: Cambridge University Press, 2000.

TSAMBOULAS, D.; VERMA, A.; MORAITI, P. Transport infrastructure provision and operations: why should governments choose private-public partnership?. Research in Transportation Economics, v. 38, n. 1, p. 122-127, 2013. Disponível em:<http://www.sciencedirect.com/science/article/pii/S0739885912000492>. Acesso em: 11 abr. 2017. 
TSERNG, H.P. et al. Proactive measures of governmental debt guarantees to facilitate public-private partnerships project. Journal of Civil Engineering and Management, v. 20, n. 4, p. 548-560, 2014. Disponível em:<http://www.scopus.com/inward/record.url?eid=2-s2.084903942073\&partnerID=tZOtx3y1>. Acesso em: 08 mar. 2017.

UNITED NATIONS ECONOMIC COMMISSION FOR EUROPE. Guidebook on promoting good governance in public-private partnerships. New York, 2008.

VANNETTE, D.L.; KROSNICK, J.A. Answering questions: a comparison of Survey satisficing and mindlessness. In: LE, A.; NGNOUMEN, C.T.; LANGER, E.J. The wiley blackwell handbook of mindfulness. New York: Wiley Blackwell, 2013. Cap.17, p.312-327.

VERBA, Y.S.; IVANOV, I.N. Sustainable development and project management: objectives and integration results. Economic and Social Changes-Facts Trends Forecast, v. 41, n. 5, p. 135-146, 2015.

VERHOEST, K. et al. How do governments support the development of public private partnerships? Measuring and Comparing PPP governmental support in 20 european countries. Transport Reviews, v. 35, n. 2, p. 18 -139, 2015. DOI: http://dx.doi.org/10.1080/01441647.2014.993746.

VIEIRA, G. A. Guiomar Assumpção Vieira: Diálogos. Entrevistador: Caproni T. Votuporanga - São Paulo. Entrevista concedida ao Fechamento da Versão Definitiva da Tese de Doutorado, 2018.

VIEIRA, S. Como escrever uma tese. São Paulo: Atlas, 2008.

WANG, Y. Evolution of public-private partnership models in American toll road development: learning based on public institutions' risk management. International Journal of Project Management, v. 33, n. 3, p. 684-696, 2015. DOI: http://dx.doi.org/10.1016/j.ijproman.2014.10.006.

WATANUKI, H.M. et al. Gestão de projetos internacionais: um estudo bibliométrico. Gestão e Produção, v. 21, p. 660-675, 2014.

WEBER, B.; STAUB-BISANG, M.; ALFEN, H.W. Infrastructure as an asset class: investment strategy, sustainability, project finance and PPP. New York: Wiley, 2016.

WIND, Y.; SAATY, T.L. Marketing applications of the analytic hierarchy process. Management Science, v. 26, n. 7, p. 641-658, 1980.

WRIGHT, J.T.C.; GIOVINAZZO, R.A. Delphi - uma ferramenta de apoio ao planejamento prospectivo. Caderno de Pesquisas em Administracão, v. 1, n. 12, p.54-65, 2000.

WU, J. et al. Government accountability within infrastructure public???private partnerships. International Journal of Project Management, v. 34, n. 8, p. 14711478, 2016. DOI: http://dx.doi.org/10.1016/j.ijproman.2016.08.003. 
XIAO-MEI, G.; XIAO-JUN, L. Application of entropy measurement in risk assessment of the engineering project of construction-agent system. Systems Engineering Procedia, v. 1, p. 244-249, 2011. Disponível em:<http://www.sciencedirect.com/science/article/pii/S2211381911000397>. Acesso em: 18 set. 2017.

XIONG, W. et al. Ex post risk management in public-private partnership infrastructure projects. Project Management Journal, v. 48, n. 3, p. 76-89, 2017.

$\mathrm{XU}, \mathrm{Y}$. et al. Critical risk factors affecting the implementation of PPP waste-to-energy projects in China. Applied Energy, v. 158, p. 403-411, 2015. DOI: http://dx.doi.org/10.1016/j.apenergy.2015.08.043.

YAMAGUCHI, H.; UHER, T.E.; RUNESON, G. Risk allocation in Pfi projects. In: ANNUAL ARCOM CONFERENCE, 17., 2001, Salford. Proceedings... Salford: University of Salford, 2001. V.1, p.885-894.

YANG, Y.; HOU, Y.; WANG, Y. On the Development of public-private partnerships in transitional economies: an explanatory framework. Public Administration Review, v. 73, n. 2, p. 301-310, 2013.

YUAN, J. et al. Selection of performance objectives and key performance indicators in public-private partnership projects to achieve Value for Money. Construction Management and Economics, v. 27, n. 3, p. 253-270, 2009.

. Cumulative effects on the change of residual value in PPP projects: a comparative case study. Journal of infrastructure systems, v. 22, n. 2, p. 5015006, 2015.

YUN, S. et al. Critical organizational success factors for public private partnership projects - a comparison of solicited and unsolicited proposals. Journal of Civil Engineering and Management, v. 21, n. 2, p. 131-143, 2015. DOI: http://www.tandfonline.com/doi/abs/10.3846/13923730.2013.802715.

ZHANG, S. et al. PPP application in infrastructure development in China: Institutional analysis and implications. International Journal of Project Management, v. 33, n. 3, p. 497-509, 2015. DOI: http://dx.doi.org/10.1016/j.ijproman.2014.06.006.

ZHANG, X. Critical success factors for public-private partnerships in infrastructure development. Journal of Construction Engineering Management, v. 131, n. 1, p. 3-14, Jan. 2005a.

ZHANG, X. Paving the way for public-private partnerships in infrastructure development. Journal of Construction Engineering Management, v. 131, n. 1, p. 3-14, Jan. 2005b.

ZHANG, X.; CHEN, S. A Systematic framework for infrastructure development through public private partnerships. IATSS Research, v. 36, n. 2, p. 88-97, 2013. DOI: http://dx.doi.org/10.1016/j.iatssr.2012.11.001. 
ZOU, W. et al. Identifying the critical success factors for relationship management in PPP projects. International Journal of Project Management, v. 32, n. 2, p. 265274, 2014. DOI: http://dx.doi.org/10.1016/j.ijproman.2013.05.004. 


\section{APÊNDICES}

\section{APÊNDICE A - PROTOCOLO DE REVISÃO BIBLIOGRÁFICA SISTEMÁTICA}

Método adotado - A pesquisa documental realizada baseou-se na revisão bibliográfica em repositório de dados eletrônicos, conhecida como a pesquisa documental indireta, em que se busca artigos e produções acadêmicas que sustentem o conteúdo exposto (WATANUKI et al., 2014). Bem como a busca na web nos portais oficiais dos órgãos governamentais dos países alvo para a captura dos marcos regulatórios que influenciam nas premissas do estudo.

Fontes de Pesquisa - Foram realizadas buscas em duas bases de dados acadêmicas: Web of Science (de propriedade da Thomson Reuters) em sua coleção principal de artigo científicos e na Scopus (de propriedade Elsevier B.V.) por sua relevância na comunidade acadêmica (JICK, 1979; CRESWELL; CLARK, 2010), para a composição da amostra inicial dois critérios foram estabelecidos. Primeiro houve a adoção do filtro de artigos mais referenciados, estabelecendo do mais para o menos citado, contudo, não houve segregação inicial por área de conhecimento, mas foi adotado o filtro de tipo de documento, selecionando apenas artigos científicos de periódicos com "double blind peer review" para que o purismo científico fosse assegurado. Segundo - para que fosse garantida a presença de artigos clássicos no trabalho o autor selecionou as mesmas chaves de buscas artigos com maior fator de impacto, mas segregando-os por áreas de conhecimento correlatas a Engenharia de Produção. Um terceiro filtro foi adotado, atribuindo os mesmos strings nas bases Google Scholars $\circledast$ e Microsoft Academics $₫$ para a captura de artigos que por ventura poderiam não tenham sido contemplados nas duas primeiras bases.

Idioma de busca nas bases de dados - As palavras pesquisadas foram no idioma inglês em função da pouca disponibilidade de textos indexados em português.

Chaves de Pesquisa - As primeiras chaves de buscas adotadas foram: "Public Private Partnership" (sob o acrônimo: PPP/PFI) + "*” + "Critical Success Factor" (sob o acrônimo: CSF) + "*”; "Private Finance Initiative" (sob o acrônimo: PFI) “*” + "Critical Success Factor" (sob o acrônimo: CSF) + "*”, com o emprego de aspas para assegurar maior restrição na pesquisa, em ambas as bases de dados e com os mesmos filtros atribuídos. A utilização do "*" foi para que embora restritiva a temática nuclear, potenciais nuances de aplicação dos termos pudessem ser capturadas e 
não expurgados da seleção textos com assuntos correlacionados com o núcleo da pesquisa.

As segundas chaves de buscas adotadas foram: "Unsolicited" + "Proposal", também com a adoção de aspas para uma pesquisa mais restritiva, nas quatro bases.

O terceiro levantamento realizado possuía os strings de busca também na língua inglesa: "Product" + "Vision", sob os mesmos critérios restritos assumidos até então, com a adoção de aspas. Contudo diferentemente das duas primeiras buscas o período temporal de alcance foi reduzido para um intervalo total de publicações em 10 anos, por ser uma temática mais madura e consolidada na literatura e por ser recorde da proposta de aplicação.

Por fim, a integração de buscas envolveu as chaves: "Unsolicited" + "Proposal" e "Product" + "Vision" não resultou em artigos e textos técnicos encontrados, sinalizando o pioneirismo potencial da temática suscitada por este trabalho.

Abordagem da investigação - $O$ estudo fundamenta-se na abordagem mista de investigação quantitativa e quantitativa, a conjugação de ambas abordagens potencializa os resultados do estudo que se comparados isoladamente (CAMPBELL et al., 1999). Em ciências sociais, o uso de métodos conjugados de avaliação de variáveis é chamado por (CAMPBELL; BAUM; MCKELVEY, 1999) de triangulação e reforçado por (VIEIRA, 2008) que desenvolveram a ideia de "operação múltipla". Eles argumentaram que mais de um método deve ser usado para o processo de validação para garantir que a variância reflita as caracteristicas da variável e não do método. Assim, a convergência ou acordo entre dois métodos, incrementa a expectativa de resultados e não um artefato metodológico". (Bouchard, 1976: p. 268, apud Todd Jick, 1979). Autores como Sandelowski (2000) entende que a abordagem qualitativa por sua vez, é uma forma adequada de se entender um fenômeno social, sendo esta predominante no trabalho, caracterizando-se como uma abordagem incorporada concomitante. A natureza do trabalho possui dupla segmentação; A primeira parte da pesquisa esta é: Básica em relação a modelagem dos Fatores Críticos de Sucesso de PMls ao contexto do recorte alvo da pesquisa e na segunda parte: Aplicada com a integração das Propriedades de Visão do Produto já desenvolvidas na literatura ao modelo de aplicação proposto que fora construído fundamentado na teoria e derivado do resultado da Survey e testado pelas entrevistas com os especialistas. 
Em suma, o trabalho tem caráter descritivo, (CLOQUELL-BALLESTER et al., 2006) ilustra que estudos desta natureza oferecem um resumo abrangente de um evento nos termos cotidianos desses eventos facilitando assim o entendimento do fenômeno aqui abordado "avaliação de PMl" de forma mais concisa por meio do mapeamento da influência das variáveis FCS de PPP/PFI e PMI interagindo com as Propriedades de Visão do Produto e o respectivo impacto no instituto PMI e por conseguinte no sucesso de Projetos realizados na modalidade de PPP/PFIs.

Amplitude de período utilizado na pesquisa - A pesquisa foi elaborada com corte transversal (CONFORTO et al., 2011) em publicações de 2000 a 2017, realizadas queries subsequentes com as mesmas chaves de busca adicionando temas correlatos, sem a definição de um período temporal específico, permitindo deste modo a inclusão dos artigos científicos clássicos.

Critérios para a inclusão e/ou exclusão de artigos - Dois critérios não mutuamente excludentes condicionaram a escolha ou não de um determinado artigo para a pesquisa, a saber: (i) Aderência ao corpus [análise semântica dos textos] da pesquisa, valendo-se de adaptação de protocolo desenvolvido por (WIND; SAATY, 1980) para o julgamento de escolha: problema e objetivo da busca, idioma do texto, fonte de consulta, palavra chave e strings de busca, método, técnica e ferramenta de análise. (ii) Fator de impacto do artigo relativo ao número de vezes que o mesmo foi referenciado por terceiros, sendo procedida atribuição ad hoc acima de 10 citações por terceiros. 


\section{APÊNDICE B - PERFIL DOS ESPECIALISTAS CONSULTADOS}

Ao todo foram realizados 3 (três) ciclos de consultas e questionamentos a especialistas do setor de PPP/PFls. Iniciando por consulta preliminar para delimitação das premissas do trabalho, consulta via Survey para validação das análises suscitadas na revisão bibliográfica sistemática e entrevistas com especialistas para validação do modelo de avaliação de PMls.

A consulta inicial contou com levantamento preliminar não estruturado aos respectivos profissionais: 
Quadro 37 - Consultados ${ }^{65}$ preliminarmente para a produção da tese (a)

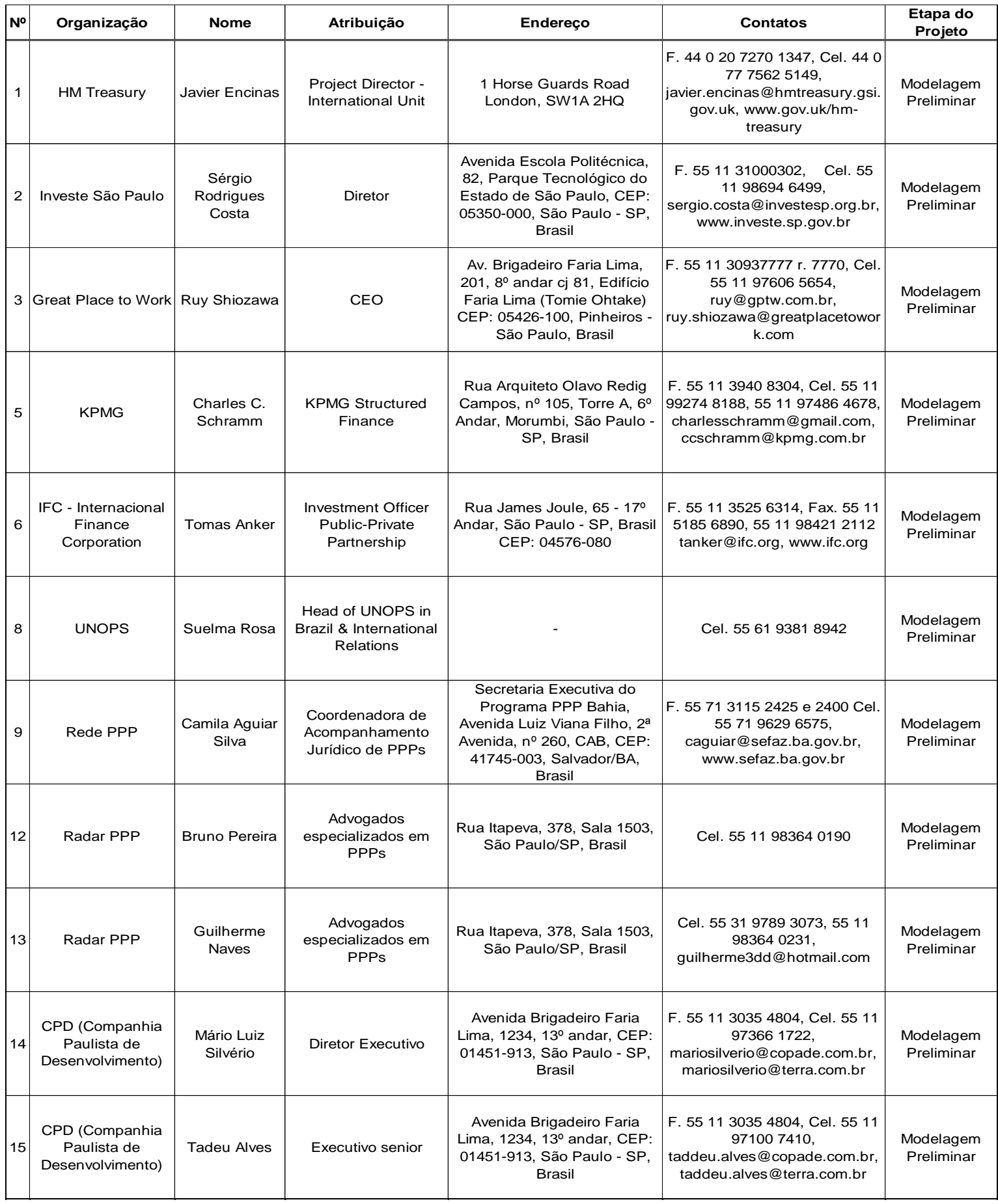

Fonte: Elaborado pelo autor (2016). 
Quadro 38 - Consultados ${ }^{66}$ preliminarmente para a produção da tese (b)

\begin{tabular}{|c|c|c|c|c|c|c|}
\hline № & Organização & Nome & Atribuição & Endereço & Contatos & $\begin{array}{c}\text { Etapa do } \\
\text { Projeto }\end{array}$ \\
\hline 16 & $\begin{array}{c}\text { EBP (Estruturadora } \\
\text { Brasileira de } \\
\text { Projeto) }\end{array}$ & $\begin{array}{c}\text { Maria Eduarda } \\
\text { Gouvêa Berto }\end{array}$ & Diretora Executiva & $\begin{array}{l}\text { Praça Floriano (Cinelândia) } \\
\text { 19, sala 2301, CEP: 20031- } \\
\text { 050 Rio de Janeiro/RJ, Brasil }\end{array}$ & $\begin{array}{c}\text { F. } 55212277 \text { 6250, } \\
\text { eduarda@ebpbrasil.com }\end{array}$ & $\begin{array}{c}\text { Modelagem } \\
\text { Preliminar }\end{array}$ \\
\hline 18 & $\begin{array}{l}\text { Moysés \& Pires } \\
\text { Sociedade de } \\
\text { Advogados }\end{array}$ & $\begin{array}{c}\text { Maurício } \\
\text { Boudakian } \\
\text { Moysés / } \\
\text { Ariovaldo Pires }\end{array}$ & $\begin{array}{c}\text { Advogados } \\
\text { especializados em } \\
\text { PPPs }\end{array}$ & $\begin{array}{c}\text { Rua Urussuí, 125, 5. andar, } \\
\text { Itaim Bibi } \\
\text { CEP.: 04542-050 | São Paulo } \\
\text { / SP }\end{array}$ & $\begin{array}{c}\text { Cel. } 5511966429118, \\
\text { mmoyses@moysespires.com.b } \\
\text { r }\end{array}$ & $\begin{array}{c}\text { Modelagem } \\
\text { Preliminar }\end{array}$ \\
\hline 20 & FESPSP & $\begin{array}{c}\text { Elcires } \\
\text { Pimenta Freire }\end{array}$ & foordenador de Projeto & $\begin{array}{c}\text { Rua General Jardim, } 482 \text { - cj } \\
63 \text { - Bairro: Vila Buarque, } \\
\text { CEP: 01223-010 São Paulo / } \\
\text { SP, Brasil }\end{array}$ & $\begin{array}{c}\text { F. } 551131237800, \text { Cel. } 5511 \\
9991512002, \\
\text { elcires@gmail.com }\end{array}$ & $\begin{array}{c}\text { Modelagem } \\
\text { Preliminar }\end{array}$ \\
\hline 21 & $\begin{array}{l}\text { Wernher von Braun } \\
\text { Centro de } \\
\text { pesquisas } \\
\text { avançadas }\end{array}$ & $\begin{array}{l}\text { Dario Sassi } \\
\text { Thober }\end{array}$ & Diretor & $\begin{array}{l}\text { Av.Alice de Castro Pupo } \\
\text { Nogueira Mattosinho, } 301 \\
\text { Alphaville, CEP: } 13098-392, \\
\text { Campinas - SP, Brasil }\end{array}$ & $\begin{array}{c}\text { F. } 551932622207 \text {, Cel. } 5519 \\
981254444, \\
\text { thober@vonbraunlabs.com.br, } \\
\text { www.vonbraunlabs.com.br }\end{array}$ & $\begin{array}{r}\text { Modelagem } \\
\text { Preliminar }\end{array}$ \\
\hline 23 & $\begin{array}{c}\text { Embaixada } \\
\text { Britânica Brasília }\end{array}$ & Silvio Aquino & Gerente de Projetos & $\begin{array}{l}\text { Quadra } 801 \text { - Conjunto K - } \\
\text { Lote } 08 \text { Av. das Nações - Asa } \\
\text { Sul CEP 70408-900 } \\
\text { Brasília/DF, Brasil }\end{array}$ & $\begin{array}{c}\text { F. } 5561332925 \text { 08, Cel. } 5561 \\
\text { 99616647, } \\
\text { silvio.aquino@fco.gov.uk }\end{array}$ & $\begin{array}{c}\text { Modelagem } \\
\text { Preliminar }\end{array}$ \\
\hline 24 & São Paulo Negócios & $\begin{array}{l}\text { Fernando } \\
\text { Pieroni }\end{array}$ & Diretor & $\begin{array}{c}\text { Rua Líbero Badaró, } 293 \text { - 9o } \\
\text { andar - cj. 9A, Bairro: Centro - } \\
\text { São Paulo/SP, Brasil }\end{array}$ & $\begin{array}{c}\text { F. } 551131064010 \text {, Cel. } 5511 \\
982895522, \\
\text { fernando.pieroni@spnegocios. } \\
\text { com, www.spnegocios.com }\end{array}$ & $\begin{array}{c}\text { Modelagem } \\
\text { Preliminar }\end{array}$ \\
\hline 25 & Revista Veja & $\begin{array}{l}\text { Giuliano } \\
\text { Guandalini }\end{array}$ & Editor & $\begin{array}{c}\text { Avenida das Nações Unidas, } \\
\text { 7221, CEP: 05425-902, São } \\
\text { Paulo/SP, Brasil }\end{array}$ & $\begin{array}{c}\text { F. } 55113037 \text { 5689, } \\
\text { gguandalini@abril.com.br }\end{array}$ & $\begin{array}{c}\text { Modelagem } \\
\text { Preliminar }\end{array}$ \\
\hline 26 & $\begin{array}{c}\text { Camargo Corrêa } \\
\text { S.A. }\end{array}$ & $\begin{array}{l}\text { Ricardo de } \\
\text { Aquino Filho }\end{array}$ & $\begin{array}{l}\text { Gerente Executivo de } \\
\text { Desenvolvimento de } \\
\text { Negócios Estruturados }\end{array}$ & $\begin{array}{c}\text { Avenida Brigadeiro Faria } \\
\text { Lima, 1663, 9a andar, Bairro: } \\
\text { Pinheiros, CEP: 01452-001 } \\
\text { São Paulo/SP, Brasil }\end{array}$ & $\begin{array}{c}\text { Cel. } 551196398 \text { 2370, } \\
\text { ricardo.aquino@camargocorrea } \\
\text {.com }\end{array}$ & $\begin{array}{c}\text { Modelagem } \\
\text { Preliminar }\end{array}$ \\
\hline
\end{tabular}

Fonte: Elaborado pelo autor (2016).

A segunda etapa do levantamento de campo contou com o encaminhamento de 300 (trezentos) questionários a profissionais e acadêmicos da iniciativa pública e privada envolvidos em todas as etapas do processo de concepção de uma PPP/PFI, pedido o enfoque na etapa de modelagem das PMIs.

66 Instituições e profissionais. 
A terceira etapa foi a arguição a especialistas para a validação do modelo índice de avaliação de propostas de PMls. Ao todo foram realizadas 12 (doze) entrevistas com profissionais e acadêmicos com as respectivas formações e conhecimentos no tema:

\section{Entrevistado(a) 01:}

Formação em Ciências Jurídicas, responsável pela Unidade de PPP/PFls do Estado de São Paulo, da Secretaria de Governo a mais de 3 anos. Com experiência pregressa na direção da São Paulo Desenvolvimento e Mobilização de Ativos SPDA. Militância jurídica no assessoramento da Diretoria Geral da ARTESP Agência Reguladora de Transportes do Estado de São Paulo.

\section{Entrevistado(a) 02:}

Advogado da área de Direito Administrativo, Infraestrutura e Regulação. Atuando em assuntos relacionados a estruturação legal da concessão de projetos e parcerias público-privadas de diferentes setores de infraestrutura (saneamento básico, transporte, aeroportos, portos, energia e trilhos). Membro fundador do Instituto Brasileiro de Direito e Ética Empresarial - IBDEE, apoiador do website do PPP Brasil e autor de artigos em infraestrutura. Atuando anteriormente como coordenador legal no Dersa - Desenvolvimento Rodoviário S/A e no Grupo Galvão Engenharia S/A, responsável por consultoria em projetos estruturados e administração estratégica de contencioso cível.

\section{Entrevistado(a) 03:}

Bacharel em Administração de Empresas pela Pontifícia Universidade Católica de Minas Gerais e em Direto pela Universidade Federal de Minas Gerais, em 2012. Sócio Fundador da empresa Radar PPP/PFI, onde coordenou a estruturação de 7 (sete) projetos de PPP/PFI de lluminação Pública, além de iniciativas de PPP/PFI e/ou Concessão no setor de meio ambiente, saúde, educação, saneamento e mobilidade urbana. Atuação Independente na Verificação de Contratos de PPP/PFI e Concessão, tal como a Concessão do Zoológico do Rio de Janeiro e PPP/PFI da Rodovia de Acesso à Praia do Paiva, em Pernambuco. 
Ocupou o cargo de Gerente de Desenvolvimento de Negócios na empresa Construcap CCPS Engenharia e Comércio S.A., sendo responsável pelas iniciativas em PPP/PFI e Concessão em que a organização participou (2012-2014), em especial a maior PPP/PFI do Setor de Saúde já assinada no Brasil (PPP/PFI dos Complexos Hospitalares de São Paulo). Foi gerente do Projeto Copa do Mundo 2014 pelo Governo do Estado de Minas Gerais (2009-2012), sendo um dos responsáveis pela modelagem e gestão do contrato de PPP/PFI do Complexo do Mineirão e a Concessão da Arena Independência.

\section{Entrevistado(a) 04:}

Economista responsável pelo desenvolvimento de novos negócios e projetos financeiros com mais de 20 anos de experiência em projetos de grande porte em infraestrutura, telecomunicações e distribuição de óleos minerais. Trabalhando em projetos em América do Sul e África. Desenvolvendo projetos de infraestrutura em Rodovias com pedágio, portos, aeroportos, hidrelétricas, termelétricas, eólicas, metrôs e setor imobiliário nos formatos - PPP/PFI, BOT, BOOT, M\&A e IPs. Interagindo projetos de "Private Equity" com fundos de investimentos, Grupos de investimento, Bancos de Investimento, Bancos de Desenvolvimento e Agências Multilaterais de Crédito - AMCs. Destacando os projetos: Projetos em PPP/PFI: Estradas de ferro e rodovias (Uruguai); Sistema de tratamento de água de São Lourenço; Projeto Lógum - Álcool duto; Concessão Saoparking; Desenvolver de mercado do sistema de concessão de ferrovias brasileiras; Projeto do Porto Mamonal (Colômbia); UHE Mphanda Nkwua (Moçambique); metro de Salvador/BA; Hidroelétrica de Belo Monte; Hidroelétrica de Jirau; Estaleiro Atlântico Sul e Rodovia pedagiada Inter-oceânica (Peru).

\section{Entrevistado(a) 05:}

Economista formado pela UFRJ, com Mestrado em administração de empresas pelo COPPEAD/UFRJ e MBAs em Gestão (INSPER) e Liderança (COPPEAD). Executivo com mais de 25 anos de experiência nos setores privado e público. No setor privado atuou por 17 anos em empresas expressivas em seus segmentos, como AmBev e Gafisa, focado em finanças, planejamento e performance tendo passado por diversas áreas. Por décadas atuou na 
administração pública da cidade do Rio de Janeiro tendo exercido as funções de diretoria na limpeza urbana, subsecretário de Concessões e PPP/PFls (com implantação de projetos como saneamento, aterro sanitário, VLT, Transolímpica, Parque Olímpico, Cemitérios), e subsecretário de Monitoramento de Metas e Resultados, tendo atuado nas áreas de planejamento estratégico, elaboração e acompanhamento de indicadores de todas as secretarias, na Central Única de Atendimento ao Cidadão (central 1746) e na área de Big Data (Pensa). Atuando hoje na área de Gestão e Políticas Públicas no INSPER.

\section{Entrevistado(a) 06:}

Doutorado em Direito Público pela SciencesPo/Paris, com um ano de pesquisa na Harvard Law School. Mestre em Direito Público pela Universidade de Paris 1 (Pantheon-Sorbonne). Mestre em Ciência Política pela London School of Economics (LSE). Consultora da International Finance Corporation - Banco Mundial. Advogada e Consultora jurídica.

\section{Entrevistado(a) 07:}

Pós-Doutor em Direito pela Columbia University School of Law (NY, EUA Visiting Scholar, (2017)). Doutor e Mestre em Direito do Estado pela Universidade Federal do Paraná (UFPR). Professor de Direito Administrativo e consultor da Unidade de PPP/PFI do Ministério do Planejamento, Orçamento em Gestão (2009). Autor das obras: Parceria Público-Privada. $2^{a}$ ed. São Paulo: Saraiva, (2013); Concessão de serviço público. $2^{a}$ ed. São Paulo: Saraiva, (2014), Alteração unilateral do contrato administrativo. São Paulo: Malheiros, (2003), e coautor do livro Licitação Pública: a Lei Geral de Licitações e o RDC - Regime Diferenciado de Contratações. São Paulo: Malheiros, (2012). Advogado e sócio de escritório especializado na área de infraestrutura.

\section{Entrevistado(a) 08:}

Bacharelado em economia pela Faculdade de Economia e Administração da Universidade de São Paulo e em direito pela Faculdade de Direito da Pontifícia Universidade Católica. Chartered Financial Analyst (CFA -1999). Líder do Núcleo de 
Infraestrutura do CLP - Centro de Liderança Pública, carreira desenvolvida no segmento financeiro, com ênfase em mercado de capitais. Larga experiência na estruturação de operações de dívidas e empréstimos externos para empresas e Estados brasileiros pelo Bank of America Merrill Lynch. Atuação no mercado de renda fixa doméstico em operações de debêntures, FIDCs e CRIs pelo Banco Itaú BBA.

\section{Entrevistado(a) 09:}

Responsável pela gestão de Contrato de Concessão Administrativa modalidade PPP/PFI - Parceria Público Privada do Sistema Penitenciário no Governo de Minas Gerais. Experiência em Gestão de Projetos e Contratos, implantação e gestão de contratos de concessões de serviços públicos na modalidade de Parcerias Público-Privadas, pelo Governo de Minas. Consultoria e Gestão de Processos - mapeamento, redesenho, padronização e controle operacional na iniciativa privada. CGE - Controladoria Geral do Estado (assessoria) e CGM do Município de Contagem (Auditoria). Bacharelado em Administração de Empresas.

\section{Entrevistado(a) 10:}

Graduação em Engenharia Técnica Industrial e MBA (IE - Business School), experiência profissional: Pall, Tennant, Envac, Philips, Forbo, Verisure e GE Lighting. Responsável pelo mercado do Projetos Estruturados PPP/PFls no mercado de Cidades Inteligentes identificando oportunidades e estruturando projetos greenfield para stakeholder (BID, governos e empresas). PPP/PFls conduzidas em: Belo Horizonte, Contagem, Vitória, São Paulo e Smart City Infra.

\section{Entrevistado(a) 11:}

Direção executiva do Semeia, com passagem pela São Paulo Negócios e Estruturadora Brasileira de Projetos - EBP; responsável pela área de assuntos econômicos e regulatórios do Instituto Acende Brasil e consultor da A.T. Kearney. Formou-se em Engenharia mecânica pela Universidade Estadual de Campinas UNICAMP, mestrado em economia e política energética pela Universidade de São 
Paulo - USP e especialista em infraestrutura e parcerias público-privadas pela Harvard Kennedy School of Government.

\section{Entrevistado(a) 12:}

Graduado em Engenharia Civil e Administração de Empresas pela Universidade Presbiteriana Mackenzie. Pós-Graduação em Controladoria pela Universidade de São Paulo/Fundação Getúlio Vargas. Diretor de Projetos de Consultoria por mais de 10 anos. Diretor em projetos de consultoria nas áreas de Planejamento Empresarial, Modelagem Institucional e Econômica e Financeira, Gestão Organizacional, Gestão de Recursos Humanos e Gestão de Tecnologia. Conhecimentos na área de infraestrutura em processos de concessões e PPP/PFIs (Parcerias Público Privadas) tendo participado da criação de projetos de bases regulatórias para o Governo Federal como para Governos Estaduais. Atualmente participa de PPP/PFIs no setor de lluminação pública no Setor Privado, em parceria com a FIPE (Fundação Instituto de Pesquisas Econômicas), e as Prefeituras de Guarulhos e de Hortolândia. 


\title{
APÊNDICE C - QUESTIONÁRIO PARA A DEFINIÇÃO DOS INDICADORES
}

\author{
UNIVERSIDADE DE SÃO PAULO - USP \\ CAMPUS DE SÃO CARLOS - ESCOLA DE ENGENHARIA DE SÃO CARLOS - EESC \\ CURSO DE PÓS-GRADUAÇÃO EM ENGENHARIA DE PRODUÇÃO
}

Questionário elaborado pelo pesquisador Tiago Vieira Caproni, doutorando em Engenharia de Produção da Escola de Engenharia de São Carlos da Universidade de São Paulo - USP, com o objetivo de obter dados consistentes e relevantes do instituto Procedimentos de Manifestação de Interesse - PMls e seus impactos na escolha de projetos de Parcerias Público-Privadas - PPP/PFls por entes públicos demandantes.

\section{INSTRUÇÕES PARA O PREENCHIMENTO DO QUESTIONÁRIO:}

- O questionário é composto por 27 questões, sendo estas: perguntas abertas, semiestruturadas e estruturadas (com questões valendo-se de escalas de concordância).

- Centre suas respostas as perguntas na modelagem de PMIs - Procedimentos de Manifestação(ões) de Interesse de PPP/PFIs - Parcerias Público-Privadas que você tenha desenvolvido ou tido contato [direto e indireto];

- Solicita-se 10 (dez) minutos de seu tempo para o preenchimento das perguntas;

- Embora existam campos para o preenchimento OPCIONAL de seus dados pessoais, estes serão protegidos e não divulgados em nenhuma hipótese, assegurados pela Lei Federal no 12.965, de 23 de abril de 2014 [Lei da Privacidade na internet], sendo o respectivo preenchimento dos dados pessoais do entrevistado utilizados exclusivamente para o encaminhamento do feedback dos resultados da pesquisa.

Desde logo, antecipo agradecimentos por contribuir com o estudo.

\section{Tiago Vieira Caproni}

Doutorando em Engenharia de Produção

Universidade de São Paulo

00 - Dados sobre você:

Prefiro não compartilhar.

Nome:

Telefone:

E-mail*:

* caso deseja receber a consolidação final dos questionários encaminhados.

01 - A sua organização é uma:

Autarquia; 
Agência setorial;

$\square$ Membros do Executivo (três esferas);

$\square$ Membros do Legislativo (servidor);

Membros do Legislativo (agente político);

$\square$ Executivos de empresa da construção civil;

$\square$ Empresas de consultoria;

Docentes universitários (Privado);

Docentes universitários (Público);

Coordenadores e Pesquisadores de Think Tank;

Representantes de unidades consulares;

Outros:

02 - Há quantos anos você trabalha com Projetos de PPP/PFls?

$\square \mathbf{0} \square \mathbf{1} \square \mathbf{2} \square \mathbf{3} \square \mathbf{4} \square \mathbf{5} \square \mathbf{6} \square \mathbf{7} \square \mathbf{8} \square \mathbf{9} \square \mathbf{1 0} \square \mathbf{1 1} \square \mathbf{1 2} \square \mathbf{1 3} \square>\mathbf{1 3}$

03 - Quantas PPP/PFIs você já teve envolvimento direto e indireto [MODELANDO]:

$\square \mathbf{0} \square \mathbf{1} \square \mathbf{2} \square \mathbf{3} \square \mathbf{4} \square \mathbf{5} \square \mathbf{6} \square \mathbf{7} \square \mathbf{8} \square \mathbf{9} \square \mathbf{1 0} \square \mathbf{1 1} \square \mathbf{1 2} \square \mathbf{1 3} \square>\mathbf{1 3}$

04 - Quantas PPP/PFIs você já teve envolvimento direto e indireto [AVALIANDO]:

$\square \mathbf{0} \square \mathbf{1} \square \mathbf{2} \square \mathbf{3} \square \mathbf{4} \square \mathbf{5} \square \mathbf{6} \square \mathbf{7} \square \mathbf{8} \square \mathbf{9} \square \mathbf{1 0} \square \mathbf{1 1} \square \mathbf{1 2} \square \mathbf{1 3} \square>\mathbf{1 3}$

05 - Quantas PPP/PFIs você já teve envolvimento direto e indireto [GERENCIANDO]:

$\square \mathbf{0} \square \mathbf{1} \square \mathbf{2} \square \mathbf{3} \square \mathbf{4} \square \mathbf{5} \square \mathbf{6} \square \mathbf{7} \square \mathbf{8} \square \mathbf{9} \square \mathbf{1 0} \square \mathbf{1 1} \square \mathbf{1 2} \square \mathbf{1 3} \square>\mathbf{1 3}$

06 - Há quantos anos você trabalha com Projetos de PMls?

$\square \mathbf{0} \square \mathbf{1} \square \mathbf{2} \square \mathbf{3} \square \mathbf{4} \square \mathbf{5} \square \mathbf{6} \square \mathbf{7} \square \mathbf{8} \square \mathbf{9} \square \mathbf{1 0} \square \mathbf{1 1} \square \mathbf{1 2} \square \mathbf{1 3} \square>\mathbf{1 3}$

07 - Quantas PMls você já teve envolvimento direto e indireto [MODELANDO]:

$\square \mathbf{0} \square \mathbf{1} \square \mathbf{2} \square \mathbf{3} \square \mathbf{4} \square \mathbf{5} \square \mathbf{6} \square \mathbf{7} \square \mathbf{8} \square \mathbf{9} \square \mathbf{1 0} \square \mathbf{1 1} \square \mathbf{1 2} \square \mathbf{1 3} \square>\mathbf{1 3}$

08 - Quantas PMIs você já teve envolvimento direto e indireto [AVALIANDO]:

$\square \mathbf{0} \square \mathbf{1} \square \mathbf{2} \square \mathbf{3} \square \mathbf{4} \square \mathbf{5} \square \mathbf{6} \square \mathbf{7} \square \mathbf{8} \square \mathbf{9} \square \mathbf{1 0} \square \mathbf{1 1} \square \mathbf{1 2} \square \mathbf{1 3} \square>\mathbf{1 3}$

09 - Quantas PMls você já teve envolvimento direto e indireto [GERENCIANDO]:

$\square \mathbf{0} \square \mathbf{1} \square \mathbf{2} \square \mathbf{3} \square \mathbf{4} \square \mathbf{5} \square \mathbf{6} \square \mathbf{7} \square \mathbf{8} \square \mathbf{9} \square \mathbf{1 0} \square \mathbf{1 1} \square \mathbf{1 2} \square \mathbf{1 3} \square>\mathbf{1 3}$

10 - Qual é o tipo de projeto de PMI mais Desenvolvido/Avaliado por sua organização [Saneamento, lluminação, etc.]:

$\mathrm{R}$ :

11 - Mais de uma empresa deve submeter PMI ao ente concedente? Se sim, quantos seriam o ideal?

Sim, Quantos?

$\square$ Não.

12 - Existe um número ideal de concorrentes a participarem de um certame de PPP/PFI?

$\square$ Não.

$\square$ Sim, Quantos? 
13 - Você acredita que a proposição de PMls no mundo em 2018 estará em:

$\square$ Em alta. $\quad \square$ Seguindo os níveis do ano anterior. $\quad \square$ Em baixa. $\quad \square$ Não saberia informar.

14 - Você acredita que a proposição de PMls no Brasil em 2018 estará em:

$\square$ Em alta. $\quad \square$ Seguindo os níveis do ano anterior. $\quad \square$ Em baixa. $\quad \square$ Não saberia informar.

15 - Atualmente quem está propondo mais PMls:

Iniciativa Privada. $\quad \square$ Iniciativa Pública. $\quad \square$ Não saberia informar.

16 - As diretrizes de um edital de projeto de PPP/PFI devem ser:

Feitas por um único projeto de PMI selecionado.

Pela junção de variáveis de mais de um projeto de PMI apresentado.

Por variáveis definidas e eleitas em consulta pública.

Por junta de especialistas, desconsiderando as PMIs.

Por contratação de instituição especializada na modelagem de PMls.

Prefiro não informar.

17 - A legislação vigente sobre as Procedimento de Manifestação de Interesse - PMls atualmente:

Torna quase impeditivo o processo de contratação da PPP/PFI.

Dificulta, mas não cessa o processo de contratação da PPP/PFI.

Não tem efeito sobre o resultado da PPP/PFI.

$\square$ Precisa de melhorias, mas não impede o processo de contratação da PPP/PFI.

Facilita o processo de contratação da PPP/PFI.

$\square$ Não posso afirmar nada sobre esta matéria.

18 - Qual país possui a melhor legislação sobre PMI na sua opinião?

Seria:

Desconheço.

19 - Há subjetivismo nas avaliações das PMls submetidas:

Concordo totalmente $\square$ Concordo $\square$ parcialmente $\square$ Neutro(a) $\square$ Discordo parcialmente $\square$ Discordo $\square$ Discordo totalmente

20 - Qual(is) variável(eis) você julga importante e atualmente preterida(s) nas avaliações de uma PMl:

Seria $(m)$ :

$\square$ Prefiro não informar.

21 - O VfM - Value for Money do Projeto é critério suficiente para assegurar que o melhor projeto seja escolhido:

Concordo totalmente $\square$ Concordo $\square$ Neutro $\square$ Discordo $\square$ Discordo totalmente

22 - Na média os Procedimentos de Manifestações de Interesse (PMls) possuem escopo:

Pouco definidos a priori resultando em projetos finais de baixa consistência.

Flexível, permitindo a adequação no curso da execução do contrato.

$\square$ Bem estabelecidos, sendo eventuais efeitos negativos decorrentes de outros fatores que não $o$ escopo. 
Prefiro não informar.

23 - Selecione 5 FATORES que você acha produzir o maior impacto POSITIVO no processo de seleção de PMls, deixando no topo da lista o mais relevante (sendo o $1^{\circ}$ o mais importante até o $5^{\circ}$ mais importante).

Propostas contrárias apresentadas;

Montante de tempo e informação disponível;

Aprovação preliminar da proposta;

$\square$ Negociação e finalização do projeto;

Valor do bônus;

Estabelecimento do preço ideal;

Transparência do processo;

$\square$ Publicação para licitação;

$\square$ Concessão apropriada de contratos e acordos;

Alinhamento estratégico de metas e objetivos;

Definição clara e documentada de escopo do projeto;

Papéis e responsabilidades claramente definidos dos participantes do projeto;

$\square$ Evitar duplicações de instalações similares;

Apoio a aquisição de terras;

Aprovação e expedição de permissões;

Subsídios construtivos;

Coordenação da Sociedade de Propósito Específico com investidores financeiros;

$\square$ Coordenação da Sociedade de Propósito Específico com arquitetos e engenheiros;

$\square$ Coordenação da Sociedade de Propósito Específico com supervisores e inspetores dos construtores;

$\square$ Boa governança;

$\square$ Coordenação da Sociedade de Propósito Específico com o construtor;

$\square$ Contramedida para evitar queixas públicas;

Rendimento mínimo garantido;

$\square$ Alocação apropriada de risco entre o setor público e privado.

24 - Selecione 5 FATORES que você acha produzir o maior impacto NEGATIVO no processo de seleção de PMls, deixando no topo da lista agora o menos relevante (sendo o $1^{\circ}$ o menos importante até 0 5o menos importante).

Propostas contrárias apresentadas; 
Aprovação preliminar da proposta;

$\square$ Negociação e finalização do projeto;

$\square$ Valor do bônus;

$\square$ Estabelecimento do preço ideal;

Transparência do processo;

Publicação para licitação;

Concessão apropriada de contratos e acordos;

Alinhamento estratégico de metas e objetivos;

Papéis e responsabilidades claramente definidos dos participantes do projeto;

$\square$ Evitar duplicações de instalações similares;

Apoio a aquisição de terras;

Aprovação e expedição de permissões;

$\square$ Subsídios construtivos;

Coordenação da Sociedade de Propósito Específico com investidores financeiros;

$\square$ Coordenação da Sociedade de Propósito Específico com arquitetos e engenheiros;

$\square$ Coordenação da Sociedade de Propósito Específico com supervisores e inspetores dos construtores;

Coordenação da Sociedade de Propósito Específico com o construtor;

Contramedida para evitar queixas públicas;

Rendimento mínimo garantido;

Informações disponíveis inconsistentes.

25 - Você poderia adicionar algum(s) FATOR(es) CRÍTICO(s) que impacta(m) as PMls não listados nas questões anteriores:

Positivos.

Desconheço fatores adicionais.

Negativos.

26 - Para reduzir o subjetivismo existente nas variáveis qualitativas presentes em Projetos de PMls, quais "Propriedades" trariam maior OBJETIVIDADE para os avaliadores (ordene da mais importante para a menos):

Clareza;

Concisão;

Priorizadora;

Comunicadora;

$\square$ Antecipadora;

Alinhada com a estratégia;

$\square$ Metafórica [Compreensão intuitiva de objetivos];

$\square$ Análoga [Que converta o intuitivo em explícito];

Acessível;

Flexível. 
27 - Das "variáveis qualitativas" encontradas nos projetos de PMls, qual(is) "propriedades" melhoria(m) o julgamento dos avaliadores do(s) projeto(s)?

\begin{tabular}{|c|c|c|c|c|c|c|c|c|c|c|c|}
\hline & & & & & & opriedades & & & & & \\
\hline & Clareza & Concisão & Priorizadora & Comunicadora & Antecipadora & $\begin{array}{l}\text { Alinhada com a } \\
\text { estratégia }\end{array}$ & Metafórica & Análoga & Acessível & Flexível & Não Aplicável \\
\hline Objetivo do Projeto & $\square$ & $\square$ & $\square$ & $\square$ & $\square$ & $\square$ & $\square$ & $\square$ & $\square$ & $\square$ & $\square$ \\
\hline Relevância Social & $\square$ & $\square$ & $\square$ & $\square$ & $\square$ & $\square$ & $\square$ & $\square$ & $\square$ & $\square$ & $\square$ \\
\hline Governança & $\square$ & $\square$ & $\square$ & $\square$ & $\square$ & $\square$ & $\square$ & $\square$ & $\square$ & $\square$ & $\square$ \\
\hline $\begin{array}{l}\text { Inovação } \\
\text { Tecnológica }\end{array}$ & $\square$ & $\square$ & $\square$ & $\square$ & $\square$ & $\square$ & $\square$ & $\square$ & $\square$ & $\square$ & $\square$ \\
\hline Responsabilidade & $\square$ & $\square$ & $\square$ & $\square$ & $\square$ & $\square$ & $\square$ & $\square$ & $\square$ & $\square$ & $\square$ \\
\hline Risco & $\square$ & $\square$ & $\square$ & $\square$ & $\square$ & $\square$ & $\square$ & $\square$ & $\square$ & $\square$ & $\square$ \\
\hline $\begin{array}{l}\text { Aspectos Jurídicos } \\
\text { Relevantes } \\
\text { Indicador de }\end{array}$ & $\square$ & $\square$ & $\square$ & $\square$ & $\square$ & $\square$ & $\square$ & $\square$ & $\square$ & $\square$ & $\square$ \\
\hline $\begin{array}{l}\text { Desempenho do } \\
\text { Projeto }\end{array}$ & $\square$ & $\square$ & $\square$ & $\square$ & $\square$ & $\square$ & $\square$ & $\square$ & $\square$ & $\square$ & $\square$ \\
\hline Investimento & $\square$ & $\square$ & $\square$ & $\square$ & $\square$ & $\square$ & $\square$ & $\square$ & $\square$ & $\square$ & $\square$ \\
\hline $\begin{array}{l}\text { Capacidade Máxima } \\
\text { de Oferta do Serviço }\end{array}$ & $\square$ & $\square$ & $\square$ & $\square$ & $\square$ & $\square$ & $\square$ & $\square$ & $\square$ & $\square$ & $\square$ \\
\hline $\begin{array}{c}\text { Custos Operacional } \\
\text { dos Serviços } \\
\text { Ofertados }\end{array}$ & $\square$ & $\square$ & $\square$ & $\square$ & $\square$ & $\square$ & $\square$ & $\square$ & $\square$ & $\square$ & $\square$ \\
\hline $\begin{array}{c}\text { Metas e Impactos } \\
\text { Ambientais }\end{array}$ & $\square$ & $\square$ & $\square$ & $\square$ & $\square$ & $\square$ & $\square$ & $\square$ & $\square$ & $\square$ & $\square$ \\
\hline Beneficiados & $\square$ & $\square$ & $\square$ & $\square$ & $\square$ & $\square$ & $\square$ & $\square$ & $\square$ & $\square$ & $\square$ \\
\hline
\end{tabular}




\section{AGRADECIMENTOS}

O meu muito obrigado por ter contribuído com esta pesquisa!

\section{TERMO DE CONSENTIMENTO}

Declaro que estou informado de que este questionário se refere à pesquisa elaborada pelo acadêmico Tiago Vieira Caproni, como fundamentação para a formulação de conteúdo de sua Tese de Doutorado junto à Universidade de São Paulo (USP), Campus de São Carlos-SP, pelo qual valido as informações supra informadas e dou anuência, inclusive para a publicação ANÔNIMA dos resultados obtidos com este trabalho. 


\title{
APÊNDICE D - FORMALIZAÇÃO DO PEDIDO DE ENTREVISTA
}

\section{UNIVERSIDADE DE SÃO PAULO - USP \\ CAMPUS DE SÃO CARLOS - ESCOLA DE ENGENHARIA DE SÃO CARLOS -EESC CURSO DE PÓS-GRADUAÇÃO EM ENGENHARIA DE PRODUÇÃO}

\author{
São Carlos - SP, Brasil, domingo, 13 de \\ maio de 2018.
}

Para: [Nome do(a) entrevistado (a)]

E-mail: [Contato de e-mail]

Atribuição: [Cargo do(a) entrevistado(a)]

Eu, Tiago Vieira Caproni, doutorando em Engenharia de Produção pela colenda Escola de Engenharia de Produção da Universidade de São Paulo (EESC/USP), sob orientação do Professor Doutor Associado Daniel Capaldo Amaral, venho mui respeitosamente, a presença de Vossa Senhoria requerer a oportunidade de realização de entrevista de fins acadêmicos contigo ou com membro(s) de vosso grupo de trabalho que possua $(\mathrm{m})$ notório conhecimento no tema Parcerias Público-Privadas - PPP/PFI e Procedimento de Manifestação de Interesse - PMI.

O propósito desta entrevista é compreender de forma mais aprofundada a perspectiva de múltiplos profissionais e acadêmicos acerca do instituto PMI - Procedimento de Manifestação de Interesse, componente do processo de estruturação de PPP/PFIs, como parte da tese de doutorado sob o título: "Modelo de indicadores para avaliação de Manifestações de Interesse em Parcerias Público-Privadas".

Focalmente o objetivo é avaliar a clareza e a consistência de indicadores propostos nesta tese em avaliações de projetos reais, considerando a carência de conteúdo para subsidiar gestores e projetistas públicos e privados na etapa de avaliação das propostas submetidas.

A entrevista demandará por volta de 1 hora e 20 minutos, conduzida no idioma português e estará dividida em 2 partes:

1. Apresentações protocolares e contextualização do núcleo da tese de doutorado;

2. Apresentação do Índice proposto e avaliação unitária dos indicadores que o compõe*:

*Material de apoio será utilizado nesta fase da entrevista para suportar o processo de escolha dos entrevistados.

O local de realização desta ficará a cargo do entrevistado, podendo ser realizada no próprio escritório deste, afim de trazer-Ihe o menor desconforto possível para o entrevistado. Outro pedido ao entrevistado é autorização para que o encontro seja gravado em áudio para melhor discussão dos temas e captura de detalhes.

Como sugestão, tem-se; Local: [Nome da cidade - Endereço do escritório do entrevistado], data: [dia da semana], [dia/mês/ano] e horário: [hh:min].

As informações obtidas na eventual entrevista contarão com sigilo de fonte garantido e serão estritamente empregadas para a validação da proposta teórica do estudo. Caso haja interesse do entrevistado, ao término dos levantamentos será elaborado um relatório consolidado das informações e compartilhado. 
Nós apreciaríamos um contato breve, considerando os arranjos logísticos necessários para operacionalizar o encontro. Na certeza do contato e sinalização positiva para o pleito, sua contribuição será de extremo valor não só para o resultado final do trabalho, mas também para o progresso do campo do conhecimento que estudamos, antecipo assim protestos de agradecimento e respeito.

Sem mais,

Tiago Vieira Caproni Doutorando em Engenharia de Produção - EESC / USP tcaproni@usp.br

Daniel Capaldo Amaral Professor Associado do Departamento de Engenharia de Produção - EESC / USP amaral@sc.usp.br 


\section{APÊNDICE E - PROTOCOLO DE ENTREVISTA COM ESPECIALISTAS}

As entrevistas com os especialistas foram conduzidas por meio de agendamento preliminar por contato telefônico e correio eletrônico. Sendo parte destas realizadas pessoalmente e parte realizadas via Skype®, as entrevistas foram realizadas no intervalo de uma semana e meia, possibilitando homogeneidade nas perspectivas dos respondentes as políticas públicas que versam sobre os institutos PPP/PFI e PMI. Na apresentação de contextualização do trabalho, houve descrição do índice "T", apresentação das perguntas e organogramas dos critérios, seguidos da metodologia empregada para a realização dos testes propostos no estudo:

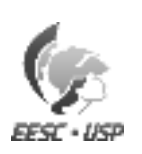

\section{UNIVERSIDADE DE SÃO PAULO - USP \\ CAMPUS DE SÃO CARLOS - ESCOLA DE ENGENHARIA DE SÃO CARLOS -EESC CURSO DE PÓS-GRADUAÇÃO EM ENGENHARIA DE PRODUÇÃO}

maio de 2018.

São Carlos - SP, Brasil, domingo, 13 de

Para: [Nome do(a) entrevistado (a)]

Atribuição: [Cargo do(a) entrevistado(a)]

Nota técnica:

O Índice "T" desenhado no estudo serve para a avaliação de Propostas de PMls submetidas pela iniciativa privada ao ente público viabilizando parâmetros mais diretos para que os árbitros de Câmara(s) Técnica(s) analisem as propostas.

Estas análises envolvem a atribuição de notas a conjunto de variáveis agrupadas em dimensões, aqui chamadas de "indicadores". Estes "indicadores" representam os elementos mínimos do escopo esperado em projetos de PMls. Tais indicadores descrevem a capacidade potencial de desempenho de uma dada proposta. A entrevista aborda a aplicação dos Métodos AHP (WIND; SAATY, 1980) e adaptação de metodologia proposta por (WIND; SAATY, 1980):

Todas as perguntas serão contextualizadas e orientado(a) o(a) entrevistado(a) sobre o método a ser utilizado no preenchimento.

1 ㄹ - O Índice "T", proposto na tese é composto pelos indicadores*:

$T=\left[I_{Q}+I_{G}+I_{Q}+I_{E}+I_{B}+I_{A}+I\right]$

* O peso de cada um dos indicadores [Onde $i$ é uma determinada proposta de Projeto e $I_{Q_{i}}$ : Indicador de Qualificação, $I_{G_{i}}:$ Indicador de Governança, $I_{O_{i}}:$ Indicador Técnico/Operacional, $I_{E_{i}}$ : Indicador Econômico, $I_{F_{i}}$ : Indicador Financeiro, $I_{A_{\mathrm{i}}}$ : Indicador Ambiental, $I_{S_{i}}$ : Indicador Social], foi atribuído por cada entrevistado por meio do método 
AHP - Analytical Hierarchy Process (CLOQUELL-BALLESTER, et al., 2006), atribuindo grau de relevância e impacto destes no escopo da proposta e por conseguinte no desempenho do projeto.

Atribua pesos as definições do Índice "T" segundo os critérios de sucesso de uma PMI, identificando o grau de importância do indicador segundo os fatores: Qualidade [perspectiva da iniciativa pública], Custo [perspectiva da iniciativa privada] e Satisfação do Cidadão [perspectiva do cidadão beneficiado pelo serviço], sendo a escolha realizada em duas rodadas, onde a segunda servirá para ajustar o grau de consistência das respostas do(a) entrevistado(a); 
Figura 24 - Dimensões de avaliação dos indicadores do índice ${ }^{67}$

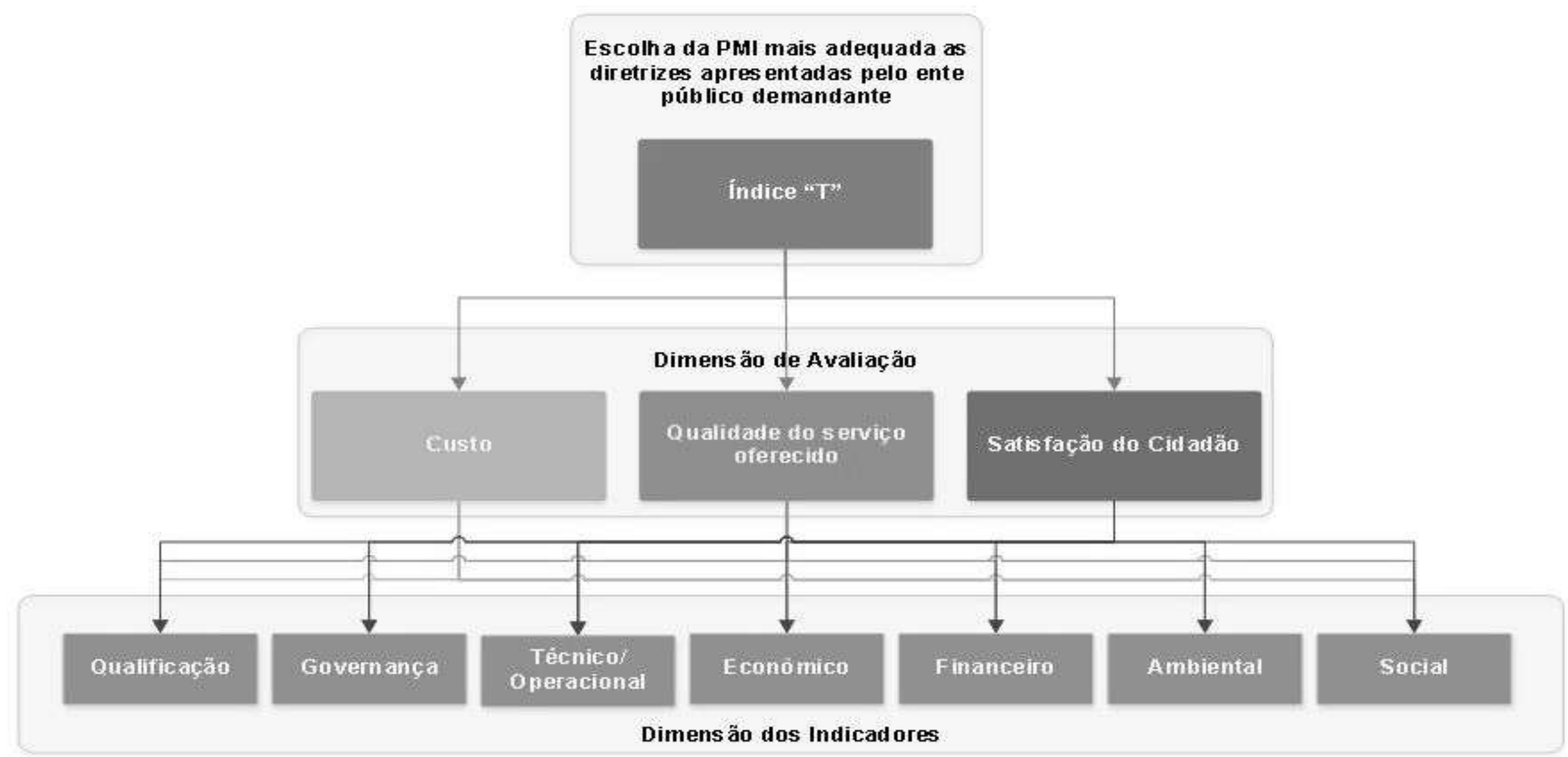

Fonte: Elaborado pelo autor.

${ }^{67}$ Realizada pelos entrevistados a luz da percepção dos Empresários, Governos e Cidadãos. 
2a A. - Atribua pesos as definições do Índice "T", avaliados em 3 (três) classes de critérios: Coerência Conceitual, Coerência Operacional e Utilidade. O objetivo é validar o Índice " $T$ " segundo os critérios de validação de indicadores propostos por (CLOQUELL-BALLESTER, et al., 2006) via método AHP proposto por (WIND; SAATY, 1980):

Segundo os critérios propostos:

- Definição;

- Relevância;

- Interpretação/Significado;

- Formulação;

- Dados e unidades;

- Método de Medida;

- Precisão da Sensibilidade;

- Confiança no Indicador;

- Confiança na fonte do Indicador;

- Disponibilidade e aplicabilidade;

- Segurança do dado informado;

- Custo da Informação. 
Figura 25 - Peso atribuído pelo entrevistado a classe do critério 68
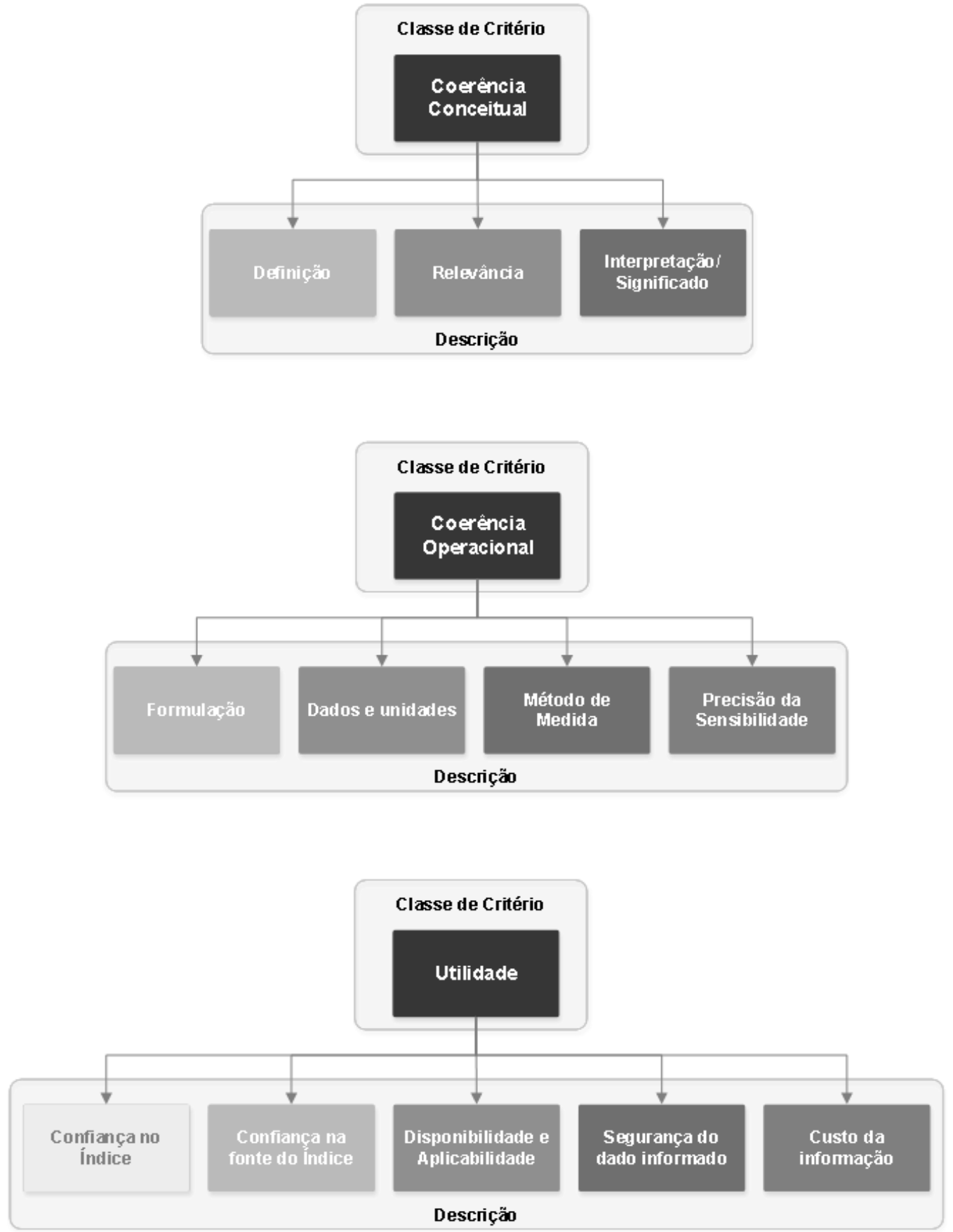

Fonte: Adaptado pelo autor.

68 Proposto por (CLOQUELL-BALLESTER, et al., 2006). 
2" B. Atribua nota ao grau de concordância sua as sentenças do Índice "T" a cada uma das descrições, nesta o(a) entrevistado(a) atribuirá nota ao grau de concordância (Escala Likert) sua as sentenças do Índice "T" a cada uma das descrições; Em que: $\square$ Concordo totalmente (5) $\square$ Concordo (4) $\square$ Neutro(a) (3) $\square$ Discordo (2) $\square$ Discordo totalmente (1)

Tabela 15 - Sentenças dos critérios avaliados pelos entrevistados ${ }^{69}$

\begin{tabular}{|c|c|c|c|c|}
\hline & & & Espe & lista \\
\hline & & & & \\
\hline & & & $\begin{array}{l}\text { Nota de Con } \\
\text { Sentença ao }\end{array}$ & $\begin{array}{l}\text { rdância da } \\
\text { idice (0 a 5) }\end{array}$ \\
\hline $\begin{array}{l}\text { Classes de } \\
\text { critérios }\end{array}$ & Descrição & Sentença relacionada ao Índice & 1a Rodada & 2a Rodada \\
\hline & Definição & $\begin{array}{l}1 \text { - O índice "T", constituído pelos indicadores: }[l q+l g+l o+l e+l f+l a+l s], \text { permite verificar se } \\
\text { uma determinada proposta de PMI atende de forma suficiente as diretrizes formuladas pelo órgão } \\
\text { concedente. }\end{array}$ & & \\
\hline $\begin{array}{l}\text { Coerência } \\
\text { Conceitual }\end{array}$ & Relevância & $\begin{array}{l}2 \text { - Os indicadores }[l q+l g+l o+l e+l f+l a+l s] \text { que compõem o índice "T" estabelecem } \\
\text { parâmetros contundentes para a avaliação dos árbitros da(s) Câmara(s) Técnica(s) a luz das } \\
\text { Propriedades de Visão do Produto definidas no modelo, para atenderem os anseios de todas as } \\
\text { partes interessadas no processo de contratação futura da Parceria Público-Privada - PPP/PFI. }\end{array}$ & & \\
\hline & Interpretação/Significado & $\begin{array}{l}3 \text { - O conjunto de variáveis dos indicadores }[l q+l g+l o+l e+l f+l a+l s] \text { avaliadas a luz das } \\
\text { Propriedades de Visão do Produtos definidas no modelo, que somados formam o índice "T" } \\
\text { possuem linguagem clara a evitar interpretações ambíguas. }\end{array}$ & & \\
\hline & Formulação & $\begin{array}{l}4 \text { - A formulação matemática do índice "T" é fácil de ser compreendida e acelera o processo de } \\
\text { escalonamento de proposta(s) mais aderente(s) a(s) necessidade(s) do órgão demandante, por } \\
\text { considerar as dimensões que devam ser quantificadas através das notas das variáveis atribuídas } \\
\text { com base nas Propriedades de Visão do Produto. }\end{array}$ & & \\
\hline $\begin{array}{l}\text { Coerência } \\
\text { Operacional }\end{array}$ & Dados e unidades & $\begin{array}{l}5 \text { - As variáveis que formam os indicadores }[l q+l g+l o+l e+l f+l a+l s] \text { do índice "T" estão em } \\
\text { unidade de medida corretas, reúnem os dados necessários expurgando os irrelevantes para a } \\
\text { escolha do projeto mais aderente a(s) necessidade }(s) \text { estabelecidas pelo órgão demandante do } \\
\text { serviço e são comparados eficazmente a luz das Propriedades de Visão do Produto eleitas no } \\
\text { modelo. }\end{array}$ & & \\
\hline & Método de Medida & $\begin{array}{l}6 \text { - Alcançar o índice "T" por meio das variáveis dos indicadores definidos por: }[l q+l g+l o+l e+ \\
\text { If }+l a+l s] \text {, permite a reprodução e comparação das propostas submetidas ao órgão demandante } \\
\text { para ao final ter-se um edital de PPP/PFI baseado na proposta com maior índice (nota final). }\end{array}$ & & \\
\hline
\end{tabular}

69 Realizada em 2 rodadas de arguições. 
Conclusão

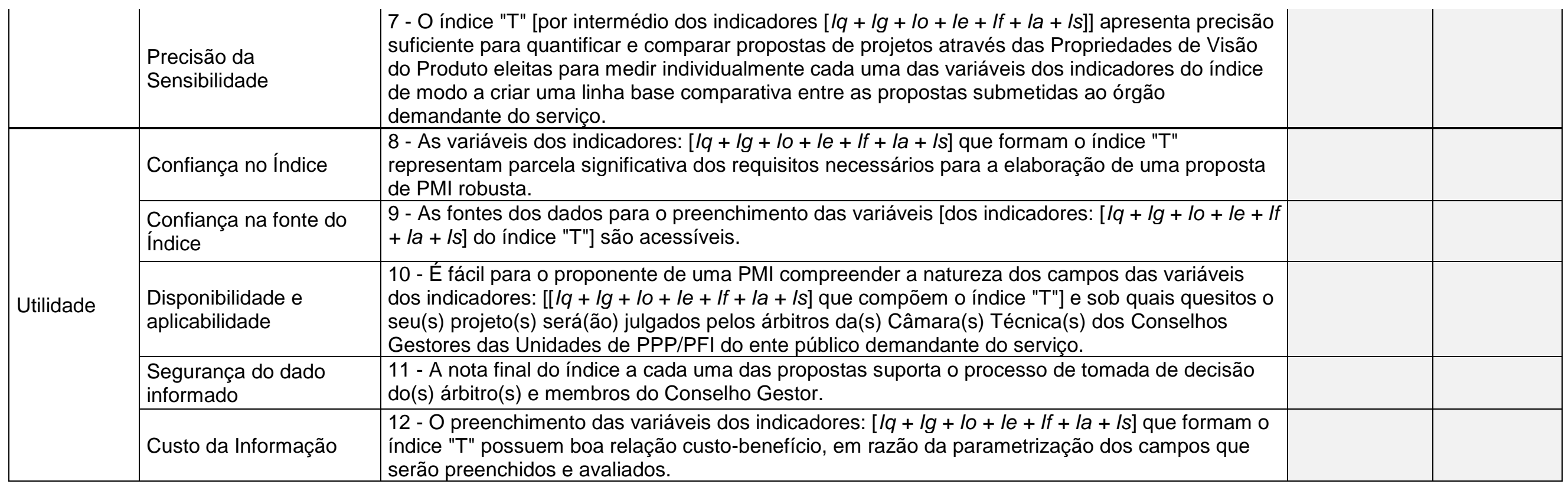

Fonte: Adaptado de (CHOU; LEATEMIA, 2016) pelo autor.

\section{3a Pergunta:}

Qual a principal contribuição do Índice "T" na avaliação de PMls para as PPP/PFIs?

Qual a principal limitação do Índice "T" na avaliação de PMls para as PPP/PFIs? 


\section{APÊNDICE F - DESCRITIVO DOS INDICADORES DO ÍNDICE “T”}

O índice "T" é estruturado pelo conjunto de sete indicadores:

$$
T_{\bar{i}}=\left[I_{Q_{i}}+I_{G_{i}}+I_{O_{i}}+I_{E_{i}}+I_{F_{i}}+I_{A_{i}}+I_{S_{i}}\right]
$$

Em que:

$$
\begin{array}{ll}
I_{Q_{i}} & =\text { Indicador de Qualificação da Proposta } i ; \\
I_{G_{\bar{i}}} & =\text { Indicador de Governança da Proposta } i ; \\
I_{O_{i}} & =\text { Indicador Técnico/Operacional da Proposta } i ; \\
I_{E_{\bar{i}}} & =\text { Indicador Econômico da Proposta } i ; \\
I_{F_{\bar{i}}} & =\text { Indicador Financeiro da Proposta } i \\
I_{A_{\bar{i}}} & =\text { Indicador Ambiental da Proposta } i \mathrm{e} \\
I_{S_{i}} & =\text { Indicador Social da Proposta. }
\end{array}
$$

Abordados nesta pesquisa como dimensões chaves para o processo de estruturação de um Procedimento de Manifestação de Interesse - PMI a atender integralmente o versado nas diretrizes apresentadas pelo órgão público interessado no provimento do serviço ao cidadão, cada um dos indicadores é descrito individualmente [campo, descrição e conteúdo] após a decomposição dos elementos que compõem o índice em si mesmo. 
Quadro 39 - Definição do Índice "T"

\section{Definição do Índice}

Campo

Indicador

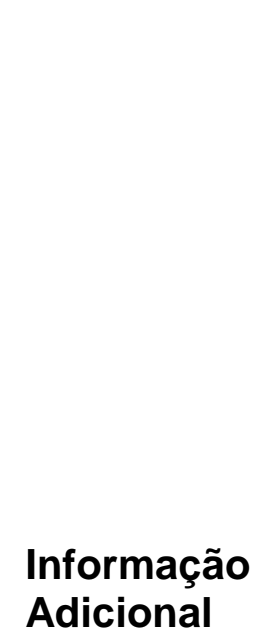

Descrição

Nome

Apresentação visual de

layout proposto para o índice

\section{Conteúdo}

Índice "T"

Figura 26 - Layout do índice "T" (nota geral) dos indicadores consolidados (a)

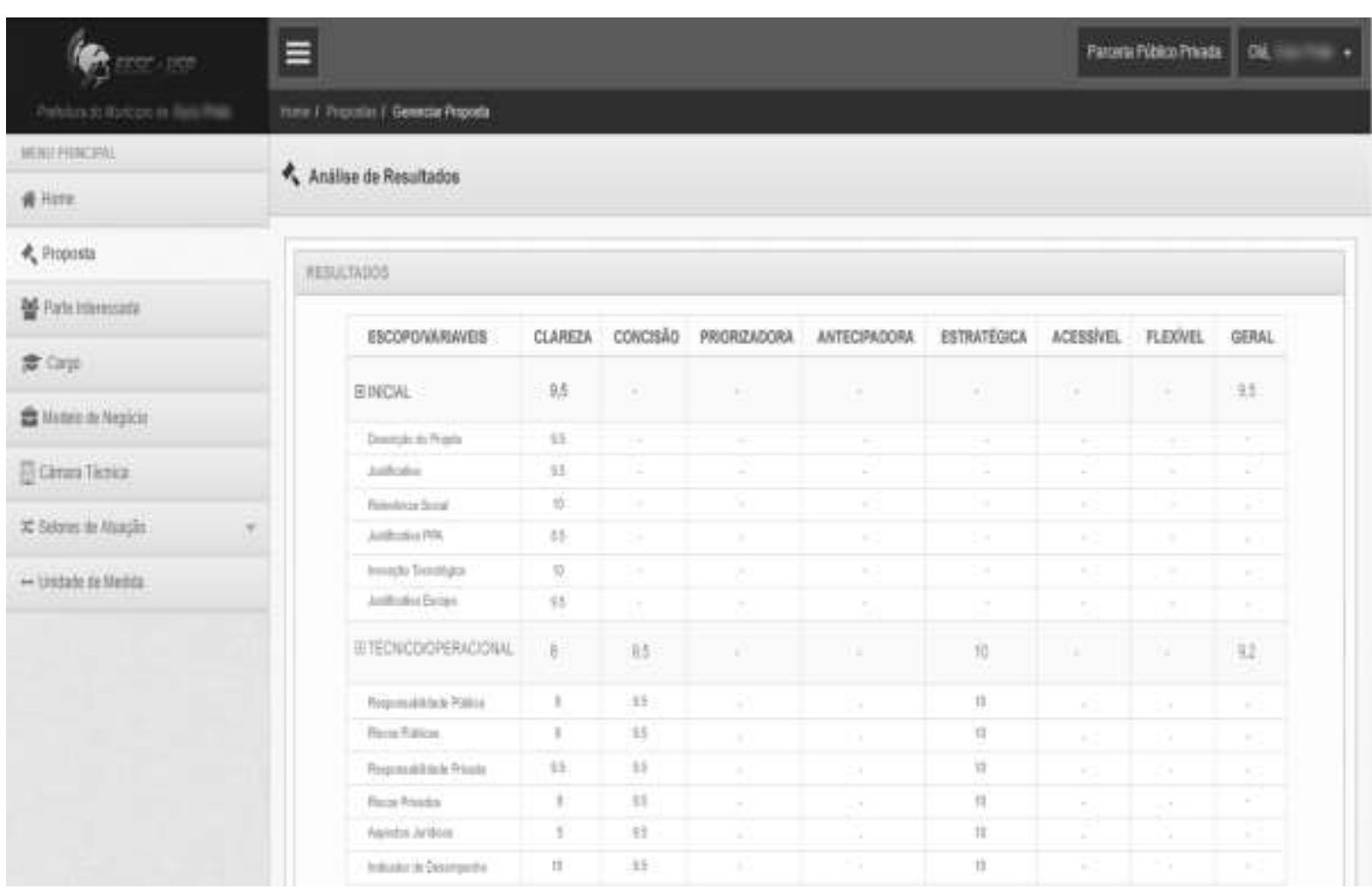

Fonte: Elaborado pelo Autor. 
Figura 27 - Layout do índice "T" (nota geral) dos indicadores consolidados (b)

Apresentação visual de layout proposto para a avaliação do indicador

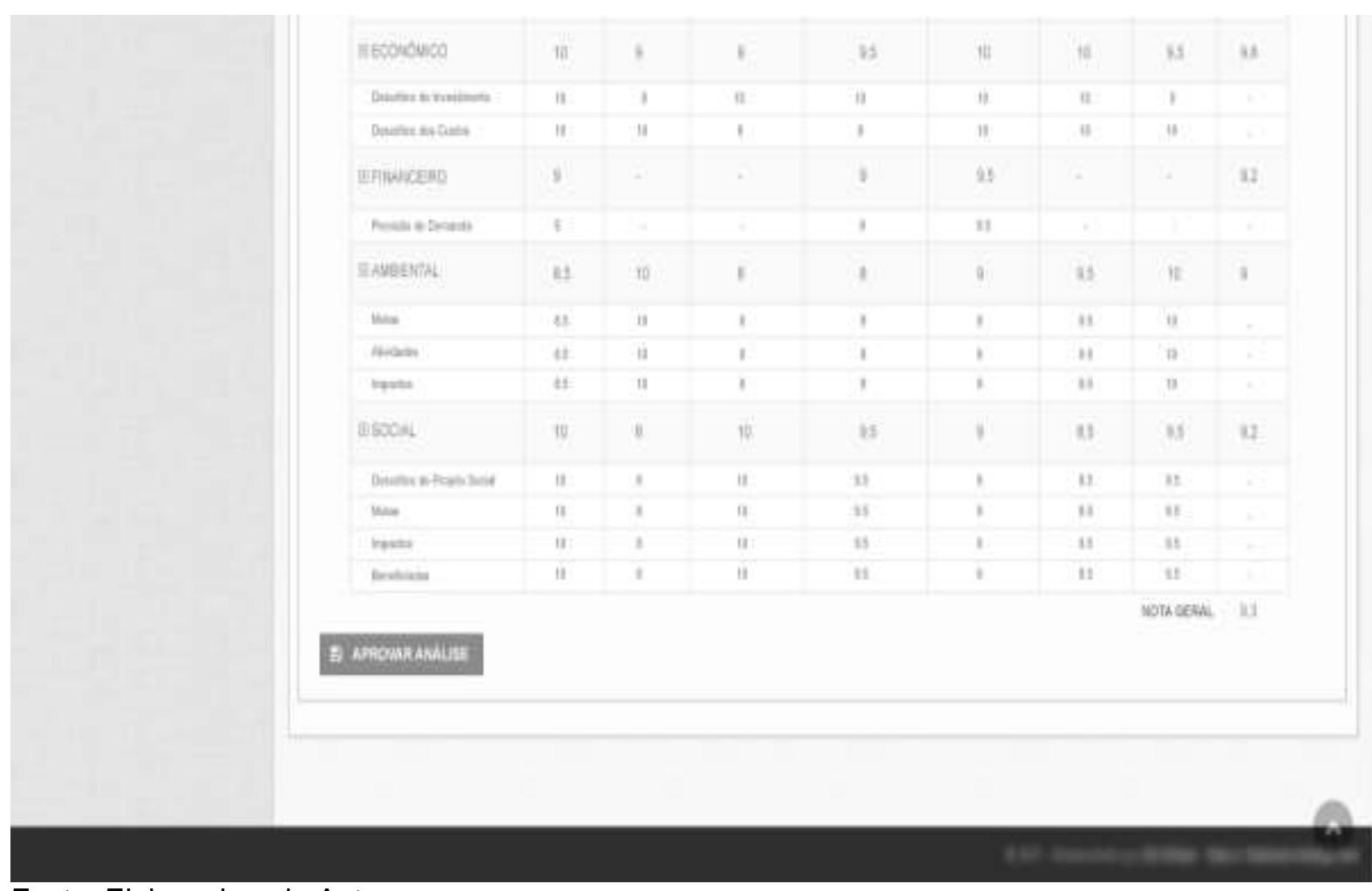

Fonte: Elaborado pelo Autor.

Fonte: Estrutura Adaptada de (CLOQUELL-BALLESTER et al., 2006) e conteúdo elaborado pelo autor

Complementarmente são apresentados as seguir a definição individual de cada uma das fórmulas e layouts dos indicadores propostos para a estruturação do índice "T", baseados em: aspectos ambientais e descritivo destes, definição conceitual, descrição do dado e da unidade, método de medida, interpretação e significado, exatidão e relevância das variáveis inseridas nas respectivas dimensões dos indicadores. 


\section{F.1 INDICADOR DE QUALIFICAÇÃO}

Quadro 40 - Descritivo do indicador Qualificador

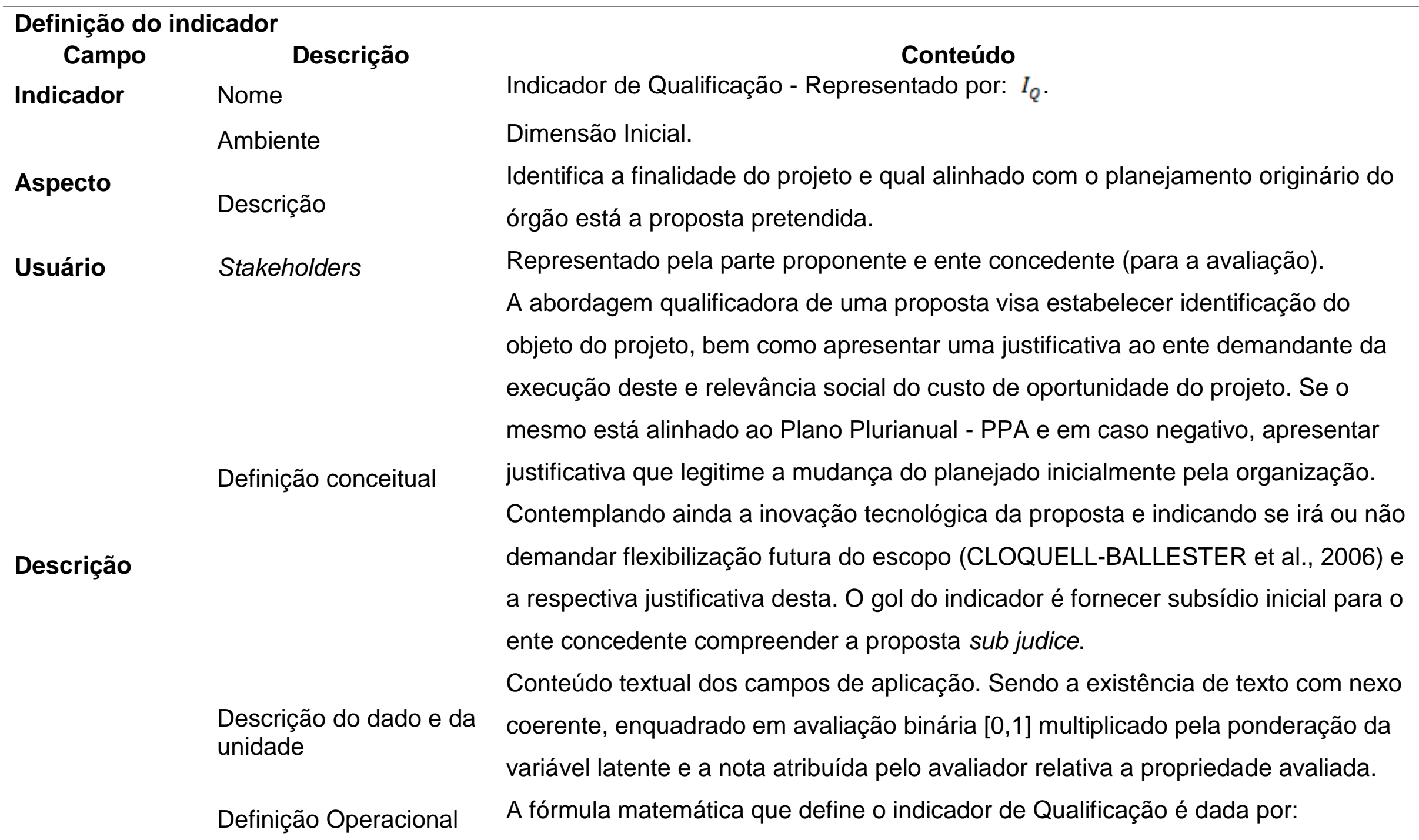




$$
I_{Q}=\sum_{i=1}^{6} \omega_{i} t_{i} \alpha_{i}
$$

Em que:

$$
\begin{aligned}
& I_{Q} \quad=\text { Indicador de Qualificação; } \\
& \omega_{i} \quad=\text { Peso ponderado da variável latente } i \text { ao indicador de } \\
& \text { referência } I_{Q} \text {; } \\
& t_{\bar{i}} \quad=\text { Texto descritivo da variável latente } i \text {; } \\
& \alpha_{i} \quad=\text { Nota atribuída (0-10) pelo(a) avaliador(a) do conteúdo } t_{i} \text { sob } \\
& \text { o aspecto da Propriedade de Visão "Clareza"; }
\end{aligned}
$$

E as variáveis latentes $i$ são representadas por:

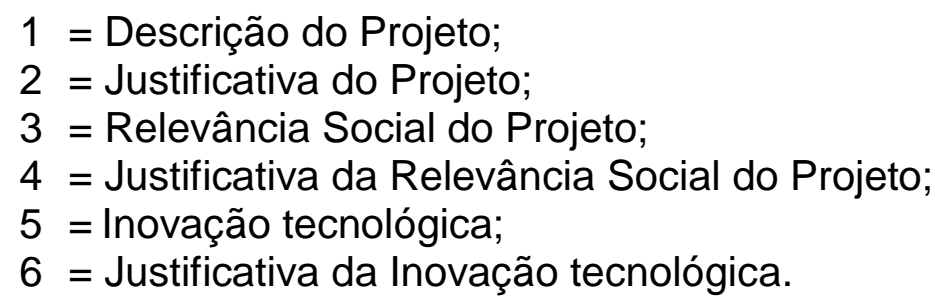

Conteúdo textual, se positivo atribuição automática de "1", se ausente de conteúdo "0". O Indicador de Qualificação é dado pela soma das avaliações ponderadas das variáveis latentes. O peso ponderado de cada um dos indicadores e das Variáveis Latentes é definido pela Câmara Técnica, seguindo os direcionamentos do Conselho Gestor, regidos pelas Diretrizes Preliminares [se existentes] determinadas pelo órgão demandante do serviço. O Pesos dos indicadores serão fornecidos pelos membros da(s) Câmara(s) Técnica(s), sendo o método AHP boa 
alternativa para a definição destes e aplicados a todos os indicadores do estudo e será representado por $(\Phi)$.

Estabelecer uma nota a Descrição do Objeto do Projeto permite determinar qual é o melhor projeto submetido com a somatória da avaliação de todos os membros eleitos para a validação da(s) Câmara(s) Técnica(s). O nível de "Clareza" do texto sobre a Inovação tecnológica do projeto permitirá aos gestores melhor adequação

Interpretação/significado do termo de referência do edital da PPP/PFI, e caso a necessidade de flexibilizar o escopo do projeto em razão de alterações tecnológicas, tal medida pode ser determinada em dispositivo do contrato dentro do limite legal, respeitando os marcos regulatórios, mas não engessando o projeto ou mesmo inviabilizando este. As notas das variáveis latentes (0 a 10) são atribuídas de acordo com a Propriedade de Visão eleita para a análise.

\section{Justificativa}

Três fatores condicionam a precisão das informações capturadas pelas variáveis e que influenciam na sensibilidade do indicador que compõe o Índice final: (i)

Alocação de pesos dados aos "indicadores" e as variáveis que compõem cada um destes para a constituição final do índice "T". Embora seja carregado de subjetivismo, os membros das Câmaras Técnicas poderiam adotar o método AHP

Exatidão para tal ponderação (PIERE; MANTESE, 2017) capturando assim a percepção dos árbitros quais indicadores e variáveis demandariam maior peso de acordo com o Planejamento Estratégico da instituição demandante do serviço. (ii) Avaliação correta dos indicadores, a avaliação do serviço a ser entregue é condicionada a inter-relação entre as variáveis do próprio indicador e seu grau de concordância e interação com as variáveis de outros indicadores para a composição de um número índice robusto, ou seja, não pode haver discrepância entre estas, pois 
inviabilizaria o indicador em si e comprometeria o valor observado no índice, pesando negativamente no resultado final da proposta avaliada. (iii) Medir a capacidade real de serviço entregue e não potencial. Dado direto, atribuído somente a variável que está sendo preenchida do indicador $I x$. O conjunto dos três fatores supracitados direcionarão a exatidão de todos os indicadores que compõe a avaliação de PMls, sendo o mesmo representado por $(\varepsilon)$.

A relevância do Indicador de Qualificação é pautar os avaliadores sobre a natureza da proposta em julgamento, bem como a justificativa da proposição e a relevância social dos atos decorrentes do objeto a ser alvo no certame de PPP/PFI.

Adicionalmente demonstra conformidade ou não com o Plano Plurianual - PPA do ente demandante, caso não esteja vinculado ao PPA, o indicador exige o

Relevância

\section{Fonte}

preenchimento de justificativa que demonstre a importância e relevância da execução da proposta, mesmo que esta não tenha sido pensada como serviço a ser realizado no plano de gestão/governo do órgão. Inovação Tecnológica prevista no projeto até então de desconhecimento operacional do ente público que justifique a contratação do serviço. E fundamentalmente se o projeto demandará adequação do escopo em função de obsolescência da tecnologia adotada e fundamentação para tal previsão contratual.

Source - World Bank Group (WBG); Unidade de Parceria Público-Privada da Secretaria Estadual de Governo do Estado de São Paulo; bibliografia acadêmica consultada e Fatores Críticos para o Sucesso - FCSs mapeados no recorte da pesquisa. Sendo o mesmo conjunto de fontes consultadas para o desenho dos indicadores e neste estudo representadas por $(\kappa)$. 
Visualizando o indicador em perspectiva, observa-se no organograma o

enquadramento deste no escopo das propostas (ii), quais variáveis ele reúne sob o julgamento de qual(is) propriedade(s) chave (iii).

Figura 28 - Definição do indicador de Qualificação

Perspectiva (ii)

Organograma de

Informação

Adicional

\section{Escopo da PMI (Procedimento de} Manifestação de Interesse)

Avaliação das Propostas submetidas sob a égide de Propriedades Chave

\section{Descritivo de}

Qualificação - Dados

Institucionais do

proponente

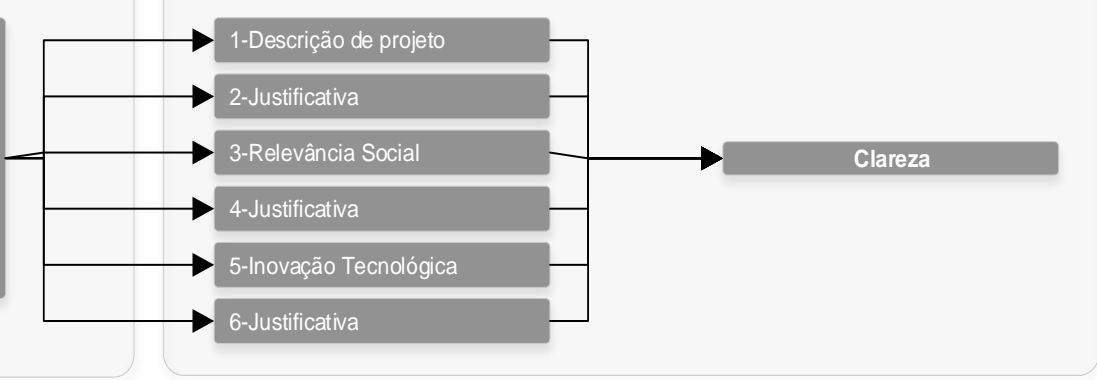

Fonte: Elaborado pelo Autor. 
Figura 29 - Layout proposto do indicador de Qualificação (a)

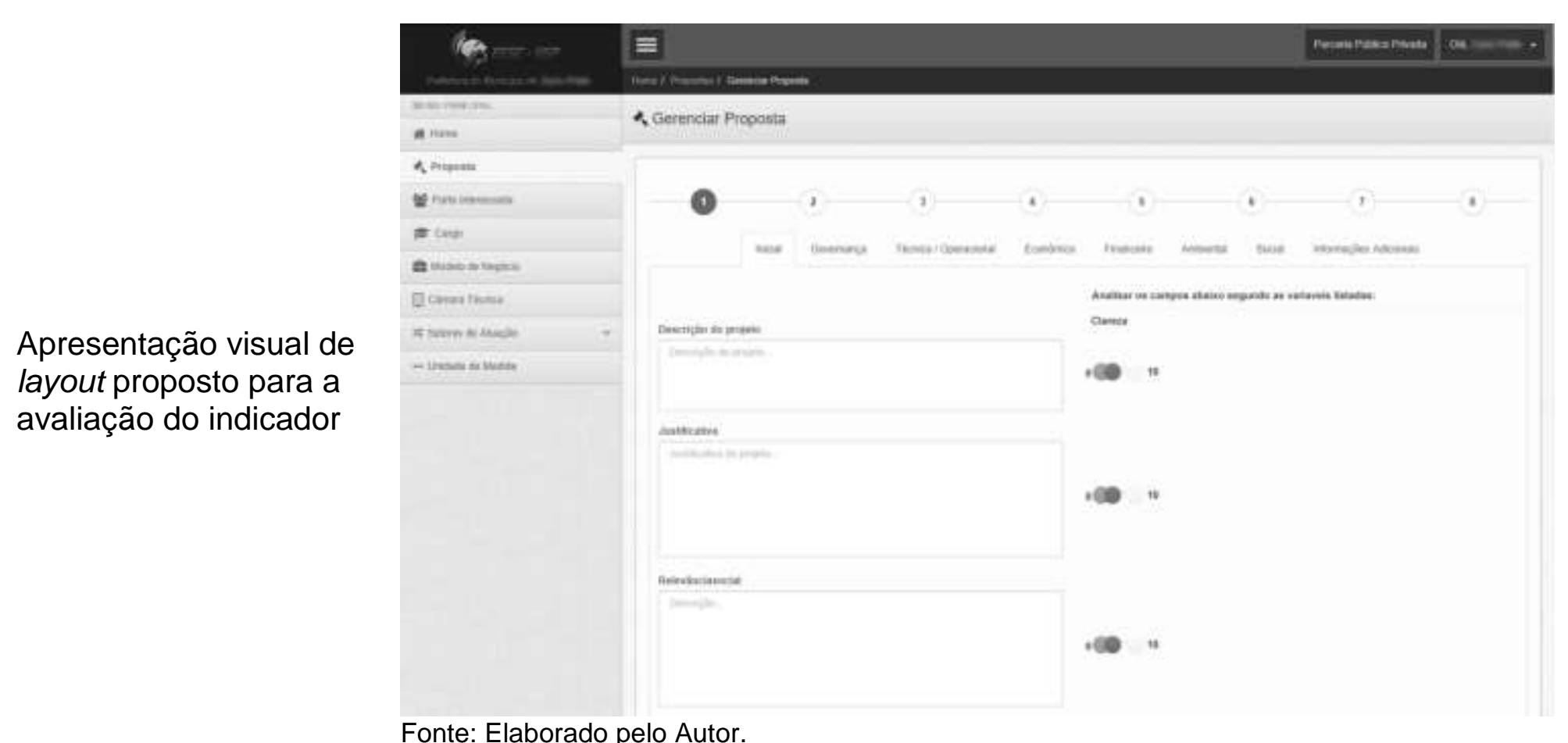


Conclusão

Figura 30 - Layout proposto do indicador de Qualificação (b)

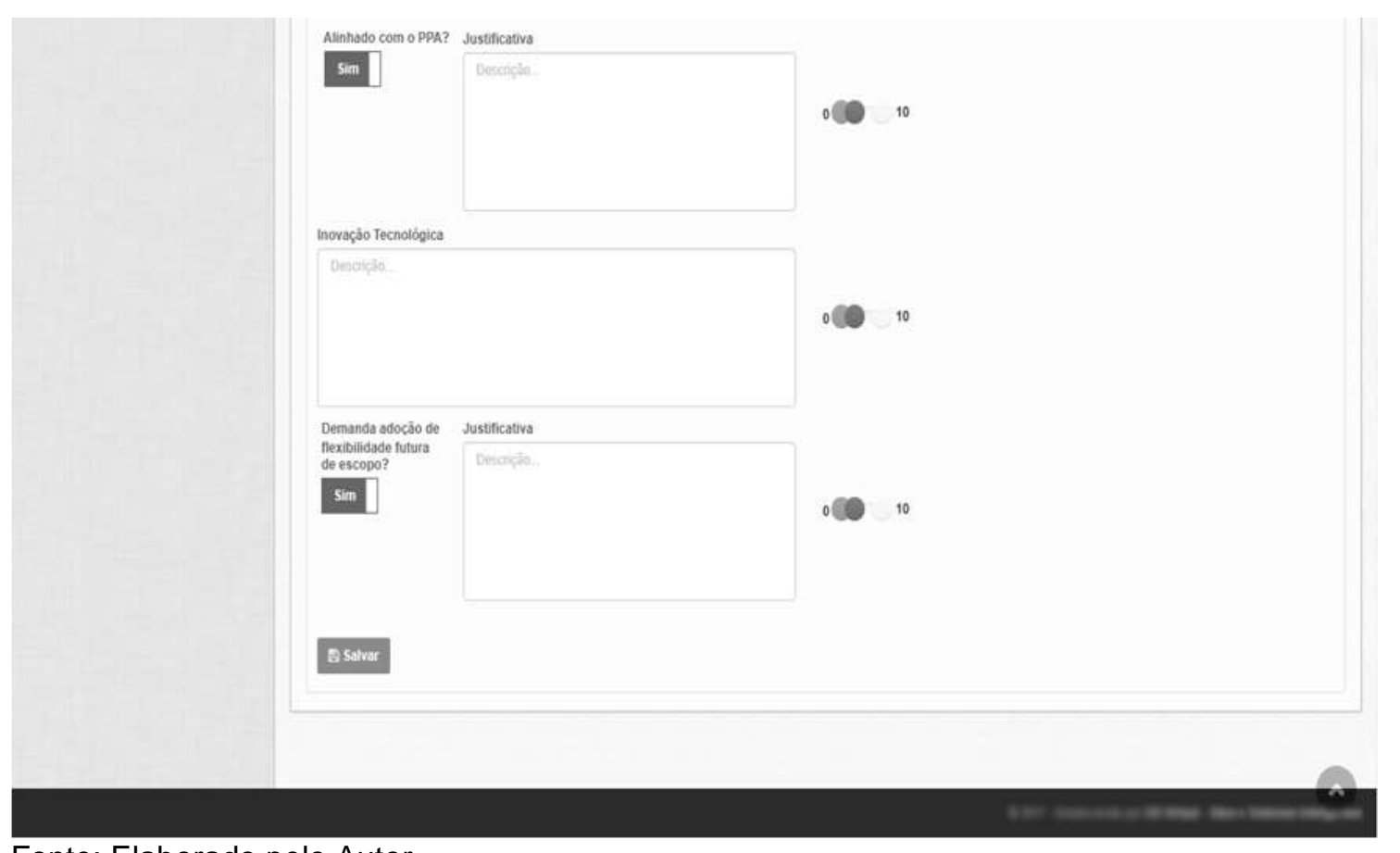

Fonte: Elaborado pelo Autor.

Fonte: Estrutura Adaptada de (CLOQUELL-BALLESTER et al., 2006) e conteúdo elaborado pelo autor. 
F.2 INDICADOR DE GOVERNANÇA

Quadro 41 - Descritivo do indicador de Governança

Definição do indicador

Campo

\section{Descrição}

Indicador Nome

Ambiente

Aspecto

Usuário

Descrição
Descrição

Stakeholders

Definição conceitual

Descrição do dado e da unidade

Definição Operacional

\section{Conteúdo}

Indicador de Qualificação - Representado por: $I_{G}$.

Dimensão de Governança, onde a rotulação das partes interessadas facilita a comunicação e acesso direto e mais claro as atribuições e responsabilidades dos envolvidos.

Estabelece nomenclatura para os operadores do(s) projeto(s), estrutura de subordinação hierárquica nas atribuições relativas ao projeto e mecanismos de contatos entre as partes.

Parte proponente e ente concedente (para a avaliação).

O gol do Indicador é fornecer subsídio informativo sobre partes representadas no projeto para o ente concedente compreender a proposta sub judice.

Conteúdo textual dos campos de aplicação. Sendo a existência de texto com nexo coerente, enquadrado em avaliação binária $[0,1]$ recebendo nota "1", multiplicado pelo peso ponderado do Indicador determinado pela(s) Câmara(s) Técnica(s) ao Indicador.

A fórmula matemática que define o Indicador de Governança é dada por atribuição binária [0;1] a existência ou não de preenchimento do formulário, multiplicada pelo peso relativo atribuído pela(s) Câmara(s) Técnica(s) ao Indicador.

Dos 7 (sete) indicadores propostos no estudo apenas o indicador de governança 
não possuirá avaliação das variáveis inseridas a luz das Propriedades de Visão do Produto, sendo o seu peso ponderado exclusivamente pela existência ou não do descritivo de governança no escopo da proposta de projeto submetido ao ente demandante.

O Indicador de Governança, não pode ser confundido com o conceito de Governança Corporativa, que segundo a United Nations Economic Commission For Europe - UNECE (2008) é o processo de tomada de decisão pelo qual as decisões são implementadas (ou não implementadas). Além disso, a governança corporativa pode ser definida como um esforço de um empreendimento de equilíbrio entre os objetivos econômicos e sociais da empresa, bem como entre os objetivos individuais e coletivos das partes interessadas. Uma análise da governança centra-se nos partidos formais e informais que estão envolvidos no processo de tomada de decisão, bem como na sua implementação, e pode ser

Justificativa Interpretação/significado usado em vários contextos, como: governança corporativa, governança internacional, governança nacional, incluindo a governança do projeto (ABEDNEGO; OGUNLANA, 2006).

Já o conceito abordado pelo Indicador de "Governança" aduz a configuração dos grupos de trabalho do projeto e a respectiva variabilidade deste, alterando-se de acordo com o tamanho e escopo da proposta. A(s) Câmara(s) Técnica(s) definem o peso ponderado do Indicador Governança em relação aos outros Indicadores, apenas se não preenchido este Indicador, o mesmo receberá nota 0 (zero), condicionando a uma nota final total do Índice "T" menor, penalizando a proposta em análise. 
Exatidão

Relevância

Fonte
A exatidão do indicador é dada por $(\varepsilon)$.

As PPP/PFIs têm se mostrado como instituto apto a preencher o binômio: escassez e resultado. Do primeiro, em razão da dificuldade do Estado em demandar dos contribuintes mais recursos financeiros, oriundos de sua fonte de receitas - tributos, impactando na sensível relação de confiança e respaldo político de gestores públicos com a população. O segundo ponto, advém da entrega de resultados ao cidadão por meio de serviços remunerados ao ente privado atrelados a métricas do serviço realizado, validados por terceira parte ou pelo próprio ente contratante. Podendo variar de acordo com a qualidade e medida verificada do serviço fornecido. A flexibilidade da iniciativa privada aos marcos regulatórios contratuais cíveis e trabalhistas resultam em maior capacidade de entrega de resultados mais céleres.

O Indicador Governança orienta os avaliadores na identificação dos Stakeholders e Matriz de Responsabilidade ou Matriz RACI - Responsible, Accountable, Consulted and Informed, (PMI, 2013, p. 261) permitindo melhor gestão, acesso e controle das partes envolvidas e assertividade nos esclarecimentos de pontos obscuros encontrados nos projetos por parte daqueles que fizeram parte de sua modelagem.

A modelagem do conjunto de dados teve sua origem fundamentada nas fontes segundo $(\kappa)$. 
Figura 31 - Definição do indicador de Governança

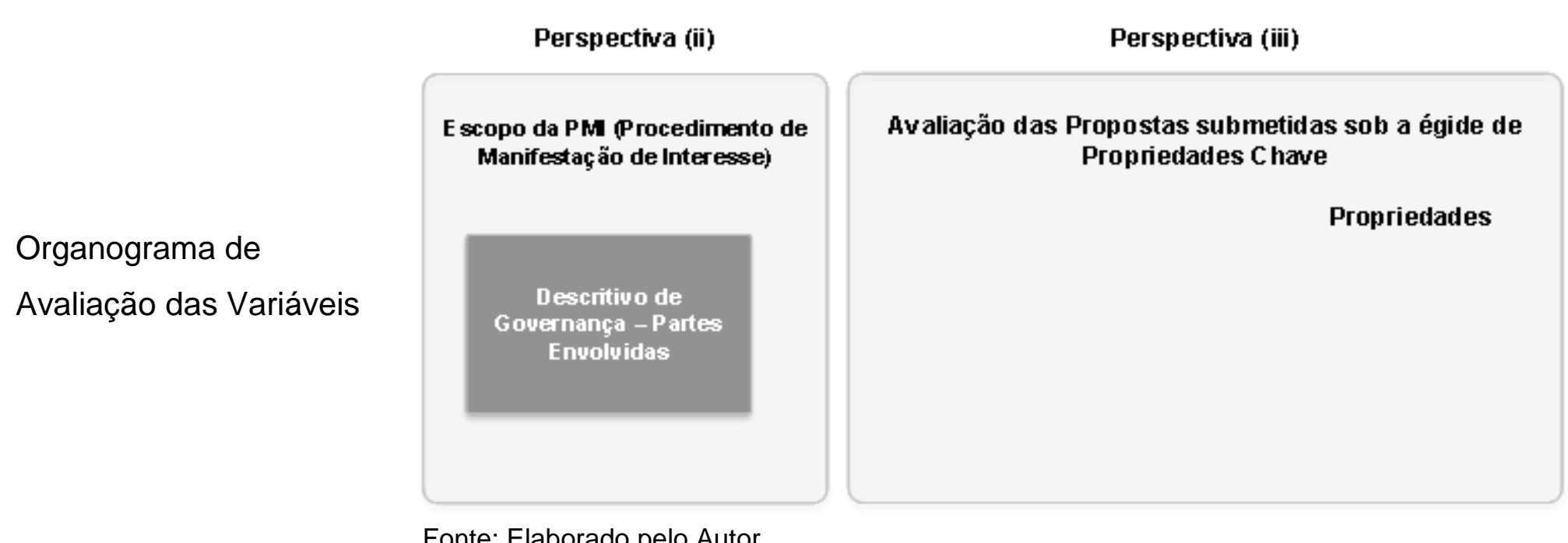

Fonte: Elaborado pelo Autor. 
Conclusão

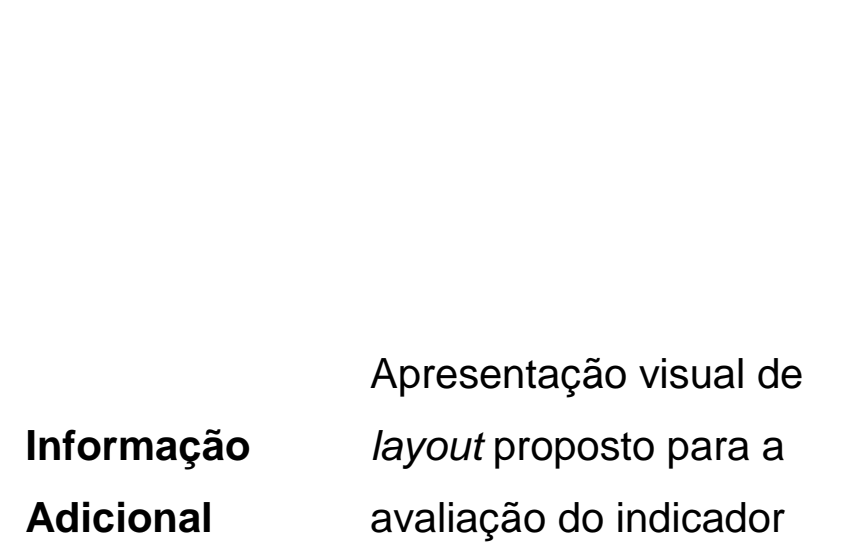

Figura 32 - Layout proposto do indicador de Governança

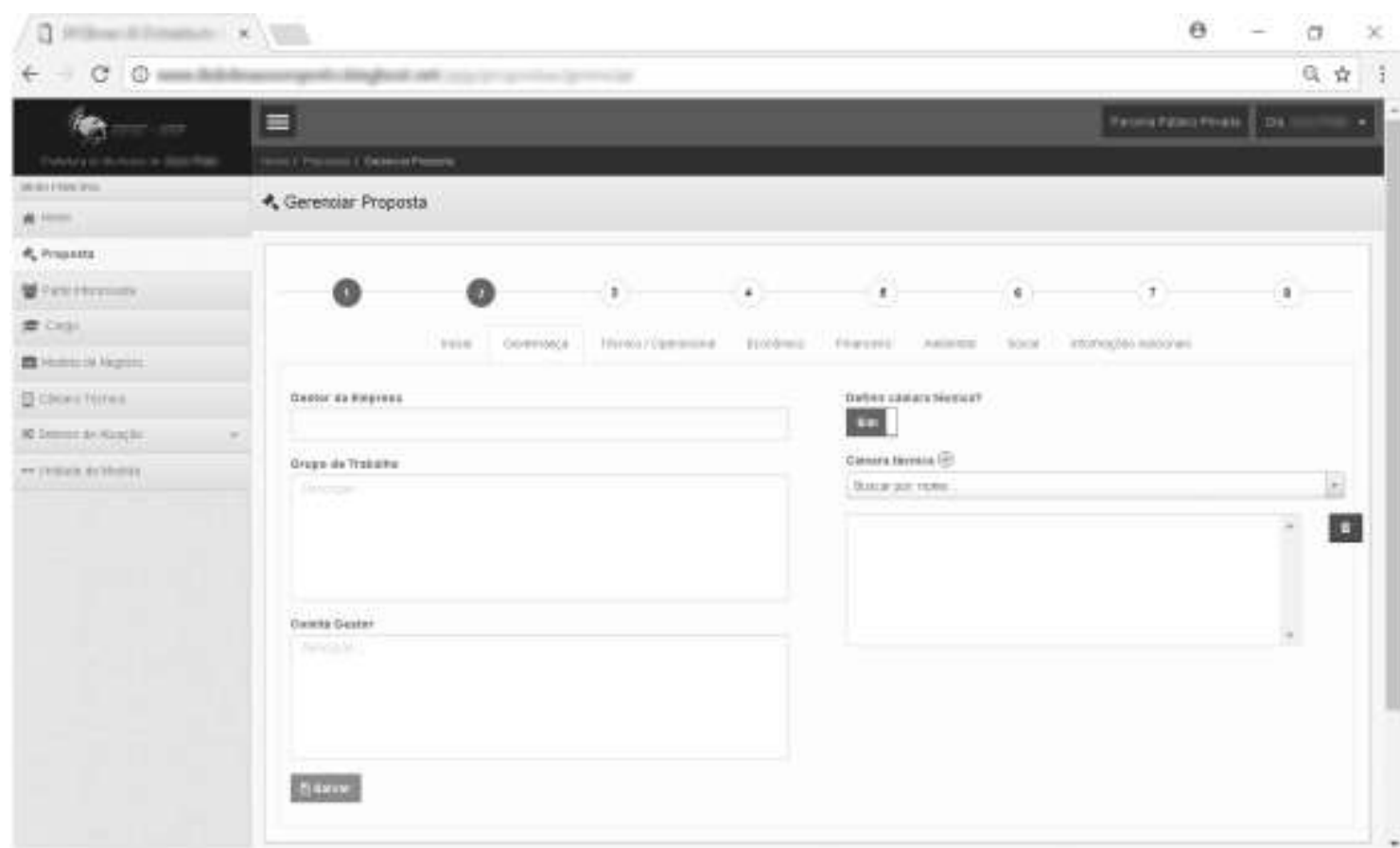

Fonte: Elaborado pelo Autor.

Fonte: Estrutura Adaptada de (CLOQUELL-BALLESTER et al., 2006) e conteúdo elaborado pelo autor. 


\section{F.3 INDICADOR TÉCNICO/OPERACIONAL}

Quadro 42 - Descritivo do indicador Técnico/Operacional

Definição do indicador

Campo

Descrição

Indicador

Nome

Ambiente

Aspecto

Descrição

Usuário

Stakeholders

Definição conceitual

Descrição do dado e da unidade

Descrição

\section{Conteúdo}

Indicador Técnico/Operacional - Representado por: $I_{O}$.

É o descrito na Dimensão Técnico/Operacional.

Estabelece pontos de riscos nos projetos e responsabilidades entre as partes pactuantes operacional e jurídico. Bem como de que forma será medido o nível de desempenho do serviço entregue e qual a frequência.

Parte proponente e ente concedente (para a avaliação).

O gol do Indicador é fornecer subsídio técnico e operacional para o ente concedente compreender a proposta sub judice.

Conteúdo textual dos campos de aplicação. Sendo a existência de texto com nexo coerente, enquadrado em avaliação binária $[0,1]$ multiplicado pela ponderação da variável latente e a nota atribuída pelo avaliador relativa a propriedade avaliada. A fórmula matemática que define o Indicador Técnico/Operacional é dada por:

$I_{Q}=\frac{1}{3} \sum_{i=1}^{6} \omega_{i} t_{i}\left[\alpha_{i}+\beta_{i}+\varepsilon_{i}\right]$

Em que:

$I_{O} \quad=$ Indicador Técnico/Operacional; 


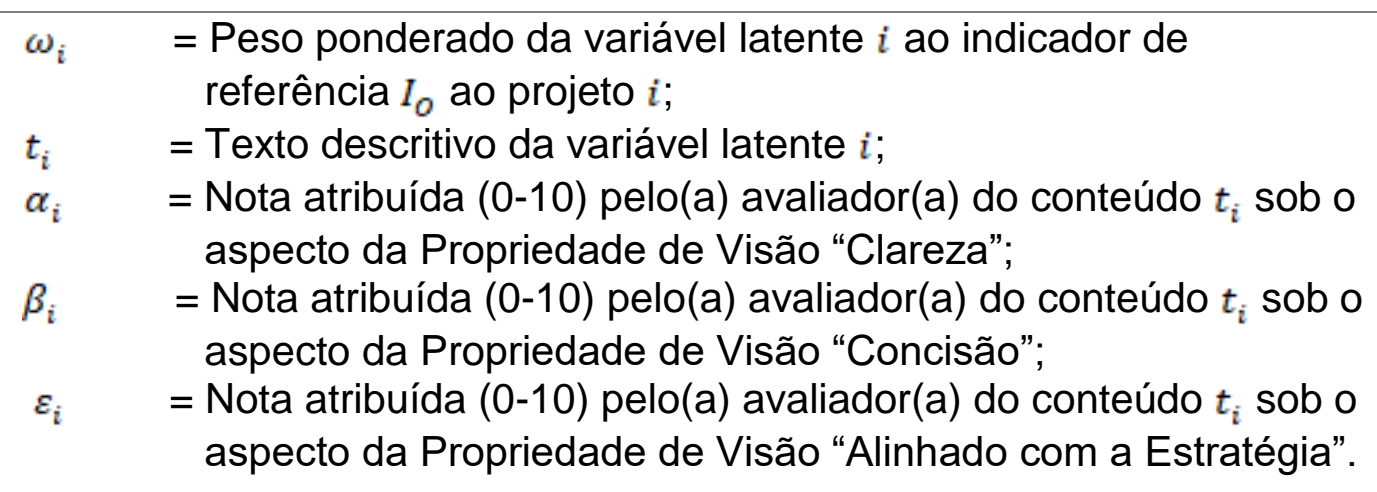

$\mathrm{E}$ as variáveis latentes $i$ são:

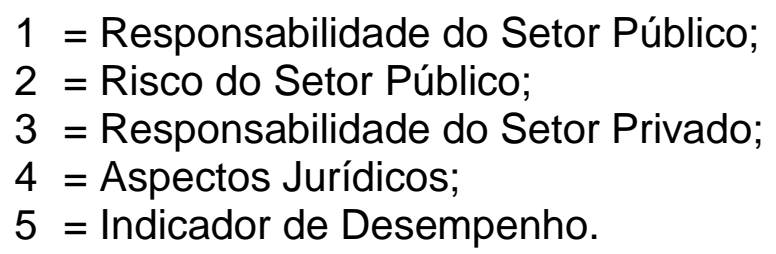

Método de Medida

\section{Justificativa}

Interpretação/significado
O Método de Medida do indicador é descrito por $(\Phi)$.

Define-se na dimensão deste Indicador, se as variáveis latentes do projeto: Riscos e Responsabilidades, público e privado, estão claramente estabelecidas, bem como se apresentam concisão suficiente a cessar interpretações dúbias sobre as variáveis e se as variáveis estão alinhadas com a estratégia da empresa. Outra consideração do Indicador é se a(s) peça(s) jurídica(s) que compõe a proposta está(ão) em conformidade com os ditames das diretrizes da administração pública. E por fim, os indicadores de desempenho são verificados se atingem clareza, concisão suficientes e se esta forma de medida é possível de servir como instrumento de auxílio na definição de políticas estratégicas. As notas das 
variáveis latentes (0 a 10) são atribuídas de acordo com a Propriedade de Visão eleita para a análise.

Exatidão

Relevância

\section{Fonte}

Origem dos dados
A exatidão do indicador é dada por $(\varepsilon)$.

O Indicador Técnico/Operacional serve de anteparo para a mitigação de problemas potenciais, descrevendo as Responsabilidades e os Riscos de ambos os lados, público e privado. $E$ os aspectos jurídicos significativos que não foram considerados nas diretrizes preliminares apresentadas pelo órgão demandante e não encontrados nas legislações correntes de PPP/PFls que regem a contratação do serviço em questão.

A modelagem do conjunto de dados teve sua origem fundamentada nas fontes segundo $(\kappa)$.

Visualizando 0 indicador em perspectiva, observa-se no organograma 0 enquadramento deste no escopo das propostas (ii), quais variáveis ele reúne sob o julgamento de qual(is) propriedade(s) chave (iii). 
Figura 33 - Definição do indicador Técnico/Operacional

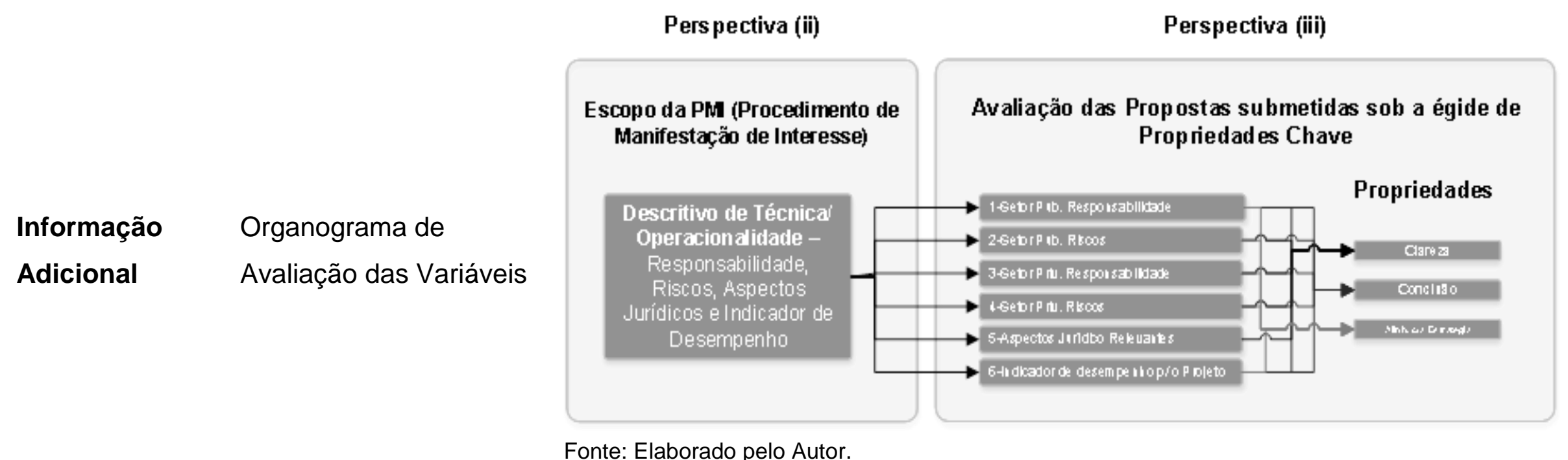

Fonte: Elaborado pelo Autor. 
Figura 34 - Layout proposto do indicador Técnico/Operacional (a)

Apresentação visual de

layout proposto para a avaliação do indicador

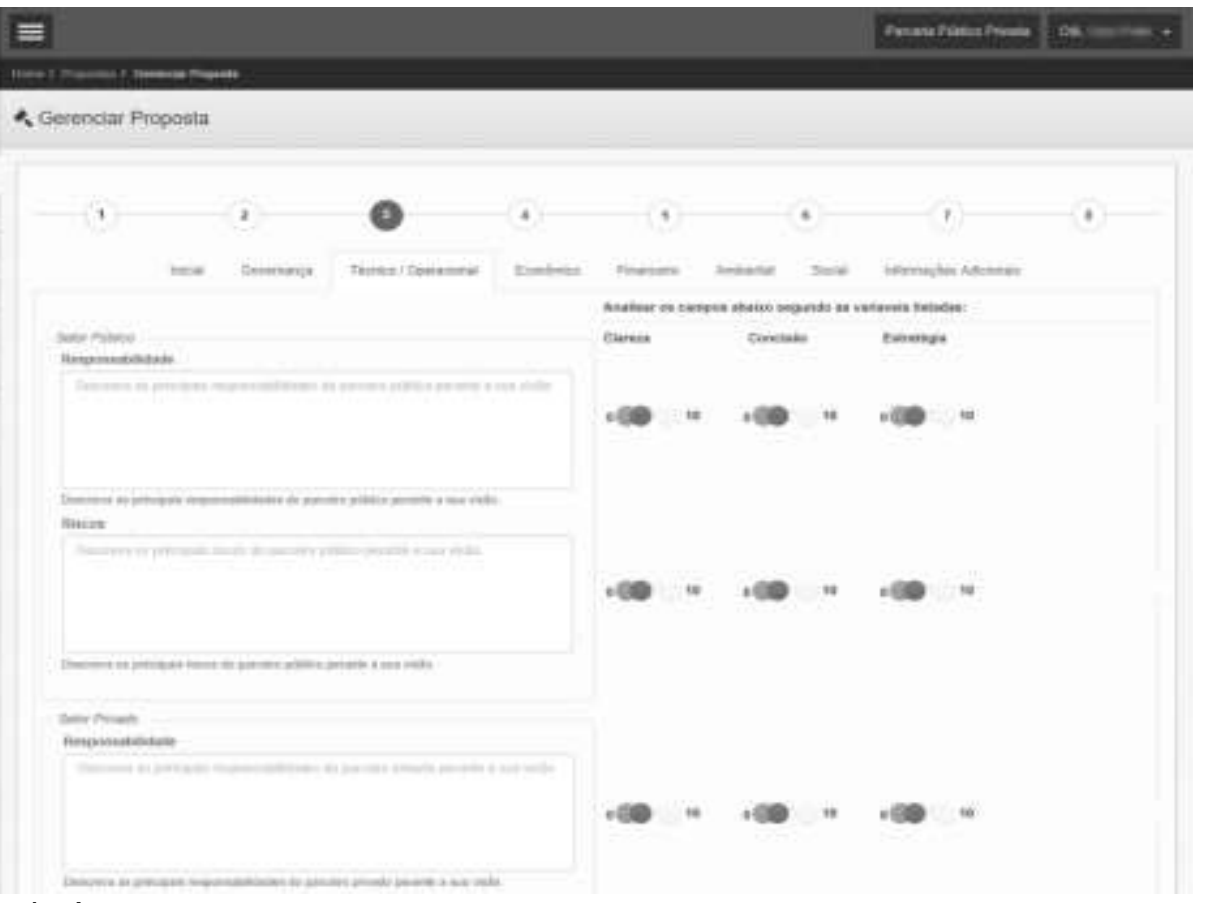

Fonte: Elaborado pelo Autor. 
Conclusão

Figura 35 - Layout proposto do indicador Técnico/Operacional (b)

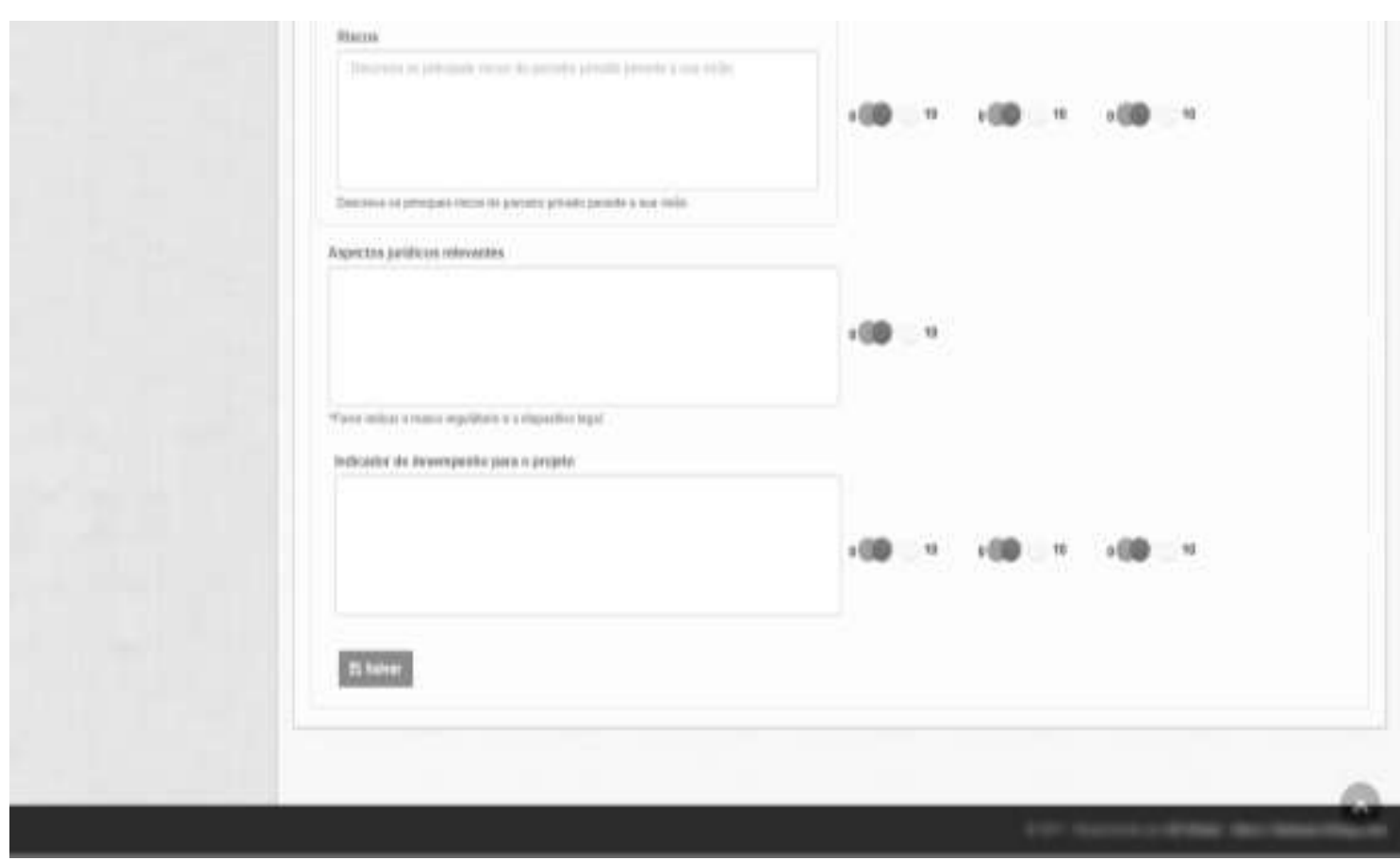

Fonte: Elaborado pelo Autor.

Fonte: Estrutura Adaptada de (CLOQUELL-BALLESTER et al., 2006) e conteúdo elaborado pelo autor. 
F.4 INDICADOR ECONÔMICO

Quadro 43 - Descritivo do indicador Econômico

\begin{tabular}{|c|c|c|}
\hline \multicolumn{3}{|c|}{ Definição do indicador } \\
\hline Campo & Descrição & Conteúdo \\
\hline \multirow[t]{2}{*}{ Indicador } & Nome & Indicador Econômico - Representado por: $I_{E}$. \\
\hline & Ambiente & É o descrito na Dimensão Econômica. \\
\hline Aspecto & Descrição & $\begin{array}{l}\text { llustra os parâmetros de aporte de capital pela SPE e os custos de manutenção da } \\
\text { operação. }\end{array}$ \\
\hline \multirow[t]{3}{*}{ Usuário } & Stakeholders & Parte proponente e ente concedente (para a avaliação). \\
\hline & Definição conceitual & $\begin{array}{l}\text { O gol do indicador é fornecer subsídio relativos a viabilidade econômica para o } \\
\text { ente concedente compreender a proposta sub judice. }\end{array}$ \\
\hline & $\begin{array}{l}\text { Descrição do dado e da } \\
\text { unidade }\end{array}$ & $\begin{array}{l}\text { Conteúdo textual dos campos de aplicação. Sendo a existência de texto com nexo } \\
\text { coerente, enquadrado em avaliação binária }[0,1] \text { multiplicado pela ponderação da } \\
\text { variável latente e a nota atribuída pelo avaliador relativa a propriedade avaliada. } \\
\text { A fórmula matemática que define o Indicador Econômico é dada por: }\end{array}$ \\
\hline \multirow[t]{3}{*}{ Descrição } & & $I_{E}=\frac{1}{7} \sum_{I=1}^{2} \omega_{i} t_{i}\left(\alpha_{i}+\beta_{i}+\varphi_{i}+\lambda_{i}+\vartheta_{i}+\delta_{i}+\gamma_{i}\right)$ \\
\hline & Definição Operacional & $\begin{array}{l}\text { Em que: } \\
\qquad I_{E}=\text { Indicador Econômico; }\end{array}$ \\
\hline & & $\begin{array}{l}\omega_{i}=\text { Peso ponderado da variável latente } i \text { ao indicador de referência } I_{E} ; \\
t_{i}=\text { Texto descritivo da variável latente } i \\
\alpha_{i}=\text { Nota atribuída }(0-10) \text { pelo(a) avaliador(a) do conteúdo } t_{i} \text { sob o }\end{array}$ \\
\hline
\end{tabular}




\section{Justificativa}

aspecto da Propriedade de Visão "Clareza";

$\beta_{i}=$ Nota atribuída (0-10) pelo(a) avaliador(a) do conteúdo $t_{i}$ sob o aspecto da Propriedade de Visão "Concisão";

$\varphi_{i}=$ Nota atribuída (0-10) pelo(a) avaliador(a) do conteúdo $t_{i}$ sob o aspecto da Propriedade de Visão "Priorizadora";

$\lambda_{i}=$ Nota atribuída (0-10) pelo(a) avaliador(a) do conteúdo $t_{i}$ sob o aspecto da Propriedade de Visão "Antecipadora";

$\vartheta_{i}=$ Nota atribuída (0-10) pelo(a) avaliador(a) do conteúdo $t_{i}$ sob o aspecto da Propriedade de Visão "Alinhada com a Estratégia";

$\delta_{\bar{i}}=$ Nota atribuída (0-10) pelo(a) avaliador(a) do conteúdo $t_{\bar{i}}$ sob o aspecto da Propriedade de Visão "Acessível";

$\gamma_{i}=$ Nota atribuída (0-10) pelo(a) avaliador(a) do conteúdo $t_{\bar{i}}$ sob o aspecto da Propriedade de Visão "Flexível";

E as variáveis latentes $i$ são:

1 = Investimento;

2 = Custo Operacional.

Método de Medida

O Método de Medida do indicador é descrito por $(\Phi)$.

Os Investimentos e custos operacionais versados nas propostas são textualmente apresentados e avaliados pelos membros da(s) Câmara(s) Técnica(s) sob a perspectiva das Propriedades de Visão do Produto: "Clareza", "Concisão", "Priorizadora", "Antecipadora", "Alinhamento com a Estratégia", "Acessível" e "Flexível". Por refletir o núcleo da proposta, embora estas variáveis possuam possibilidade de interpretação ampla, estas são avaliadas em 7 (sete) dimensões. As notas das variáveis latentes $(0$ a 10$)$ são atribuídas de acordo com a Propriedade de Visão eleita para a análise.

Exatidão 
Relevância

\section{Fonte}

Origem dos dados

\section{Informação} Adicional

A narrativa dos investimentos necessários para a realização da PPP/PFI e os Custos Operacionais desta possibilitarão aos avaliadores da(s) Câmara(s) Técnica(s) a verificação de viabilidade do projeto, evitando e contemplando no certame sob quais conduções serão aceitos realinhamentos de valores das contraprestações e/ou o alcance total do serviço prestado.

A modelagem do conjunto de dados teve sua origem fundamentada nas fontes segundo $(\kappa)$.

Visualizando o indicador em perspectiva, observa-se no organograma o enquadramento deste no escopo das propostas (ii), quais variáveis ele reúne sob o julgamento de qual(is) propriedade(s) chave (iii).

Figura 36 - Definição do indicador Econômico

Pers pectiva (ii)

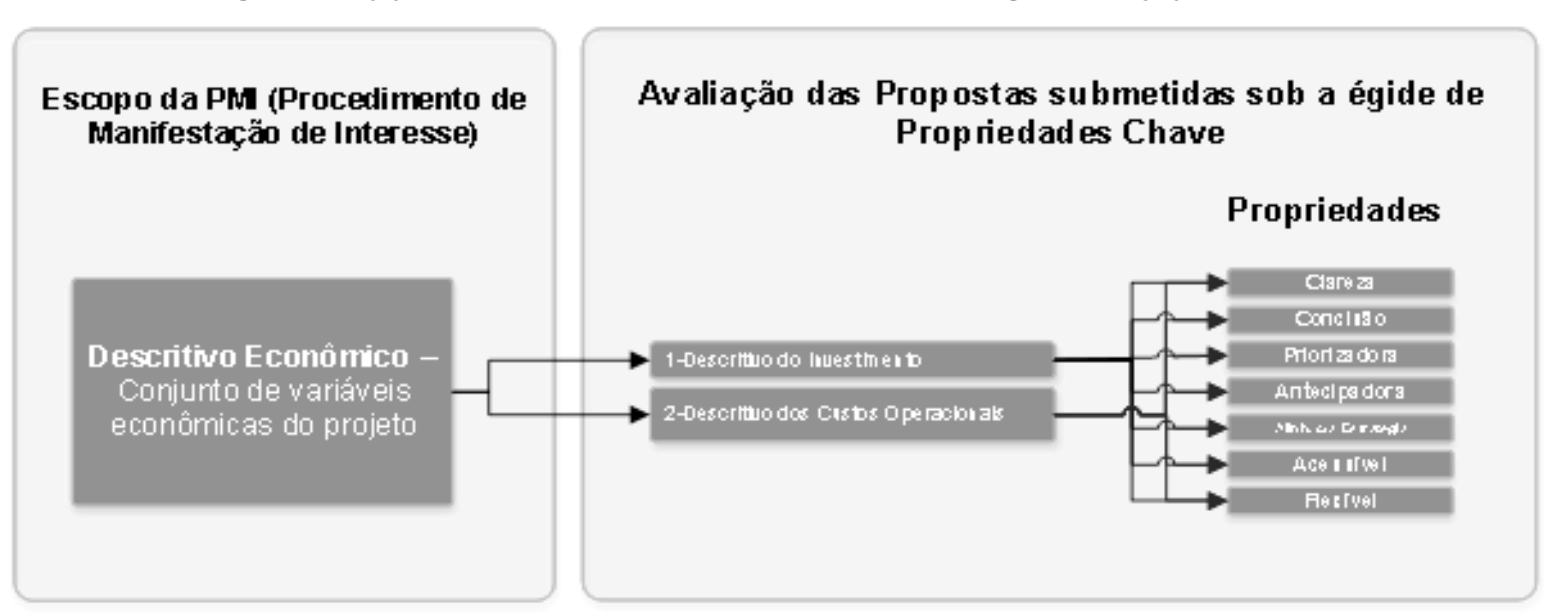

Fonte: Elaborado pelo Autor.

\section{Perspectiva (iii)}

Propriedades Chave

Propriedades
Organograma de

Avaliação das Variáveis 


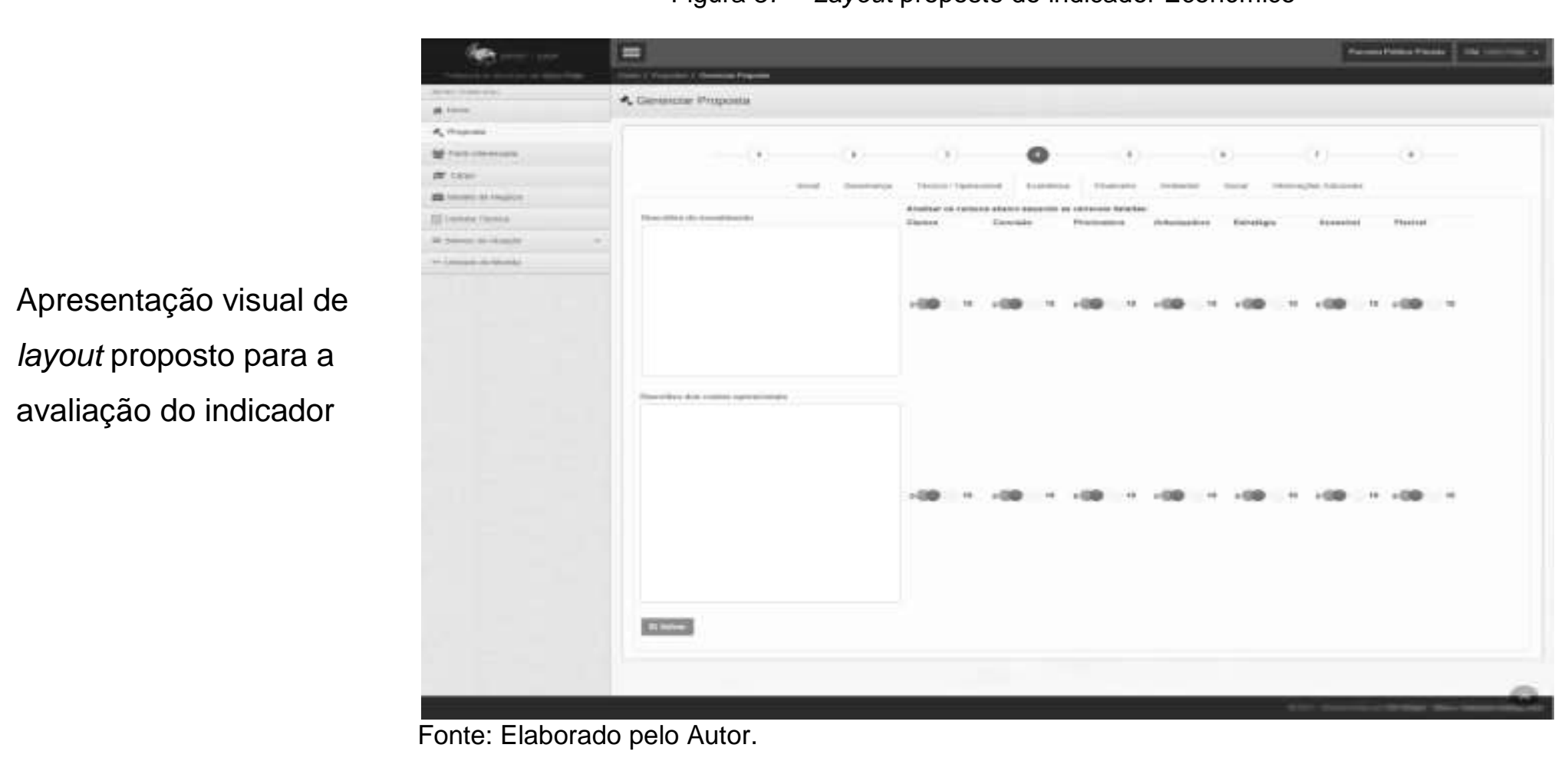

Fonte: Estrutura Adaptada de (CLOQUELL-BALLESTER et al., 2006) e conteúdo elaborado pelo autor. 
F.5 INDICADOR FINANCEIRO

Quadro 44 - Descritivo do indicador Financeiro

\begin{tabular}{|c|c|c|c|}
\hline \multicolumn{4}{|c|}{ Definição do indicador } \\
\hline Campo & Descrição & & Conteúdo \\
\hline Indicador & $\begin{array}{l}\text { Nome } \\
\text { Ambiente }\end{array}$ & \multicolumn{2}{|c|}{ Indicador Financeiro - Representado por: $I_{F}$. } \\
\hline Aspecto & Descrição & \multicolumn{2}{|c|}{$\begin{array}{l}\text { Mensura a quantidade de indivíduos beneficiados pelo serviço a ser entregue pela } \\
\text { SPE. }\end{array}$} \\
\hline Usuário & Stakeholders & \multicolumn{2}{|c|}{$\begin{array}{l}\text { O gol do Indicador é fornecer unidades de medidas (referenciais) para que o ente } \\
\text { concedente compreenda a proposta sub judice. }\end{array}$} \\
\hline Decaricñn & $\begin{array}{l}\text { Descrição do dado e da } \\
\text { unidade }\end{array}$ & \multicolumn{2}{|c|}{$\begin{array}{l}\text { Conteúdo textual dos campos de aplicação. Sendo a existência de texto com nexo } \\
\text { coerente, enquadrado em avaliação binária }[0,1] \text { multiplicado pela ponderação da } \\
\text { variável latente e a nota atribuída pelo avaliador relativa a propriedade avaliada. } \\
\text { A fórmula matemática que define o Indicador Financeiro é dada por: }\end{array}$} \\
\hline \multirow{2}{*}{ Descrição } & & $\begin{array}{l}\text { Em que: } \\
\qquad I_{F}\end{array}$ & = Indicador Financeiro; \\
\hline & Definição Operacional & $\begin{array}{l}\omega_{i} \\
t_{i} \\
\alpha_{i} \\
\lambda_{i}\end{array}$ & $\begin{aligned}= & \text { Peso ponderado da variável latente } i \text { ao indicador de referência } \\
& I_{F} ; \\
= & \text { Texto descritivo da variável latente } i ; \\
= & \text { Nota atribuída }(0-10) \text { pelo(a) avaliador(a) do conteúdo } t_{i} \text { sob o } \\
& \text { aspecto da Propriedade de Visão "Clareza"; } \\
= & \text { Nota atribuída }(0-10) \text { pelo(a) avaliador(a) do conteúdo } t_{i} \text { sob o } \\
& \text { aspecto da Propriedade de Visão "Antecipadora"; }\end{aligned}$ \\
\hline
\end{tabular}


$\vartheta_{i}=$ Nota atribuída (0-10) pelo(a) avaliador(a) do conteúdo $t_{\bar{i}}$ sob o aspecto da Propriedade de Visão "Alinhada com a Estratégia";

E as variáveis latentes $i$ são dados por:

1 = Previsão de Demanda do Serviço Prestado.

Método de Medida

Interpretação/significado

\section{Justificativa}

\section{Exatidão}

Relevância

Fonte
O Método de Medida do indicador é descrito por $(\Phi)$.

A estimativa da quantidade e capacidade de entrega será avaliada neste Indicador, por meio das Propriedades de Visão do Produto: "Clareza",

"Antecipadora" (para prever e dirimir problemas e oscilação positiva ou negativa da demanda do projeto) e se está possui "Alinhamento com a Estratégia" do ente demandante, razão que condiciona a existência de representantes da(s)

Câmara(s) Técnica(s) que possuam interface direta com a alta direção do ente demandante do serviço, ou profundo conhecimento do plano estratégico do ente. As notas das variáveis latentes (0 a 10) são atribuídas de acordo com a Propriedade de Visão do Produto eleita para a análise.

A exatidão do indicador é dada por $(\varepsilon)$.

O Indicador Financeiro, embora exija a descrição de apenas um dado: "Previsão de Demanda dos Serviços Prestados", será a informação válida para a base de cálculo para a formatação da métrica de avaliação do serviço entregue ao cidadão. 
segundo $(\kappa)$.

Visualizando o indicador em perspectiva, observa-se no organograma o enquadramento deste no escopo das propostas (ii), quais variáveis ele reúne sob o julgamento de qual(is) propriedade(s) chave (iii).

Figura 38 - Definição do indicador Financeiro

\section{Informação \\ Adicional \\ Organograma de \\ Avaliação das Variáveis}

Perspectiva (ii)

Perspectiva (iii)

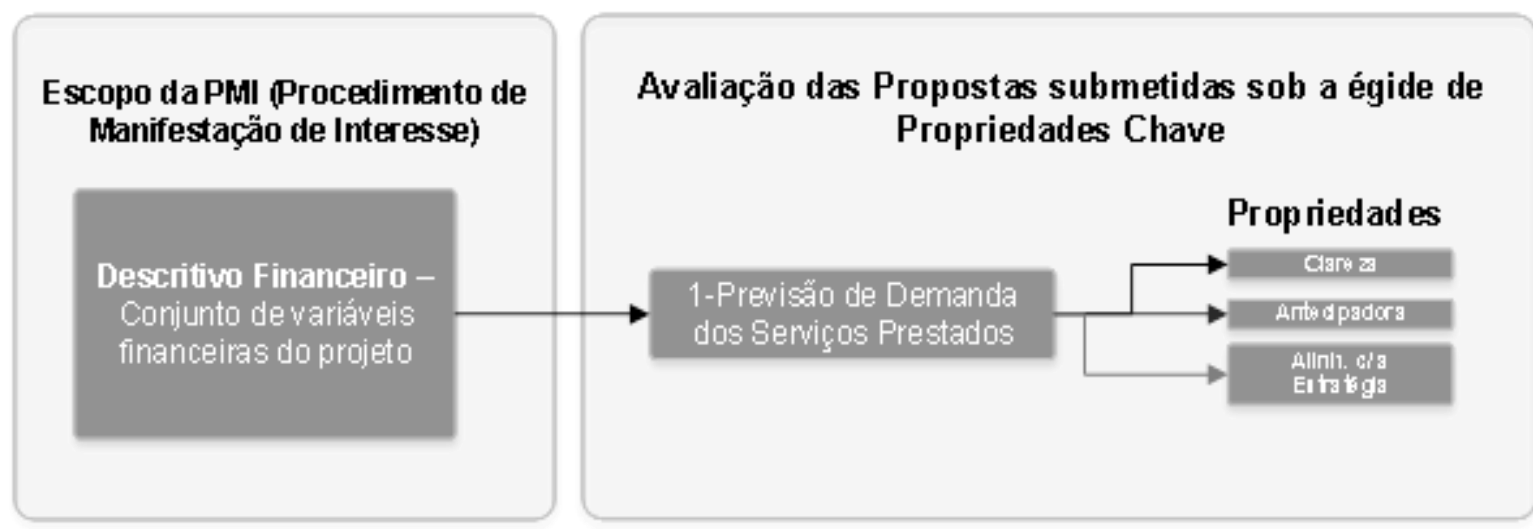

Fonte: Elaborado pelo Autor. 
Conclusão

Figura 39 - Layout proposto do indicador Financeiro

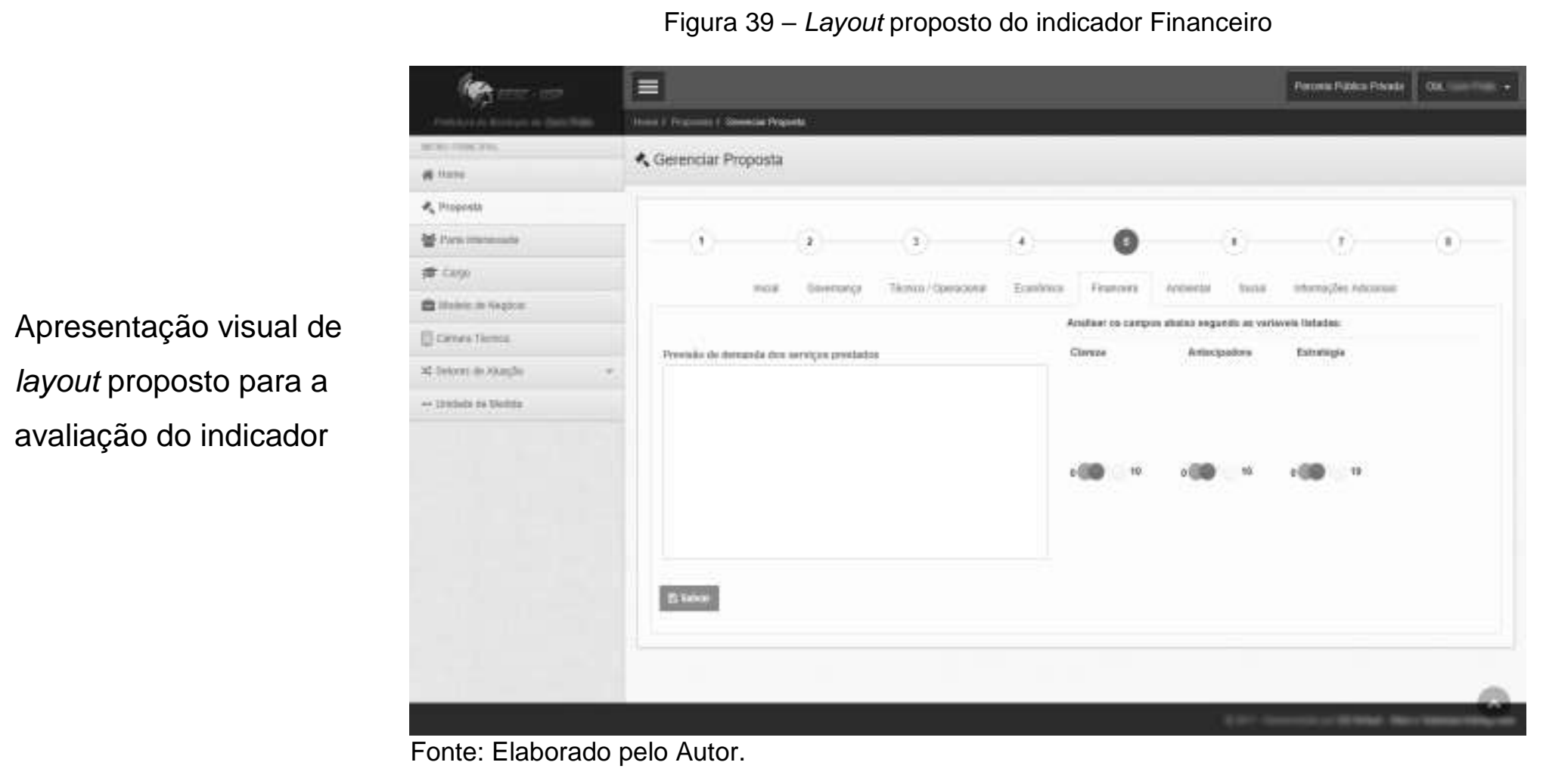

Fonte: Estrutura Adaptada de (CLOQUELL-BALLESTER et al., 2006) e conteúdo elaborado pelo autor. 
F.6 INDICADOR AMBIENTAL

Definição do indicador

Campo

\section{Descrição}

Indicador

Nome

Aspecto

Usuário

Ambiente

Descrição

Stakeholders

Definição conceitual

Descrição do dado e da unidade

\section{Descrição}

Quadro 45 - Descritivo do indicador Ambiental

\section{Conteúdo}

Indicador Ambiental - Representado por: $I_{A}$.

Dado pelos elementos versados na Dimensão Ambiental.

Mensura quais impactos ambientais decorrem do projeto.

Parte proponente e ente concedente (para a avaliação).

O gol do Indicador é fornecer dados sobre potenciais passivos ambientais decorrentes do projeto para o ente concedente compreender a proposta sub judice.

Conteúdo textual dos campos de aplicação. Sendo a existência de texto com nexo coerente, enquadrado em avaliação binária $[0,1]$ multiplicado pela ponderação da variável latente e a nota atribuída pelo avaliador relativa a propriedade avaliada. A fórmula matemática que define o Indicador Ambiental é dada por:

$$
I_{A}=\frac{\frac{1}{4} \omega_{1} t_{1}\left(\alpha_{1}+\beta_{1}+\lambda_{1}+\varepsilon_{1}\right)+}{\frac{1}{2} \omega_{2} t_{2}\left(\varphi_{2}+\gamma_{2}\right)+}
$$

Definição Operacional

$$
\text { Em que: }
$$

$I_{A} \quad=$ Indicador Ambiental;

$\omega_{i}=$ Peso ponderado da variável latente $i$ ao Indicador de referência $I_{A}$;

$t_{\bar{i}} \quad=$ Texto descritivo da variável latente $i$

$\alpha_{i} \quad=$ Nota atribuída (0-10) pelo(a) avaliador(a) do conteúdo $t_{i}$ sob o 
aspecto da Propriedade de Visão "Clareza";

$\beta_{\bar{i}}=$ Nota atribuída (0-10) pelo(a) avaliador(a) do conteúdo $t_{\bar{i}}$ sob o aspecto da Propriedade de Visão "Concisão";

$\lambda_{i}=$ Nota atribuída (0-10) pelo(a) avaliador(a) do conteúdo $t_{i}$ sob o aspecto da Propriedade de Visão "Antecipadora";

$\varepsilon_{i} \quad=$ Nota atribuída (0-10) pelo(a) avaliador(a) do conteúdo $t_{i}$ sob o aspecto da Propriedade de Visão "Alinhada com a Estratégia";

$\varphi_{i}=$ Nota atribuída (0-10) pelo(a) avaliador(a) do conteúdo $t_{i}$ sob o aspecto da Propriedade de Visão "Priorizadora";

$\gamma_{i}=$ Nota atribuída (0-10) pelo(a) avaliador(a) do conteúdo $t_{\bar{i}}$ sob o aspecto da Propriedade de Visão "Flexível";

$\kappa_{\tilde{i}}=$ Nota atribuída (0-10) pelo(a) avaliador(a) do conteúdo $t_{i}$ sob o aspecto da Propriedade de Visão "Acessível";

Em que as variáveis latentes $i$ são dadas por:

$$
\begin{aligned}
& 1=\text { Metas } ; \\
& 2=\text { Atividades; } \\
& 3=\text { Impactos } .
\end{aligned}
$$

Método de Medida

\section{Justificativa}

Interpretação/significado
O Método de Medida do indicador é descrito por $(\Phi)$.

A interpretação deste Indicador é validar quais atividades serão executadas e se estas ações estão descritas de forma concisa; de forma a priorizar e antecipar a gestão dos passivos ambientais mais críticos circunscritos no raio de abrangência do projeto; se a proposta possui metas de manejo ambiental de rejeitos derivados do ação principal e se a política ambiental do ente demandante do serviço contempla tal ação ou se pode contar com entidades correlatas para auxiliar na gestão dos resíduos e reduzir custos e se a proposta ambiental do projeto é acessível (contemplando tecnologia já dominada e de custo enquadrava no valor 
da contrapartida do projeto) e se é flexível suficiente para abarcar eventos inesperados (exemplos: catástrofes ocasionadas por eventos naturais ou decorrentes de falhas no processo). As notas das variáveis latentes ( 0 a 10) são atribuídas de acordo com a Propriedade de Visão eleita para a análise.

Exatidão

Relevância

\section{Fonte}

Origem dos dados
A exatidão do indicador é dada por $(\varepsilon)$.

O Indicador Ambiental, atrela: "Metas", "Atividades" e "Impactos", exigindo que os desenvolvedores das propostas ilustrem as consequências derivadas do(s) serviço(s) a ser(em) prestado(s). Elencando os danos ambientais decorrentes da execução do serviço se por ventura existirem, bem como as "Metas" para a redução ou neutralização do passivo potencial, por meio de "Atividades" mitigadoras dos "Impactos". A taxatividade dos textos, permite aos avaliadores preverem potenciais problemas e ponderar positivamente a nota atribuída ao projeto que explicita os problemas potencias sem receio de ser penalizado na avaliação final.

A modelagem do conjunto de dados teve sua origem fundamentada nas fontes segundo $(\kappa)$.

Visualizando o indicador em perspectiva, observa-se no organograma o enquadramento deste no escopo das propostas (ii), quais variáveis ele reúne sob o julgamento de qual(is) propriedade(s) chave (iii). 


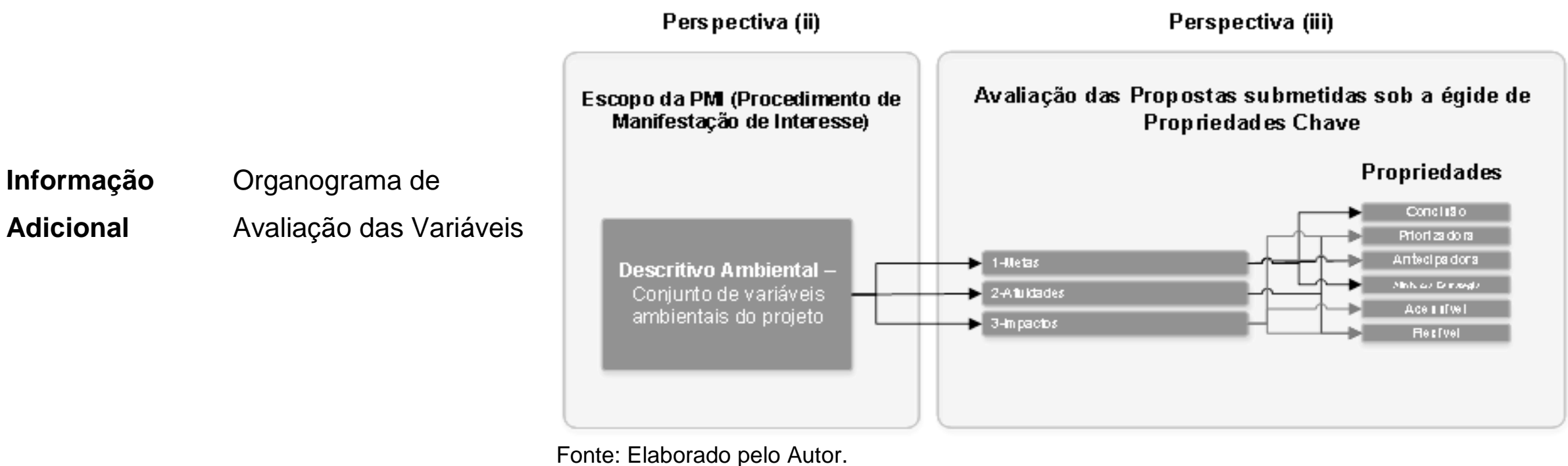


Conclusão

Figura 41 - Layout proposto do indicador Ambiental

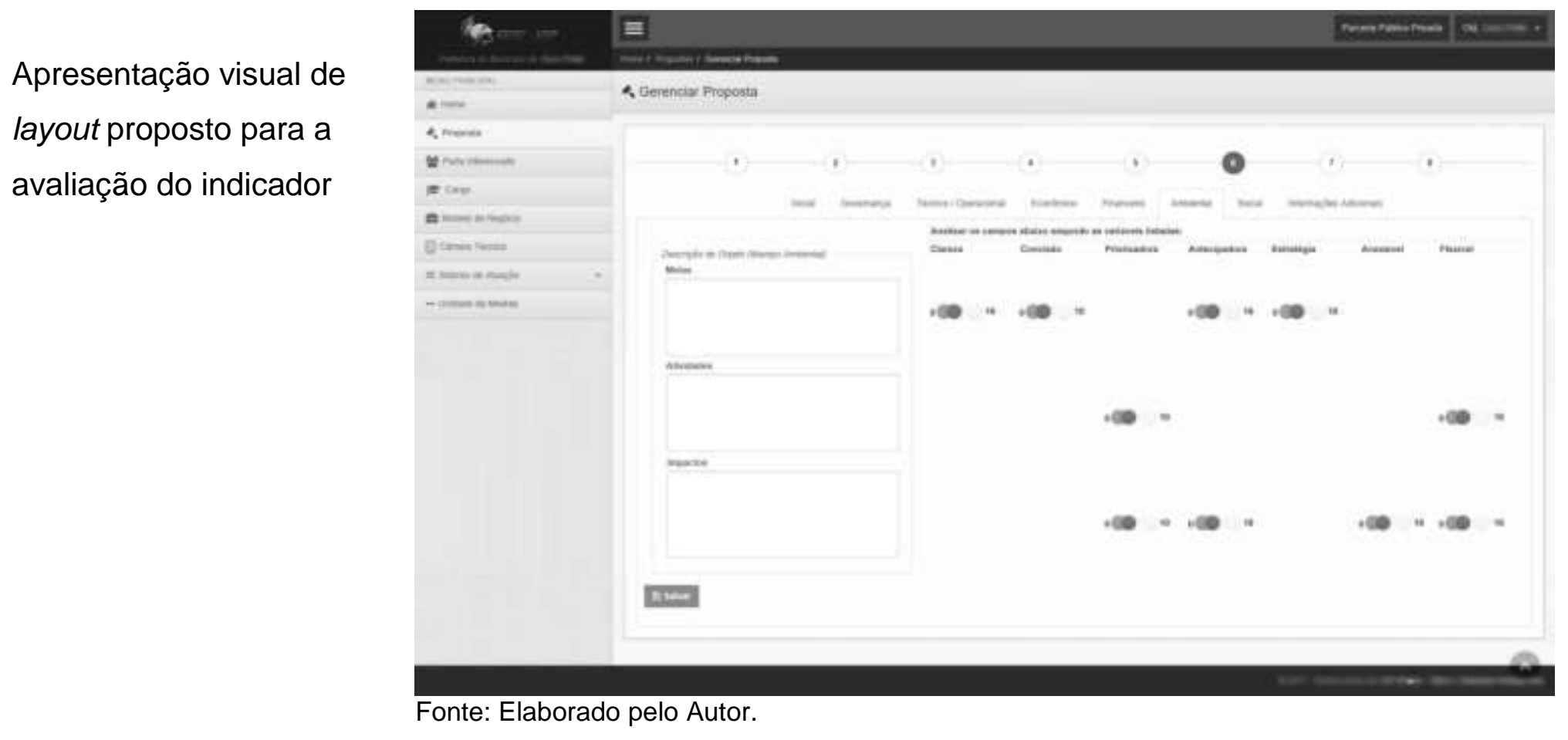

Fonte: Estrutura Adaptada de (CLOQUELL-BALLESTER et al., 2006) e conteúdo elaborado pelo autor. 


\section{F.7 INDICADOR SOCIAL}

Quadro 46 - Descritivo do indicador Social

\section{Definição do indicador}

Campo

Indicador

Nome

Aspecto

Usuário

Ambiente

Descrição

Stakeholders

Definição conceitual

Descrição do dado e da unidade

\section{Descrição}

\section{Descrição}

\section{Conteúdo}

Indicador Ambiental - Representado por: $I_{S}$.

Dado pelos elementos versados na Dimensão Social.

Mensura a interface do projeto com o cidadão.

Parte proponente e ente concedente (para a avaliação).

O gol do Indicador é disponibilizar para o ente concedente quais atos e ações do executivo junto a iniciativa privada serão convertidos em benefício real ao cidadão da(s) comunidade(s) impactada pela proposta sub judice.

Conteúdo textual dos campos de aplicação. Sendo a existência de texto com nexo coerente, enquadrado em avaliação binária $[0,1]$ multiplicado pela ponderação da variável latente e a nota atribuída pelo avaliador relativa a propriedade avaliada.

A fórmula matemática que define o Indicador Social é dada por:

$$
I_{S}=\begin{gathered}
\omega_{1} t_{1} \alpha_{1}+ \\
\frac{1}{4} \omega_{2} t_{2}\left(\alpha_{2}+\beta_{2}+\lambda_{2}+\vartheta_{2}\right)+ \\
\frac{1}{4} \omega_{3} t_{3}\left(\varphi_{3}+\lambda_{3}+\delta_{3}+\gamma_{3}\right)+ \\
\omega_{4} t_{4} \alpha_{4}
\end{gathered}
$$

Em que: 
$\omega_{i} \quad=$ Peso ponderado da variável latente $i$ ao Indicador de referência $I_{s}$;

$t_{\bar{i}} \quad=$ Texto descritivo da variável latente $i$

$\alpha_{\bar{i}} \quad=$ Nota atribuída pelo(a) avaliador(a) do conteúdo $t_{\bar{i}}$ sob o aspecto da Propriedade de Visão "Clareza";

$\beta_{i}=$ Nota atribuída pelo(a) avaliador(a) do conteúdo $t_{i}$ sob o aspecto da Propriedade de Visão "Concisão";

$\lambda_{i}=$ Nota atribuída pelo(a) avaliador(a) do conteúdo $t_{i}$ sob o aspecto da Propriedade de Visão "Antecipadora";

$\vartheta_{i}=$ Nota atribuída pelo(a) avaliador(a) do conteúdo $t_{i}$ sob o aspecto da Propriedade de Visão "Alinhada com a Estratégia";

$\varphi_{i}=$ Nota atribuída pelo(a) avaliador(a) do conteúdo $t_{i}$ sob o aspecto da Propriedade de Visão "Priorizadora";

$\delta_{\tilde{i}}=$ Nota atribuída pelo(a) avaliador(a) do conteúdo $t_{\bar{i}}$ sob o aspecto da Propriedade de Visão "Acessível";

$\gamma_{i}=$ Nota atribuída pelo(a) avaliador(a) do conteúdo $t_{\bar{i}}$ sob o aspecto da Propriedade de Visão "Flexível";

Em que as variáveis latentes $i$ são:

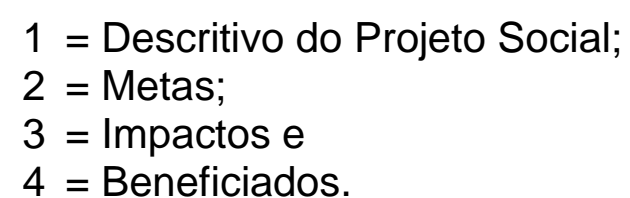

Método de Medida

\section{Justificativa}

Interpretação/significado

O Método de Medida do indicador é descrito por $(\Phi)$.

O Indicador Social destaca as premissas necessárias para que a PPP/PFI por meio de dispositivos e/ou infraestruturas entregue serviços aos cidadãos com maior qualidade e menor custo aos cofres públicas, sendo estas premissas estabelecidas neste Indicador, avaliadas pela(s) Câmara(s) Técnica(s): o descritivo do projeto, as metas envolvidas, os impactos e os beneficiados sob as dimensões 
das propriedades: "Clareza”, "Concisão”, "Prioridade”, “Antecipação", "Alinhamento com a Estratégia" do ente demandante, "Acessibilidade" do dado ao cidadão comum e "Flexibilidade" da variável ao contexto temporal do curso de vigência do projeto, por meio da atribuição de notas ( 0 a 10) das variáveis a cada uma das dimensões.

Exatidão

Relevância

\section{Fonte}

A exatidão do indicador é dada por $(\varepsilon)$.

O Indicador Social, destaca além dos "Beneficiados" com o projeto, quais atos serão feitos para o maior alcance social possível, de que forma serão conduzidas tais ações e como serão medidos os impactos. A análise de tal Indicador e destaque publicitário deste (no projeto selecionado) gera legitimidade do instituto PPP/PFI ao órgão gestor, quando os resultados e impactos são medidos antes e depois da contratação do serviço.

A modelagem do conjunto de dados teve sua origem fundamentada nas fontes segundo $(\kappa)$.

Visualizando o indicador em perspectiva, observa-se no organograma o enquadramento deste no escopo das propostas (ii), quais variáveis ele reúne sob o julgamento de qual(is) propriedade(s) chave (iii). 
Figura 42 - Definição do indicador Social

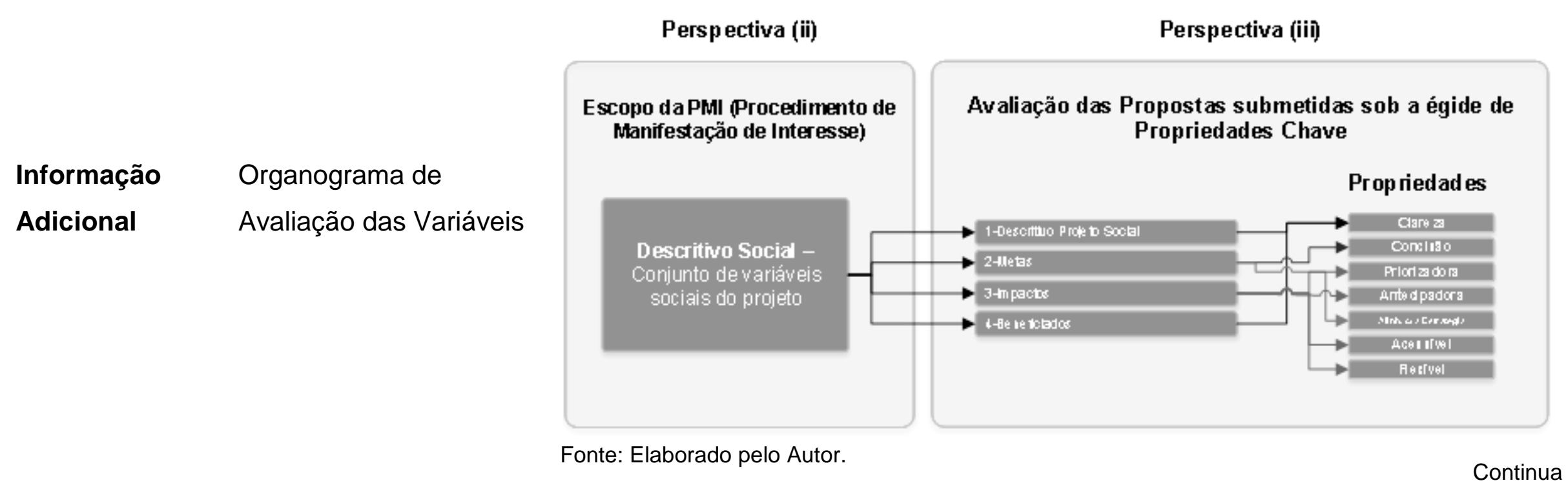


Conclusão

Figura 43 - Layout proposto do indicador Social

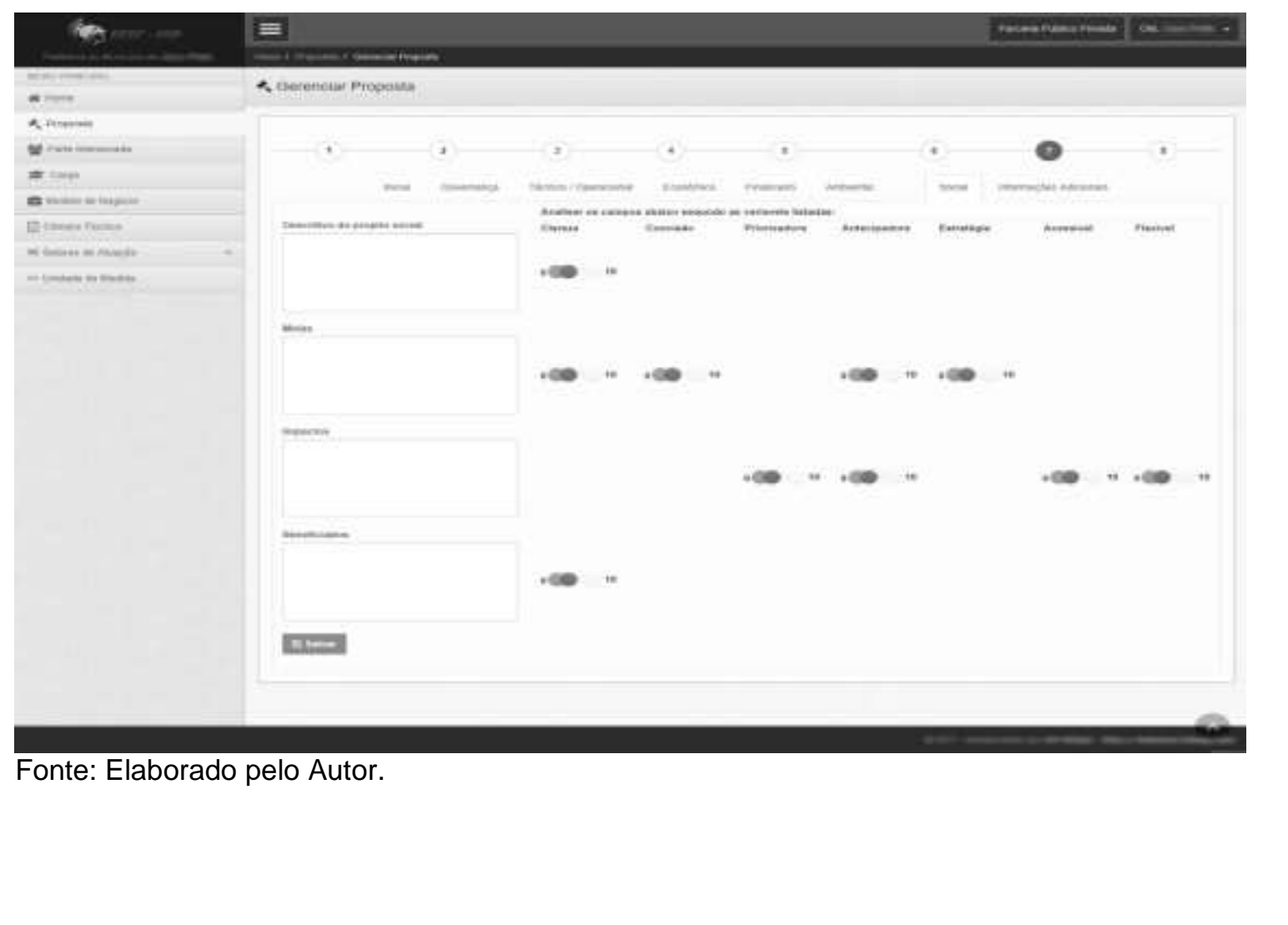

Fonte: Estrutura Adaptada de (CLOQUELL-BALLESTER et al., 2006) e conteúdo elaborado pelo autor. 
APÊNDICE G - DADOS DA PESQUISA DE CAMPO

Tabela 16 - Questão 3.B da pesquisa com especialistas

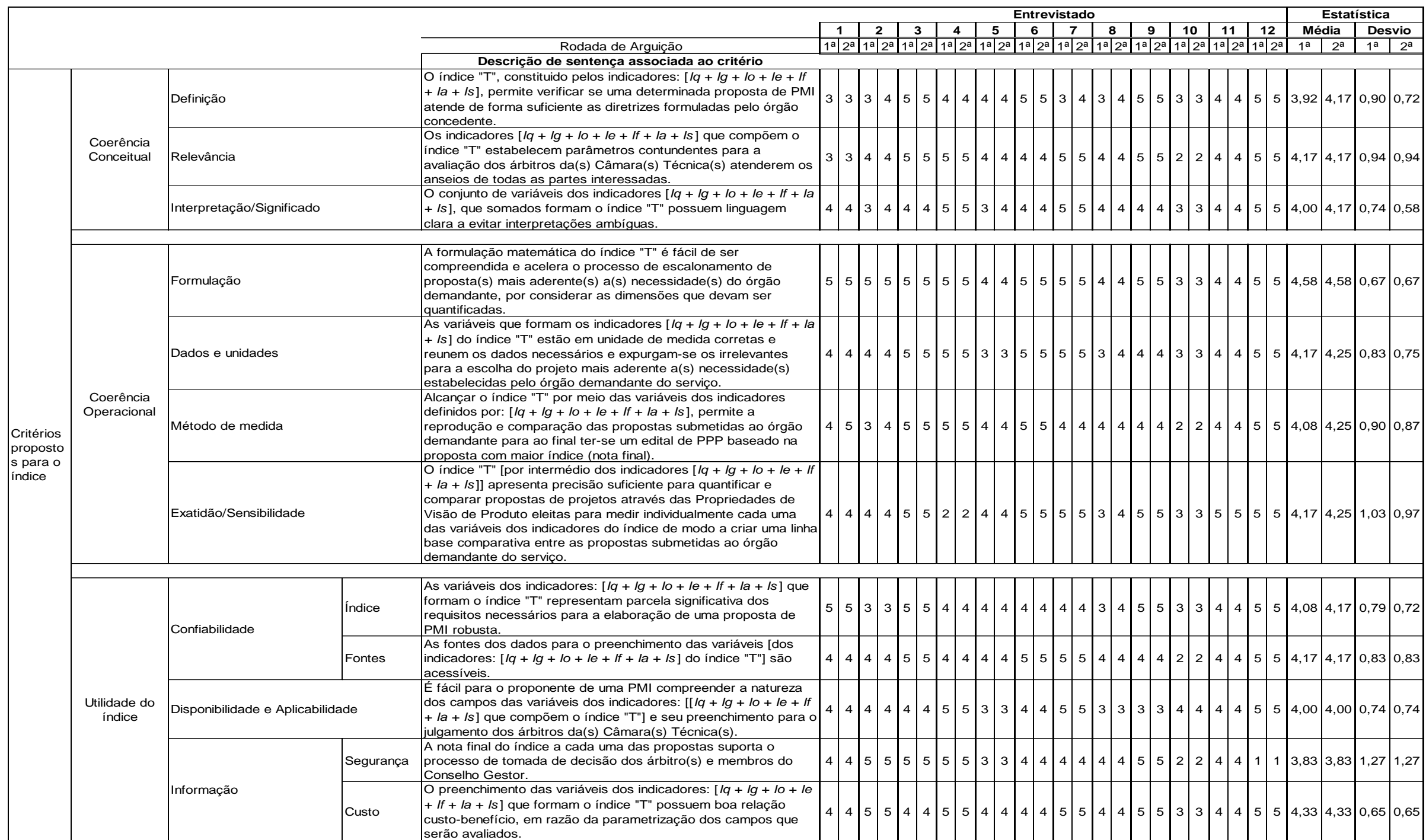

Fonte: Estrutura adaptado de (CLOQUELL-BALLESTER, et al., 2006; PIERE; MANTESE, 2017) pelo Autor. 


\section{GRÁFICOS}

Gráfico 12 - Questão 3.B da pesquisa com especialistas
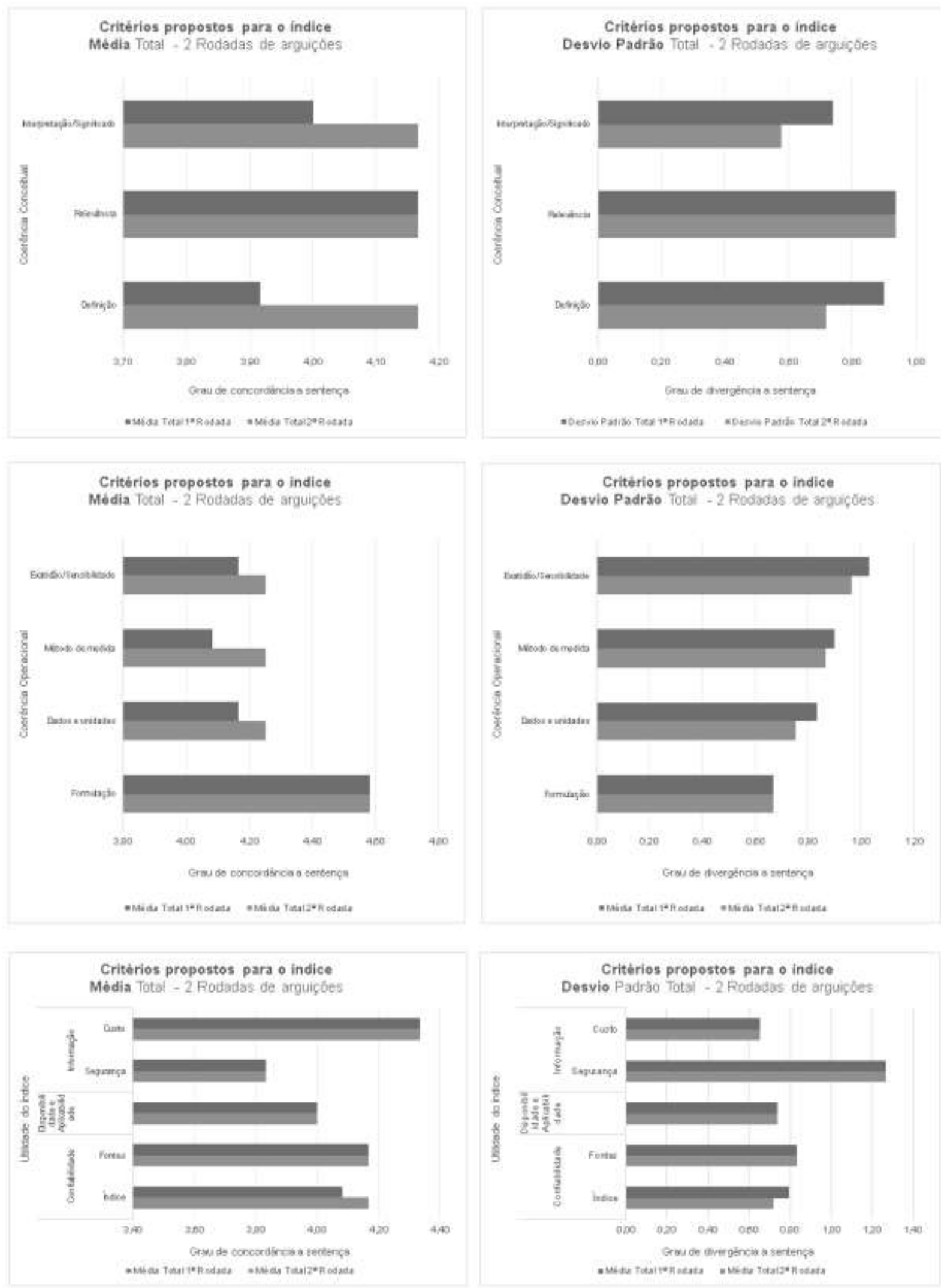

Fonte: Elaborado pelo Autor. 


\section{APÊNDICE H - AVALIAÇÃO AGREGADA ÍNDICE "T”}

Tabela 17 - Consolidação dos dados de nota de avaliação agregada

\begin{tabular}{|c|c|c|c|c|c|c|c|c|c|}
\hline & & \multirow{2}{*}{\multicolumn{2}{|c|}{$\frac{\text { Entrevistado }}{\sum 12 \text { Entrevistas }}$}} & \multicolumn{4}{|c|}{ Estatística } \\
\hline & & & \multirow[b]{2}{*}{ Rodada de Arguição } & & & \multirow{2}{*}{\multicolumn{2}{|c|}{\begin{tabular}{|l|l|} 
Média \\
\end{tabular}}} & \multirow{2}{*}{\multicolumn{2}{|c|}{\begin{tabular}{|l|l|}
$\begin{array}{c}\text { Desvio } \\
\text { Padrấ }\end{array}$ \\
$1^{\mathrm{a}}$ & $2^{\mathrm{a}}$ \\
\end{tabular}}} \\
\hline & & & & $1^{1^{3}}$ & $22^{\mathrm{a}}$ & & & & \\
\hline & & & \begin{tabular}{|l} 
Descrição de sentença associada ao critério \\
\end{tabular} & & & & & & \\
\hline \multirow{3}{*}{$\begin{array}{l}\text { Critérios } \\
\text { propost } \\
\text { os para } \\
\text { o indice }\end{array}$} & \multirow{3}{*}{$\begin{array}{l}\text { Coerência } \\
\text { Conceitual }\end{array}$} & Definição & 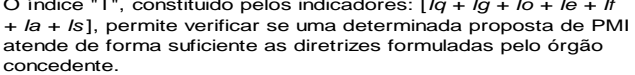 & $\ldots$ & & 3,92 & 4,17 & 0,90 & 0,72 \\
\hline & & Relevância & 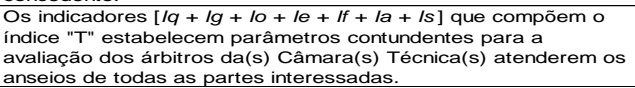 & $\ldots$ & $\ldots$ & 4,17 & 4,17 & 0,94 & 0,94 \\
\hline & & Interpretação/Significado & 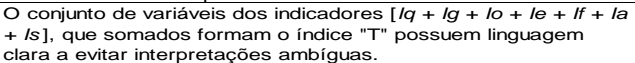 & $\cdots$ & $\cdots$ & 4,00 & 4,17 & 0,7 & 0,58 \\
\hline
\end{tabular}
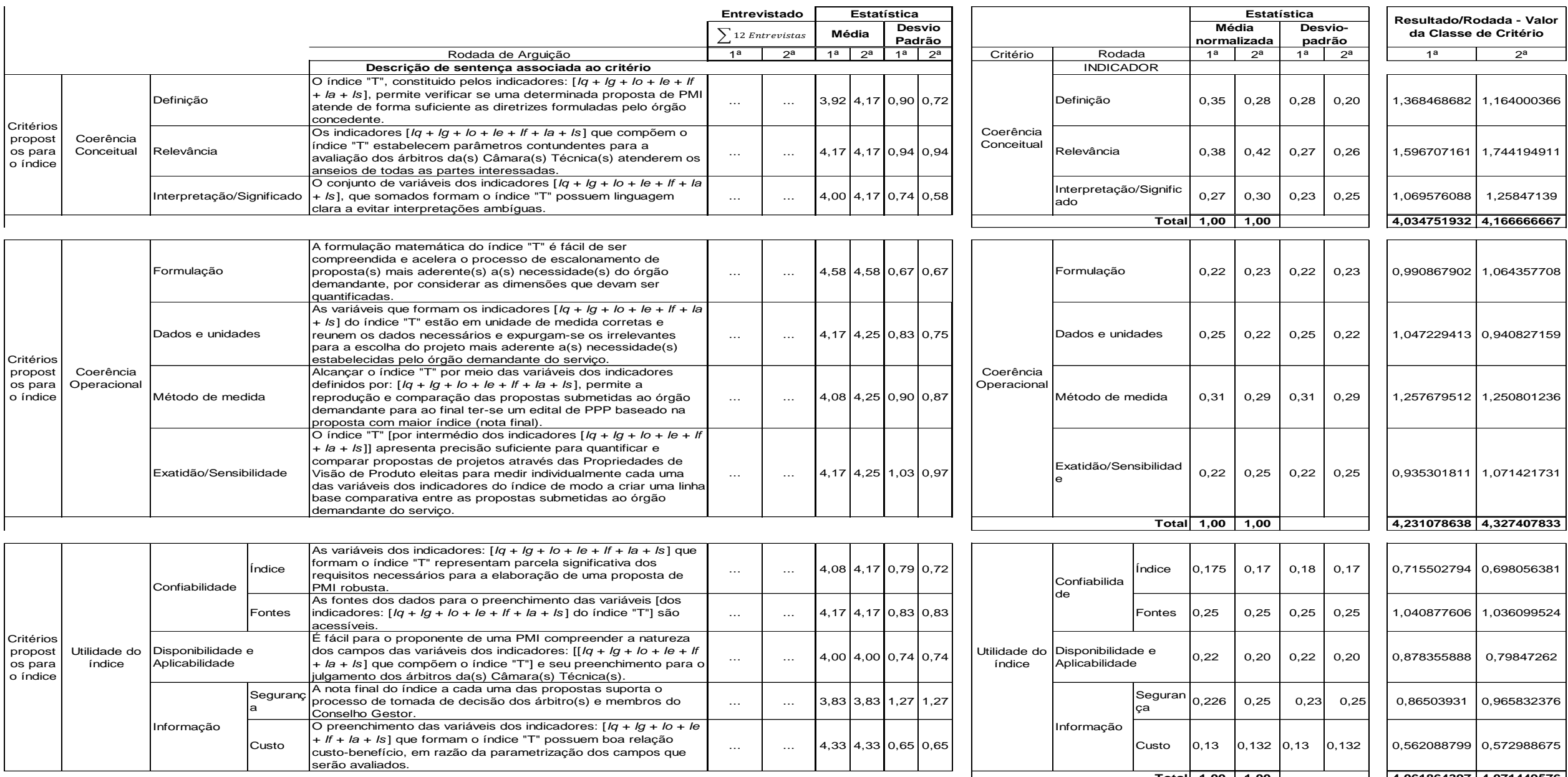

As variáveis dos indicadores: $[1 /+19+10+10+11+10+10] 9$ (1)

\begin{tabular}{|l|l|l|l|l|l|l|}
\hline$\cdots$ & $\cdots$ & 4,08 & 4,17 & 0,79 & 0,72 \\
\hline$\cdots$ & $\cdots$ & 4,17 & 4,17 & 0,83 & 0,83 \\
\hline & $\cdots$ & $\cdots$ & 4,00 & 4,00 & 0,74 & 0,74 \\
\hline$\cdots$ & $\cdots$ & 3,83 & 3,83 & 1,27 & 1,27 \\
\hline & $\cdots$ & 4,33 & 4,33 & 0,65 & 0,65 \\
\hline
\end{tabular}

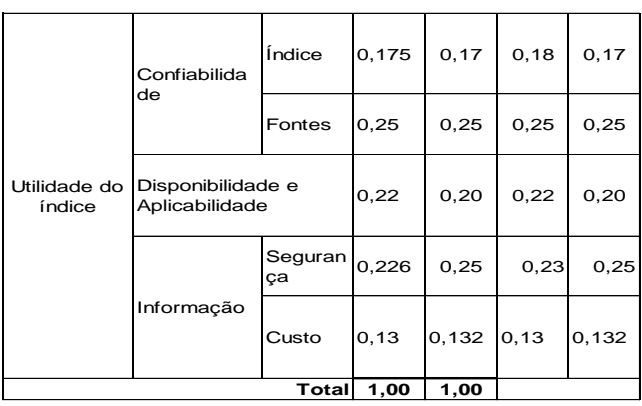

\begin{tabular}{|l|l|}
\hline 0,715502794 & 0,698056381 \\
\hline 1,040877606 & 1,036099524 \\
\hline 0,878355888 & 0,79847262 \\
\hline 0,86503931 & 0,965832376 \\
\hline 0,562088799 & 0,572988675 \\
\hline $\mathbf{4 , 0 6 1 8 6 4 3 9 7}$ & $\mathbf{4 , 0 7 1 4 4 9 5 7 6}$ \\
\hline
\end{tabular}

Fonte: Elaborado pelo Autor. 